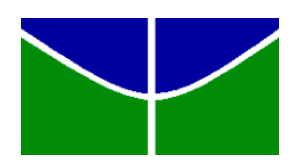

UNIVERSIDADE DE BRASÍLIA FACULDADE DE CIÊNCIA DA INFORMAÇÃO PÓS-GRADUAÇÃO EM CIÊNCIA DA INFORMAÇÃO

A INFLUÊNCIA DO LETRAMENTO INFORMACIONAL NA APRENDIZAGEM DE ESTUDANTES DO 9 ANO DO ENSINO FUNDAMENTAL

Brasília

2015 



\title{
A INFLUÊNCIA DO LETRAMENTO INFORMACIONAL NA APRENDIZAGEM DE ESTUDANTES DO 9 ANO DO ENSINO FUNDAMENTAL
}

\begin{abstract}
Dissertação apresentada ao Programa de Pós-Graduação em Ciência da Informação da Universidade de Brasília como requisito parcial para a obtenção do grau de Mestre em Ciência da Informação.
\end{abstract}

Orientadora: Profa. Dra. Kelley Cristine Gonçalves Dias Gasque. 


\section{Ficha catalográfica}

M113i Macedo, Murillo de Melo.

A influência do letramento informacional na aprendizagem de estudantes do $9^{\circ}$ ano do ensino fundamental / Murillo de Melo Macedo. -2015.

285f. : il. ; $30 \mathrm{~cm}$.

Dissertação (Mestrado) - Universidade de Brasília, Faculdade de Ciência da Informação, Programa de Pós-Graduação em Ciência da Informação, 2014.

Orientação: Kelley Cristine Gonçalves Dias Gasque.

1. Letramento Informacional. 2. Aprendizagem. 3. Educação Básica. I. Gasque, Kelley Cristine Gonçalves Dias. II. Título.

CDU: $37.01: 02$ 


\section{FOLHA DE APROVAÇÃO}

Título: A influência do letramento informacional na aprendizagem de estudantes do $9^{\circ}$ ano do ensino fundamental.

Autor (a): Murillo de Melo Macedo

Área de concentração: Gestão da informação

Linha de pesquisa: Comunicação e Mediação da Informação

Dissertação submetida à Comissão Examinadora designada pelo Colegiado do Programa de Pós-graduação em Ciência da Informação da Faculdade em Ciência da Informação da Universidade de Brasília como requisito parcial para obtenção do título de Mestre em Ciência da Informação.

Dissertação aprovada em: 01 de abril de 2015.

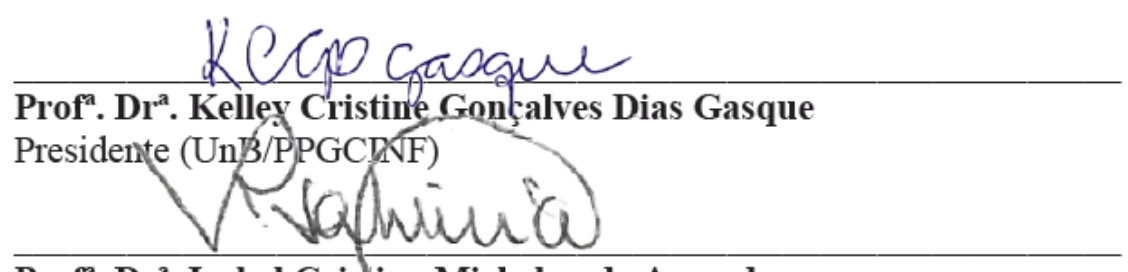

Prof $^{\text {a }}$. Dr ${ }^{a}$. Isabel Crisłina Michelan de Azevedo

Membro Externo (UFS)

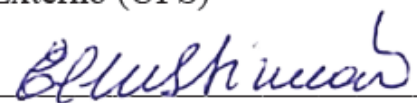

Prof $^{a}$. Dra Elmira Luzia Melo Soares Simeão

Membro Interno (UnB/PPGCINF)

Prof. Dr. Rosemeire Barbosa Tavares

Suplente (UnB/PPGCINF) 


\section{DEDICATÓRIA}

Aos meus pais, Peron Bispo de Macedo e Maria da Cruz de Melo Macedo, e ao meu irmão Marcus de Melo Macedo, por me apoiarem incondicionalmente. Obrigado por me ajudarem a enfrentar as dificuldades da vida, e acima de tudo, por nunca terem me deixado desistir. Vocês são o meu grande exemplo!

À Priscila Rizzo, minha noiva, por compreender todos os momentos em que estive ausente. Obrigado por todo amor e carinho, e por estar ao meu lado durante todo este tempo. 


\section{AGRADECIMENTOS}

Agradecimentos especiais à professora Dra. Kelley Cristine Gonçalves Dias Gasque, por ter acreditado em mim desde o primeiro instante. Grato por todo o incentivo, pelos momentos de aprendizado e pela convivência. Obrigado por ter influenciado não apenas a minha vida acadêmica, mas profissional também. Acima de tudo, obrigado pela paciência, pela dedicação, pelo carinho e pelo cuidado. Serei eternamente grato!

Às professoras Dra. Isabel Cristina Michelan de Azevedo, Dra. Elmira Luzia Melo Soares Simeão e Dra. Rosemeire Barbosa Tavares, por gentilmente terem aceitado fazer parte da banca examinadora e pelas importantes considerações feitas para a melhoria deste trabalho.

Ao professor Álvaro Loureiro, que prontamente me permitiu realizar esta pesquisa junto aos seus estudantes. Grato pela abertura e por todos os momentos de partilha. Foi uma experiência enriquecedora!

Aos meus familiares, que direta ou indiretamente, contribuíram para que eu me estabelecesse na cidade de Brasília. Obrigado a todos pelo apoio!

Aos amigos Anderson Nascimento, Flor Silvestre e Leila Ribeiro, por todos os momentos de convivência e compartilhamento de saberes.

A Deus, por ter me dado forças para chegar até aqui. 
"O desafio para a educação no século XXI é o de preparar os alunos para utilizar a informação no local de trabalho, em suas vidas pessoais, e como cidadãos responsáveis".

Carol Kuhlthau 


\section{RESUMO}

Analisa a influência do letramento informacional na aprendizagem dos estudantes do $9^{\circ}$ ano do Ensino Fundamental por meio de pesquisa quase experimental realizada com dois grupos de aprendizes da disciplina Ensino Religioso em colégio católico confessional, na cidade de Brasília-DF. Para tanto, os estudantes tiveram os conhecimentos prévios identificados, posteriormente, o grupo quase experimental teve orientações e acesso ao guia básico de letramento informacional e, por fim, após propor resolução de um problema aos grupos, foi possível comparar os níveis de aprendizagem obtidos entre eles. O estudo utilizou a metodologia de métodos mistos, com aplicação da pesquisa-ação prática combinado ao desenho quase experimental. As técnicas de pesquisa empregadas foram o questionário, a observação participativa e os mapas conceituais, complementados com relatórios, avaliação e entrevista não estruturada. Os resultados revelaram avanço pouco significativo no desempenho acadêmico do grupo quase experimental, demonstraram também que os estudantes pesquisados ainda não possuem as competências do LI consideradas necessárias para $\circ 9^{\circ}$ ano do Ensino Fundamental, mas sinalizaram mudanças importantes na aprendizagem dos estudantes, em especial, nos aspectos relacionados ao comportamento.

Palavras-chave: Letramento Informacional. Aprendizagem. Educação Básica. 


\begin{abstract}
The dissertation analyzes the influence of information literacy in the learning process of elementary students in 9th grade, through a quasi-experimental study with two groups of learners. The study happened during some classes of Religious Education subject in a Catholic school in Brasília-DF. First, it was identified the students' prior knowledge. Later, the quasi-experimental group had guidelines and access to basic guide of information literacy, and finally, it was possible to compare learning levels obtained between them after propose solving a problem to the groups. The study used the methodology of mixed methods, with application of action research combined with quasi-experimental design. The research techniques used were the questionnaire, the participant observation and the conceptual maps, supplemented with reports, evaluation and unstructured interview. The results showed little significant improvement in academic performance in the quasi-experimental group. The study also showed that students of basic education do not have the skills of information literacy deemed necessary; on the other hand, it demonstrated important changes in students' learning, especially in the attitudinal aspects.
\end{abstract}

Keywords: Informational Literacy. Learning. Basic Education. 


\section{LISTA DE ILUSTRAÇÕES}

Figura 1 Relação causal com variável interveniente___ 20

Figura 2 Diagrama do componente curricular Ensino Religioso___ 26

Figura 3 Metodologia utilizada pelos autores_ 49

Figura 4 Espiral de aprendizagem hierárquica em letramento informacional

Figura 5 Relação entre variáveis___ 62

$\begin{array}{lll}\text { Figura } 6 & \text { Modelo Teórico da pesquisa___ } & 67\end{array}$

$\begin{array}{lll}\text { Figura } 7 & \text { Principais ações para realizar a pesquisa-ação___ } & 74\end{array}$

Figura 8 Modelo de mapa mental criado com a ferramenta Simple-

Mind+__ 81

Figura 9 Somatório dos resultados (Questão A)__ 86

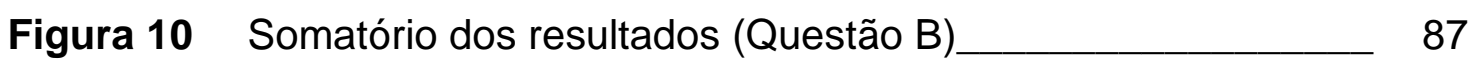

Figura 11 Somatório dos resultados (Questão C)___ 88

Figura 12 Somatório dos resultados (Questão D)__ 89

Figura 13 Somatório dos resultados (Questão E)___ 90

Figura 14 Somatório dos resultados (Questão F)__ 91

Figura 15 Somatório dos resultados (Questão G)___ 92

Figura 16 Somatório dos resultados (Questão $\mathrm{H}) \_93$

Figura 17 Gráfico comparativo entre respostas__ 94

Figura 18 Distribuição média das notas - Indicador 1A___ 96

Figura 19 Distribuição média das notas - Indicador 1B___ 97

Figura 20 Distribuição média das notas - Indicador 1C___ 98

Figura 21 Distribuição média das notas - Indicador 1D__ 99

Figura 22 Distribuição média das notas - Indicador 2A__ 100

Figura 23 Distribuição média das notas - Indicador 2B___ 101

Figura 24 Distribuição média das notas - Indicador 2C_ 102

Figura 25 Distribuição média das notas - Indicador 2D__ 103

Figura 26 Distribuição média das notas - Indicador 3A__ 104

Figura 27 Distribuição média das notas - Indicador 3B__ 105

Figura 28 Distribuição média das notas - Indicador 3C__ 106

Figura 29 Distribuição média das notas - Indicador 4A__ 107

Figura 30 Distribuição média das notas - Indicador 4B__ 108 
Figura 31 Distribuição média das notas - Indicador 4C 109

Figura 32 Distribuição média das notas - Indicador 4D 110

Figura 33 Somatório das notas obtidas em cada um dos indicadores 112

Figura 34 Nota máxima obtida em cada um dos indicadores 113

Figura 35 Nota mínima obtida em cada um dos indicadores 114

Figura 36 Gráfico comparativo (Aprendizagem Mediada x Não Mediada) 131 


\section{LISTA DE QUADROS}

Quadro 1 As quatro forças que moldam o desenvolvimento humano

Quadro 2 Conteúdos e habilidades de letramento informacional para o 9응 ano do ensino fundamental 46

Quadro 3 Exemplos da relação entre variáveis independente e dependente 72

Quadro 4 Perguntas codificadas 84

Quadro 5 Indicadores utilizados na avaliação do trabalho 95

Quadro 6 Relatório descritivo (Indicador 1A) 115

Quadro 7 Relatório descritivo (Indicador 1B) 116

Quadro 8 Relatório descritivo (Indicador 1C) 118

Quadro 9 Relatório descritivo (Indicador 1D) 119

Quadro 10 Relatório descritivo (Indicador 2A) 120

Quadro 11 Relatório descritivo (Indicador 2B) 121

Quadro 12 Relatório descritivo (Indicador 2C) 122

Quadro 13 Relatório descritivo (Indicador 2D) 123

Quadro 14 Relatório descritivo (Indicador 3A) 124

Quadro 15 Relatório descritivo (Indicador 3B) 125

Quadro 16 Relatório descritivo (Indicador 3C) 126

Quadro 17 Relatório descritivo (Indicador 4A) 127

Quadro 18 Relatório descritivo (Indicador 4B) 128

Quadro 19 Relatório descritivo (Indicador 4C) 129

Quadro 20 Relatório descritivo (Indicador 4D) 130

Quadro 21 Quadro de codificação 132

Quadro 22 Definição das Unidades de Análise 133

Quadro 23 Definição das Categorias Iniciais 150

Quadro 24 Definição das Categorias Intermediárias 167

Quadro 25 Definição das Categorias Finais 168 


\section{LISTA DE TABELAS}

Tabela 1 Média dos alunos que obtiveram nota em pelo menos um indicador 


\section{LISTA DE ABREVIATURAS}

\begin{tabular}{|l|l|}
\hline ACRL & Association of College and Research Libraries \\
\hline ALA & American Library Association \\
\hline AASL & American Association of School Librarians \\
\hline CI & Ciência da Informação \\
\hline CRA & Centro de Recursos de Aprendizagem \\
\hline IFLA & International Federation of Library Associations \\
\hline LI & Letramento Informacional \\
\hline SCONSUL & Society of College, National and University Libraries \\
\hline TI & Tecnologia da Informação \\
\hline TICs & Tecnologias de Informação e Comunicação \\
\hline UMBRASIL & União Marista do Brasil \\
\hline SPSS & Statistical Package for Social Science \\
\hline
\end{tabular}


$\begin{array}{lll}1.1 & \text { DEFINIÇÃO DO PROBLEMA___ } & 19\end{array}$

$\begin{array}{lll}1.2 \text { DEFINIÇÃO DA HIPÓTESE DE PESQUISA__ } & 19\end{array}$

$\begin{array}{lll}1.3 & \text { OBJETIVOS__ } & 21\end{array}$

$\begin{array}{lll}1.3 .1 & \text { Objetivo geral___ } 21\end{array}$

$\begin{array}{lll}\text { 1.3.2 Objetivos específicos___ } 21 & 21\end{array}$

$\begin{array}{lll}1.4 & \text { JUSTIFICATIVA___ }\end{array}$

$\begin{array}{lll}1.5 & \text { ESTRUTURA DA PESQUISA___ } & 27\end{array}$

2 REVISÃO DE LITERATURA__ 28

$\begin{array}{lll}2.1 & \text { APRENDIZAGEM__ } 28\end{array}$

2.1.1 Teoria da aprendizagem - Cognitivismo _ 30

2.2 CONCEITO DE INFORMAÇÃO___ 36

$\begin{array}{lll}\text { 2.2.1 Uso da informação no contexto escolar___ } & 37\end{array}$

$\begin{array}{lll}2.3 & \text { LETRAMENTO INFORMACIONAL___ } & 39\end{array}$

2.3.1 Letramento informacional na educação básica___ 41

2.3.2 Letramento informacional: pesquisas na educação básica___ 47

2.3.3 Letramento informacional: pesquisas no ensino superior__ 58

3 REFERENCIAL TEÓRICO___ 65

4 METODOLOGIA_ 68

4.1 PROCEDIMENTOS METODOLÓGICOS DA PESQUISA___ 72

$\begin{array}{lll}\text { 4.1.1 População___ } & 76\end{array}$

$\begin{array}{lll}\text { 4.1.2 Caracterização da amostra___ } & 78\end{array}$

$\begin{array}{lll}\text { 4.1.3 Instrumentos de coleta de dados__ } & 78\end{array}$

$\begin{array}{lll}\text { 4.1.4 Tratamento e apresentação dos dados___ } & 83\end{array}$

4.1.4.1 Dados Quantitativos____ 84

$\begin{array}{lll}\text { 4.1.4.2 Dados Qualitativos___ } & 132\end{array}$

5 APRESENTAÇÃO E ANÁLISE DOS RESULTADOS___ 169

$6 \quad$ CONCLUSÕES E RECOMENDAÇÕES__ 179 $\begin{array}{ll}\text { REFERÊNCIAS_ } & 181\end{array}$

APÊNDICE A - MODELO DE QUESTIONÁRIO___ 189

APÊNDICE B - ROTEIRO DE OBSERVAÇÃO___ 191 
APÊNDICE C - ROTEIRO DE AVALIAÇÃO DO TRABALHO

APÊNDICE D - ROTEIRO DE TRABALHO

APÊNDICE E - ENTREVISTA

APÊNDICE F - OBSERVAÇÕES

204

APÊNDICE G - ESTRUTURA DE UM TRABALHO ACADÊMICO

244

ANEXO 1 - TEXTO DE APOIO

262

ANEXO 2 - MAPAS MENTAIS: GRUPO QUASE EXPERIMENTAL

(1

274

ANEXO 3 - MAPAS MENTAIS: GRUPO QUASE EXPERIMENTAL

(2 $2^{\text {a }}$ ELABORAÇÃO)

279

ANEXO 4 - MAPAS MENTAIS: GRUPO CONTROLE 


\section{INTRODUÇÃO}

Diante do ininterrupto crescimento da oferta e demanda por informação, é fundamental que o papel da escola seja, também, o de ensinar como os estudantes devem lidar com tal questão. É importante que eles, ainda em fase escolar, sejam orientados e capacitados para localizar, selecionar, organizar e comunicar informações, por meio de experiências de aprendizado. Para tanto, é fundamental identificar processos que garantam aos estudantes aprendizado efetivo. Nesse sentido, entende-se que a prática do Letramento Informacional (LI) constitui-se em alternativa viável para a aprendizado ao longo da vida.

O crescimento constante do volume de informações cria facilidades para o acesso, mas também barreiras para a busca e seleção da informação. Isso fica evidente, principalmente no contexto escolar, em que grande parte dos estudantes sente-se perdido ao realizar algum tipo de pesquisa. Entender o processo dinâmico da informação e aprender a lidar com ela são tarefas necessárias nos primeiros anos escolares. Associado a isso, é importante reconhecer que os novos estudos sobre aprendizagem apontam para outra perspectiva de ensino, não mais relacionada com a mera transmissão de saberes, mas com o foco na resolução de problemas. Tal fato reflete a necessidade da aplicação de novos processos de aprendizagem, em especial nas escolas de ensino básico.

Com base neste contexto, o presente trabalho tem o propósito de analisar a influência do processo de LI na aprendizagem de estudantes da educação básica ${ }^{1}$. O estudo utiliza a metodologia dos métodos mistos sequenciais, com ênfase no método de pesquisa da pesquisa-ação prática, combinada ao desenho quase experimental. A pesquisa foi realizada com estudantes de 90 ano do Ensino Fundamental, em colégio católico confessional na cidade de Brasília-DF.

\footnotetext{
${ }^{1}$ De acordo com o Art. $22^{\circ}$ da Lei de Diretrizes e Bases da Educação Nacional (LDB), a educação básica "tem por finalidades desenvolver o educando, assegurando-lhe a formação comum indispensável para o exercício da cidadania e fornecer-lhes meios para progredir no trabalho e em estudos posteriores". A educação básica está organizada em "pré-escola", "ensino fundamental" e "ensino médio".
} 


\subsection{DEFINIÇÃO DO PROBLEMA}

A questão básica, que norteia o desenvolvimento da pesquisa, pode ser representada com o problema a seguir:

Qual a influência do letramento informacional na aprendizagem dos estudantes na educação básica?

A definição do problema é feita com base na revisão de literatura e, em caso de pesquisas com alcance explicativo, está intimamente relacionada com a definição da hipótese de pesquisa. A hipótese representa uma resposta provisória para a pergunta de pesquisa e será ou não confirmada ao final do estudo. A hipótese definida para esta pesquisa é apresentada no item a seguir.

\subsection{DEFINIÇÃO DA HIPÓTESE DE PESQUISA}

As hipóteses podem ser definidas como explicação provisória para a relação entre duas ou mais variáveis. Em estudos qualitativos, as hipóteses são revistas e aperfeiçoadas conforme 0 andamento da pesquisa. No caso das pesquisas de abordagem quantitativa, as hipóteses são formuladas após a definição do problema e só se adequam aos estudos de alcance correlacional, explicativo ou descritivo (HERNÁNDEZ SAMPIERI; FERNÁNDEZ COLLADO; BAPTISTA LUCIO, 2013).

Esta pesquisa caracteriza-se como de alcance exploratório/explicativo, estando portanto apta para a definição de hipóteses. Nesse sentido, a hipótese $\left(\mathrm{H}_{1}\right)$ formulada foi:

\section{$\mathrm{H}_{1}$ : A aprendizagem dos estudantes de $9^{\circ}$ ano do ensino fundamental está relacionada positivamente com a utilização de técnicas de LI em situação de resolução de problemas/investigação.}

Pode-se perceber que a hipótese apresentada possui duas variáveis vinculadas: "aprendizagem dos estudantes" e "letramento informacional", e 
mais uma variável que pode interferir na relação entre ambas: "ensino fundamental". A primeira delas é chamada de variável dependente e a segunda de variável independente. A variável entre as duas é chamada de variável interveniente. Para Hernández Sampieri, Fernández Collado e Baptista Lucio (2013), este tipo de hipótese é definida como "hipótese causal com variável interveniente". Isto significa que a presença da variável interveniente pode modificar a relação entre a variável independente e a dependente.

A representação da hipótese e suas variáveis pode ser vista na Figura 1. A variável independente é representada pela letra $\mathbf{X}$, a variável dependente pela letra $\mathbf{Y}$ e a variável interveniente pelo traço no centro.

Figura 1 - Relação causal com variável interveniente

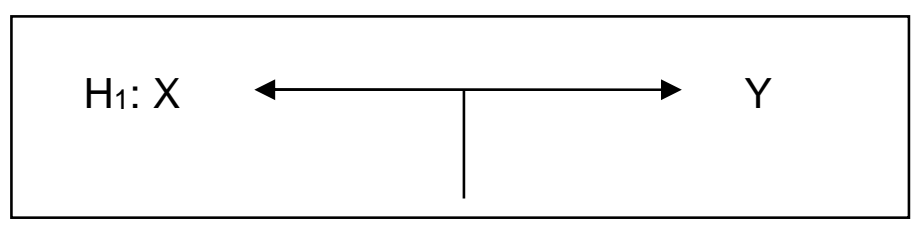

Fonte: Elaboração própria

A medição de uma variável só é possível mediante a especificação de cada uma delas. Essa especificação é chamada de "definição operacional" (HERNÁNDEZ SAMPIERI; FERNÁNDEZ COLLADO; BAPTISTA LUCIO, 2013), isto é, cada variável precisa indicar como será medida posteriormente. No escopo desta pesquisa, as variáveis são medidas da seguinte forma:

Variável independente: letramento informacional (medido mediante aplicação de questionário, elaboração de mapas mentais, observação e orientação sobre a elaboração de trabalhos escolares).

Variável dependente: aprendizagem (medida a partir de trabalho realizado na disciplina, debates realizados com os estudantes, perguntas/respostas e relatórios entregues pelos estudantes e entrevista com o professor da disciplina).

Com base na descrição das variáveis, é possível definir os objetivos propostos para a pesquisa. 


\subsection{OBJETIVOS}

O presente trabalho propõe atender aos seguintes objetivos:

\subsubsection{Objetivo Geral}

Analisar a influência do processo de Letramento Informacional na aprendizagem de estudantes em sala de aula.

\subsubsection{Objetivos específicos}

- Identificar os conhecimentos prévios dos grupos participantes do quase experimento;

- Elaborar roteiro básico de Letramento Informacional para o grupo do quase experimento;

- Aplicar roteiro básico de Letramento Informacional para o grupo do quase experimento;

- Envolver os grupos participantes em processo de resolução de problemas/investigação;

- Comparar os níveis de aprendizagem dos grupos participantes do quase experimento;

- Identificar como o Letramento Informacional interferiu na aprendizagem dos estudantes.

\subsection{JUSTIFICATIVA}

O presente tópico aborda questões relativas à justificativa da pesquisa e contribuições para Ciência da Informação, mediante estudos relacionados à busca e ao uso da informação e a importância para o contexto educacional. Além disso, aponta a necessidade de orientação e capacitação dos estudantes da educação básica para novas experiências de aprendizado. Por fim, indica o 
LI como prática que pode favorecer a criação de métodos de ensino mais eficientes, e como processo que busca garantir aprendizagem ao longo da vida.

A produção e o consumo de informações crescem de forma exponencial, especialmente com o uso das novas tecnologias de informação e comunicação (TICs). Nunca se produziu tanta informação, e ao mesmo tempo, nunca se consumiu tanta informação como nos dias de hoje. Isso cria não apenas facilidades, mas também inúmeros problemas, principalmente relacionados à busca, recuperação e ao uso. No contexto educacional, o fato se agrava ainda mais, visto que grande parte dos estudantes não possui orientação adequada para lidar com o grande volume de informações. Para Gasque e Tescarolo (2010), as pessoas agem, muitas vezes, de forma intuitiva quando buscam e usam informação, pois não têm oportunidade de sistematizar o conhecimento necessário para realizar tal tarefa. A intuição, muitas vezes, pode implicar em perda de tempo, uma vez que a busca por conteúdo relevante (ou o uso propriamente dito da informação) fica comprometido se não houver sistematização do ensino dos conteúdos de LI.

O crescente universo informacional cria dificuldades relacionadas ao acesso dos aprendizes à informação de qualidade. Isso porque há disponibilização de um número ilimitado de fontes de informação e, ao mesmo tempo, há também falta de conhecimento dos mecanismos que permitem filtrar, organizar ou mesmo se apropriar da informação. Por isso, observa-se a necessidade urgente de reforma curricular, que deve ser feita com base nos questionamentos sobre as políticas educacionais vigentes. Assim, o foco deve voltar para uma "cultura da informação", isto é, a informação inserida nos processos educacionais (DUDZIAK, 2003).

Compartilhando da mesma visão, Bransford, Brown e Cocking (2007) afirmam que a nova ciência da aprendizagem enfatiza a necessidade de repensar o modelo educacional vigente, mudando o foco do que é ensinado, da maneira que se ensina e de como se avalia a aprendizagem. Como apontado por Kuhlthau (2001, online), ao se preparar para o mundo fora da escola, os estudantes precisam desenvolver capacidades de aprendizado a partir de informações do cotidiano, isto é, aquelas presentes em situações da vida real. Tais informações não foram tratadas ou selecionadas e tampouco organizadas 
para o uso. Nesse sentido, estar orientado para lidar efetivamente com a informação é fundamental.

Com o desenvolvimento tecnológico, o estudante torna-se cada vez mais responsável pela própria aprendizagem, principalmente pela diversidade de recursos disponíveis e pelas mudanças nos processos de ensino. Tal fato pode ser confirmado por Limberg (1999) ao apresentar evidências de que os métodos de ensino estão mudando de uma visão de transmissão da aprendizagem para uma aprendizagem baseada em problemas. Para ela, isso implica em maior uso de bibliotecas e de grande variedade de fontes de informação, o que exige cooperação mais estreita entre bibliotecários e professores.

Na mesma linha de pensamento, Dudziak (2003) ressalta que as práticas pedagógicas buscam transferir o foco da aprendizagem do professor para o aprendiz e dos conteúdos para processos de aprendizagem, dando ênfase a formação completa do indivíduo. Isso favorece a criação de um novo modelo de aprendizado, que privilegia a utilização dos recursos informacionais disponíveis, com foco na aprendizagem e resolução de problemas. Esse modelo cria condições para que a rotina de buscar e utilizar a informação, de forma crítica e contextualizada, seja um processo natural entre os aprendizes.

Diante deste contexto, é possível observar que a busca e o uso de informações para o processo de aprendizagem constituem-se ponto crítico em sala de aula. Limberg (1999) argumenta que os professores enfatizam o tema do trabalho de pesquisa e subestimam o processo de busca das informações por parte dos educandos. Nesse sentido, Gasque e Tescarolo (2010) defendem a formação continuada dos professores como necessidade crucial para aprenderem e auxiliarem os estudantes a lidarem com o grande volume de informação.

Em estudo realizado com estudantes de ensino médio, Limberg (1999) aponta que o conhecimento pode ser ampliado e intensificado, a partir de experiências de uso da informação. Ela demonstrou que a capacidade de buscar informações está diretamente relacionada com a obtenção de informações de qualidade, originada de diferentes pontos de vista. $O$ estudo reforça a ideia de que os aprendizes precisam ser orientados para melhor utilização da informação. Se estas experiências forem viabilizadas ainda em fase escolar, os resultados podem ser cada vez mais significativos. 
Outros autores reforçam esta ideia, ao argumentarem que diante do atual contexto informacional,

\begin{abstract}
[o estudante] precisa aprender estratégias que o ajudem a selecionar as informações relevantes para torná-las significativas, isto é, relacionar as novas informações com o que já se conhece para estabelecer uma vinculação entre elas. Quanto mais relações entre as informações o aluno consegue estabelecer, menos mecânica se torna sua aprendizagem. As propostas inovadoras na área educacional parecem ter como finalidade conferir autonomia aos educandos para que saibam administrar o próprio conhecimento e consigam aprender continuamente, utilizando suas próprias capacidades cognitivas ao longo da vida (GASQUE; TESCAROLO, 2010, p.50).
\end{abstract}

Nesse sentido, reconhece-se também a primordialidade de mais estudos sobre interação e uso da informação por parte de estudantes. Limberg (1999) deixa isso claro ao identificar poucas pesquisas sobre a interação entre a forma como os estudantes buscam e usam a informação para tarefas de aprendizagem e o que eles realmente aprendem sobre o assunto. Viabilizar pesquisas desta natureza pode garantir maior entendimento dos processos de aprendizagem em ambiente escolar.

Os Padrões de Competência Informacional para o Ensino Superior, propostos pela Association of College and Research Libraries (ACRL), apontam que uma pessoa capaz de lidar com a informação, tem condições de saber se uma informação é necessária, como acessá-la de forma eficaz e eficiente, e como avaliar fontes de forma crítica; além de ter condição de assimilar tais informações, transformando-as em conhecimento (ALA, 2000). O aprendiz aprende, portanto, a aprender e utiliza a informação para enriquecer a aprendizagem. Para Claxton (2005), o aprender a aprender torna possível a aprendizagem ao longo da vida.

Considerando a importância do aprendizado ao longo da vida, a presente pesquisa analisou a influência do processo de LI na aprendizagem de estudantes de $9^{\circ}$ ano do Ensino Fundamental, na disciplina de Ensino Religioso, em colégio católico confessional na cidade de Brasília-DF. O estudo realizou-se por meio da metodologia dos métodos mistos sequenciais, com aplicação do método de pesquisa da pesquisa-ação prática, utilizando o desenho quase experimental. 
A escolha pelos métodos mistos (abordagem qualitativa e quantitativa) se deu pela necessidade de visão mais ampla sobre o fenômeno a ser estudado, devido ao grau de complexidade. Além disso, busca minimizar os pontos fracos encontrados nos métodos de pesquisa utilizados, permitindo que ambos se complementem.

É importante definir que o colégio escolhido para o estudo (Colégio Marista de Brasília) é uma instituição católica confessional, com valores relacionados à espiritualidade, ao espírito de família, à simplicidade, à presença significativa, ao senso de justiça e amor ao trabalho. Possui atualmente, cerca de 2.300 alunos do ensino fundamental e é considerado um colégio tradicional na cidade de Brasília, com mais de 50 anos de existência. A instituição tem a missão de "formar bons cristãos e virtuosos cidadãos", com base na formação integral dos estudantes, cultivando solidariedade, amor ao próximo e paz. O motivo da escolha por este colégio se deu em virtude da ligação profissional existente entre o pesquisador e a instituição.

A escolha pela disciplina de Ensino Religioso ${ }^{2}$ ocorreu, em primeiro lugar, em virtude da parceria existente entre o professor da disciplina e o bibliotecário da escola (responsável por este estudo). Ambos já tinham realizado atividades em conjunto, o que reforçou a possibilidade de implementação desta pesquisa junto às turmas em que ele ministrava aulas. $O$ segundo aspecto, diz respeito ao fato da disciplina de Ensino Religioso apresentar conteúdo mais flexível que as demais (no contexto escolhido, o professor não está "preso" ao livro didático) e possuir caráter interdisciplinar (o componente agrega abordagens sociológicas, antropológicas entre outras). Isso fez com que o pesquisador tivesse mais chances de realizar o estudo no ambiente da sala de aula, sem comprometimento da sequência de conteúdo a ser ministrado.

A disciplina de Ensino Religioso tem como objeto de estudo o "Fenômeno Religioso" e a "Religiosidade". De acordo com o documento "Tessituras do Currículo Marista: matrizes curriculares da educação básica"3, fenômeno religioso pode ser entendido como um complexo de manifestações relacionadas a

\footnotetext{
${ }^{2}$ Conforme Lei 9.475/97, "O Ensino Religioso, de matrícula facultativa, é parte integrante da formação básica do cidadão, constitui disciplina dos horários normais das escolas públicas de Ensino Fundamental, assegurado o respeito à diversidade cultural e religiosa do Brasil, vedadas quaisquer formas de proselitismo".

${ }^{3}$ Obra não publicada.
} 
experiências religiosas individuais e coletivas. Pode também ser percebido como um fenômeno eminentemente humano. A religiosidade, por sua vez é dinâmica e "ganha forma, ritmo e intensidade" a partir do fenômeno religioso. Ela se torna efetiva e se desenvolve por meio da expressividade, comunicabilidade e linguagem. A compreensão de ambos os fenômenos, implica imersão mais profunda em aspectos como a diversidade religiosa, textos sagrados entre outros. A Figura 2 demonstra a organização da Matriz Curricular Marista de Ensino Religioso.

Figura 2 - Diagrama do Componente Curricular Ensino Religioso

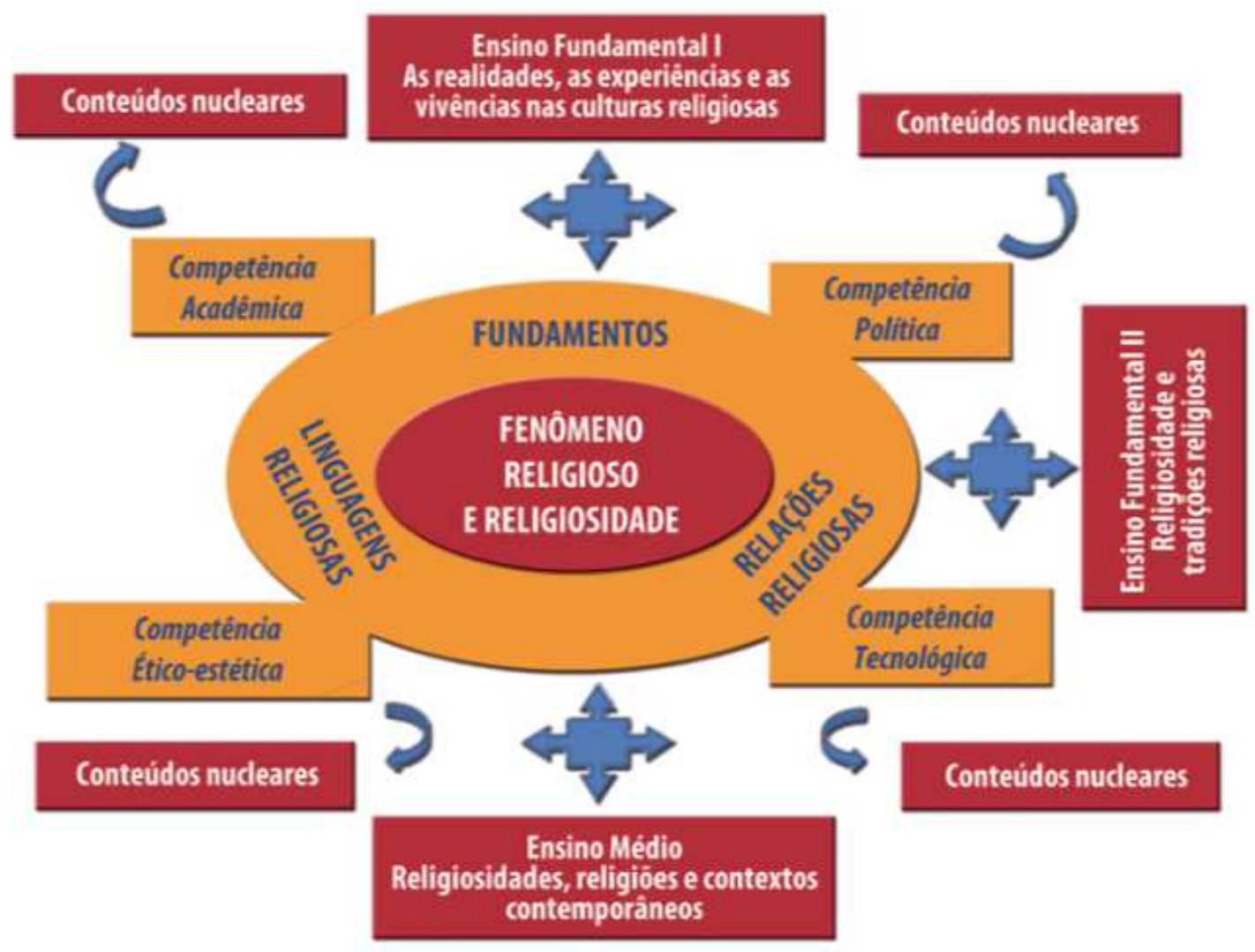

Fonte: Extraído de "Tessituras do Currículo Marista: Matrizes curriculares da educação básica: área de ciências humanas e suas tecnologias" (Obra não publicada).

Associado a isso, a escolha pelo $9^{\circ}$ ano se deu por seu estágio acadêmico avançado (aspecto necessário em virtude do teor da pesquisa) e pelo fato deste pesquisador já ter trabalhado com grande parte do grupo um ano antes (os alunos estavam no $8^{\circ}$ ano), o que facilitou a interação. 
A presente pesquisa pretende contribuir para a Ciência da Informação, ampliando ainda mais o objeto de estudo. Do ponto de vista teórico, tal aspecto valoriza a linha de pesquisa em Comunicação e Mediação da Informação, pois fornece mais subsídios para a continuidade das pesquisas. Do ponto de vista prático, o estudo contribui com o grupo de pesquisa "Aprendizagem, Comportamento \& Letramento Informacional", por reforçar pesquisas aplicadas sobre 0 processo de aprendizagem de LI na educação básica.

\subsection{ESTRUTURA DA PESQUISA}

O trabalho organiza-se em seis capítulos. O primeiro aborda o problema, os objetivos e a justificativa da pesquisa. O segundo capítulo refere-se à revisão de literatura, abrangendo estudo sobre o estado da arte do tema proposto, conceitos de aprendizagem, a teoria cognitivista e o processo de LI. O terceiro capítulo apresenta o modelo teórico da pesquisa e os principais conceitos utilizados no estudo. O quarto capítulo descreve os procedimentos metodológicos utilizados, estabelecidos na metodologia, e traz detalhes da realização da pesquisa-ação. O quinto capítulo é destinado à apresentação dos resultados obtidos nas etapas quantitativa e qualitativa da pesquisa e o último capítulo referese às conclusões e recomendações. 


\section{REVISÃO DE LITERATURA}

A presente revisão de literatura aborda os conceitos relacionados ao processo de $\mathrm{LI}$ e a relação com a aprendizagem dos estudantes na educação básica. Apresenta discussões relevantes na área estudada, e baseia-se em estudo do estado da arte sobre o tema proposto. A revisão procura identificar, consultar e propiciar materiais úteis para a realização do estudo. É o momento de obter e "recompilar" informações relevantes para estruturar o problema de pesquisa. (HERNÁNDEZ SAMPIERI; FERNÁNDEZ COLLADO; BAPTISTA LUCIO, 2013)

\subsection{APRENDIZAGEM}

O conceito de aprendizagem evoluiu significativamente nas últimas décadas. $\mathrm{O}$ avanço científico, especialmente os estudos relacionados ao cérebro humano, apresenta novas e revolucionárias descobertas, principalmente sobre como as pessoas aprendem. A variedade de definições demonstra a complexidade do assunto e o interesse de diversos autores em pesquisar tal processo. No contexto educacional, Houdé (2011) afirma que a aprendizagem modifica a capacidade de realização de uma tarefa com base na interação com o ambiente. Para Lefrançois (2008), a aprendizagem diz respeito às mudanças "no potencial de comportamento", oriundas da experiência, e não está relacionada a fatores como fadiga, amadurecimento, doenças, drogas ou lesões.

Com base em novos estudos, os conceitos de aprendizagem vinculamse, de forma mais clara, ao que acontece dentro do cérebro. Para Kandel (2009), aprendizagem corresponde a alterações que ocorrem nas células nervosas do cérebro. $O$ autor argumenta que quando uma célula está envolvida no processo de aprendizado, ela literalmente cresce. Para ele, em se tratando do aspecto fisiológico, o cérebro se exercitou, isto é, absorveu informação e relacionou conceitos e memórias de forma diferente. Isso provoca mudança nas células nervosas. Lefrançois (2008) argumenta que a aprendizagem depende das conexões entre os neurônios que são formadas no cérebro, caracterizando-se como um processo neurológico invisível e interno. 
De acordo com os autores Bransford, Brown e Cocking (2007), a aprendizagem muda a estrutura física do cérebro, isto é, o reorganiza. Tal reorganização cerebral demonstra que a aprendizagem configura-se como um processo adaptativo, em que mudanças de comportamento (quando são relativamente permanentes) permitem que os organismos evoluam (LEFRANÇOIS, 2008). Tal fato pode ser exemplificado, quando os animais precisam aprender e lembrar onde encontrar alimentos, reconhecer inimigos, evitar substâncias perigosas e se manter longe de situações dolorosas ou de risco.

Pozo (2004) reconhece a importância dos conhecimentos prévios para a aprendizagem, os quais são próprios de cada sujeito. Os novos estudos sobre aprendizagem humana apontam que as pessoas elaboram o novo conhecimento e o entendimento com base nos conhecimentos anteriores e naquilo que acreditam. Tal fato torna-se evidente, ao se perceber que os seres humanos chegam à educação formal com vários conhecimentos, habilidades, crenças e conceitos prévios. Tudo isso influencia diretamente o que percebem sobre 0 ambiente e o modo como organizam e interpretam tal percepção. Isso influencia capacidades como recordação, raciocínio, solução de problemas e aquisição de novos conhecimentos (BRANSFORD; BROWN; COCKING, 2007).

Do ponto de vista educacional, estudos apontam que a aprendizagem melhora quando os professores valorizam os conhecimentos prévios e as crenças trazidas pelos estudantes, e quando utilizam esse conhecimento como ponto de partida para o ensino em sala de aula. Nesse sentido, entende-se que uma nova aprendizagem está baseada na transferência de uma aprendizagem prévia. Para Bransford, Brown e Cocking (2007), apesar das pesquisas apontarem uma nova tendência para o ensino, muitas escolas ainda atuam de forma bastante tradicional, com ênfase na "memória não compreensiva".

Nesse sentido, é importante ressaltar que o processo de aprendizagem envolve tempo e requer mudanças significativas em grande parte dos currículos de ensino. Os estudantes precisam de tempo para aprender e processar informações, isto é, não se pode aprender com pressa (BRANSFORD; BROWN; COCKING, 2007). Isso demonstra que a aprendizagem se caracteriza como processo contínuo e que se desenvolve ao longo da vida. Aprender ao 
longo da vida requer pensar estrategicamente sobre o próprio caminho que leva ao aprendizado ${ }^{4}$, e isso exige responsabilidade.

A aprendizagem é uma atividade que ocorre de formas e dimensões diferentes. À medida que se aprende, é possível ser mais eficiente. Nesse sentido, a aprendizagem não é vista como algo feito esporadicamente, em locais especiais ou em períodos específicos da vida, ela é parte da natureza. Isso permite que ela modifique não somente o conhecimento e a ação, mas também o próprio ser (CLAXTON, 2005).

O ato de aprender está relacionado com a busca e o uso de informações, com base na utilização de recursos variados, que permitem "descobrir" e "reconstruir" um conjunto específico de conceitos na estruturação do conhecimento (GASQUE; TESCAROLO, 2010). Isso permite que o indivíduo tenha entendimento sobre o que acontece no mundo e possa transformá-lo. O LI possui papel importante neste processo.

Para tanto, é necessário entender que as primeiras concepções de aprendizagem foram baseadas em estudos anteriores, conhecidos como "teorias da aprendizagem" ou "teorias comportamentais". De acordo com Lefrançois (2008), tais teorias surgiram com base em estudos psicológicos que buscavam entender o comportamento humano. Conhecer as teorias da aprendizagem é fundamental para ensinar habilidades de LI (MOKHTAR; MAJID; FOO, 2008). Em virtude do foco desta pesquisa (resolução de problemas/investigação), e diante de aproximação importante entre as chamadas Ciências Cognitivas e a Ciência da Informação, optou-se por abordar neste estudo apenas a teoria cognitivista.

\subsubsection{Teoria da aprendizagem - Cognitivismo}

Entre as várias teorias da aprendizagem difundidas na literatura, uma das mais conhecidas é a teoria cognitivista. Para Lefrançois (2008), a base conceitual da teoria a relaciona com eventos intelectuais como "solução de problemas, processamento de informação, pensamento e imaginação". Mokhtar, Majid e Foo (2008) explicam que a orientação cognitivista tem como

\footnotetext{
${ }^{4}$ A capacidade de pensar sobre a própria aprendizagem é definida pelos autores Bransford, Brown e Cocking (2007), como "aprendizagem ativa" ou "metacognição".
} 
foco os processos mentais internos de conhecimento. Para Coutinho (2008), na perspectiva cognitivista, a aprendizagem é percebida como um processo ativo do "sujeito que apreende e organiza a informação", partindo de problemas, expectativas, hipóteses e descobertas.

Os primeiros estudos cognitivos basearam-se na psicologia da Gestalt, que definia que as pessoas não aprendem por tentativa e erro, mais sim por insight 5 . Tal fato, pode ser confirmado a partir de dois motivos principais. $O$ primeiro refere-se ao fato da Gestalt se preocupar com questões como percepção, consciência, solução de problemas e insights, e o segundo, por ter rejeitado o mecanicismo excessivo do behaviorismo ${ }^{6}$, a incompletude e inadequação para explicar os processos mentais superiores. Dentro do âmbito educacional, a teoria da Gestalt é mais rica e eficaz que a teoria do condicionamento, pois busca explicar questões vinculadas à resolução de problemas (PILETTI, 2013).

Um dos teóricos que contribuiu para o desenvolvimento do cognitivismo foi Donald Hebb (1904-1985). Ele argumentava que para compreender a aprendizagem e o comportamento, era necessário observar o que acontece no cérebro. De acordo com esses estudos, impulsos transmitidos de forma repetida entre dois neurônios, leva à "facilitação" entre essas duas células (LEFRANÇOIS, 2008). A facilitação permanente configura-se como aprendizagem. Aspectos como "preparação" e "atenção" foram considerados na teoria de Hebb de importância fundamental para os professores. Para ele, a preparação está relacionada com a escolha de respostas apropriadas, e se a aprendizagem está prestes a acontecer, então a atenção é essencial. Ambos os termos também estão ligados ao processo de "motivação" (conceito fundamental na teoria de Hebb), descrito como condição essencial para que a aprendizagem ocorra.

Hebb, entre outros, trouxeram inúmeras contribuições para o desenvolvimento da teoria cognitivista. Entretanto, as mais importantes foram aquelas feitas por estudiosos como Jerome Bruner, Jean Piaget e Lev Vygotsky.

\footnotetext{
${ }^{5} \mathrm{O}$ termo insight é descrito por Lefrançois (2008) como "a percepção das relações entre elementos de uma situação-problema", isto é, "significa solucionar um problema pela percepção das relações entre todos os elementos importantes da situação".

${ }^{6}$ Teoria que se preocupa de forma explícita com o comportamento, e mais especificamente, com os aspectos que são observáveis (LEFRANÇOIS, 2008).
} 
Nos estudos de Bruner (1915-?) sobre a mente humana, evidencia-se três grupos de invenções notáveis para o desenvolvimento humano. O primeiro diz respeito ao desenvolvimento de objetos simples (alavancas, roldanas etc.) e armas (facas, machadinhas etc.), que ampliaram a capacidade motora do ser humano. Isso fez com que o homem ficasse mais forte e rápido, melhor preparado para a construção de abrigos, menos vulnerável a predadores e catástrofes naturais. O segundo grupo de invenções foram responsáveis pela ampliação dos sentidos. Para Lefrançois (2008), objetos como o telescópio, o rádio, a televisão, entre outros, fizeram com que os sentidos humanos como visão, audição e tato ficassem cada vez mais aguçados. O terceiro e último grupo diz respeito às novas invenções que favoreceram o raciocínio humano, isto é, as capacidades intelectuais. São representadas pelas teorias e sistemas simbólicos humanos, incluindo linguagens e sistemas de computador.

$O$ autor argumenta também que esses estudos permitiram a Bruner elaborar a "teoria das representações", que sugere que o desenvolvimento da criança acontece paralelo ao desenvolvimento das invenções humanas. A primeira forma de representação, chamada "representação enativa", relaciona-se com o período de evolução humana voltado para a ampliação das capacidades motoras. O estágio seguinte, denominado "representação icônica" (baseada em ícones, ou imagens), envolve o uso de imagens mentais referentes aos objetos ou eventos. Esse estágio corresponde ao período em que as invenções humanas ampliaram as capacidades sensoriais. O último estágio diz respeito à forma mais avançada de representação, definida como "representação simbólica". Ela evoluiu de forma paralela ao desenvolvimento de invenções que ampliaram as capacidades intelectuais.

Lefrançois (2008) deixa claro que a teoria da representação de Bruner é importante para o cognitivismo, por explicar como as pessoas constroem as representações, favorecendo o uso do raciocínio sistematizado, o compartilhamento dos conhecimentos (principalmente a partir da linguagem) e o desenvolvimento da própria cultura humana. Essas representações foram tratadas como "categorias", também entendidas como "sistemas de classificação", fazendo com que as pessoas interagissem com o ambiente, Ihes permitindo tratar eventos ou objetos distintos como se fossem equivalentes. 
No âmbito educacional, os estudos de Bruner o fizeram defender o uso de técnicas pelas quais as crianças fossem encorajadas a descobrir, por conta própria, fatos e relações. Para tanto, ele pensou em um currículo em forma de espiral como a melhor alternativa para o contexto escolar. Um currículo com essa estrutura desenvolveria novamente os mesmos tópicos em diferentes níveis de dificuldade e em idades ou sucessivas ou em níveis de graduação distintos. Para Lefrançois (2008), isso quer dizer que nos anos iniciais, os alunos poderiam aprender conceitos mais simples de um determinado assunto, e que nos anos seguintes, eles voltariam aos conceitos discutidos anteriormente, mas agora com níveis conceituais que se tornariam gradativamente mais complexos.

O autor acrescenta, que além de Bruner, Jean Piaget (1896-1980) também desenvolveu teorias de grande importância para o cognitivismo. Com base na utilização do "método clínico" (técnica de entrevista que ele utilizou para estudar crianças), ele aperfeiçoou seus estudos buscando compreender seus estágios cognitivos. Para Piaget, o desenvolvimento da criança acontece por meio de uma série de estágios, que caracterizam o desenvolvimento de novas capacidades. Cada estágio representa um nível mais avançado de adaptação.

Essa percepção fez com que Piaget desenvolvesse a "teoria dos estágios", definindo a progressão do desenvolvimento da criança por meio de quatro estágios e alguns subestágios, quais sejam: 1. Sensório-motor (do nascimento aos 2 anos), 2. Pré-operacional (dos 2 aos 7 anos) - tendo como subestágios o preconceitual (dos 2 aos 4anos) e o intuitivo (dos 4 aos 7 anos) - 3 . Operações concretas (dos 7 aos 11 ou 12 anos) e 4. Operações formais (dos 11 aos 12 ou dos 14 aos 15 anos). Esses estágios são descritos pelas características que identificam as crianças de um determinado estágio e pela aprendizagem que ocorre antes da transição para o estágio seguinte (LEFRANÇOIS, 2008).

Os estudos de Piaget caracterizam a sua teoria como uma "teoria do desenvolvimento humano", devido à sua ênfase no desenvolvimento do conhecimento. Entretanto, também é caracterizada como uma teoria da aprendizagem, especialmente por definir o desenvolvimento da criança a partir de quatro grandes forças. Essas forças, assim como suas implicações educacionais, podem ser visualizadas no Quadro 1. 
Quadro 1 - As quatro forças que moldam o desenvolvimento humano

\begin{tabular}{|c|c|c|}
\hline Força & Explicação & Implicação educacional \\
\hline Equilibração & $\begin{array}{l}\text { A tendência em manter equilí- } \\
\text { brio entre assimilação (resposta } \\
\text { que utiliza aprendizagem prévia) } \\
\text { e acomodação (mudança de } \\
\text { comportamento em resposta ao } \\
\text { ambiente). }\end{array}$ & $\begin{array}{l}\text { É necessário proporcionar às crianças, } \\
\text { atividades com nível ótimo de dificul- } \\
\text { dade - nem tão difíceis a ponto de } \\
\text { elas se sentirem exageradamente } \\
\text { desafiadas, nem tão fáceis a ponto de } \\
\text { não quererem nenhuma acomodação. }\end{array}$ \\
\hline Maturação & $\begin{array}{l}\text { As forças genéticas que, embo- } \\
\text { ra não determinem o comporta- } \\
\text { mento, estão relacionadas ao } \\
\text { seu desdobramento. }\end{array}$ & $\begin{array}{l}\text { Os professores precisam saber algu- } \\
\text { ma coisa sobre como as crianças pen- } \\
\text { sam e aprendem - sobre seu nível de } \\
\text { maturação e compreensão, para oti- } \\
\text { mizar as experiências educacionais. }\end{array}$ \\
\hline $\begin{array}{l}\text { Experiência } \\
\text { ativa }\end{array}$ & $\begin{array}{l}\text { A interação com objetos e even- } \\
\text { tos reais permite aos indivíduos } \\
\text { descobrir coisas e inventar } \\
\text { (construir) representações men- } \\
\text { tais do mundo. }\end{array}$ & $\begin{array}{l}\text { Essa força apoia um currículo constru- } \\
\text { tivista, aquele no qual o aprendiz é } \\
\text { envolvido ativamente no processo de } \\
\text { descobrir e aprender. }\end{array}$ \\
\hline Interação social & $\begin{array}{l}\text { A interação com as pessoas } \\
\text { resulta na elaboração de ideias } \\
\text { sobre as coisas, as pessoas e } \\
\text { sobre si mesmo. }\end{array}$ & $\begin{array}{l}\text { As escolas precisam oferecer amplas } \\
\text { oportunidades para a integração alu- } \\
\text { no-aluno e professor-aluno nas áreas } \\
\text { acadêmicas (sala de aula) e não aca- } \\
\text { dêmicas (playground, biblioteca etc.) }\end{array}$ \\
\hline
\end{tabular}

Fonte: Extraído de Lefrançois (2008).

As teorias de Piaget tiveram grande inserção no âmbito educacional. Os estudos impactaram o currículo escolar, assim como procedimentos e práticas de instrução e mensuração. O que se pode perceber, é que tanto os estudos de Piaget, quanto os de Bruner demonstram que aprendizagem não é apenas "deslocar itens de fora para dentro da criança" (LEFRANÇOIS, 2008, grifo do autor). Pelo contrário, essas teorias fizeram com que a criança passasse a ter papel central no processo de aprendizagem, favorecendo o desenvolvimento do construtivismo?

Outro teórico representativo para o cognitivismo foi Vygotsky (1896 1934). Sua teoria ficou conhecida como "cognitiva/cultural" por estar diretamen-

7 Definido como "uma abordagem para ensinar e aprender que dá à criança papel central e ativo na construção do conhecimento" (LEFRANÇOIS, 2008, grifos do autor). 
te relacionada com a interação da criança com o meio social. Para ele, o desenvolvimento da cognição está intimamente envolvido com a interação social. Para Vygotsky, a utilização de ferramentas e símbolos por parte dos seres humanos, favoreceu o desenvolvimento da cultura. A existência da cultura era vista como uma das principais diferenças entre os humanos e os animais. Para demonstrar isso, Vygostsky diferencia entre as "funções mentais elementares" e as "funções mentais superiores" (LEFRANÇOIS, 2008, grifos do autor).

As "funções elementares" estão relacionadas aos comportamentos naturais dos seres humanos, que não são aprendidos, mas que já nascem com ele. A capacidade dos recém-nascidos de sugar, chorar ou mesmo balbuciar são exemplos de funções elementares. Em contrapartida, quando a criança cresce, e interage com o meio social (ou com a cultura), as "funções elementares" se transformam em "funções elementares superiores". Elas incluem todas as atividades que são consideradas "pensamento", como por exemplo, a resolução de problemas e a imaginação.

O desenvolvimento das funções superiores, entretanto, só é possível pelo uso da linguagem. Sem a linguagem, a inteligência da criança tem capacidade puramente prática, similar ao dos animais, como os macacos. Nesse sentido, pode-se perceber que o desenvolvimento cognitivo é fruto da "interação verbal" existente entre a criança e os adultos.

Foi com base nesta percepção que Vygostsky desenvolveu o conceito de "zona de desenvolvimento proximal". Relação que permite que o aprendizado aconteça para ambas as partes do processo, ou seja, ao ensinar, o professor aprende com e sobre a criança, assim como a criança aprende em decorrência das ações do professor (LEFRANÇOIS, 2008). Além disso, com a ajuda de um adulto, ou de uma criança mais velha, uma criança que precisa resolver determinado tipo de atividade (relacionada a um nível de aprendizagem diferente do seu), poderá respondê-la com maior facilidade. Isso fará com que a "zona de desenvolvimento proximal" desta criança esteja mais elevada do que de outra que não teve ajuda, podendo abranger uma "esfera maior de funções mentais".

Fato considerado interessante no processo de desenvolvimento da teoria cognitivista, é que ela teve grande influência nos estudos da Ciência da Informação, especialmente após a década de 80, quando, de acordo com Roza- 
dos (2003), ela "passa a ser fortemente cognitivista". Para a autora, a preocupação das ciências ditas cognitivas é entender a forma como os homens pensam, como lidam com a informação e como se apropriam do conhecimento. Essa apropriação é sempre complexa, pois as estruturas de conhecimento de cada pessoa são alteradas constantemente. Neste momento, a abordagem cognitivista se aproxima da Ciência da Informação, pois a faz perceber e trabaIhar com esse conhecimento individual que está em constante mudança; em constante processo de "reestruturação". Tal fato é especialmente importante, quando o indivíduo busca satisfazer suas necessidades de informação.

Nesse sentido, faz-se necessário apresentar algumas considerações sobre o conceito de informação, tornando este termo mais claro.

\subsection{CONCEITO DE INFORMAÇÃO}

Como se pôde perceber, a teoria cognitivista trouxe enormes contribuições para o desenvolvimento de estudos sobre a aprendizagem, além de ter sido importante para o próprio desenvolvimento da Ciência da Informação. Nesse sentido, dando continuidade ao entendimento sobre o processo de LI, será exposto conceito que pode ser considerado sua peça-chave.

O termo informação tem sido conceituado por inúmeros autores, não apenas no âmbito da Ciência da Informação, mas em diversas áreas do conhecimento. Como afirmam Capurro e Hjorland (2007), várias disciplinas científicas utilizam o conceito de informação dentro de um contexto próprio e relacionado a fenômenos específicos. Os autores argumentam, que a partir do modelo de comunicação de Shannon ${ }^{8}$, a palavra informação ganhou influência nas diversas áreas da sociedade, tornando-se um modismo, tanto em língua inglesa, como em outros idiomas.

Esse "modismo" pode ser facilmente compreendido por meio de simples busca pelo termo "informação" em qualquer buscador na internet. No meio acadêmico, o termo é recuperado em quase dois milhões de links, e em busca mais genérica, o resultado ultrapassa a casa dos sessenta milhões de links.

\footnotetext{
8 Os autores se referem ao modelo de comunicação proposto por Shannon em 1948, conhecido como "Teoria Matemática da Comunicação" ou "Teoria da Informação".
} 
Em virtude disso, o conceito de informação, muitas vezes, é transformado em algo difuso e de difícil compreensão. Freire (2006) afirma, por exemplo, que informação é um conceito de difícil tradução teórica, pois é um fenômeno dinâmico, que está presente nas várias atividades humanas. Pinheiro e Loureiro (1995) também argumentam que informação é termo complexo, de acepções múltiplas e riqueza semântica.

Para Cunha e Cavalcanti (2008), informação no contexto da biblioteconomia e da documentação, é vista como registro de conhecimento que pode ou não ser necessário a uma decisão. A informação, em definição mais ampla, refere-se a uma prova que sustenta ou apoia um fato. Para Wurman (2005), o que é entendido como informação para um indivíduo, pode representar apenas dados vazios para outro. Nesse sentido, se não há significado para você, não é informação.

$\mathrm{Na}$ Ciência da Informação, Capurro e Hjorland (2007) afirmam que o uso do termo, implica ter em mente que informação é aquilo que é informativo para alguém e que o que é informativo, varia de acordo com as necessidades de interpretação e habilidades de cada indivíduo. Isso quer dizer que uma informação só passa a se caracterizar como tal, quando está associada a outros fatores, como necessidades e habilidades individuais.

Tais habilidades e necessidades estão presentes em diversos tipos de situação, mas parece ser no ambiente educacional que elas ficam mais aparentes. Isso porque é exatamente neste ambiente, que elas funcionam como "matéria prima" para a aprendizagem. Entretanto, ao passo que elas podem tornar o aprendizado mais satisfatório, também podem comprometê-lo, dependendo de como se dá o seu uso.

\subsubsection{Uso da informação no contexto escolar}

No contexto escolar, a informação é base para a estruturação dos conteúdos e das disciplinas e pode ser entendida como equivalente aos conteúdos de aprendizagem. Encontra-se registrada em diversos formatos, mas é nos livros didáticos que ela ganha mais expressividade. Eles buscam sintetizar conteúdo, dividindo-os por disciplinas e por ano. Dentro do ambiente escolar, po- 
dem ser considerados como as principais fontes de informação para grande parte dos estudantes e dos professores.

Durante algum tempo, a busca e o uso da informação em sala de aula, resumiu-se apenas a uma simples consulta ao livro didático, mas com o desenvolvimento da internet e das TICs, essa consulta se ampliou para outras fontes. Hoje, qualquer site é potencialmente informativo. Isso dá aos estudantes, possibilidades de aprendizado constante, não apenas na escola, mas em todo lugar. Neste caso, o uso do livro didático passou a ser complementado com o uso frequente da internet.

Tal fato fez com que os estudantes passassem a ter acesso a uma imensidão de informações, muitas vezes, não estruturada e de confiabilidade duvidosa. O desafio de se encontrar informação relevante para complementação dos estudos, tornou-se enorme. Apesar de muitos livros didáticos já trazerem incorporado ao texto, endereços eletrônicos para acessar conteúdo específico na internet, muitos alunos preferem buscar informações simplesmente digitando o que precisam em um site de busca. Essa facilidade garantiu maior independência e autonomia aos estudantes, mas passou a ser motivo de problema e preocupação em sala de aula. Informações encontradas em fontes inadequadas podem ser pouco confiáveis ou mesmo apresentar falhas graves em relação a conceitos ou mesmo ao conteúdo em si.

Diante de tal situação, é necessário que o papel do professor, e da escola como um todo, se amplie, isto é, a busca e o uso da informação no contexto da sala de aula precisa de um olhar diferenciado por parte desses atores. Encontrar e utilizar informação relevante na internet não parece ser tarefa fácil, pois exige do estudante habilidades que, muitas vezes, ele ainda não domina. $\mathrm{Na}$ ausência de tais habilidades, o aluno fica refém de sites que apresentam pouca profundidade no conteúdo que disponibilizam. Essa pouca profundidade é logo percebida no conteúdo dos trabalhos escolares e pesquisas solicitadas pelos professores, que muitas vezes se baseiam em apenas uma fonte. A oportunidade de complementação da aprendizagem, é comprometida pela falta de habilidade para se buscar e usar conteúdo relevante disponível na internet.

Para reverter o cenário atual, é preciso que o uso da informação no ambiente escolar seja visto como parte fundamental no processo de aprendizagem. Aprender conteúdos que facilitem a busca, a seleção e o uso da informa- 
ção, pode garantir maiores oportunidades de sucesso na vida acadêmica dos estudantes. Além disso, pode Ihes permitir maior autonomia, isto é, maior independência nos seus processos de escolha. Aprender ao longo da vida tornouse um desafio na atual "sociedade da aprendizagem" (GASQUE; TESCAROLO, 2010), e para tanto, serão necessários novos processos de aprendizagem, como o LI.

\subsection{LETRAMENTO INFORMACIONAL}

O LI é considerado um processo de aprendizagem, que vem se estruturando desde a década de 1940. A ideia foi apresentada pela primeira vez nos Estados Unidos, por meio do documento Information Power: building parterships for learning. Esse documento aborda a função educativa do bibliotecário e propõe habilidades que os estudantes precisam dominar para serem competentes na busca e uso da informação. Originalmente em língua inglesa, a expressão information literacy ganhou inúmeras traduções ao redor do mundo ${ }^{9}$, e foi usada pela primeira vez na década de 1970 (CAMPELLO, 2009).

O conceito foi influenciado pelo construtivismo por surgir na época em que pesquisadores da biblioteconomia e da ciência da informação se familiarizavam com as teorias construtivistas no contexto educacional. Assim, termos como "aprendizagem independente", "aprender a aprender", "aprendizagem ao longo da vida", passaram a fazer parte do discurso do LI (CAMPELLO, 2009). Campello (2003) afirma que as teorias construtivistas contribuíram para o surgimento da estratégia didática denominada resource based learning [aprendizagem baseada em recursos]. Ela enfatizava o uso variado de fontes e de tecnologias de informação, e influenciou o LI. Para Campello (2009), os estudos de usuários desenvolvidos na época, também influenciaram o referido processo.

É possível notar que o LI não se preocupa apenas com a busca e uso da informação, mas almeja desenvolver um aprendizado ao longo da vida. Isso faz com que a informação seja utilizada para tomar decisões e resolver problemas.

\footnotetext{
${ }^{9}$ Diferenças entre os diversos conceitos existentes na literatura não serão foco desta pesquisa.
} 
É, portanto, um processo contínuo que envolve informação, conhecimento e inteligência (DUZIAK, 2003). Isso se reveste de importância cada vez mais crescente na sociedade atual, principalmente com a valorização da informação e do conhecimento como ativos básicos para o desenvolvimento social e econômico.

Para Gasque (2012, p.28), o LI refere-se ao processo de desenvolvimento de "competências para localizar, selecionar, acessar, organizar, usar informação e gerar conhecimento, visando à tomada de decisão e à resolução de problemas". Esse conjunto de competências são necessárias no contexto atual, principalmente pelas inúmeras possibilidades de aprendizado, pelas quais as pessoas passaram a ter acesso. O papel de ensinar não está mais restrito aos ambientes formais de aprendizagem (escolas e universidades), o que demonstra a importância crescente do LI na busca pela autonomia do aprendizado.

Salleh et al. (2011) explica que o excesso de informações não cria, por si só, cidadãos mais informados. Para isso é necessário utilizar um conjunto de habilidades específicas para utilizar a informação de forma eficaz. Para Gasque e Tescarolo (2010), a implementação do LI ao longo da vida acadêmica favorece o processo pedagógico e o aprendizado a longo da vida. Na visão de Kuhlthau (2001, online), LI é a capacidade de se utilizar a informação de forma significativa em todos os aspectos da vida.

Dudziak (2003) ressalta que o LI ${ }^{10}$ está relacionado com processo de internalização de conceitos, atitudes e habilidades necessários à compreensão da dinâmica do universo informacional, com o intuito de proporcionar aprendizado ao longo da vida. Por sua vez, Bhatt (2011) defende que o LI pode ser entendido como um conjunto de competências que contribuem para que o cidadão participe ativa e inteligentemente do processo de tomada de decisões relativas às suas tarefas. $O$ processo não está relacionado apenas com saber utilizar computadores e acessar informações, mas principalmente com a avaliação da natureza e impacto da informação em relação à sua infraestrutura técnica e seu contexto social, cultural e filosófico.

\footnotetext{
10 O termo "Letramento informacional" substitui aqui o termo information literacy, utilizado originalmente pela autora em língua inglesa, apenas na tentativa de uniformizar a terminologia ao longo do trabalho.
} 
Campello (2009, grifo da autora) afirma que atualmente, grande parte dos autores entende que o LI não é um objeto físico a ser alcançado, "mas um continuum de habilidades, familiaridades e eficiências relativas ao uso da informação, representado por graus crescentes de domínio". Nesse sentido, o LI é visto sob outra perspectiva, isto é, ele extrapola a noção de processo de aprendizagem, e se amplia como "instrumento de emancipação política" ou com valores ligados à "informação para a cidadania" (DUDZIAK, 2003). Como afirma Hepworth (2009), o LI pode ser entendido como um conjunto de habilidades responsáveis por capacitar o indivíduo para agir de forma crítica e participativa no mundo, dando a ele condições de interferir ativamente nos processos de aprendizagem. Essa participação ativa pode garantir ao cidadão, maior nível de igualdade, capacitando-o para tomar decisões mais acertadas, o que tende a reduzir discrepâncias sociais.

Atualmente, países desenvolvidos e em desenvolvimento têm reconhecido a importância do LI para os cidadãos e têm implementado programas que desenvolvam habilidades e competências de LI entre estudantes de todos os níveis (SALLEH et al., 2011). Muitos destes programas têm sido desenvolvidos em escolas de educação básica.

\subsubsection{Letramento informacional na educação básica}

O desafio atual da escola é educar crianças e jovens para lidarem com um mundo pleno de tecnologia e rico em informações (KUHLTHAU, 2001, online). Vislumbrar um novo modelo de aprendizagem que favoreça esse processo, não parece ser tarefa fácil. Como afirmam Gasque e Tescarolo (2010), as principais dificuldades para se consolidar o processo do LI no modelo educacional vigente, estão vinculadas a cinco fatores principais: (1) à dificuldade de mudar a cultura pedagógica; (2) à formação inadequada dos professores; (3) à concepção de ensino-aprendizagem; (4) à organização do currículo e (5) à ausência de infraestrutura adequada de informação.

Duziak (2003) também confirma essa dificuldade, ao afirmar que mudar os paradigmas educacionais no sentido da inclusão do LI não é tarefa simples, visto que se trata de um longo processo de mudança cultural e educacional. Ela acrescenta que apesar da existência de novos projetos, ainda não se tem 
discussão ampla sobre a implementação de projeto educacional voltado para a informação. Para a autora, o importante é integrar o LI ao currículo, de forma que ele seja visto como parte do contexto de aprendizagem do estudante, e não como uma disciplina isolada.

Nesse sentido, fica claro que a escola enfrentará grandes desafios para se inserir neste novo contexto. Serão necessários inúmeros esforços para mudar uma realidade historicamente construída, em que seja priorizado um conceito de aprendizagem, com foco no estudante e que tenha como princípio a aprendizagem ao longo da vida. Como afirma Dudziak (2003), a educação de qualidade deve privilegiar a investigação, a autonomia crítica e a busca criativa. Infelizmente, como afirmam Gasque e Tescarolo (2010), o aspecto tradicional da educação cria dificuldades para que o aprendiz interaja com o "objeto de conhecimento". Campello (2009) confirma tais questões ao afirmar que o LI não será adotado como prática pela escola, se não for visto pelos educadores como parte das ações pedagógicas e se for tratado pelos bibliotecários de forma isolada.

Um bom exemplo de programa que pode ser desenvolvido em escolas de ensino básico foi o proposto por Kuhlthau (2002). Em tradução brasileira, o livro "Como usar a biblioteca na escola: um programa de atividades para o ensino fundamental", traz um conjunto de atividades que buscam desenvolver habilidades de localização e interpretação nos estudantes. De acordo com a autora, as atividades são apresentadas de forma inter-relacionadas, constituindo-se em um modelo hierárquico em que uma atividade ajuda na aprendizagem de outra mais complexa. A proposta do programa é de que haja desenvolvimento gradual das habilidades para se utilizar recursos de informação (partindo das séries iniciais).

O programa propõe atividades que contemplem desde a educação infantil (com crianças de aproximadamente quatro anos) até as séries finais do ensino fundamental (por volta dos 14 anos). Entretanto, a autora argumenta que isso vai depender do nível de desenvolvimento do aluno e da proposta pedagógica da escola, podendo incluir crianças menores de quatro anos e avançar com estudantes com mais 14 anos.

Nesse sentido, o programa foi dividido em fases e etapas. A primeira fase busca preparar as crianças para a utilização da biblioteca e corresponde ao 
período inicial da educação infantil, indo até o momento em que ocorre a alfabetização. A segunda fase, destina-se ao uso dos recursos informacionais e acontece no período destinado às séries iniciais do ensino fundamental ( $2^{\circ}$ ao $5^{\circ}$ ano). Por fim, a terceira fase busca desenvolver nos estudantes de $6^{\circ}$ ao $9^{\circ}$ ano, habilidades para conviver em uma sociedade com abundância de informações.

Na primeira fase do programa, são desenvolvidas duas etapas. A primeira trata de atividades para desenvolver atitudes positivas com relação à biblioteca e aos recursos informacionais. A segunda, busca envolver as crianças em atividades de contação de histórias, favorecendo o encantamento pelo livro e estimulando a alfabetização. O programa também leva em consideração as experiências anteriores de cada uma das crianças, no que diz respeito ao livro e à biblioteca. Nesse sentido, a autora afirma que algumas crianças participarão das atividades dessa etapa por um tempo maior de duração, enquanto outras avançarão rapidamente para a etapa seguinte. O ritmo do programa, a ser dado pela escola, será determinado pela vivência das crianças, baseando-se nas suas experiências e necessidades (KUHLTHAU, 2002).

$\mathrm{Na}$ segunda fase, destinada ao uso de recursos informacionais, as crianças passam a exercitar habilidades de leitura, ainda baseadas na escuta de histórias contadas no espaço da biblioteca. A criança passa a ter contato com um maior número de livros, aprendendo a localizar os preferidos e começa a ler de forma mais independente. Ela passa a associar a biblioteca a um espaço interessante, com livros que Ihe chamam a atenção. Após ouvir histórias, a criança é estimulada a discutir a respeito do que foi lido, além de ser convidada a dramatizar ou ilustrar personagens da história. As atividades propostas nesta fase ajudam as crianças a iniciar um processo de análise e avaliação sobre 0 que foi visto, lido ou ouvido. Terão a oportunidade de relembrar, resumir e falar com as próprias palavras sobre o que ouviram.

É nesta fase também, que se busca estimular o uso independente dos recursos informacionais, dando ao estudante maior independência na busca por informações para a realização de trabalhos escolares. Nesta etapa, as crianças deixam de utilizar apenas os livros infantis e passam a explorar todo o ambiente de informação que a cerca. Neste momento, é importante que as crianças aprendam noções básicas de como a informação está organizada na 
biblioteca e como ela pode ser recuperada. Isso permite maior autonomia por parte do estudante na busca por materiais de interesse. Além disso, conhecendo a coleção, ele passa a ter contato com diversidade de assuntos, o que amplia o seu universo de conhecimento.

A terceira e última fase, busca dar ao estudante maior compreensão sobre o ambiente de informações que o rodeia. Ele passa a ter autonomia para consultar catálogos e encontrar as informações de que precisa. Baseados nas habilidades desenvolvidas nas outras duas fazes, os estudantes se preparam para deixar a biblioteca do ensino fundamental para usar, de forma mais independente, coleções de bibliotecas maiores. Nesta fase, é recomendado revisar sobre as habilidades aprendidas anteriormente, utilizando-se jogos para estimular a participação dos estudantes, além de prever atividades complementares para os alunos que ainda estão com dificuldades.

$\mathrm{Na}$ última fase, também são estimuladas técnicas de pesquisa e produção textual, uso de fontes variadas para a elaboração de pesquisas escolares, além de estimular a leitura e a apreciação literária. Nessa fase de transição, os alunos se preparam para deixar o ambiente das escolas de ensino fundamental (repleto de solidariedade) para conviverem em ambiente mais independente, em escolas de nível médio.

Buscando justificar a proposta, Kuhlthau (2002) argumenta que habilidades para uso da biblioteca e dos recursos informacionais não são aspectos isolados do projeto pedagógico da escola. Para a autora, tais habilidades (assim como a leitura e a escrita) são usadas para alcançar outros objetivos de aprendizagem. Neste sentido, as habilidades propostas no programa devem estar vinculadas aos conteúdos programáticos. As atividades desenvolvidas em sala de aula devem exigir a utilização de habilidades para utilizar a biblioteca e a informação.

Para tanto, é necessário haver integração entre o programa desenvolvido e a sala de aula. Isso requer planejamento que envolva tanto o bibliotecário, quanto os professores. Dudziak (2003) recomenda que os programas de LI sejam desenvolvidos no ambiente escolar com a cooperação entre administradores, bibliotecários, docentes e técnicos.

Além do programa elaborado por Kuhlthau, outros modelos têm sido desenvolvidos. Dentre eles, o modelo proposto por Gasque (2012) sobre a im- 
plementação do LI na educação básica por meio de projetos de trabalho. Baseado em estudos de autores como John Dewey, a autora propõe que o LI seja posto em prática por meio da resolução de problemas e com o uso do pensamento reflexivo. O pensamento reflexivo pode ser desenvolvido por meio da utilização dos projetos de trabalho como recursos de aprendizagem e como instrumento para desenvolver a capacidade de buscar e usar a informação.

Diferentemente do que algumas pessoas acreditam, os projetos de trabalho são distintos das pesquisas escolares tradicionais. No ambiente escolar, as pesquisas são solicitadas, muitas vezes, como uma simples tarefa de casa. Muitas não possuem roteiro, e em alguns casos, não possuem orientação adequada por parte dos professores. Os estudantes basicamente buscam informações, na maioria das vezes, para responder questões pontuais, que não exigem tanto esforço. Quando exigem, nem sempre possuem "enfoque globalizador". Os projetos de trabalho se diferenciam das atividades de busca de informação, pois tem a função de organizar conteúdos de ensino-aprendizagem, com base na abordagem globalizante, isto é, na relação entre os diversos saberes "para além da acumulação do conhecimento" (GASQUE, 2012).

Os projetos de trabalho estão baseados no método científico. Isso significa que são sistematizados e que a aprendizagem se inicia com um problema de pesquisa, e finaliza com a conclusão, mesmo que provisória. Esse processo exige que o estudante possua habilidades diferenciadas para cumprir com cada uma destas etapas. Conforme a autora, com base na problematização, o estudante precisa identificar o tipo de informação necessária para solucionar sua questão. Além disso, ele precisa utilizar fontes de informação, com base em estratégias de busca.

Tais projetos requerem a participação efetiva dos estudantes em sala de aula. A proposição sobre conteúdos e temas a serem trabalhados, passa a não ser apenas tarefa do professor, mas parte também das curiosidades e indagações dos aprendizes. Assim, eles participam do processo de busca de informações, fazendo com que se situem diante da informação a partir das próprias possibilidades e recursos. Neste caso, os conteúdos de busca e uso da informação são ensinados de forma contextualizada, sem a necessidade de ações isoladas. Para Gasque (2012), eles devem ser sistematizados no currículo 
educacional, ao longo dos projetos de trabalho e vinculados às diversas áreas de conhecimento.

Nesse sentido, a autora propõe que os conteúdos de LI sejam divididos entre os vários anos escolares. Para que o processo se torne efetivo, é necessário que seja feito de acordo com as necessidades educacionais de cada instituição. Além dos conteúdos, são apresentadas habilidades a serem desenvolvidas nas crianças e adolescentes. O Quadro 2 apresenta modelo sugerido para estudantes do $9^{\circ}$ ano do ensino fundamental.

Quadro 2 - Conteúdos e habilidades de letramento informacional para o 9a ano do ensino fundamental

\begin{tabular}{|c|c|}
\hline CONTEÚDOS & HABILIDADES \\
\hline Pesquisa & $\begin{array}{l}\text { - Emprega os elementos principais que devem constar na } \\
\text { construção do texto - introdução, desenvolvimento e conclusão. } \\
\text { - Descreve os tipos de conhecimentos - conhecimento } \\
\text { empírico, conhecimento científico, conhecimento filosófico, } \\
\text { conhecimento teológico. } \\
\text { - Pesquisa assuntos em várias fontes e elabora texto relacionando } \\
\text { as informações. } \\
\text { - Utiliza roteiro de pesquisa com a síntese das normas - Referência } \\
\text { bibliográfica,Apresentação de relatórios técnico-científicos e Su- } \\
\text { mário - procedimentos da ABNT para apresentação da pesquisa. } \\
\text { - Elabora monografia sobre assunto de interesse. }\end{array}$ \\
\hline Glossário & $\begin{array}{l}\text { - Define glossário. } \\
\text { - Elabora glossários. }\end{array}$ \\
\hline Relatório & $\begin{array}{l}\text { - Explica relatório. } \\
\text { - Descreve os elementos principais de um relatório. } \\
\text { - Elabora relatórios. }\end{array}$ \\
\hline Resenha & $\begin{array}{l}\text { - Define resenha. } \\
\text { - Elabora resenhas. }\end{array}$ \\
\hline Resumo & $\begin{array}{l}\text { - Emprega a técnica de resumo - leitura geral, identificação das } \\
\text { ideias gerais, detecção das articulações lógicas, construção do } \\
\text { texto, revisão. } \\
\text { - Compreende que deve deter-se particularmente nas ideias da } \\
\text { introdução, dos inícios de parágrafos e da conclusão, que muitas } \\
\text { vezes resumem as ideias principais. } \\
\text { - Elabora resumo informativo. }\end{array}$ \\
\hline $\begin{array}{l}\text { Citação } \\
\text { bibliográfica }\end{array}$ & $\begin{array}{l}\text { - Define plágio. } \\
\text { - Compreende que a citação das fontes dá autoridade ao texto. } \\
\text { - Reconhece os tipos de citação - direta, indireta, mista. } \\
\text { - Emprega a norma de citação da ABNT. }\end{array}$ \\
\hline $\begin{array}{l}\text { Técnica de } \\
\text { seminário / } \\
\text { apresentação oral } \\
\text { de trabalhos }\end{array}$ & $\begin{array}{l}\text { - Identifica as características da boa apresentação. } \\
\text { - Possui noção da postura adequada à apresentação. } \\
\text { - Estabelece a estrutura expositiva do trabalho com previsão do } \\
\text { tempo e recursos. } \\
\text { - Apresenta oralmente a pesquisa aos colegas. }\end{array}$ \\
\hline Esquema & - Sintetiza as informações em um esquema. \\
\hline $\begin{array}{l}\text { Acompanhamento } \\
\text { de estudos em casa }\end{array}$ & $\begin{array}{l}\text { - Conhece o cronograma de aulas. } \\
\text { - Planeja as atividades semanais e diárias de estudo. } \\
\text { - Utiliza a agenda escolar para orientar os seus trabalhos. } \\
\text { - Utiliza caderno de estudos para anotações dos assuntos } \\
\text { estudados. }\end{array}$ \\
\hline
\end{tabular}

Fonte: Extraído de Gasque (2012). 
Os exemplos citados representam algumas das possibilidades de implementação de práticas de LI no contexto da educação básica. Como argumentado anteriormente, a viabilidade das propostas está atrelada ao contexto escolar e à participação efetiva dos principais atores educacionais. Em virtude dos variados modelos existentes faz-se necessário realizar mais pesquisas que possam testar tais propostas no intuito de aperfeiçoá-las e torná-las cada vez mais adequadas para a realidade estudada. $O$ tópico seguinte aborda as pesquisas realizadas sobre $o$ assunto.

\subsubsection{Letramento informacional: pesquisas na educação básica}

Apesar das dificuldades de implementação das práticas de LI, levantadas anteriormente, pesquisas apontam que novos conhecimentos são produzidos para melhorar significativamente a capacidade das pessoas de se tornarem aprendizes ativos, isto é, prontos para entender assuntos complexos e preparados para transferir o aprendizado para novos problemas e cenários (BRANSFORD; BROWN; COCKING, 2007). Isto significa que mais pessoas precisam aprender a lidar com a busca e o uso de informações ao longo da vida.

Experiências com a implementação de programas de LI são realizadas em vários países. Entre eles, estudos realizados com estudantes em fase escolar são particularmente importantes para essa pesquisa. Contudo, diante da inexistência de volume considerável de trabalhos com este foco, optou-se também por abordar pesquisas realizadas com estudantes universitários. Nesse sentido, são apresentados trabalhos realizados com estudantes do ensino fundamental e médio, de acordo com pesquisas de Mokhtar, Majid e Foo (2008); Williamson et al. (2007) e Kovalik (2013); e com estudantes do ensino superior como os estudos de Bhatt (2011), Salleh et al. (2011) e Hsieh e Holden (2010).

Os estudos realizados por Mokhtar, Majid e Foo (2008), em pesquisa "quase experimental" que mostra a contribuição do LI na melhoria do desempenho acadêmico dos estudantes, foram realizados em quatro escolas de ensino fundamental em Cingapura, localizada no sudeste Asiático. A revisão de literatura trata de temas como LI, pedagogia, teorias e estilos de aprendizagem, teoria da experiência de aprendizagem mediada de Feuerstein e teoria das in- 
teligências múltiplas de Gardner. A hipótese levantada pelos autores foi a de que os estudantes aprendem competências de LI de forma mais eficaz quando os professores utilizam aulas ou atividades de aprendizagem baseadas nos interesses da turma.

De acordo com os autores, o sistema educacional de Cingapura passou a contar com currículo que priorizava a aprendizagem baseada em projetos. No caso, os alunos deveriam possuir competências de investigação substanciais, a fim de realizar bem o projeto de trabalho. A mudança de currículo teve impacto na experiência e na carga de trabalho dos docentes. Os professores eram esperados em sala de aula não apenas para transmitir o conhecimento que sabiam, mas também para trabalhar a investigação e o LI com os estudantes. $O$ impacto também foi motivado pelo número pequeno de bibliotecários escolares, nas escolas de Cingapura, capacitados para lidar com programas de LI.

Sob essa perspectiva, o objetivo da pesquisa foi determinar como professores e bibliotecários escolares, que trabalhavam com formação para o LI, podiam facilitar a aprendizagem dos estudantes por meio de abordagens de ensino baseadas pedagogicamente no LI. Para tanto, foram selecionadas, aleatoriamente, duas escolas que participaram do que os autores chamaram de "programa de intervenção de aprendizagem mediada" e "programa de intervenção de inteligências múltiplas" (MOKHTAR; MAJID; FOO, 2008, tradução nossa). O primeiro deles envolveu a participação de 279 estudantes e o segundo, 197, com idades ente 13 e 15 anos. A metodologia utilizada pelos autores pode ser vista, de forma resumida, na Figura 3. 
Figura 3 - Metodologia utilizada pelos autores

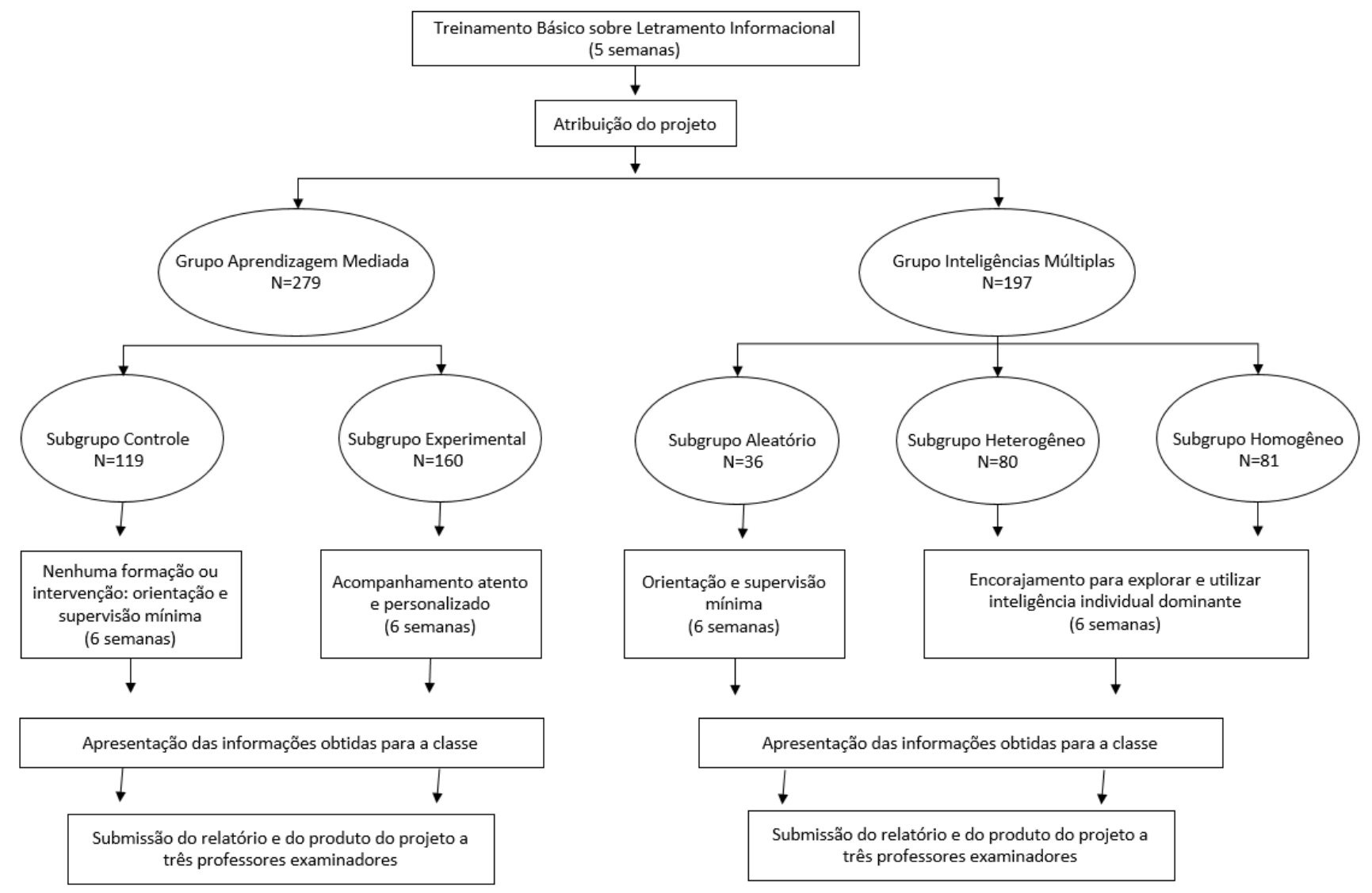

Fonte: Extraído de Mokhtar, Majid e Foo (2008), com adaptações. 
De acordo com a metodologia, os estudantes de ambos os grupos passaram por formação para desenvolver habilidades básicas de LI. O treinamento durou cinco semanas e foi composto por palestras, atividades práticas e em grupo para ajudar os estudantes a aprenderem habilidades iniciais de LI. Após o treinamento, foram definidos dois projetos, um para cada grupo. O grupo de "aprendizagem mediada" ficou com o tema "reciclagem" e o grupo de "inteligências múltiplas" ficou com o tema "ética e sociedade". Para os autores, as escolas solicitaram estes tópicos para cumprir as exigências curriculares (MOKHTAR; MAJID; FOO, 2008, tradução nossa).

Após definição dos projetos, cada grupo foi orientado a buscar informações com base nos respectivos temas. Ao final, deveriam apresentar relatório com a trajetória do projeto e produto final, além de apresentar o projeto para a turma. Neste momento, o grupo de "aprendizagem mediada" foi dividido, aleatoriamente, em subgrupos (de cinco alunos) experimental e de controle. O subgrupo experimental recebeu treinamento e orientação sobre como aplicar as competências aprendidas de LI no projeto. Enquanto o subgrupo recebia orientação e se reunia uma hora por semana com os pesquisadores, o subgrupo de controle recebeu supervisão mínima.

O grupo de "inteligências múltiplas" passou por processo distinto. Os estudantes preencheram questionário com 56 itens sobre inteligências múltiplas, de acordo com a teoria proposta por Gardner, com objetivo de definir a inteligência dominante de cada participante. Após o preenchimento, os estudantes foram divididos em três subgrupos (também com cinco alunos): (1) ao acaso, (2) heterogêneo e (3) homogêneo. De acordo com os autores, os estudantes do subgrupo heterogêneo foram agrupados com base em mistura de "inteligência dominante individual", enquanto que os estudantes do subgrupo homogêneo foram agrupados com base em "inteligência individual uniforme" (MOKHTAR; MAJID; FOO, 2008, tradução nossa). Os subgrupos heterogêneo e homogêneo tiveram supervisão dos pesquisadores, sendo encorajados a explorar e utilizar a inteligência individual ao realizar a tarefa, enquanto o subgrupo aleatório recebeu supervisão mínima.

Ao final de 11 semanas, os estudantes de ambos os grupos apresentaram os relatórios e o produto do projeto, que foram submetidos a três professores examinadores independentes, que analisaram e avaliaram os trabalhos, 
com base em uma proposta de avaliação pré-definida pelos pesquisadores. A pontuação do projeto foi definida pela média entre as três notas atribuídas pelos professores, e ao todo, as notas poderiam variar de 0 a 125 pontos.

Após análises estatísticas dos resultados, percebeu-se que o subgrupo experimental do grupo "aprendizagem mediada" teve desempenho mais satisfatório que o subgrupo controle. Em relação ao grupo "múltiplas inteligências", os resultados apontaram desempenho superior dos subgrupos organizados de forma homogênea e heterogênea, em relação ao subgrupo organizado aleatoriamente. Os testes realizados, indicaram diferenças significativas entre os estudantes que receberam supervisão e os não orientados. Os dados do estudo foram enriquecidos com entrevistas de grupo, pré-testes e intervenções realizadas pelos pesquisadores.

$\mathrm{Na}$ discussão sobre os resultados, os autores afirmam que em relação ao grupo de "aprendizagem mediada" ficou claro que as competências do LI não podem ser aprendidas simplesmente por meio de treinamentos rápidos. As competências devem ser reforçadas por meio de treinamento mais próximo, feito de forma mediada, de modo que os estudantes possam identificar lacunas de aprendizagem, corrigi-las e melhorar o aprendizado sob a supervisão e orientação de especialistas. Para os autores, um mediador que faça as perguntas certas e que orientem os estudantes a refletir sobre a sua própria aprendizagem, faz muita diferença. Eles afirmam ainda, que os estudantes eram mais capazes de aplicar as competências aprendidas em seus relatórios por causa das perguntas feitas pelo mediador. Perguntas do tipo "porque vocês utilizaram essas fontes de informação e não outras?" (MOKHTAR; MAJID; FOO, 2008, tradução nossa), fizeram com que os pesquisadores identificassem quais grupos tinham realmente aprendido a aplicar as competências adquiridas anteriormente.

Para os pesquisadores, aulas planejadas de forma colaborativa, permitem uma aprendizagem mais ampla para os estudantes, isto é, faz com que eles aprendam e apliquem perfeitamente habilidades de LI dentro do currículo.

Os resultados da pesquisa apontaram a necessidade de que o LI seja ensinado e reforçado, gradualmente, desde a educação básica. De acordo com os autores, isto irá assegurar a continuidade da aprendizagem dos estudantes na aplicação das habilidades de LI. A pesquisa apontou também, que os estu- 
dantes de ensino básico ainda não possuem as competências necessárias sobre o LI. Os autores sugerem portanto que a prática do LI seja integrada ao currículo escolar e ensinada em etapas, começando no nível da educação básica.

Neste caso, o LI seria trabalhado nas escolas de forma gradual, do ensino fundamental, passando pelo médio até chegar ao ensino superior. Os autores afirmam que o LI é um processo de aprendizagem ao longo da vida e que deve começar cedo na vida de uma pessoa. Aprender gradualmente faz com que os estudantes desenvolvam mais competências e adquiram experiências por meio da educação formal e informal.

Nesse sentido, seria necessário um modelo pedagógico de LI que pudesse traduzir esse processo. A Figura 4 aponta o modelo sugerido pelos autores.

Figura 4 - Espiral de aprendizagem hierárquica em letramento informacional

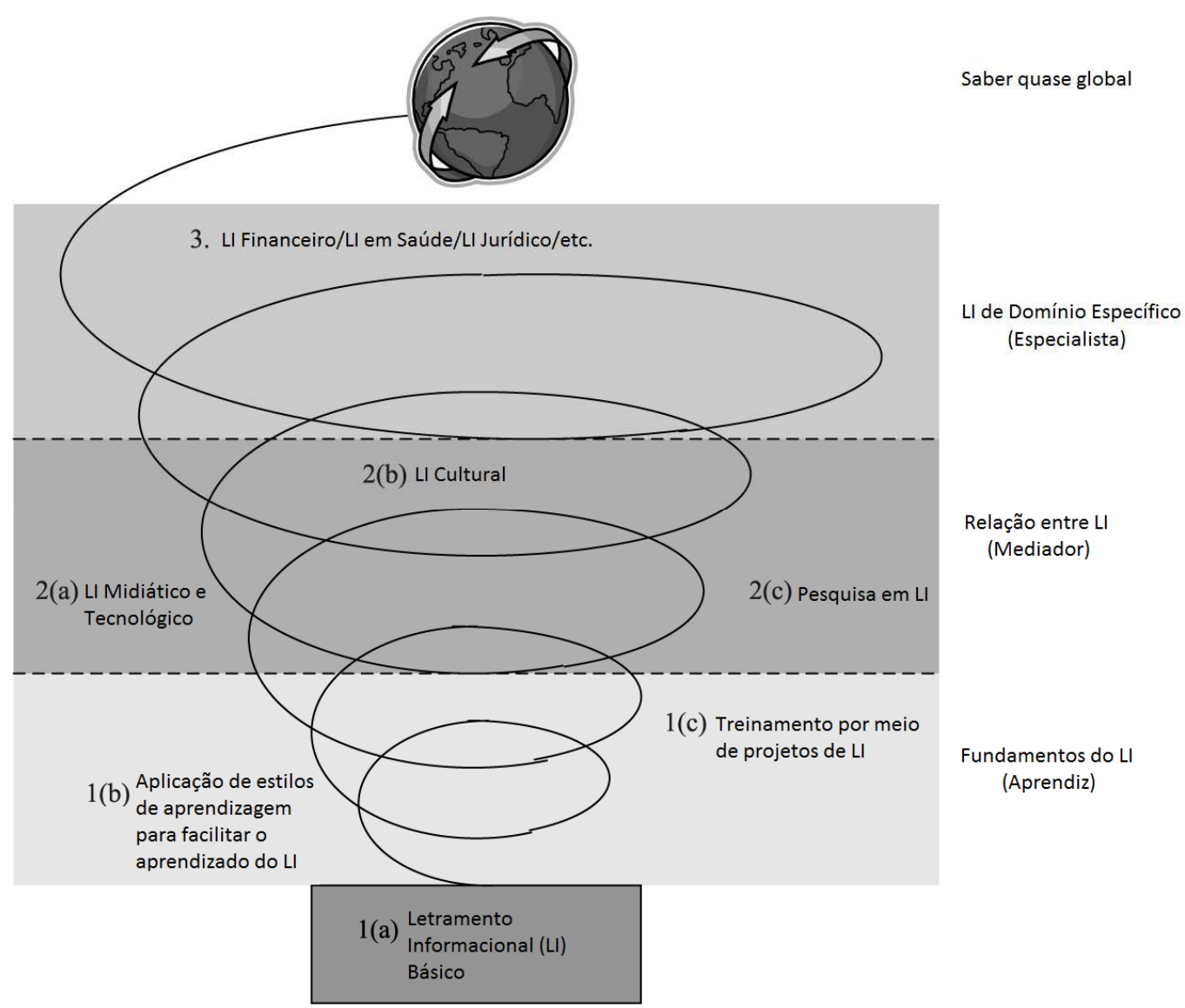

Fonte: Extraído de Mokhtar, Majid e Foo (2008), com adaptações. 
O modelo em espiral indica proximidade da pesquisa realizada, com a proposta de "currículo em espiral", defendida por Jerome Bruner. De acordo com o modelo, os estudos sobre LI estariam divididos em "nível básico", "intermediário", "específico" e "saber quase global" (MOKHTAR; MAJID; FOO, 2008, tradução nossa).

No nível básico, os estudantes teriam as primeiras noções sobre o assunto, aplicariam estilos de aprendizagem e teriam formação por meio de projetos de LI. No nível intermediário, os estudantes aprenderiam a relacionar diferentes tipos de LI, como o midiático, a tecnologia da informação, o letramento cultural e a pesquisa. O nível específico propiciaria ao estudante domínios especializados sobre letramento financeiro, letramento em saúde, letramento jurídico entre outros. A partir deste nível, os estudantes poderiam lidar com um "saber quase global".

Em suas considerações finais, os autores afirmam que pesquisas similares devem ser feitas, principalmente no âmbito do ensino fundamental. Além disso, apontam que o processo de aprendizagem por meio do LI não pode ser feito de forma transitória, mas deve ser visto como processo contínuo e que seja baseado em proposta pedagógica apropriada.

Outra pesquisa na educação básica foi realizada por Williamson et al. (2007). Em artigo que aborda busca e uso de informações e a ligação entre o uso de boas práticas e a prevenção sobre o uso do plágio em ambiente eletrônico, os autores abordam questões tais como: preferências de fontes de informação, confiabilidade das fontes, atitudes de busca de informação, registro, uso e atribuição de fontes de informação, entre outras. Para tanto, realizaram pesquisa qualitativa em quatro escolas australianas, com estudantes de diferentes fazes do ensino médio.

O método utilizado para a realização do estudo foi o etnográfico filosófico e as técnicas foram a observação, entrevista e análise de documentos. Os dados levantados referem-se à primeira fase do projeto (dividido em três partes), intitulado "Uso inteligente da informação". O principal objetivo foi analisar as atitudes dos estudantes para buscar e utilizar informações e entender sua aprendizagem com base na compreensão e reconhecimento do plágio (WILLIAMSON et al., 2007). 
As amostras foram selecionadas nas quatro escolas e foram representadas por estudantes de anos escolares diferentes. Os grupos tinham 22, 11, 18 e 15 alunos respectivamente. A observação inicial foi realizada em sala de aula e na biblioteca, no momento em que os alunos faziam seus trabalhos. Posteriormente, os estudantes passaram por entrevistas no momento de realização do trabalho e depois que o trabalho estivesse concluído. Nesta última etapa, a entrevista tinha como foco o que os alunos tinham aprendido com a busca e uso das informações e a compreensão deles sobre plágio. Professores e bibliotecários também foram entrevistados para saber qual a percepção que cada um tinha sobre essa questão.

Ao final, os trabalhos elaborados pelos estudantes foram analisados e comparados com as fontes de informação originais, no intuito de perceber a existência e a extensão do plágio. Livros e sites foram consultados, de acordo com as referências indicadas. A existência de plágio nos trabalhos foi definida com cores diferentes, permitindo aos pesquisadores determinar o percentual de plágio existente.

Em revisão de literatura, os autores apresentaram dados de outras pesquisas e abordaram informações sobre a utilização da internet na elaboração de trabalhos. $\mathrm{Na}$ análise dos dados da pesquisa, a preferência pelo uso da internet na elaboração de trabalhos, por parte dos estudantes pesquisados, ficou clara. Em várias citações recolhidas nas entrevistas, os estudantes deram evidências de tal preferência. A facilidade em se pesquisar no Google, assim como a baixa frequência de uso da biblioteca ou mesmo a comodidade de fazer o trabalho em casa, foram alguns dos argumentos. Mesmo estudantes que apontaram o livro como fonte de informação mais segura, ainda consideravam a internet como fonte mais "conveniente" (WILLIAMSON et al., 2007, tradução nossa).

A revisão de literatura também levantou questões sobre as dificuldades que estudantes apresentam na utilização da internet. Entre elas estão a falta de percepção sobre o conceito de palavra-chave e falta de estratégias de busca e navegação. Em análise realizada pelos autores, ficou evidente que a autoconfiança dos jovens era grande no uso da internet, mas que eles apresentam pouca "sofisticação" quando a questão é busca e uso de informações (WILLIAMSON et al., 2007, tradução nossa). Em virtude desta dificuldade, muitos estu- 
dantes buscam ajuda. Às vezes na família, ou com seus professores e bibliotecários.

Ao analisar os dados levantados, os autores identificaram que vários estudantes pesquisados acreditavam já possuir habilidades necessárias para realizar as tarefas exigidas pelo trabalho. Isto é, grande parte dos alunos achava que não aprenderia nada de novo sobre como buscar e utilizar informações. Isso pôde ser percebido nas falas de cada um deles registrada nas entrevistas. Alguns, entretanto, apontaram que aprenderam algo diferente no processo.

Em pergunta feita a professores e bibliotecários sobre o porquê dos alunos cometerem plágio, os pesquisadores identificaram que isso geralmente acontece para se economizar tempo e por exigir menos esforço. Perceberam também que a falta de gestão do tempo por parte dos alunos, também favorece o plágio. Deixar o trabalho para a última hora, pode levar os alunos a cometerem plágio. Ao todo, dois terços dos estudantes participantes da pesquisa utilizaram a internet como principal fonte de busca de informações. Em toda a pesquisa, os alunos que cometeram plágio, tinham preferencialmente, feito 0 trabalho utilizando a internet.

A conclusão da pesquisa aponta que a confiança dos estudantes em buscar informação era, muitas vezes, pouco fundamentada. Estudantes que tiveram mais contato com professores e bibliotecários, foram mais influenciados com informações de qualidade. Para os autores, mesmo os estudantes mais velhos não tinham conseguido desenvolver boas práticas para se evitar o uso do plágio.

Outra pesquisa que envolveu estudantes em fase escolar foi a realizada por Kovalik (2013). Ele estudou como alunos do ensino médio, na cidade de Columbus, Ohio, utilizam habilidades de LI para realizar projetos de pesquisa. O trabalho foi feito com 289 estudantes que utilizaram o LI em processo de investigação. Parte deste grupo, foi convidado posteriormente para participar de entrevista, contribuindo com maiores detalhes sobre seu processo de busca e uso de informações. Os resultados foram analisados sob o ponto de vista do papel do bibliotecário escolar neste contexto de aprendizagem.

A revisão de literatura levantada pela autora apresenta informações sobre a importância do LI para estudantes dos mais variados níveis de ensino. Entretanto, o fato de estarem próximos do ensino superior, colocam os estu- 
dantes de ensino médio em posição de destaque nesta questão. Possuir habilidades de LI, torna-se componente diferenciado, que pode gerar impacto na formação e na vida profissional desses alunos. Nos vários estudos analisados, a autora relata que os estudantes são capazes de buscar e utilizar informações variadas. Entretanto, não apresentam competências adequadas para analisálas criticamente e considerá-las relevantes ou não.

Apesar das incertezas que muitos estudantes encontram nos momentos iniciais de busca de informação, a revisão aponta que eles normalmente não procuram ajuda de bibliotecários. Geralmente confiam nos próprios amigos ou na instrução que acreditam ter sobre o assunto. Apesar dos esforços realizados por professores, os bibliotecários escolares são apontados como fundamentais nesse processo. Contudo, só podem exercer o seu papel se os alunos estiverem certos de que precisam de ajuda.

Para realizar a pesquisa, a autora se baseou em três questões principais: 1) Quais são as percepções dos alunos de ensino médio sobre o processo de pesquisa; 2) Onde eles buscam informação e a quem pedem ajuda e 3) Como eles utilizam os recursos da biblioteca (KOVALIK, 2013, tradução nossa). Durante o projeto de pesquisa, houve colaboração de bibliotecários de escolas de ensino médio e de um docente da universidade local.

A pesquisa foi apresentada aos estudantes em dia previamente combinado e a explicação do objetivo e de como os estudantes poderiam participar do projeto, foi feita pelo docente. Após assinarem termo de consentimento, os alunos receberam questionário com 28 itens que deveriam completar. Foi sondada a possibilidade do questionário ser disponibilizado de forma eletrônica, mas a ideia foi descarta. Os pesquisadores tiveram receio de que muitos alunos optariam em sair do processo se tivessem que visitar um site para responder as perguntas. Ao todo, foram preenchidos 289 questionários, em um tempo médio de 15 min. cada.

Após esta etapa, foram escolhidos, aleatoriamente, 28 participantes para entrevista. O contato foi realizado pelos bibliotecários, entretanto, apenas 19 estudantes concordaram em participar. Na semana seguinte à pesquisa, foram agendados dois dias, com horários de $20 \mathrm{~min}$., para os alunos participarem. Além das perguntas formuladas para o momento, os alunos foram estimulados 
a darem informações complementares. As entrevistas foram realizadas em salas separadas, na biblioteca da escola.

O instrumento de pesquisa utilizado no estudo, foi baseado em pesquisa anterior, realizada pela pesquisadora Carol Kuhlthau, relacionada à percepção do aluno sobre o processo de pesquisa. Para o questionário, foram utilizadas 20 perguntas elaboradas pela autora e mais oito complementares, elaboradas pelos pesquisadores, totalizando 28 perguntas. Os itens foram respondidos com base em escala tipo Likert, com a seguinte pontuação: (1) "quase nunca", (2) "raramente", (3) "às vezes", (4) "muitas vezes" e (5) "quase sempre". No caso das entrevistas, foram elaboradas 13 perguntas relacionadas ao aprendizado dos estudantes sobre o processo de pesquisa durante o ensino médio. Os dados recolhidos no questionário foram transpostos para o computador, gerando estatísticas e os dados das entrevistas foram analisados de forma qualitativa, buscando-se identificar temas ou padrões comuns (KOVALIK, 2013).

Com relação aos dados estatísticos, especificamente sobre a percepção dos estudantes com o processo de pesquisa, os resultados apontaram, entre outras coisas, que mais da metade dos alunos já tinham um foco claro sobre o assunto antes de usar a biblioteca. A grande maioria sinalizou que suas pesquisas ficaram mais claras à medida que eles iam reunindo informações. Além disso, eles ficavam mais interessados na pesquisa com o passar do tempo. Entretanto, mais da metade dos estudantes responderam que "às vezes", "raramente" ou "quase nunca" preferem localizar todos os recursos de informação antes de lê-los. Cerca de $10 \%$ dos alunos apontaram que "muitas vezes" ou "quase sempre" ficam confusos ao iniciar uma pesquisa e quase todos responderam que precisam de outros livros para a realização da pesquisa.

No que se refere ao local de busca e a quem pedem ajuda, a biblioteca da escola foi indicada por mais da metade dos estudantes, como sendo o local onde eles encontram informações para o projeto de pesquisa. Entretanto, cerca de $52 \%$ dos respondentes disseram que "quase nunca" ou "raramente" visitam a biblioteca várias vezes, quando tem algum projeto de pesquisa para fazer. Cerca de $75 \%$ consideram útil conversar com outras pessoas sobre o tema a ser pesquisado, contudo, $49 \%$ dizem que "quase nunca" ou "raramente" pedem ajuda aos bibliotecários escolares. Quase o mesmo total de respondentes, 
também afirmam não pedir ajuda para localizar materiais específicos na biblioteca.

Com relação à pergunta sobre como os estudantes utilizam os recursos da biblioteca, os resultados mostraram que mais da metade dos estudantes "quase nunca" ou "raramente" utilizam a biblioteca da escola, a não ser que seja para fazer trabalhos relacionadas com atividades da escola. Entretanto, cerca de um terço dos respondentes disseram procurar a biblioteca para levar livros de leitura pra casa. Os dados mostraram também, que os estudantes costumam utilizar apenas a biblioteca da escola para realizar pesquisas. Somente $16 \%$ apontou que costuma utilizar mais de uma biblioteca para fazer pesquisas. Por fim, cerca de $50 \%$ dos respondentes sinalizou que "muitas vezes" ou "quase sempre" se aprende em um curso com a elaboração de projetos de pesquisa (KOVALIK, 2013).

A conclusão do trabalho afirma que os estudantes foram bem sucedidos na utilização dos recursos da biblioteca para elaboração dos seus projetos de pesquisa. Além disso, ficou claro que os alunos aprenderam mais sobre os temas investigados. Eles puderam compreender que o processo de pesquisa leva tempo e requer utilização de diferentes fontes e recursos de informação, com apresentação de perspectivas diferenciadas. Para que esse processo de aprendizagem seja mantido e estimulado, Kovalik (2013) afirma ser necessário que professores e bibliotecários trabalhem juntos, estruturando propostas de aprendizagem em que o bibliotecário seja inserido como parte integrante do processo, mantendo interação direta com os alunos, contribuindo efetivamente para o processo de ensino e favorecendo a aprendizagem ao longo da vida.

Apesar de não retratarem a realidade da educação básica, estudos sobre LI, realizados no âmbito universitário, também contribuem para elaboração desta pesquisa. Neste sentido, o tópico seguinte abordará pesquisas no âmbito do ensino superior.

\subsubsection{Letramento informacional: pesquisas no ensino superior}

Estudos sobre LI no meio universitário são mais comuns que os realizados na educação básica. Tal fato pode ser explicado em virtude do pioneirismo das universidades e bibliotecas universitárias na participação e realização de 
pesquisas sobre o assunto. Esse pioneirismo teve início nos anos 1970, primeira utilização do termo LI (CAMPELLO, 2009), e tem se consolidado ao redor do mundo. Atualmente, pesquisas no meio acadêmico são realizadas em diversos países, apresentando resultados relevantes para aplicação prática e estudos futuros.

O trabalho realizado por Bhatt (2011), por exemplo, apresenta levantamento da organização de programas de LI nas universidades e bibliotecas universitárias na Índia. O estudo destaca o aumento do uso de modelos e padrões de LI nas bibliotecas, com ênfase na aplicação das TICs, em virtude do aumento exponencial de informação.

Em revisão de literatura, o autor deixa claro que existem muitos estudos sobre LI, mas afirma que a existência de instrumentos que avaliem a competência dos alunos, e não a instrução dada pelas bibliotecas, ainda é escassa. Ele apresenta também, modelos e padrões de LI já testados e bem aceitos ao redor do mundo. Ganham destaque o Society of College, National and University Libraries (SCONUL), o The Big 6, o Information Literacy Standards for Student Learning, publicado pela Associação Americana de Bibliotecários Escolares (AASL), o Information Literacy Standards, elaborado pela Federação Internacional das Associações de Bibliotecas e Bibliotecários (IFLA), o National Educacional Techonology Standards, e o Information Literacy Competecncy Standards for Higher Education, estruturado pela Associação das Bibliotecas Universitárias e de Pesquisa (ACRL).

O modelo SCONSUL é utilizado para promover a excelência nos serviços de bibliotecas universitárias e nacionais em todo o Reino Unido e na Irlanda. Está baseado em sete habilidades principais, a saber: (1) reconhecimento da necessidade de informação, (2) distinção das formas em que a informação pode ser tratada, (3) construção de estratégias para localizar a informação, (4) capacidade para localizar e acessar informações, (5) comparar e avaliar informações de diferentes fontes, (6) transmitir informações aos outros de forma adequada, e (7) capacidade de síntese e construção de conhecimento com base na informação existente (BHATT, 2011).

O modelo The Big 6 é conhecido por algumas pessoas como "estratégia de resolução de problemas de informação". Com o The Big 6, os alunos podem lidar com qualquer problema envolvendo informação. $O$ modelo divide a apren- 
dizagem em seis etapas: definição de tarefas; estratégias de busca de informação; localização e acesso da informação; uso da informação; síntese e avaliação. Além disso, envolve outras quatro fases relacionadas com a preparação da pesquisa, o acesso aos recursos, o processamento das informações e a transferência da aprendizagem obtida.

Dentre os padrões, os definidos pela ACRL são mais populares e foram amplamente testados. Eles utilizam indicadores de desempenho que são elaborados com o intuito de fornecer orientação para o desenvolvimento de métodos de avaliação, além de instrumentos e estratégias para medir os resultados da aprendizagem dos alunos. Podem ser utilizados também para avaliar habilidades de LI em professores e bibliotecários.

Na pesquisa de Bhatt (2011) são apresentados cinco padrões ACRL. O primeiro padrão de LI aponta que um aluno letrado informacionalmente tem condições de determinar a extensão da informação de que necessita. Para este padrão, são apresentados como exemplo, quatro indicadores de desempenho: (1) o aluno letrado informacionalmente define e articula sua necessidade de informação; (2) identifica uma variedade de tipos e formatos de fontes potenciais de informação; (3) considera benefícios e custos para adquirir a informação necessária e (4) reavalia a natureza e extensão da necessidade de informação.

Os quatro padrões restantes afirmam que: o aluno letrado informacionalmente acessa as informações de forma eficaz e eficiente; avalia criticamente e incorpora a informação selecionada à sua base de conhecimentos e valores; usa a informação de forma eficaz para alcançar um objetivo específico; e compreende muitas das questões econômicas, sociais, éticas e legais sobre 0 acesso e uso da informação (BHATT, 2011).

Além dos padrões $A C R L$, o autor também aponta alguns definidos pela IFLA. Tais padrões são agrupados em três componentes. O primeiro diz respeito ao acesso à informação de forma eficaz e eficiente. É analisado se o usuário define ou reconhece sua necessidade de informação; se busca fazer algo para encontrar a informação; se expressa ou define sua necessidade de informação; se inicia o processo de busca; se localiza informações; se identifica e avalia fontes potenciais de informação; se desenvolve estratégias de busca e acessa as fontes selecionadas e por fim, se recupera as informações selecionadas. 
O segundo componente está relacionado com a avaliação crítica que 0 usuário faz da informação e de como ela determina qual informação é melhor ou mais útil. Capacidade de análise, interpretação, síntese, avaliação e organização da informação são observados neste componente.

O terceiro e último componente identifica se o usuário utiliza a informação de forma precisa e criativa. É observado entre outras coisas, se ele encontra novas maneiras de comunicar a informação encontrada, se respeita questões éticas e legais sobre o uso da informação e se respeita padrões estéticos de apresentação.

O uso de tais modelos e padrões tem se justificado em virtude dos avanços e inovações trazidas pelas TICs. No caso específico da Índia, isso mudou toda a filosofia do LI no país (BHATT, 2011). Para o autor, as bibliotecas passaram a se preocupar com programas que ajudassem seus usuários a desenvolver a capacidade de identificar necessidades de informação, a buscar recursos para atender a essas necessidades e a comunicar o conhecimento resultante deste processo.

O autor sugere que os programas de LI desenvolvidos por universidades na Índia se tornem obrigatórios para estudantes de graduação, pós-graduação e pesquisadores. Além disso, instalações como laboratórios de informática devem ser utilizadas para treinamento prático dos usuários. Para conseguir isso de forma adequada, é necessário que bibliotecas e profissionais da informação tenham competências adequadas em diversas áreas, assim como possuir conhecimentos de várias fontes de informação com as competências pedagógicas apropriadas.

Outra pesquisa conduzida no meio universitário foi realizada por Salleh et al. (2011). Os autores buscaram analisar o efeito do LI sobre o desempenho acadêmico de estudantes de graduação em universidade pública da Malásia. A pesquisa foi realizada com base em curso de formação sobre LI dado pela biblioteca da universidade durante a semana inicial de aulas. A hipótese é que o LI possibilita que os estudantes do ensino superior aprendam de forma mais eficaz e desenvolvam o pensamento criativo.

O estudo foi realizado a partir do método quantitativo e se baseou na seguinte questão: até que ponto o LI tem efeito sobre o desempenho acadêmico dos estudantes? Para tanto, os autores apresentaram duas hipóteses de 
pesquisa: $\left(\mathrm{H}_{0}\right)$ Não há efeito significativo do LI sobre o desempenho acadêmico dos estudantes; e $\left(\mathrm{H}_{1}\right)$ Há efeito significativo do LI sobre o desempenho acadêmico dos estudantes (SALLEH et al., 2011, tradução nossa). O modelo conceitual apresentou três variáveis independentes e uma variável dependente. A relação entre elas pode ser vista na Figura 5.

Figura 5 - Relação entre variáveis

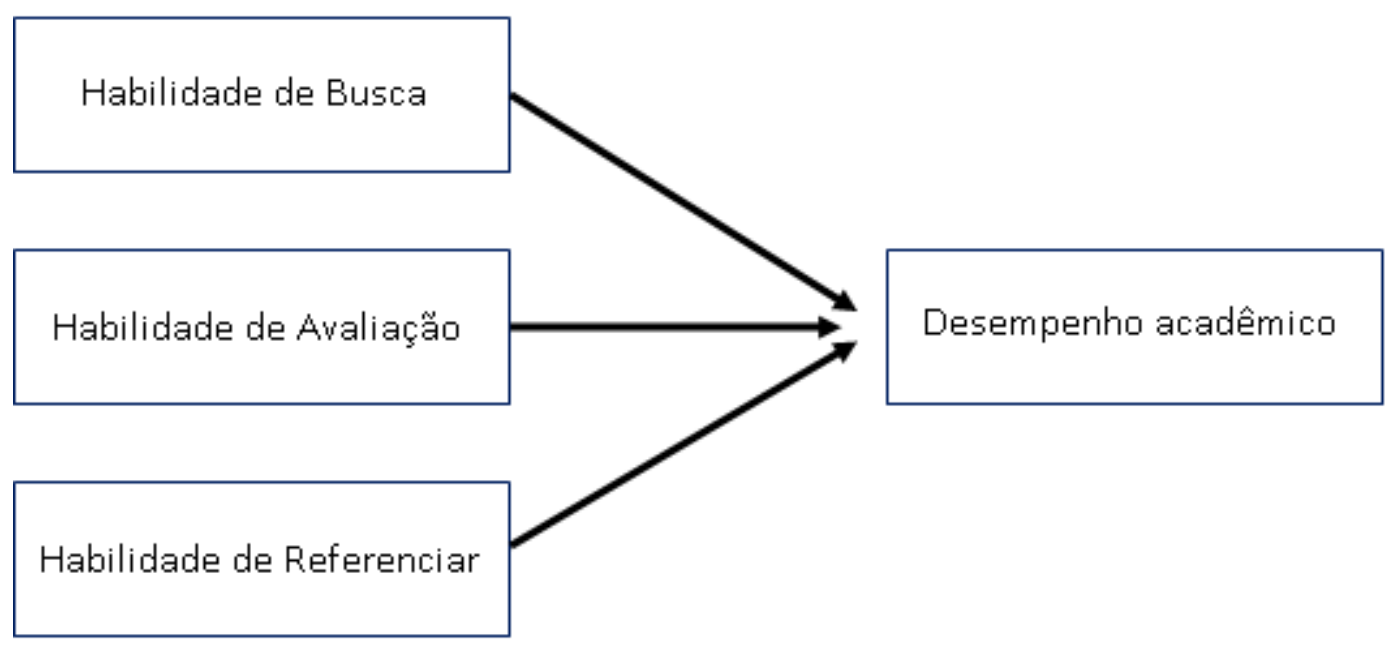

Fonte: Extraído de Mokhtar, Majid e Foo (2008), com adaptações.

O método de pesquisa utilizado foi a aplicação de questionários e os dados foram analisados por meio do software Statistical Package for Social Science (SPSS). Após análise, os autores identificaram que a hipótese $\mathrm{H}_{0}$, definida como "hipótese nula" tinha sido confirmada. Isso demostrou que não houve efeito significativo do LI no desempenho dos estudantes pesquisados. Uma das explicações dadas pelos autores é a de que o modelo conceitual definido foi pouco confiável e que seria necessário considerar e analisar outras variáveis independentes tais como habilidades de estudo, habilidades de pesquisa e escrita acadêmica (SALLEH et al., 2011). Os resultados da pesquisa foram, portanto, inconsistentes com pesquisas anteriores. Isto é, não confirmaram estudos que apontam a melhoria do desempenho acadêmico por meio do LI.

Apesar de resultados conflitantes com o de outras pesquisas, os autores recomendam que programas de LI sejam incorporados nos currículos universitários. Além disso, afirmam que professores devem estar aptos a orientarem os seus alunos e precisam encontrar espaço nas suas aulas para trabalhar con- 
ceitos de LI. Apontam também a necessidade de colaboração entre as faculdades, bibliotecários e outros profissionais da informação, assim como a existência de planejamento e orçamento, para que tais programas obtenham sucesso.

Diferentemente de estudos que apontam a necessidade de programas mais amplos sobre LI, Hsieh e Holden (2010) demonstraram que uma única sessão de instrução pode ter efeito positivo para a aprendizagem. Em estudo de caso realizado com estudantes universitários em New Jersey, Estados Unidos, os autores analisaram a eficácia da sessão única de LI sobre a aprendizagem de estudantes que tiveram esta sessão integrada ao seu currículo.

A pesquisa foi realizada durante três semestres, e contou com a participação de 373 alunos do curso de Tecnologia da Informação (TI). Foi viabilizada por meio de parceria entre a biblioteca e a faculdade de TI. Apesar da possibilidade de enriquecimento do processo, os pesquisadores não estabeleceram um grupo de controle. Os instrumentos de pesquisa foram o pré e pós-teste, com perguntas de múltipla escolha e verdadeiro ou falso, aplicados uma semana antes e uma semana depois da instrução, respectivamente. Para evitar inconsistências no resultado, ambos os testes foram idênticos, permitindo análise dos mesmos conceitos antes e depois de sua aplicação.

Ao todo foram avaliadas 15 questões envolvendo 11 objetivos sobre serviços e recursos da biblioteca. Tudo foi estruturado para ser analisado de forma eletrônica, por meio do "Sistema de Gestão de Curso" da faculdade (HSIEH; HOLDEN, 2010, tradução nossa). Segundo os autores, esse formato foi utilizado porque instrumentos como entrevistas e perguntas abertas são muito demorados, o que comprometeria o tempo de aula dos alunos e o tempo de trabalho dos bibliotecários.

A análise dos resultados foi feita com a aplicação de testes específicos. Os dados apontaram melhora significativa nas respostas após aplicação do pós-teste, mas também indicaram pontos fracos na compreensão dos alunos sobre conceitos de LI. Além disso, os autores afirmam, que embora os bibliotecários tivessem tentado ensinar todos os 11 objetivos, evidências apontaram que alguns temas são muito complicados para serem compreendidos em apenas uma sessão de instrução sobre LI. Avaliação de recursos web e avaliação de fontes de informação são dois exemplos de assuntos que exigem mais tempo de instrução (HSIEH; HOLDEN, 2010). 
Para os autores, a pesquisa também apontou que muitos dos alunos consideraram importante o aprendizado sobre LI. Grande parte deles reconheceram que tinham aprendido coisas novas e úteis e $78 \%$ concordaram que o que tinham aprendido poderia ser utilizado na sua vida acadêmica. Entretanto, percebeu-se que apesar dos resultados positivos, a sessão única de instrução sobre LI será mais satisfatória se fizer parte de um sistema mais integrado, em que conceitos-chave sejam trabalhados por vários instrutores em momentos diversos.

Tais pesquisas demonstram a diversidade de propostas sobre LI desenvolvidas ao redor do mundo. O estudo dos resultados apresentados, assim como o estudo dos teóricos da área, favorecem a definição de conceitos relevantes para este trabalho. $O$ tópico a seguir apresentará os conceitos adotados no referencial teórico desta pesquisa. 


\section{REFERENCIAL TEÓRICO}

O referencial teórico refere-se aos conceitos-chave adotados na pesquisa e às inter-relações entre eles. Primeiramente, adota-se a definição de aprendizagem em consonância com Lefrançois (2008), que a conceitua como mudança no potencial de comportamento e não apenas mudança no comportamento. Isso acontece porque nem sempre os efeitos permanentes da experiência ficam aparentes. Muitas vezes, é necessário que haja oportunidade para confirmar a aprendizagem. A leitura de um livro pode implicar, por exemplo, em mudanças na capacidade de se realizar algo, assim como, pode interferir no desempenho do indivíduo para realizar determinada tarefa. Essa aprendizagem pode ficar latente até que apareça ocasião favorável para que seja explicitada.

No contexto educacional, é fundamental que as oportunidades para se confirmar a aprendizagem sejam abundantes. Cabe à escola, permitir que os estudantes tenham experiências de aprendizado diversas, a partir de diferentes processos de aprendizagem. Nesse sentido, é importante afirmar que a aprendizagem também é influenciada pelo tipo de disciplina ou conteúdo que se quer aprender. No escopo dessa pesquisa, ela relaciona-se ao aprendizado do componente Ensino Religioso, disciplina com características e conteúdos próprios, ministrada regularmente na instituição de ensino escolhida para a pesquisa. Importante afirmar, que essa disciplina não busca levar os estudantes a aderirem a determinada confissão religiosa.

O estudo baseia-se também no conceito de LI apresentado por Gasque (2012). Para ela, o termo se configura como processo de aprendizagem capaz de desenvolver competências para localizar, selecionar, acessar, organizar, usar informação e gerar conhecimento, visando à tomada de decisão e à resolução de problemas. Esse processo busca garantir a autonomia do aprendiz e permite que ele aprenda ao longo da vida.

Tratando da questão da informação, adota-se o conceito apresentado por Capurro e Hjorland (2007), que afirmam que informação é aquilo que é informativo para alguém e que o que é informativo, varia de acordo com as necessidades de interpretação e habilidades de cada indivíduo. Isso quer dizer que uma informação só passa a se caracterizar como tal, quando está associada a fatores como necessidades e habilidades individuais. Apesar do termo 
"informação" não aparecer explicitamente no Modelo Teórico apresentado na Figura 6, entende-se que ela permeia todo o processo.

Nesta pesquisa, o termo "Ensino Fundamental" refere-se ao segmento que atende estudantes do $1^{\circ}$ ao $9^{\circ}$ ano. É caracterizado como variável interveniente, pois é determinante na relação existente entre as variáveis $\mathrm{X}$ e Y. Apesar da influência que tem sobre as outras variáveis, a variável interveniente não foi objeto de análise neste estudo.

Os conceitos de aprendizagem mediada e não mediada estão relacionados ao fato de um grupo de estudantes receber orientações sobre a prática do LI (aprendizagem mediada), enquanto o outro grupo não recebe orientação (aprendizagem não mediada). A definição de grupos intactos vincula-se ao fato da pesquisa se realizar com grupos formados previamente (ex. turmas de estudantes), isto é, sem escolhas aleatórias para a realização do quase experimento.

Desse modo, o modelo representa situação que ocorre diante de um problema/investigação, em que um grupo que recebe influência de determinado processo de aprendizagem tende a apresentar determinada aprendizagem como resultado. Nesse caso, o processo de aprendizagem representa a variável independente e a aprendizagem resultante, a variável dependente. Considerando que o processo de aprendizagem pode variar em dois níveis (aprendizagem mediada e aprendizagem não mediada), entende-se que a aprendizagem resultante também irá variar (“Aprendizagem A" e "Aprendizagem B"). 


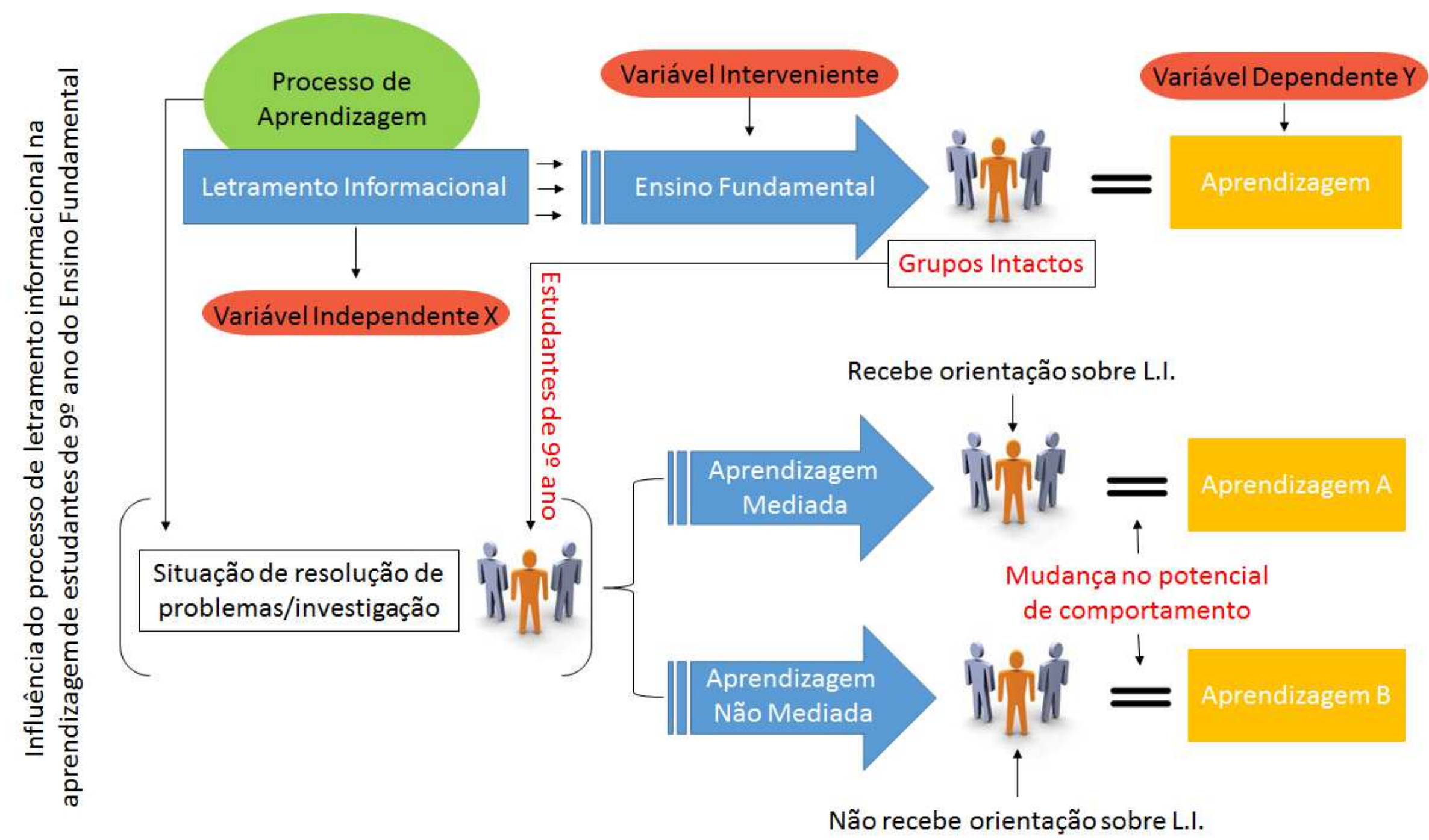

Fonte: Elaboração própria. 


\section{METODOLOGIA}

O presente estudo pode ser caracterizado como de alcance exploratório e explicativo. Para Hernández Sampieri, Fernández Collado e Baptista Lucio (2013), a escolha por um dos quatro alcances (exploratório, descritivo, correlacional e explicativo) pode ser definida por dois fatores: a revisão de literatura (estado da arte do conhecimento sobre o problema de pesquisa) e a perspectiva que o pesquisador quer dar ao estudo.

O estudo configura-se como exploratório, pois a revisão de literatura apontou poucas pesquisas que buscassem entender a relação entre $\mathrm{LI}$ e a aprendizagem de estudantes da educação básica. Também não identificou estudos com o foco pretendido por este pesquisador, isto é, exemplos experimentais ou quase experimentais que apontassem a relação entre as variáveis $\mathrm{LI}$ e aprendizagem na realidade de estudantes do $9^{\circ}$ ano do ensino fundamental, ou relacionadas com a disciplina de Ensino Religioso.

Além do caráter exploratório, a pesquisa também tem foco explicativo. 0 intuito é encontrar explicação para fenômeno que envolve as variáveis "letramento informacional" e "aprendizagem" e por que ambas estão relacionadas. Buscou-se saber se a aprendizagem dos estudantes de $9^{\circ}$ ano melhoraria nas aulas de Ensino Religioso com a utilização de técnicas de LI.

Para melhor compreensão, é necessário destacar que os estudos exploratórios permitem a familiaridade do pesquisador com fenômenos pouco conhecidos ou desenvolvidos em contextos específicos ou ainda não estudados. O objetivo é examinar um problema ou tema de pesquisa sobre o qual ainda se tem muitas dúvidas ou realizar um estudo partindo de novas perspectivas (HERNÁNDEZ SAMPIERI; FERNÁNDEZ COLLADO; BAPTISTA LUCIO, 2013).

Os estudos explicativos, também chamados de "testes de hipótese" (SEKARAN, 2003), têm o propósito de dar explicação para fenômenos específicos, buscando determinar as causas. O principal enfoque é explicar por que um fenômeno ocorre e sob quais condições ele se manifesta, ou por que existe relação entre duas ou mais variáveis (HERNÁNDEZ SAMPIERI; FERNÁNDEZ COLLADO; BAPTISTA LUCIO, 2013). Nesta pesquisa, testou-se a hipótese: "A aprendizagem dos estudantes de 9 ํ ano do ensino fundamental está rela- 


\section{cionada positivamente com a utilização de técnicas de Ll em situação de resolução de problemas/investigação".}

Além do alcance exploratório e explicativo, a concepção filosófica proposta nesse estudo é a pragmática. O pragmatismo pode ser entendido como a busca por soluções práticas para se realizar pesquisa, com base em critérios e desenhos apropriados para determinadas situações e contextos (HERNÁNDEZ SAMPIERE; FERNÁNDEZ COLLADO; BAPTISTA LUCIO, 2013). Na concepção pragmática, os enfoques qualitativo e quantitativo são considerados úteis e de importância equivalente. Segundo os autores, apesar de estarem em correntes filosóficas distintas (o enfoque quantitativo faz parte da concepção positivista ou pós-positivista e o qualitativo da cognitivista), a proposta pragmática não vê como impeditivo a utilização combinada de métodos distintos em um estudo, desde que seja com fins de complementação. Por complementação, entende-se a possibilidade de se obter visão mais aprofundada do fenômeno estudado com o uso de ambos os métodos.

Nesse sentido, a metodologia utilizada para a realização do estudo foi a pesquisa de métodos mistos, baseada em abordagem qualitativa e quantitativa. Esse modelo de pesquisa é definido por Creswell (2010) como aquele em que o pesquisador elabora ou amplia os achados de um método com os de outro método. Isso significa que a pesquisa pode iniciar com métodos qualitativos e, em seguida, ser complementada com métodos quantitativos ou vice-versa. $O$ propósito é permitir que um método contribua na aplicação do outro (com elementos que os enriqueçam) ou que minimizem ou eliminem pontos fracos. $\mathrm{Pa}$ ra Hernández Sampiere, Fernández Collado e Baptista Lucio (2013), os métodos mistos integram de forma sistemática os métodos qualitativos e quantitativos, permitindo visão mais ampla do fenômeno estudado. Afirmam ainda que mesmo integrados, cada método pode conservar a estrutura e procedimentos originais, devendo, entretanto, considerar o vínculo existente entre os dados obtidos por ambos os métodos. De acordo com Creswell (2010), este tipo de estudo se inicia com a generalização de resultados para uma população, oriundos de estudo mais amplo, para depois se concentrar na coleta de dados mais específicos.

Diante disso, o estudo pode ser visto como de natureza aplicada, isto é, busca encontrar soluções para problemas práticos ou imediatos em situações 
reais. Na pesquisa, os problemas relacionam-se com o processo de aprendizagem e a relação com a prática do LI, e tem o propósito de trazer soluções para questões cotidianos vivenciadas por alunos no ambiente escolar (KOTHARI, 2004).

O ambiente da pesquisa pode ser descrito como natural, por ser realizado no contexto de aprendizagem dos estudantes, isto é, na própria escola, dentro de sala de aula. Nesse sentido, pode-se estabelecer também o horizonte temporal da pesquisa como "desenho transversal". Hernández Sampiere, Fernández Collado e Baptista Lucio (2013) explicam que as pesquisas com desenho transversal são aquelas em que os dados são coletados em um único momento para descrever variáveis e analisar as inter-relações. A população abrangeu alunos de 9o ano do ensino fundamental na disciplina de Ensino Religioso de colégio confessional católico. As variáveis analisadas foram as práticas de $\mathrm{LI}$ e a aprendizagem dos estudantes. Os dados obtidos podem apontar tendências a serem consideradas em determinado contexto de ensino.

Para tanto, o método de pesquisa utilizado foi pesquisa-ação. A escolha baseou-se no contexto da pesquisa que requeria a resolução de problemas cotidianos, relacionados à aprendizagem dos estudantes em sala de aula. $\mathrm{A}$ pesquisa-ação é um dos desenhos básicos da pesquisa qualitativa. Neste caso, o termo "desenho" está relacionado com a "abordagem" a ser utilizada no processo de pesquisa (HERNÁNDEZ SAMPIERE; FERNÁNDEZ COLLADO; BAPTISTA LUCIO, 2013).

A pesquisa-ação pode ser dividida em dois desenhos fundamentais, "prático" e "participativo" (HERNÁNDEZ SAMPIERE; FERNÁNDEZ COLLADO; BAPTISTA LUCIO, 2013). O desenho prático implica: (1) estudar as práticas locais do grupo; (2) envolver indagações individuais ou em equipe; (3) centrarse no desenvolvimento e na aprendizagem dos participantes; (4) resolver o problema, introduzir uma melhoria ou gerar mudança por meio de um plano de ação e (5) exercer liderança em conjunto - pesquisador e membros do grupo. O desenho participativo, por sua vez, busca: (1) estudar temas sociais, (2) ressaltar a colaboração do grupo, (3) concentrar-se na melhoria do nível de vida e do desenvolvimento humano e (4) emancipar os participantes e o pesquisador. No caso, esse estudo baseou-se na pesquisa-ação prática. 
Para Tripp (2005), a pesquisa-ação busca refletir sobre a prática comum, identificando o que melhorar. Ela é reconhecida como um dos inúmeros tipos de investigação-ação, que utiliza de outras técnicas de pesquisa para informar a ação necessária e melhorar a prática. De acordo com Hernández Sampiere, Fernández Collado e Baptista Lucio (2013), existem três fases consideradas essenciais no processo de pesquisa-ação e que interagem entre si como em uma espiral: (1) observar; (2) pensar e (3) agir. A primeira delas relaciona-se com construir "um esboço do problema e coletar dados", a segunda em "analisar e interpretar", e a terceira fase, em "resolver problemas e implementar meIhorias".

A pesquisa-ação deve ser usada nas situações em que se pretende resolver problemas do cotidiano e melhorar práticas concretas. Possui como vantagens a transformação e melhoria de um contexto, a colaboração efetiva dos grupos para detectar necessidades e implementar os resultados da pesquisa e a emancipação dos participantes do estudo (HERNÁNDEZ SAMPIERE; FERNÁNDEZ COLLADO; BAPTISTA LUCIO, 2013). As desvantagens referem-se ao pouco controle sobre variáveis independentes (supostas causas), ter amostra de pesquisa restrita e pouco representativa, solucionar problemas práticos e específicos e gerar resultados que não podem ser generalizados - tendo apenas relevância local (COHEN; MANION; MORRISON, 2011). Apesar das desvantagens, ela é mais apropriada à pesquisa em questão por se tratar de metodologia amplamente aplicada na área educacional e que busca solucionar problemas relacionados ao contexto do ensino-aprendizagem (ENGEL, 2000).

Nesta pesquisa, além do desenho prático (abordagem qualitativa), utilizou-se o desenho quase experimental (abordagem quantitativa), também de uso frequente em investigações educacionais, conforme Coutinho (2006), e de acordo com estudos realizados por Mokhtar, Majid e Foo (2008). Pesquisa quase experimental pode ser entendida como um desenho da pesquisa quantitativa, que se diferencia dos "pré-experimentos" e dos "experimentos puros" por trabalhar com grupos "intactos" (HERNÁNDEZ SAMPIERE; FERNÁNDEZ COLLADO; BAPTISTA LUCIO, 2013), isto é, grupos definidos antes da realização do experimento (como os estudantes de uma sala de aula, por exemplo).

Os desenhos experimentais permitem a manipulação intencional de uma ou mais "variáveis independentes" (supostas causas) para analisar as conse- 
quências que essa manipulação tem sobre uma ou mais "variáveis dependentes" (supostos efeitos) em situação de controle para o pesquisador (HERNÁNDEZ SAMPIERE; FERNÁNDEZ COLLADO; BAPTISTA LUCIO, 2013). A pesquisa quase experimental manipula variáveis independentes, mas possui grau de segurança ou confiabilidade menor que o das pesquisas experimentais em relação à equivalência dos grupos (veja relação entre as variáveis no Quadro 3).

Os quase experimentos garantem, entretanto, maior controle das variáveis independentes, se comparado com a pesquisa-ação. Esse fato busca justificar o uso da pesquisa quase experimental no contexto desse estudo. Nos experimentos "puros", os grupos são escolhidos aleatoriamente, permitindo maior possibilidade de generalização dos resultados. Na pesquisa quase experimental, essa generalização é mais difícil.

Quadro 3 - Exemplos da relação entre variáveis independente e dependente

\begin{tabular}{|l|l|c|}
\hline $\begin{array}{l}\text { Variável independente } \\
\text { (suposta causa) }\end{array}$ & Influi em... $\rightarrow$ & $\begin{array}{c}\text { Variável dependente } \\
\text { (suposto efeito) }\end{array}$ \\
\hline Um tratamento psicológico & Reduz... $\rightarrow$ & Depressão \\
\hline Um novo motor revolucionário & Aumenta... $\rightarrow$ & Velocidade \\
\hline Programa de letramento informacional & Melhora... $\rightarrow$ & Aprendizagem \\
\hline
\end{tabular}

Fonte: Adaptado de Fernández Sampiere; Fernández Collado; Baptista Lucio (2013).

\subsection{PROCEDIMENTOS METODOLÓGICOS DA PESQUISA}

A pesquisa foi realizada com duas turmas de estudantes do $9^{\circ}$ ano (grupos intactos) na disciplina de Ensino Religioso, de um colégio privado na cidade de Brasília-DF. Cada turma possui características similares, como número de pessoas, faixa etária, presença de homens e mulheres em número proporcional, condições ambientais e de ensino equivalentes. Tais características demonstram equivalência entre os grupos. A escolha das turmas foi motivada pelo professor da disciplina, com base na percepção sobre a aprendizagem de ambos os grupos. A proposta de trabalho/projeto foi de responsabilidade do professor, considerando o conteúdo pedagógico da disciplina. O modelo utili- 
zado baseia-se nas ações necessárias para realizar a pesquisa-ação, apresentado na Figura 7. 
Figura 7 - Principais ações para realizar a pesquisa-ação

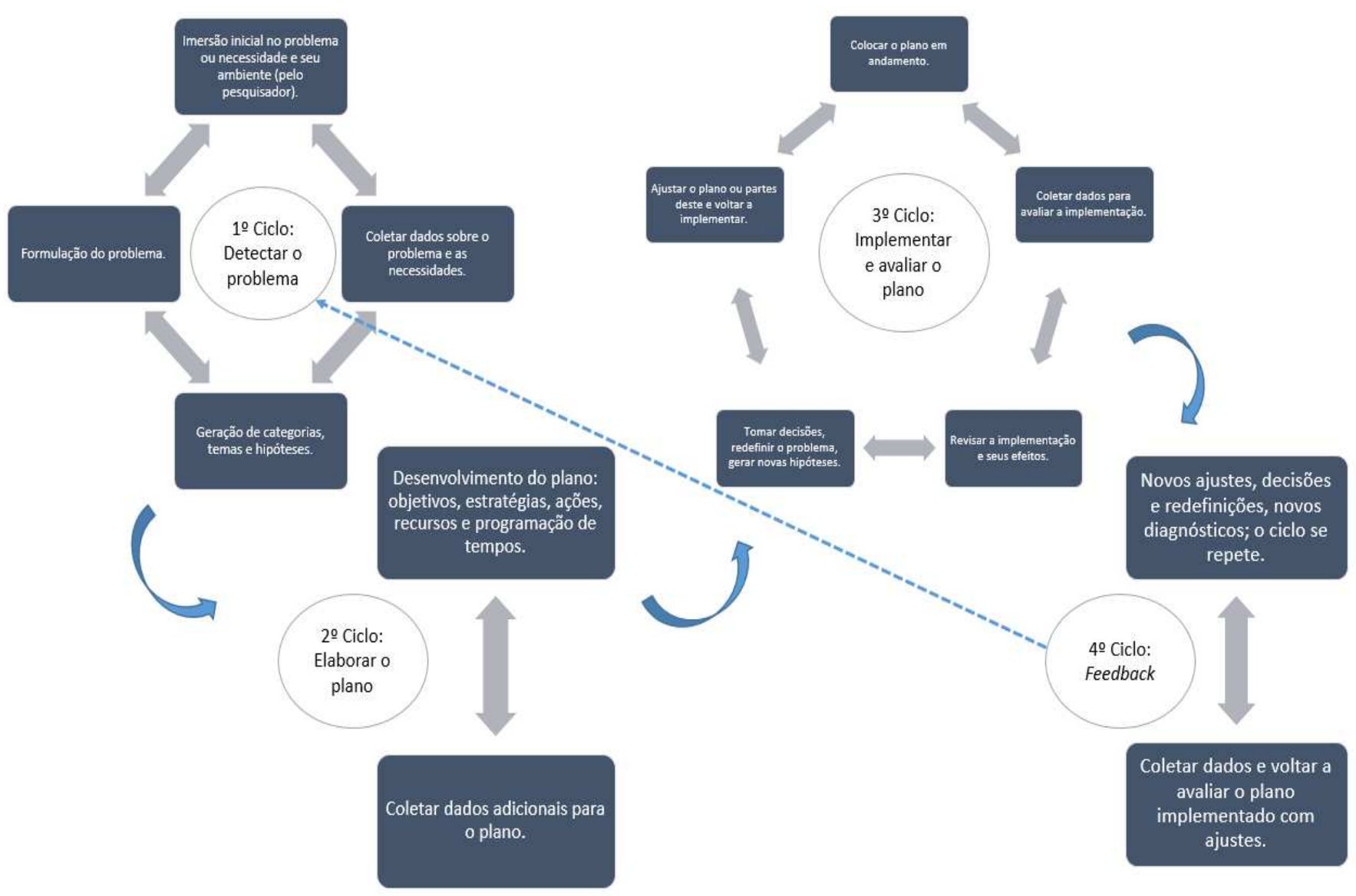

Fonte: Extraído de Hernández Sampiere, Fernández Collado e Baptista Lucio (2013), com adaptações. 
No caso desta pesquisa, a variável independente é o "letramento informacional" e a dependente é a "aprendizagem". A primeira variável foi desdobrada em dois níveis: 1) aprendizagem mediada e 2) aprendizagem não-mediada. Portanto, foram dois grupos (controle e quase experimental). O grupo de controle "aprendizagem não-mediada" não recebeu nenhum tipo de informação sobre técnicas de LI, pois a suposição é a de que os conteúdos apontados fossem de domínio dos estudantes. O grupo quase experimental "aprendizagem mediada" recebeu orientações específicas sobre técnicas de LI e foram acompanhados pelo pesquisador. Ambos os grupos desenvolveram proposta de trabalho definida pelo professor da disciplina.

No primeiro ciclo (detectar o problema), foi levantada a seguinte questão: quais dificuldades são demonstradas pelos estudantes na elaboração de um trabalho de Ensino Religioso? Para responder tal pergunta, realizou-se a observação de duas turmas de aprendizes (imersão inicial no problema), em um período de elaboração de trabalho (situação problema/investigação). Na próxima etapa (coleta de dados sobre o problema), observou-se como os estudantes buscavam informações na internet (como eles estruturavam o trabalho, que tipo de recomendações recebiam, quais dificuldades apresentavam para resolver o problema de pesquisa). A observação foi participativa, isto é, o papel do observador é conhecido (Creswell, 2010), com interação do pesquisador junto aos aprendizes, e foi complementada com aplicação de questionário. Na última etapa do primeiro ciclo (formulação de categorias, temas e hipóteses sobre o problema), observou-se se o aprendizado de conteúdos de LI possibilitou que estudantes estruturassem melhor os trabalhos escolares, garantindo maior fixação de conteúdo e melhoria do aprendizado.

No segundo ciclo (elaborar o plano) desenvolveu-se roteiro básico de LI (fase de desenvolvimento do plano), conforme "conteúdos de aprendizagem"11 definidos por Gasque (2012). Na fase posterior (coletar dados adicionais para o plano), levantaram-se os conhecimentos prévios dos estudantes de ambos os grupos sobre os conteúdos de aprendizagem, relacionados ao LI, com base na construção de mapas mentais. Mapa mental ou conceitual pode

\footnotetext{
${ }^{11}$ Conteúdos de aprendizagem referem-se as "várias atividades e procedimentos que integram o processo de busca e uso da informação, que permitem o desenvolvimento da consciência e a obtenção de resultados mais eficazes" (GASQUE; CUNHA, 2010).
} 
ser compreendido como técnica de organização do conhecimento. É uma representação gráfica que descreve a relação de ideias transpostas a partir do pensamento, relação esta construída ao longo do processo de aprendizagem e que foi sendo "arquivada" na memória (LIMA, 2004). O mapa elaborado pelos participantes deste estudo teve como tema o processo de "pesquisa", um dos conteúdos do LI.

No terceiro ciclo (implementar e avaliar o plano), o roteiro foi operacionalizado (colocado em andamento) mediante orientação dada pelo pesquisador ao longo de quatro semanas de trabalho (o planejamento inicial previu abordar noções sobre texto científico, elaboração de pesquisa, seleção de material, elaboração de relatórios e citações; entretanto precisou ser alterado). As fases posteriores de coleta de dados, revisão e implementação, tomadas de decisões e ajuste do plano ou de partes do plano foram implementadas em conjunto entre professor e pesquisador, com a participação efetiva dos estudantes pertencentes ao grupo quase experimental.

No quarto ciclo (feedback), coletaram-se novos dados por meio da elaboração de um novo mapa conceitual (aplicado apenas ao grupo quase experimental), com o intuito de avaliar se a aprendizagem sobre os conceitos estudados foi modificada. Além disso, consideraram-se as avaliações feitas pelo professor, os relatórios entregues e as percepções dos alunos sobre o trabalho. Ajustes e novas decisões poderiam ser tomadas, fazendo o ciclo se repetir. $\mathrm{Na}$ última etapa, analisou-se se o roteiro básico de LI aplicado em um dos grupos teve influência significativa na aprendizagem dos estudantes.

\subsubsection{População}

O Colégio Marista de Brasília (Maristinha) é uma instituição católica confessional, com valores relacionados à espiritualidade, ao espírito de família, à simplicidade, à presença significativa, ao senso de justiça e amor ao trabalho. Foi fundado em 1962 pelos irmãos maristas e, atualmente, possui cerca de 2.800 alunos, divididos entre educação infantil e ensino fundamental. É considerado um colégio tradicional na cidade de Brasília, com mais de 50 anos de existência. A instituição tem a missão de "formar bons cristãos e virtuosos ci- 
dadãos", com base na formação integral dos estudantes, cultivando solidariedade, amor ao próximo e paz.

A proposta pedagógica é baseada nos ideais do fundador da Instituição Marista, São Marcelino Champagnat, que tem como princípio educar e evangelizar crianças e jovens, tornando Jesus Cristo conhecido e amado, formando bons cristãos e virtuosos cidadãos. A figura de "Maria Boa Mãe", é presença importante dentro da instituição, vista como "inspiração" para os maristas. O processo de ensino busca articular fé, cultura e vida, dentro de uma educação vista como "integral". Para tanto, o processo é considerado "pedagógicopastoral", e busca desenvolver nos estudantes a postura crítica, o desenvolvimento das relações, a valorização da vida e a relação com Deus.

A disciplina de Ensino Religioso é trabalhada como qualquer outro componente curricular no Colégio, com aulas regulares e avaliações. Tem o conteúdo proposto pela Matriz Curricular da União Marista do Brasil (UMBRASIL), mas diferentemente da maioria das disciplinas, não trabalha com livro didático específico. Nesse sentido, as aulas tornam-se mais interdisciplinares e o conteúdo é conduzido por meio de pesquisas e com abordagens sociológicas e antropológicas. Essas características, associadas ao pouco "engessamento" do componente, contribuiu para que esse estudo fosse realizado. Além disso, é importante sinalizar que houve grande interesse e abertura por parte do professor da disciplina.

As turmas de $9^{\circ}$ ano, escolhidas para a realização desse estudo, foram definidas com o auxílio do professor. A escolha foi motivada pelo nível de aprendizagem demonstrado por ambos os grupos (que são acompanhados pelo professor desde o início do ano de 2014). O grupo definido como "quase experimental" foi escolhido como sendo aquele com maior dificuldade de aprendizagem em relação ao grupo controle. A escolha também foi motivada pela interação existente entre o pesquisador e a maior parte do grupo, em virtude de parcerias anteriores realizadas no ano de 2013. 


\subsubsection{Caracterização da amostra}

A amostra do estudo é composta por 77 alunos do $9^{\circ}$ ano do ensino fundamental, com idades entre 14 e 15 anos, divididos em dois grupos de 38 e 39 estudantes.

\subsubsection{Instrumento de coleta de dados}

A pesquisa utilizou três técnicas de coleta de dados, quais sejam, os questionários, observação participante e mapa mental. A primeira, os questionários com perguntas fechadas e pré-codificadas são instrumentos quantitativos bastante utilizados para coletar dados e se referem a um conjunto de perguntas relacionadas a uma ou mais variáveis que serão mensuradas na pesquisa (HERNÁNDEZ SAMPIERE; FERNÁNDEZ COLLADO; BAPTISTA LUCIO, 2013).

No caso, a variável é o "letramento informacional". O questionário buscou mensurar se os estudantes utilizavam alguns dos conteúdos do LI no processo de aprendizagem por meio da pesquisa e elaboração de trabalhos escolares. O modelo de questionário (APÊNDICE A) foi aplicado no primeiro ciclo da pesquisa-ação.

O questionário foi pré-testado em horário de aula, com dez alunos do $6^{\circ}$ ano, da mesma instituição de ensino, convidados para responder as perguntas. Os estudantes compareceram ao segundo andar do Centro de Recursos de Aprendizagem (CRA) do Colégio Marista de Brasília após autorização da professora de história que ministrava aula naquele horário específico. Eles foram escolhidos de forma aleatória. A escolha do local se deu pela possibilidade dos estudantes responderem o questionário sem interferência de outros colegas. Eles foram separados em duplas e ficaram em cinco mesas, separados uns dos outros (dois alunos por mesa). Após orientações iniciais, eles receberam caneta e deram início ao preenchimento. O questionário foi aplicado às $11 \mathrm{~h} 30$ do dia 16 de abril de 2014. Os estudantes levaram cerca de cinco minutos para responder. Dois questionamentos foram feitos com relação ao item quatro da questão A e um questionamento em relação a questão E. Após as devidas explicações, os alunos finalizaram o preenchimento. Com base nos questiona- 
mentos, o pesquisador fez duas alterações nos itens sinalizados, deixando-os mais claros para aplicação futura.

O questionário final da pesquisa conta com oito perguntas de múltipla escolha. Para cada pergunta havia no mínimo duas e no máximo seis opções de respostas. Antes da aplicação do questionário foi realizada breve explanação sobre a realização da pesquisa e sobre a contribuição de cada estudante neste processo. O questionário foi aplicado no CRA do Colégio Marista de Brasília, em momento de aula, nos dias 27 e 28 de maio de 2014. Para tanto, os estudantes tiveram 20 minutos. Ao final, foram coletados 71 questionários (39 referente ao grupo quase experimental e 32 ao grupo controle).

O segundo instrumento utilizado, a observação, é feito mediante anotações realizadas pelo pesquisador, dentro do contexto da pesquisa. Para Creswell (2010), existe quatro opções de observação: (1) Participante completo - o pesquisador oculta o seu papel; (2) observador como participante - o papel do pesquisador é conhecido; (3) participante como observador - o papel de observação é secundário e prevalece o papel de participante e (4) observador completo - o pesquisador observa sem participar. Nessa pesquisa, a opção de observação escolhida é a de observador como participante. Empregou-se a observação no primeiro ciclo da pesquisa-ação. A observação participante ocorreu no período de 27 de maio a 29 de julho, totalizando cerca de 12 horas/aula de observação nas salas do grupo quase experimental e cerca de seis horas/aula na sala do grupo controle. As observações foram realizadas com o uso de bloco de papel e caneta, e posteriormente transcritas para computador por meio do software Microsoft Word ${ }^{\circledR}$.

A principal vantagem da observação é que o pesquisador pode registrar as informações sempre que elas ocorrem. A desvantagem é não poder registrar informações privadas que por ventura apareceram no contexto da pesquisa. As anotações foram realizadas de maneira semiestruturada, isto é, baseada nos itens abordados no questionário, quais sejam: recursos utilizados na elaboração dos trabalhos, registro de informações, indicação de fontes consultadas, dificuldades encontradas na elaboração do trabalho e uso de conteúdos de LI. Os registros descrevem o comportamento e as atividades dos estudantes no processo de realização de pesquisa. 
O terceiro instrumento de coleta de dados foi o mapa mental, considerado uma ferramenta de representação de ideias ou conceitos na forma de diagrama (LIMA, 2004). O diagrama busca relacionar e apontar a estrutura cognitiva de determinado assunto, demonstrando as respectivas relações.

No contexto da pesquisa, os mapas mentais reúnem dados qualitativos e foram recolhidos nos ciclos 2 e 4 da pesquisa-ação. Os mapas foram confeccionados com base na ferramenta SimpleMind+, instalada em tablets disponíveis na escola. A escolha por esta ferramenta ocorreu pela facilidade de uso e interface amigável para os estudantes. Antes do desenvolvimento da atividade, foi dada orientação sobre o que são mapas mentais, com auxílio de texto de apoio (ANEXO 1). A elaboração dos mapas foi direcionada pelo pesquisador. Os mapas foram realizados dia 3 de junho (grupo quase experimental) e dia 11 de junho (grupo controle) de 2014, totalizando 2 horas/aula. Durante a aplicação dos mapas mentais foram observados baixo grau de interesse dos estudantes em relação ao texto explicativo e à apresentação de informações via TV. Entretanto, percebeu-se muita participação e euforia dos alunos no uso dos tablets e nas instruções para a confecção dos mapas ${ }^{12}$. O trabalho realizado com o grupo controle contou com número reduzido de alunos, em virtude de ser o último dia de aula. A Figura 8 apresenta modelo criado pelo professor da disciplina.

${ }^{12}$ Os mapas mentais elaborados pelos estudantes podem ser visualizados nos ANEXO 2, 3 e 4. 


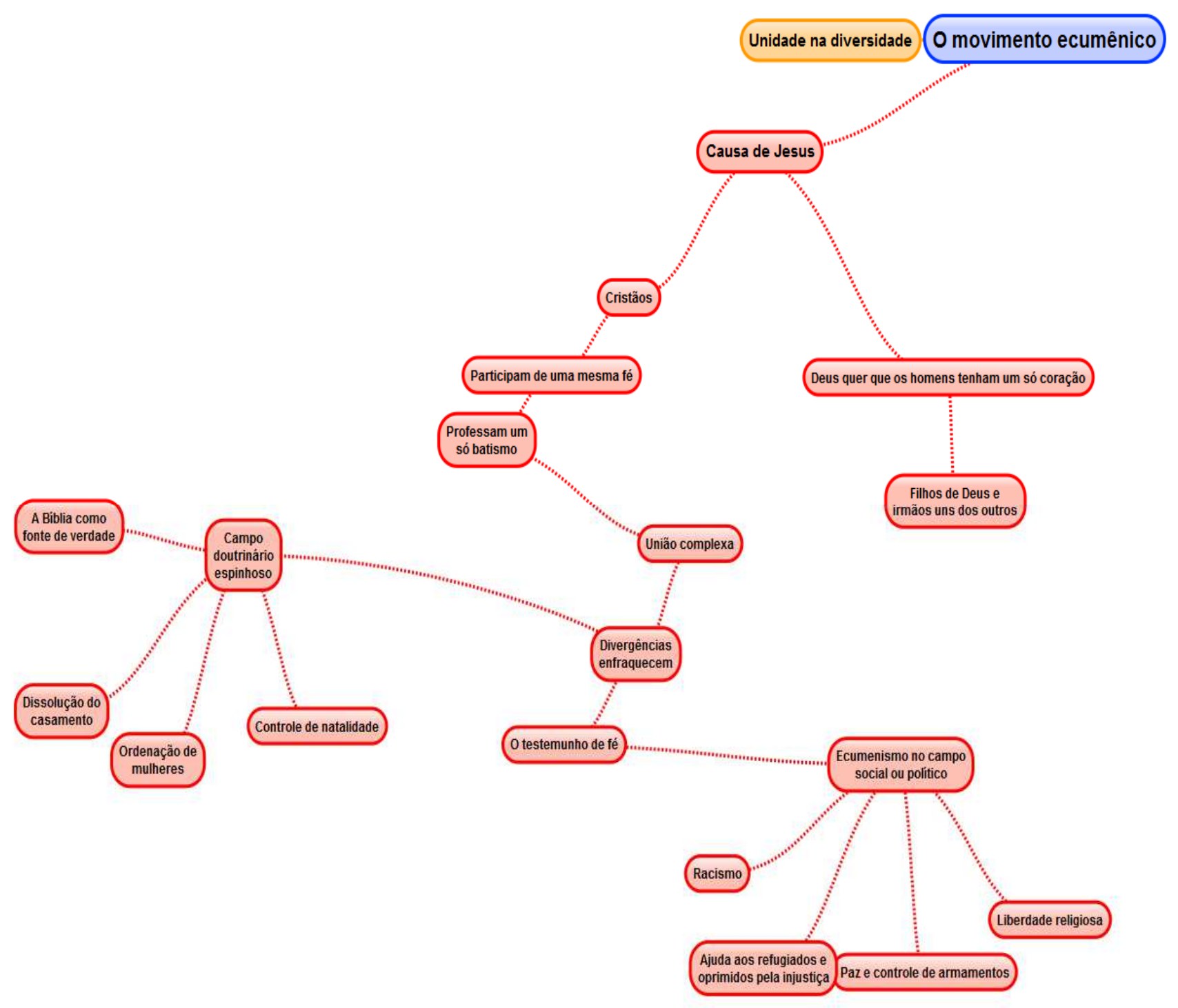

Fonte: SimpleMind+ 
As técnicas de coleta de dados foram complementadas por relatórios ${ }^{13} \mathrm{e}$ perguntas/respostas entregues pelos alunos, avaliação dos trabalhos (APÊNDICE C) e entrevista não estruturada ${ }^{14}$ (APÊNDICE E) com o professor da disciplina. Esses instrumentos também foram usados para controlar o quase experimento por meio da medição das variáveis independente e dependente. A variável independente "letramento informacional" foi mensurada por meio dos questionários, observação e mapas mentais. Para medir a variável dependente "aprendizagem" utilizaram-se relatórios elaborados pelos estudantes (sobre a construção do trabalho), entrevista com o professor da disciplina e as notas obtidas na conclusão dos trabalhos. Para a obtenção das notas, foram utilizados seis critérios propostos por Mokhtar, Majid e Foo (2008), a saber: (1) seleção e avaliação de fontes de informação; (2) utilização das informações e uso das citações; (3) conteúdo do trabalho; (4) apresentação global; (5) qualidade do produto final e (6) apresentação oral. Cada critério foi avaliado com indicadores definidos pelo pesquisador e pelo professor da disciplina. A nota final foi dada pelo professor.

Em resumo, apresentam-se os objetivos e os instrumentos de coleta de dados utilizados para alcançá-los:

Objetivo 1: Identificar os conhecimentos prévios dos grupos participantes do quase experimento.

- Aplicação de questionários, elaboração de mapas mentais e observação participante.

Objetivo 2: Elaborar roteiro básico de LI para o grupo do quase experimento.

- Elaboração de guia de normalização de trabalhos para os estudantes (APÊNDICE G).

Objetivo 3: Aplicar roteiro básico de LI para o grupo do quase experimento.

- Explicação, distribuição e aplicação do roteiro em sala de aula.

Objetivo 4: Envolver os grupos participantes em processo de resolução de problemas/investigação.

\footnotetext{
${ }^{13} \mathrm{Em}$ virtude do tempo destinado à pesquisa, os estudantes não receberam orientação específica de como elaborar relatórios. Em vista disso, o material entregue por eles representou apenas relatos simples de como foi encaminhado o trabalho da disciplina.

${ }^{14} \mathrm{~A}$ opção pela entrevista não estruturada buscou permitir que o diálogo entre pesquisador e professor fluísse de forma mais livre.
} 
- Acompanhamento do trabalho realizado na disciplina de Ensino Religioso, por meio dos debates e orientações aos alunos do grupo quase experimental.

Objetivo 5: Comparar os níveis de aprendizagem dos grupos participantes do quase experimento.

- Elaboração de novos mapas mentais, avaliação dos trabalhos, perguntas/respostas e relatórios entregues pelos estudantes.

Objetivo 6: Identificar como o LI interferiu na aprendizagem dos estudantes.

- Interpretação dos dados obtidos na pesquisa.

\subsubsection{Tratamento e apresentação dos dados}

Em virtude da metodologia utilizada, as técnicas de análise foram distintas entre si, pois se referem a dados qualitativos e quantitativos. Nesse sentido, utilizou-se a triangulação dos dados, que busca convergir/corroborar os dados obtidos em cada uma das abordagens (HERNÁNDEZ SAMPIERE; FERNÁNDEZ COLLADO; BAPTISTA LUCIO, 2013). A técnica para análise dos dados quantitativos foi realizada por meio do software para análise estatística Minitab $17^{\circledR}$. Para os dados qualitativos, utilizou-se a técnica de análise de conteúdo, por meio da definição de categorias.

Moraes (1999) explica que a análise de conteúdo é mais que uma técnica de análise de dados, representa por si só uma abordagem metodológica com características e possibilidades específicas. Para Meireles e Cendón (2010), a análise de conteúdo pode ser caracterizada como um método de tratamento da informação que identifica questões relevantes contidas nas mensagens. De acordo com as autoras, a utilização do método requer a criação de categorias relacionadas ao objeto de estudo. As categorias podem ser entendidas como o agrupamento de dados com partes comuns existentes entre eles, obtidas por meio de síntese e classificação dos elementos que constituem a mensagem (MORAES, 1999). 


\subsubsection{Dados quantitativos}

A análise quantitativa diz respeito aos dados levantados com a aplicação dos questionários e as notas obtidas pelos alunos na avaliação do trabalho. Neste caso, os questionários foram relacionados à variável "letramento informacional" e as notas obtidas à variável "aprendizagem". Como apresentado no tópico 4.1.3, foram aplicados 39 questionários ao grupo quase experimental e 32 ao grupo controle. O número de questionários respondidos variou de um grupo para outro, em virtude da ausência de sete estudantes do grupo controle no dia da aplicação. A aplicação do instrumento aos alunos ausentes não foi repetida em data posterior, pois estava inserida em contexto pré-estabelecido, isto é, os questionários deveriam ser respondidos no dia em que a pesquisa fosse iniciada pelos estudantes.

As perguntas foram codificadas seguindo o padrão questão $\mathbf{n}$, perguntas n1, n2, n3, n..., e podem ser visualizadas no Quadro 4.

Quadro 4 - Perguntas codificadas

\begin{tabular}{|l|}
\hline \multicolumn{1}{|c|}{ QUESTÃO A } \\
\hline A1 - Uso a internet em mais de 80\% dos trabalhos solicitados pelos professores \\
\hline A2 - Uso a internet para fazer metade dos trabalhos solicitados pelos professores \\
\hline A3 - Uso a internet em menos da metade dos trabalhos solicitados pelos professores \\
\hline A4 - Não uso a internet \\
\hline A5 - Outros \\
\hline \multicolumn{1}{|c|}{ QUESTÃO B } \\
\hline B1 - Enciclopédias online (ex. Wikipédia) \\
\hline B2 - Sites governamentais (ex. IBGE) \\
\hline B3 - Sites educacionais (ex. Almanaque Abril) \\
\hline B4 - Sites comerciais (ex. UOL) \\
\hline B5 - Não sei dizer \\
\hline \\
\hline C1 - Livros \\
\hline C2 - Enciclopédias \\
\hline C3 - Dicionários \\
\hline C4 - Almanaques \\
\hline C5 - Textos de apoio indicados pelo professor \\
\hline C6 - Outros \\
\hline \\
\hline D1 - Copio todo o conteúdo que preciso \\
\hline D2 - Copio apenas algumas partes do conteúdo que preciso \\
\hline
\end{tabular}




\begin{tabular}{|l|}
\hline D3 - Copio algumas partes e também escrevo o que entendi \\
\hline D4 - Não copio nada, apenas escrevo o que entendi sobre o assunto \\
\hline \multicolumn{1}{|c|}{ QUESTÃo E } \\
\hline E1 - Sim \\
\hline E2 - Não \\
\hline \\
\hline F1 - Indico apenas o site que acessei \\
\hline F2 - Além do site, indico a data em que acessei o material \\
\hline F3 - Além do site e da data, também indico o nome do autor do texto que acessei \\
\hline F4 - Indico apenas o nome do livro que utilizei \\
\hline F5 - Além do nome do livro, indico o nome do autor \\
\hline $\begin{array}{l}\text { F6 - Além do nome do livro e do autor, também indico o nome da editora e o ano em que o } \\
\text { livro foi publicado }\end{array}$ \\
\hline \\
\hline G1 - Falta de orientação sobre o conteúdo do trabalho \\
\hline G2 - Falta de orientação sobre como e onde buscar informações \\
\hline G3 - Falta de orientação sobre como estruturar o texto \\
\hline G4 - Falta de orientação sobre como fazer citações \\
\hline G5 - Não sinto nenhuma dificuldade \\
\hline
\end{tabular}

Fonte: Elaboração própria.

Após tabulação (realizada com auxílio do software Excel ${ }^{\circledR}$ ) e inserção dos dados no software Minitab1 $7^{\circledR}$, obteve-se os seguintes resultados: 
Figura 9 - Somatório dos resultados (Questão A)

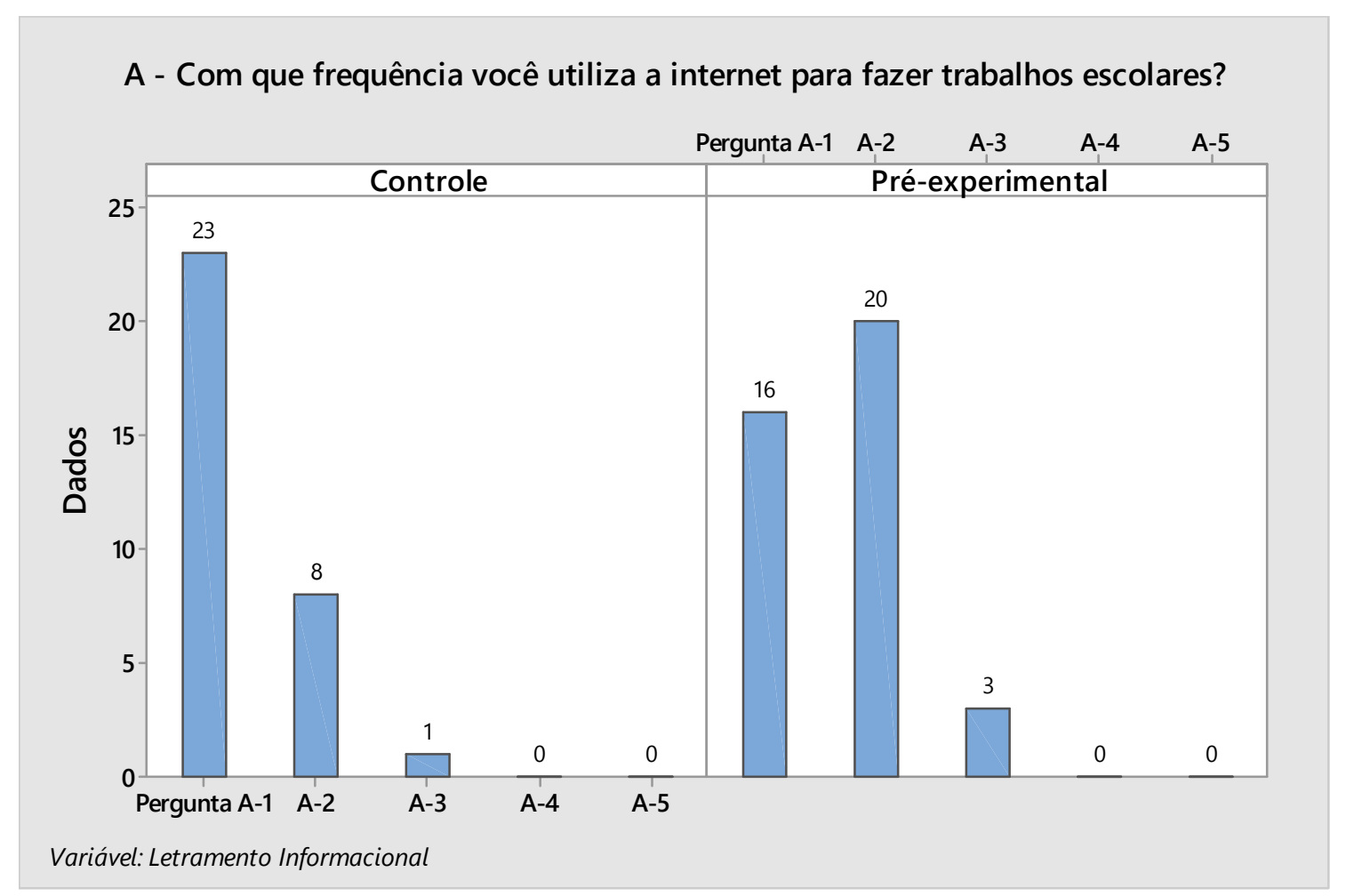

Fonte: Elaboração própria.

Em relação à questão $A$ - frequência de uso da internet para trabalhos escolares - cerca de $71 \%$ dos estudantes do grupo controle costumam utilizar a internet em mais de $80 \%$ dos trabalhos solicitados pelos professores. No caso do grupo quase experimental, a preferência cai para $41 \%$. A opção de grande parte dos estudantes do grupo quase experimental é por utilizar a internet na metade dos trabalhos solicitados pelo professor, cerca de $51 \%$. 
Figura 10 - Somatório dos resultados (Questão B)

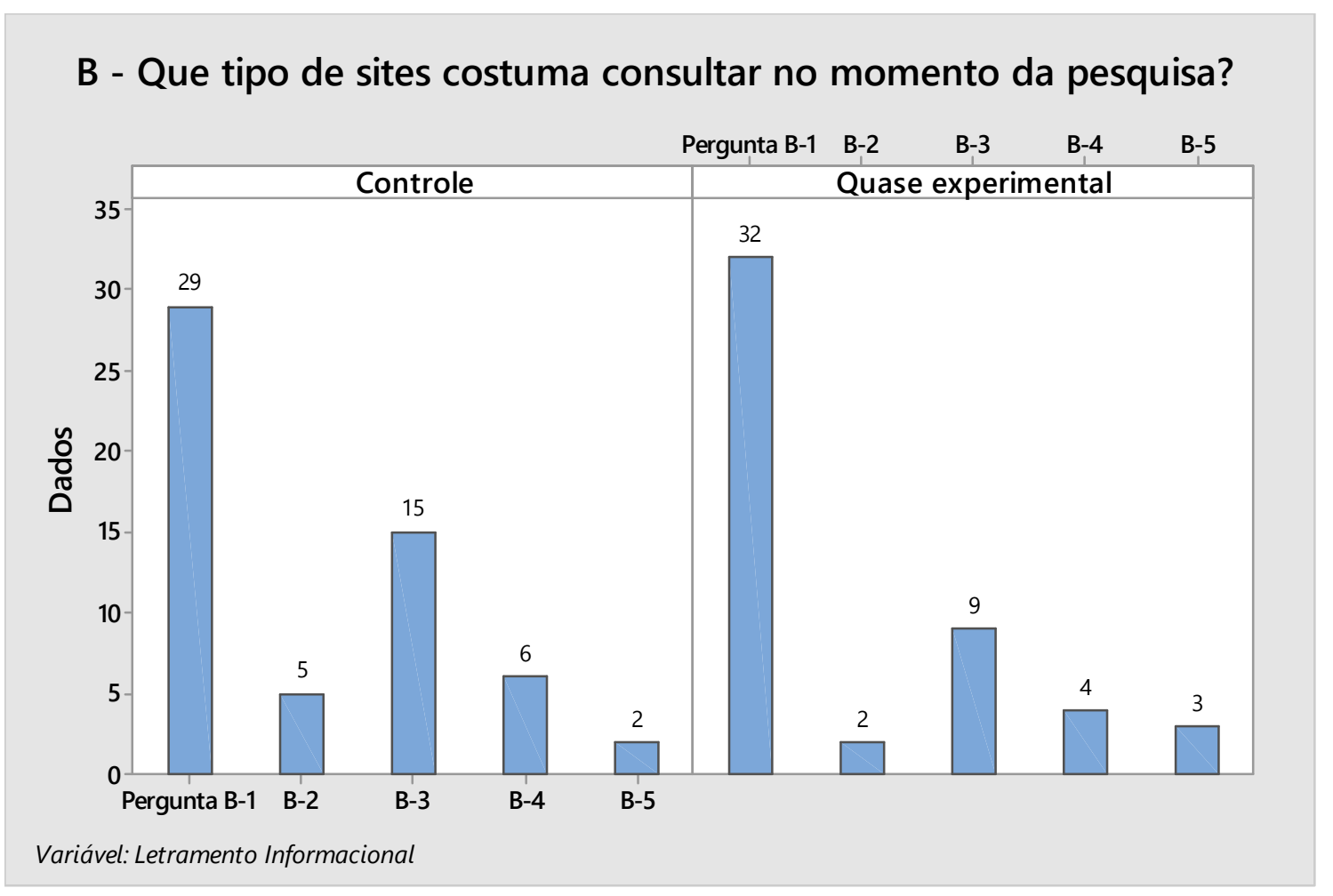

Fonte: Elaboração própria.

A questão B - tipos de sites usados na pesquisa - aponta que $90 \%$ dos estudantes do grupo controle e $82 \%$ do grupo quase experimental costumam consultar enciclopédias online no momento da pesquisa. O uso de sites educacionais aparece em segundo lugar, com $46 \%$ e $23 \%$ respectivamente. 
Figura 11 - Somatório dos resultados (Questão C)

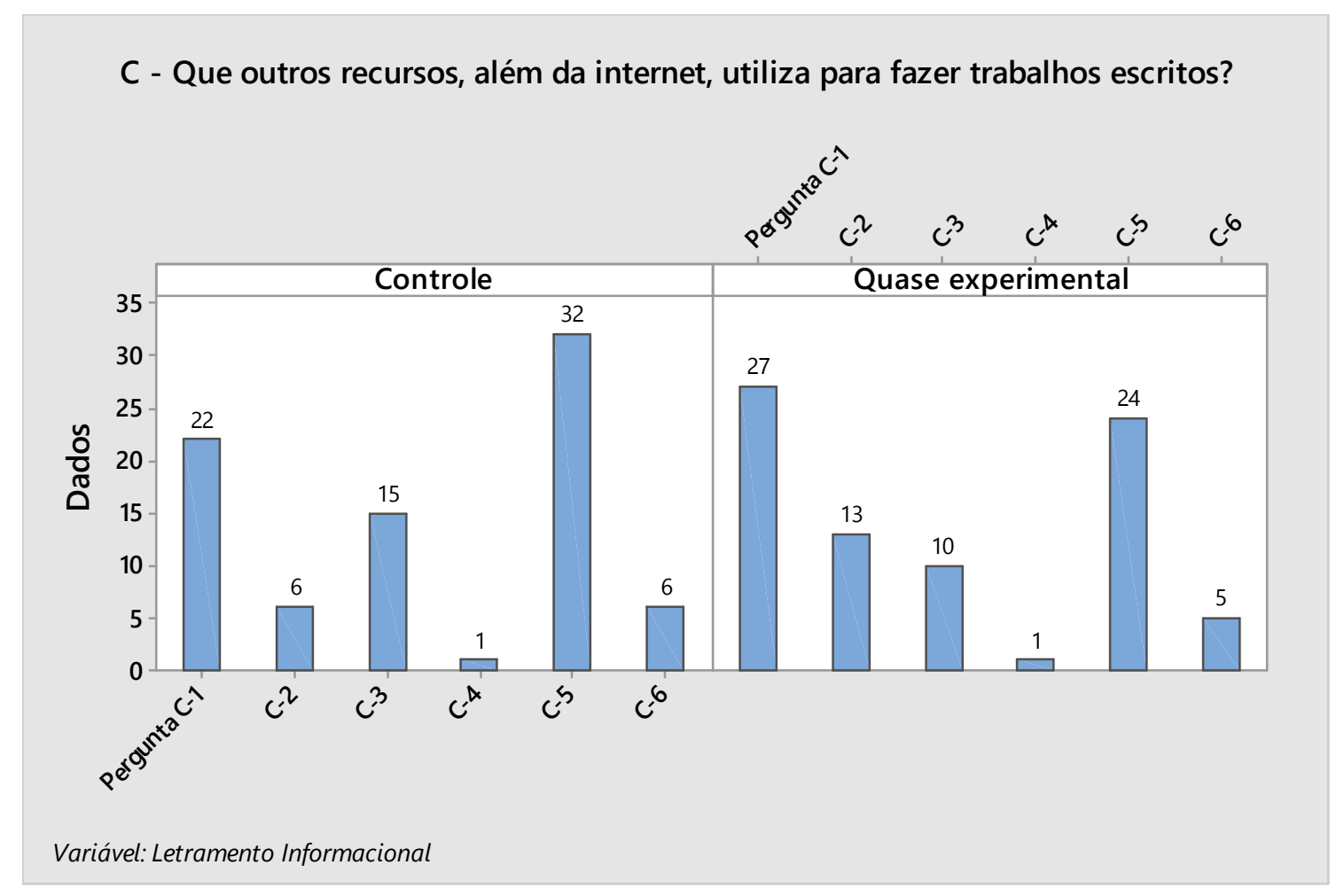

Fonte: Elaboração própria.

A questão $C$ - Uso de outros recursos para realizar o trabalho - mostra que os estudantes também costumam utilizar outros recursos, além da internet, na elaboração dos trabalhos escolares. A preferência de $100 \%$ dos alunos do grupo controle é por textos de apoio indicados pelo professor. No caso do grupo quase experimental, a preferência é pela utilização de livros, cerca de $70 \%$. A segunda opção por parte dos estudantes do grupo controle também são os livros, com $69 \%$. 


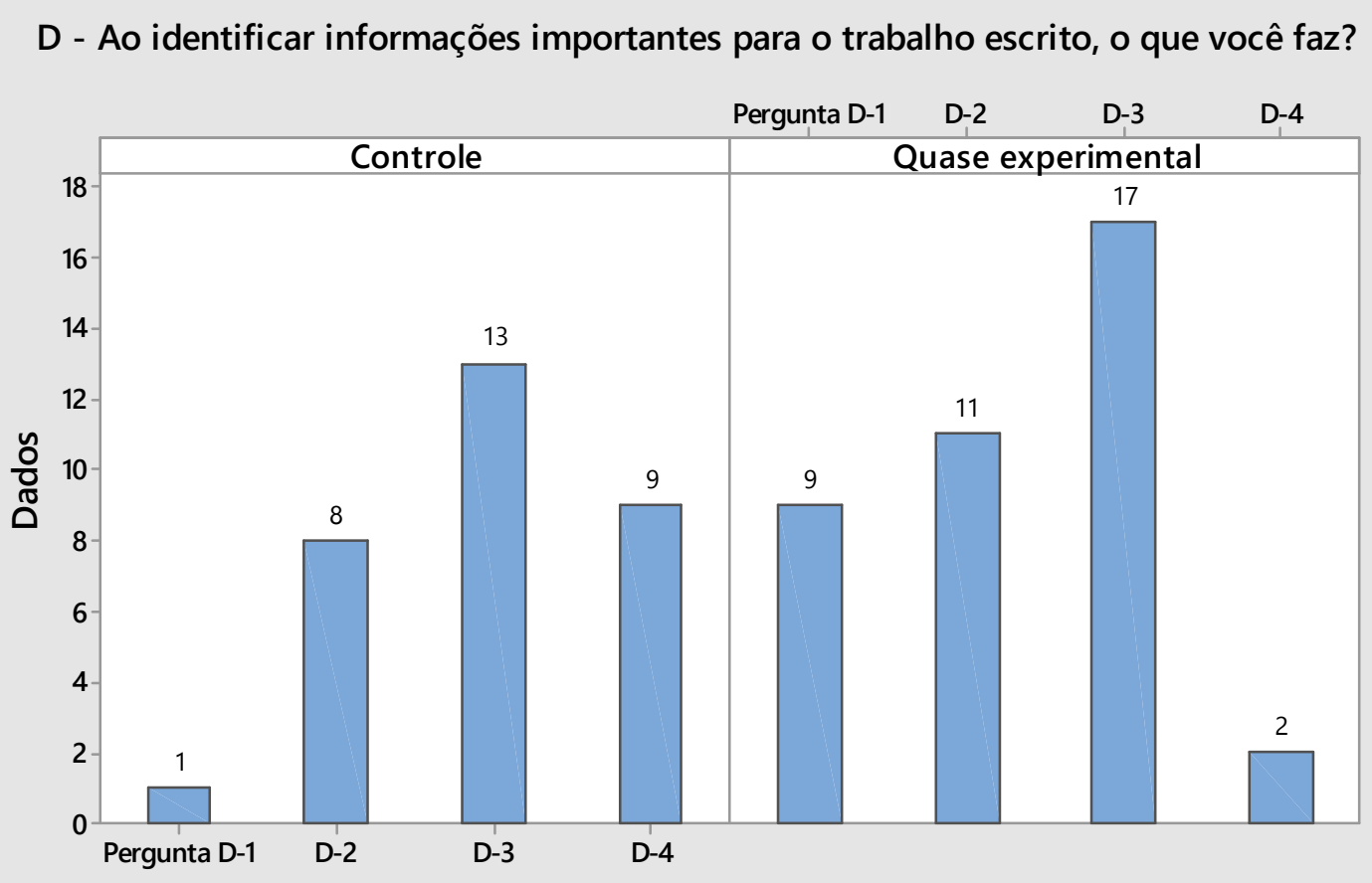

Variável: Letramento Informacional

Fonte: Elaboração própria.

A questão $D$ - estratégias usadas após identificar informações importantes para o trabalho escrito - mostra que após utilização de sites e outros recursos, é feito o registro do conteúdo relevante. Cerca de $40 \%$ dos estudantes do grupo controle e $43 \%$ do grupo quase experimental afirmam copiar partes do conteúdo e também escrevem o que entenderam. Na segunda opção, $28 \%$ do grupo controle afirmam não copiar nada, apenas escrevem o que entenderam sobre o assunto. Esse número cai para $5 \%$ no caso dos estudantes do grupo quase experimental. Entretanto, a opção de copiar todo o conteúdo necessário foi apontada por $23 \%$ do grupo quase experimental, enquanto que só $3 \%$ do grupo controle fazem esta escolha. 
Figura 13 - Somatório dos resultados (Questão E)

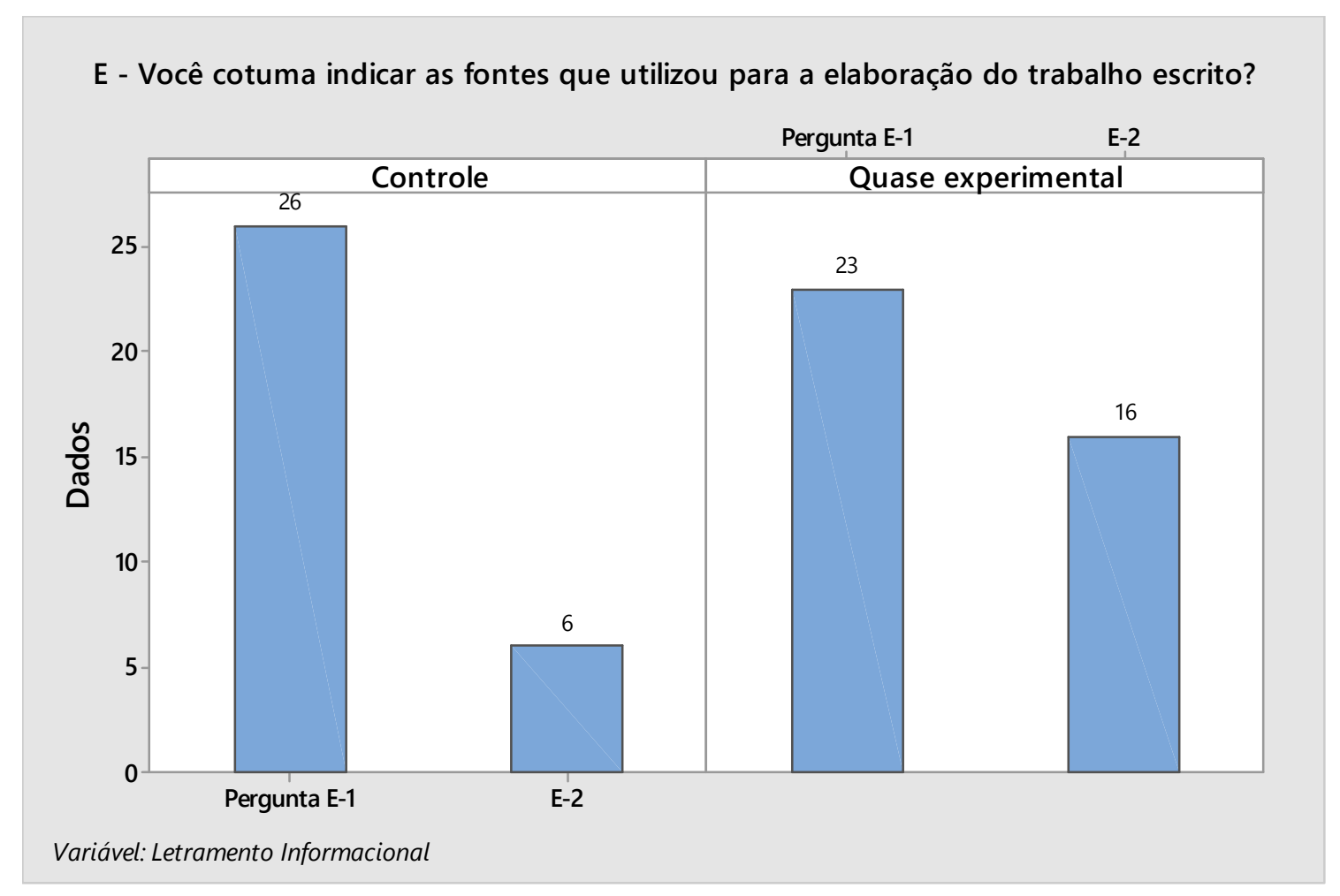

Fonte: Elaboração própria.

Na questão $E$ - indicação de fontes utilizadas no trabalho - os dados mostram que após selecionarem as informações relevantes, do total de respondentes, $81 \%$ do grupo controle e cerca de $60 \%$ do grupo quase experimental, afirmam fazer essa indicação. Entre as justificativas apontadas para a não utilização desta prática, os estudantes responderam: "porque esqueço", "porque eu acho que os professores deveriam confiar nos alunos", "somente quando o professor pede", "porque não acho necessário", e até mesmo "porque sou preguiçoso". Em contrapartida, as justificativas para a utilização demonstram um conhecimento prévio importante por parte de alguns estudantes: "para que as pessoas saibam de onde eu tirei a informação", "para depois facilitar a busca", "para que se alguém tiver interesse, poder buscar mais sobre o assunto". 


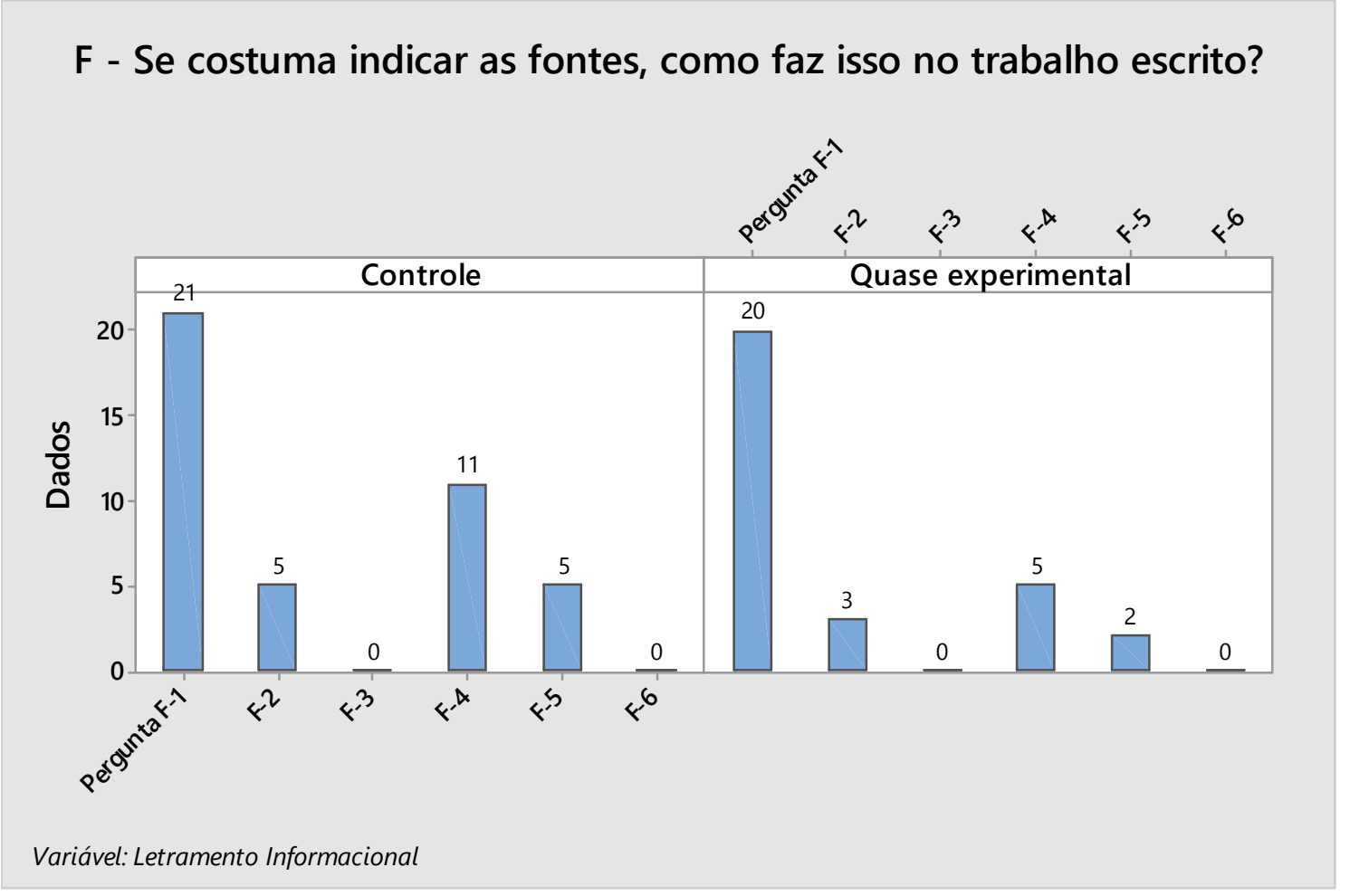

Fonte: Elaboração própria.

A questão $\mathrm{F}$ - como indicar fontes no trabalho escrito - mostra que mais da metade dos estudantes de ambos os grupos (65\% controle e $51 \%$ quase experimental) costuma indicar apenas o site que acessaram. Quando a opção é indicar além do site, a data em que o material foi acessado na internet, o valor cai para $15 \%$ e $7 \%$ respectivamente. Quando o material consultado está em formato impresso, $34 \%$ do grupo controle e $12 \%$ do grupo quase experimental sinalizaram que indicam apenas o nome do livro que foi utilizado. Esse percentual é ainda menor, quando a opção é indicar, além do nome do livro, o nome do autor. São $15 \%$ de respondentes do grupo controle e apenas $5 \%$ do grupo quase experimental. 
Figura 15 - Somatório dos resultados (Questão G)

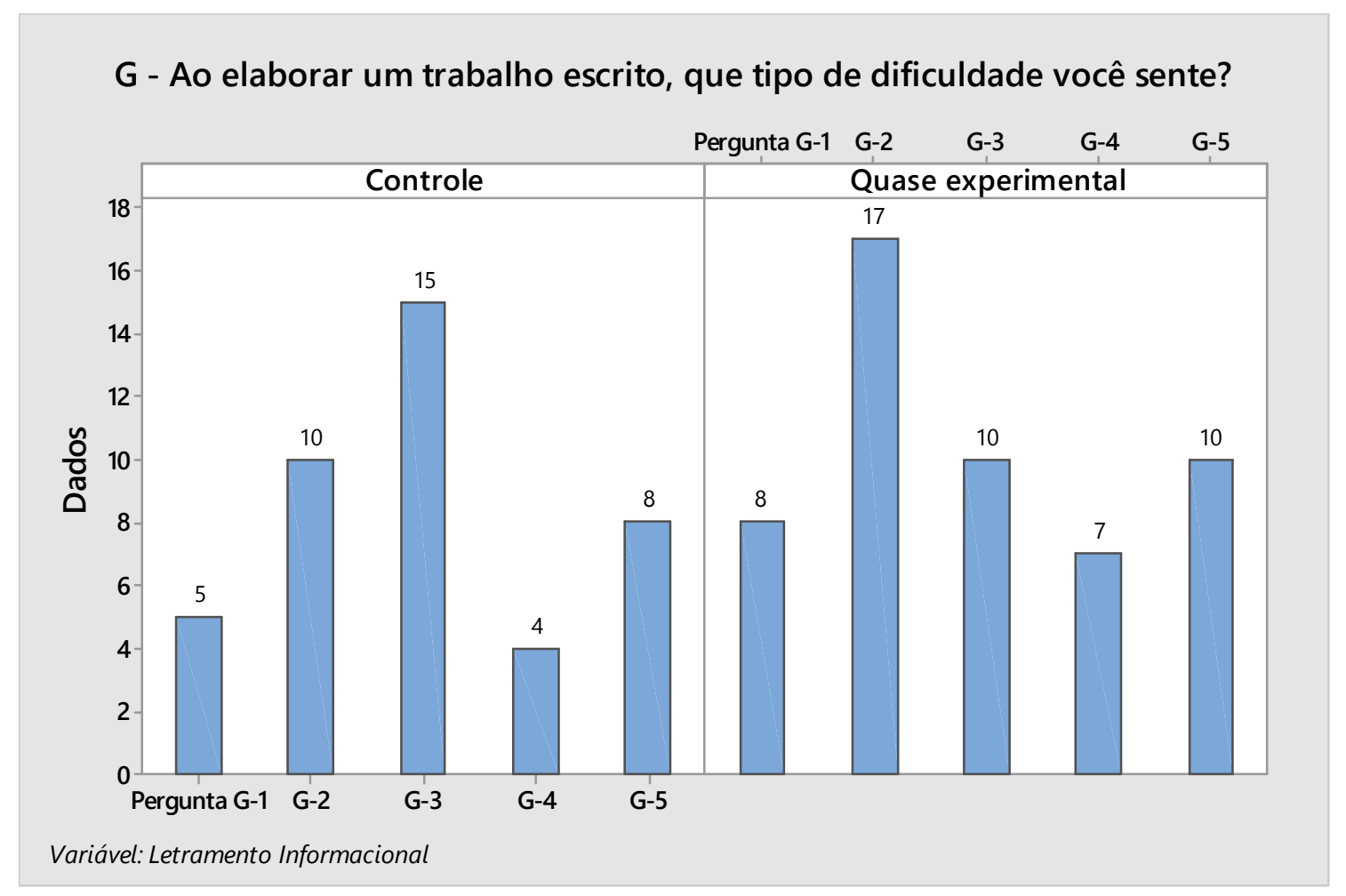

Fonte: Elaboração própria.

A questão $\mathrm{G}$ - dificuldades na elaboração do trabalho - apresenta que para cerca de $47 \%$ dos estudantes do grupo controle, a maior dificuldade está relacionada com a falta de orientação sobre como estruturar o texto. Para o grupo quase experimental (43\%), a maior dificuldade está relacionada com a falta de orientação sobre como e onde buscar informações. Observou-se que $25 \%$ dos estudantes de ambos os grupos não sente nenhuma dificuldade ao elaborar um trabalho escrito. 
Figura 16 - Somatório dos resultados (Questão H)

H - Qual ou quais conteúdos você utiliza para a realização de trabalhos escolares?

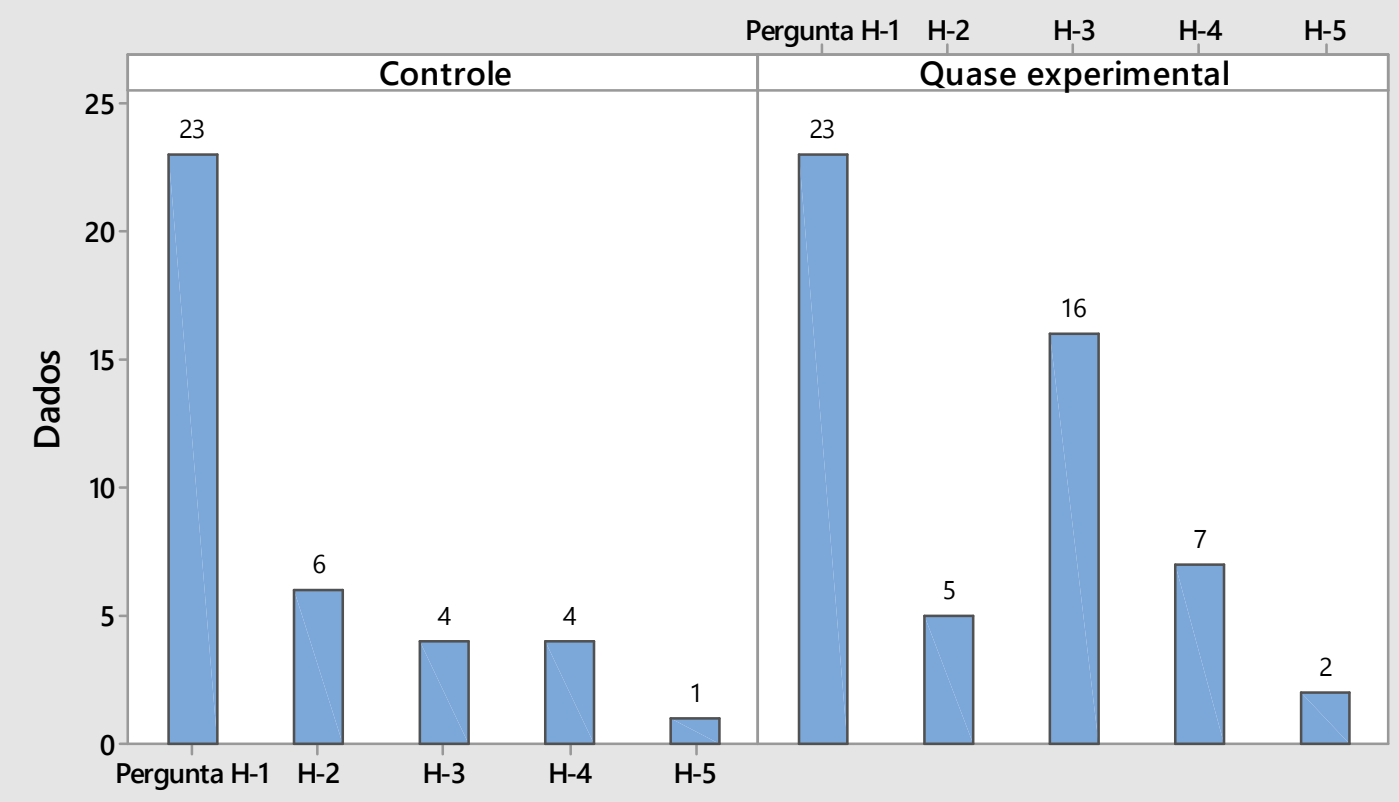

Variável: Letramento Informacional

Fonte: Elaboração própria.

A questão $\mathrm{H}$ - conteúdos utilizados para a realização de trabalhos escolares - apresenta que do total de respondentes, $71 \%$ do grupo controle e cerca de $60 \%$ do grupo quase experimental afirmam que utilizam o conteúdo "orientação sobre pesquisa". Cerca de 19\% dos estudantes do grupo controle e $13 \%$ do grupo quase experimental utilizam o conteúdo "elaboração de relatórios". Em relação ao conteúdo "elaboração de resenhas", $41 \%$ do grupo quase experimental afirma utilizar este conteúdo e apenas $12 \%$ do grupo controle. Quando o conteúdo diz respeito à "elaboração de citações", $12 \%$ do grupo controle e cerca de $18 \%$ do grupo quase experimental dizem utilizar. 


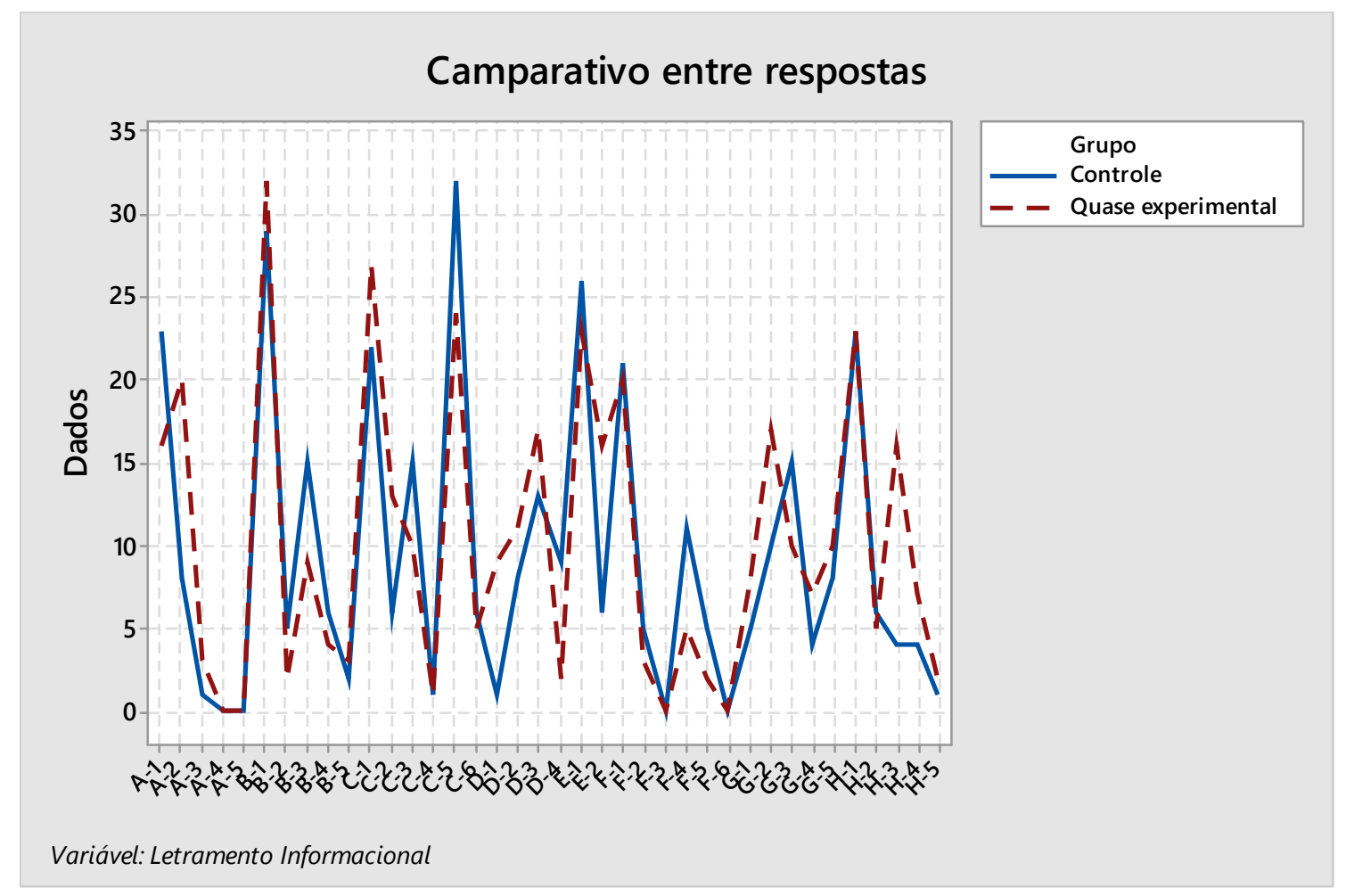

Fonte: Elaboração própria.

Em suma, os resultados da aplicação do questionário mostraram variações nas respostas de ambos os grupos (Figura 17). As características do grupo controle foram: usam a internet para realizar mais de $80 \%$ dos trabalhos solicitados pelos professores, usam enciclopédias on-line para pesquisas, usam textos de apoio, copiam parte do conteúdo do trabalho, indicam apenas o site como fonte, apresentam dificuldade com a falta de orientação sobre como estruturar o texto e usam, na maioria dos casos, a orientação para pesquisa como conteúdo de LI.

Em relação ao grupo quase experimental, identificaram-se as características: usam a internet para realizar mais da metade dos trabalhos solicitados, usam enciclopédias on-line para pesquisas, usam livros como apoio, copiam parte do conteúdo do trabalho, indicam apenas o site como fonte, apresentam dificuldade com a falta de orientação sobre como e onde buscar informação e usam, em mais da metade dos casos, a orientação para pesquisa como conteúdo de LI. 
Após identificação das estratégias dos estudantes na etapa inicial do trabalho, ambos os grupos tiveram as notas obtidas no trabalho final analisadas.

As notas de avaliação foram atribuídas pelo professor da disciplina de acordo com os indicadores: (1) seleção e avaliação de fontes de informação; (2) utilização das informações e uso das citações; (3) conteúdo do trabalho e (4) apresentação global. Após identificação dos critérios avaliados, definiram-se que os indicadores 5 (qualidade do produto final) e 6 (apresentação oral) não seriam utilizados para a atribuição da nota. Isso porque a qualidade do trabalho foi analisada no indicador "apresentação global" e por ter sido decidido que não haveria apresentação oral. O indicador "entrega do trabalho" foi acrescentado, por solicitação do professor, mas não foi incluído na análise dos dados.

Os indicadores e respectivas subdivisões podem ser visualizados no

\section{Quadro 5.}

Quadro 5 - Indicadores utilizados na avaliação do trabalho

\begin{tabular}{|l|}
\hline \multicolumn{1}{|c|}{ INDICADOR 1 - Seleção e avaliação da informação } \\
\hline 1A - Usa fontes de informação variadas \\
\hline $\begin{array}{l}\text { 1B - Seleciona fontes de informação apropriadas para diferentes necessi- } \\
\text { dades de informação }\end{array}$ \\
\hline 1C - Seleciona informações confiáveis e com autoria \\
\hline 1D - Capaz de extrair informações relevantes \\
\hline INDICADOR 2 - Utilização das informações e uso das citações \\
\hline 2A - Faz paráfrase (isto é, não copia e cola) \\
\hline 2B - Faz referência ou utiliza citações de forma adequada \\
\hline 2C - Inclui citações apropriadas \\
\hline 2D - Apresenta fontes consultadas \\
\hline \multicolumn{1}{c|}{ INDICADOR 3 - Conteúdo do trabalho } \\
\hline 3A - Informação relevante \\
\hline 3B - Informação atualizada \\
\hline 3C - Ideias e soluções viáveis \\
\hline \multicolumn{1}{c|}{ INDICADOR 4 - Apresentação global } \\
\hline 4A - Gramática (usa a norma culta corretamente) \\
\hline 4B - Escrita \\
\hline 4C - Sentenças coerentes (frases articuladas) \\
\hline 4D - Atende ao formato exigido \\
\hline INDICADOR 5 - Entrega do trabalho \\
\hline 5A - Entrega na data estabelecida \\
\hline
\end{tabular}

Fonte: Elaboração própria. 
Durante o período de 26 de maio a 8 de agosto de 2014, o trabalho de pesquisa foi realizado em dupla pelos alunos. Tal configuração foi definida pelo professor da disciplina com intuito de evitar que em grupos grandes, os estudantes deixassem de se empenhar em prol de um ou dois colegas que geralmente fazem o trabalho. A escolha das duplas ficou a critério dos estudantes e foi mediada pelo professor. Ao todo foram formadas 19 duplas, em cada uma das turmas, na etapa inicial do trabalho. Entretanto, no período de entrega do material produzido, apenas 12 duplas de cada grupo ("controle" e "quase experimental") entregaram os trabalhos para análise. Durante o desenvolvimento da atividade, três estudantes do grupo quase experimental foram transferidos de sala. Para não terem o trabalho comprometido, os alunos que ficaram sozinhos acabaram sendo incorporados em outras duplas, acarretando a formação de três trios. Tal fato fugiu do que foi estabelecido previamente para o andamento da pesquisa, mas acabou sendo necessário. Os estudantes que não entregaram o trabalho não obtiveram nota.

Diante do número de trabalhos entregues e das notas atribuídas pelo professor, chegaram-se aos seguintes resultados:

Figura 18 - Distribuição média das notas - Indicador $1 \mathrm{~A}$

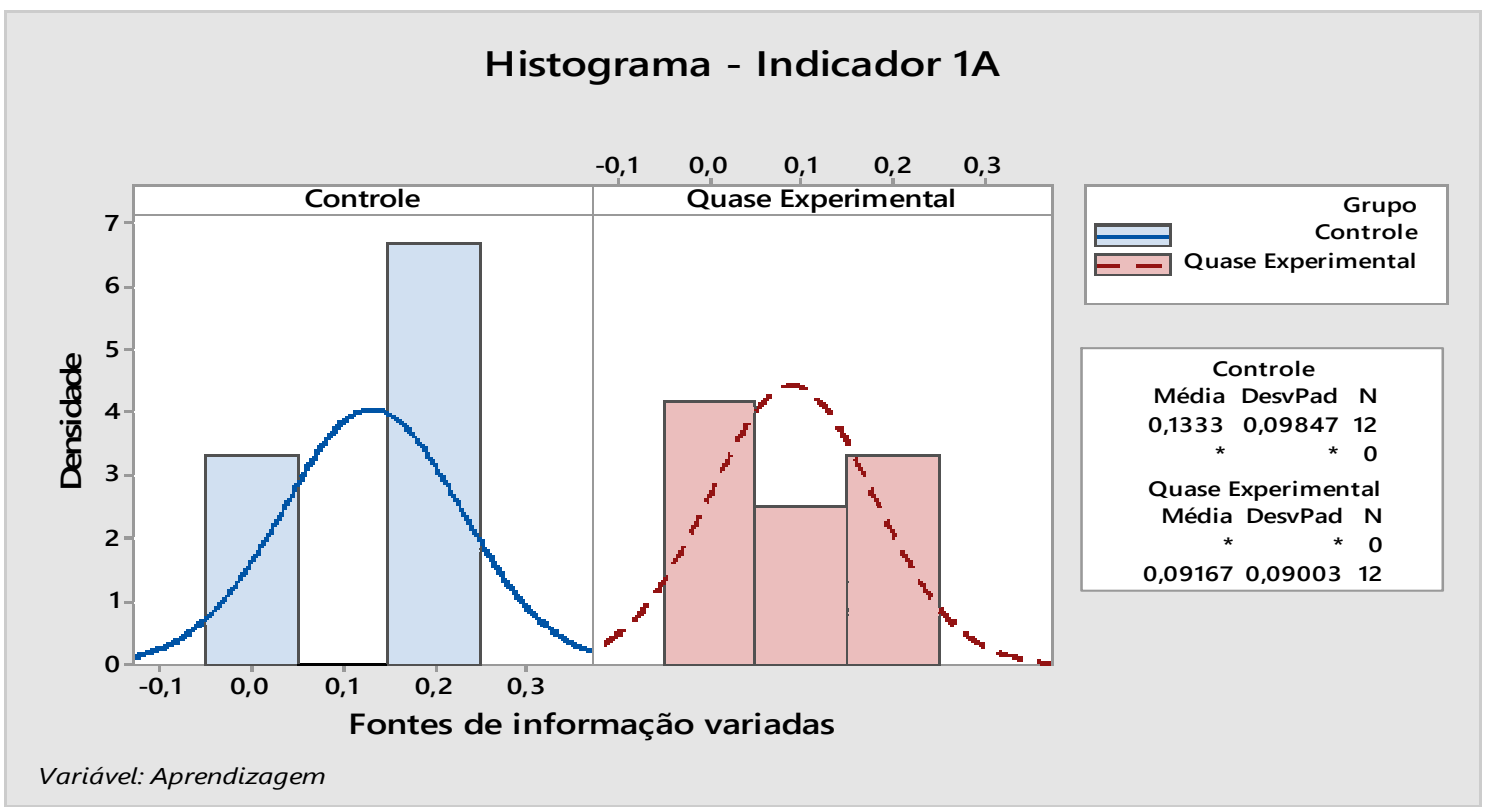

Fonte: Elaboração própria. 
O indicador $1 \mathrm{~A}$ - Fontes de informação variadas - apresenta que do total de trabalhos entregues, cerca de $55 \%$ dos estudantes do grupo controle e cerca de $25 \%$ do grupo quase experimental obtiveram nota 0,2. Além disso, $16 \%$ de estudantes do grupo quase experimental obtiveram nota 0,1 no indicador. Do total, cerca de $25 \%$ do grupo controle e $30 \%$ do grupo quase experimental não obtiveram nota neste indicador. Considerando que o valor total da nota do indicador é de 0,2, o grupo controle demonstrou utilizar mais fontes de informação variadas no momento de elaboração do trabalho escrito. O grupo obteve melhor desempenho se comparado ao grupo quase experimental. Cerca de metade dos aprendizes conquistaram nota máxima no indicador.

Figura 19 - Distribuição média das notas - Indicador $1 B$

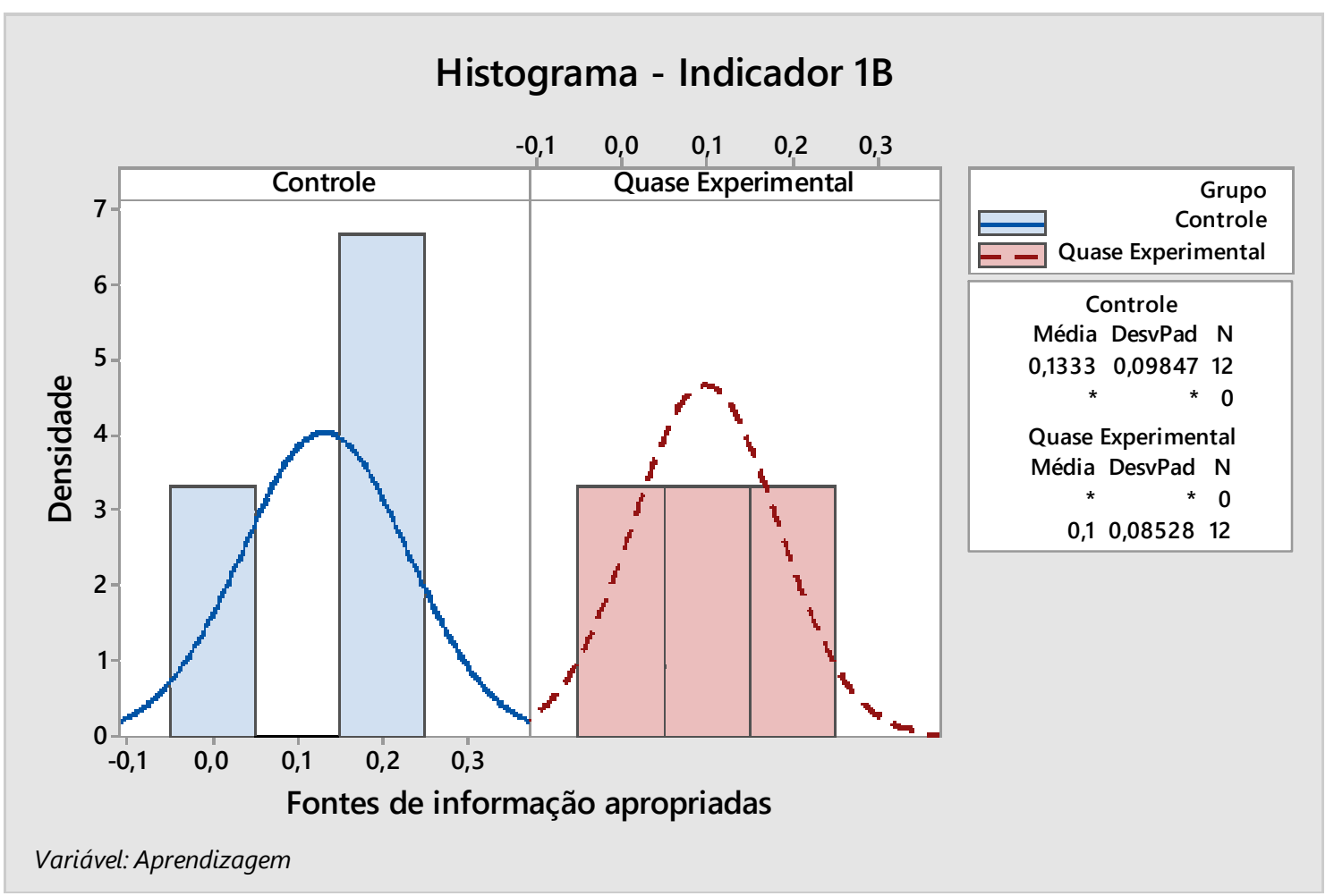

Fonte: Elaboração própria.

O indicador 1B - Fontes de informação apropriadas - mostra que do total de trabalhos entregues, cerca de $55 \%$ dos estudantes do grupo controle e cerca de $25 \%$ do grupo quase experimental obtiveram nota 0,2 . Das notas restantes, cerca de $25 \%$ do grupo quase experimental obteve 0,1 no indicador. $25 \%$ de ambos os grupos não obtiveram nota. Considerando que o valor total da nota do indicador é de 0,2 , o grupo controle demonstrou utilizar fontes de 
informação mais apropriadas. O grupo obteve desempenho mais satisfatório se comparado ao grupo quase experimental. Cerca de metade dos aprendizes atingiu nota máxima no indicador.

Figura 20 - Distribuição média das notas - Indicador $1 C$

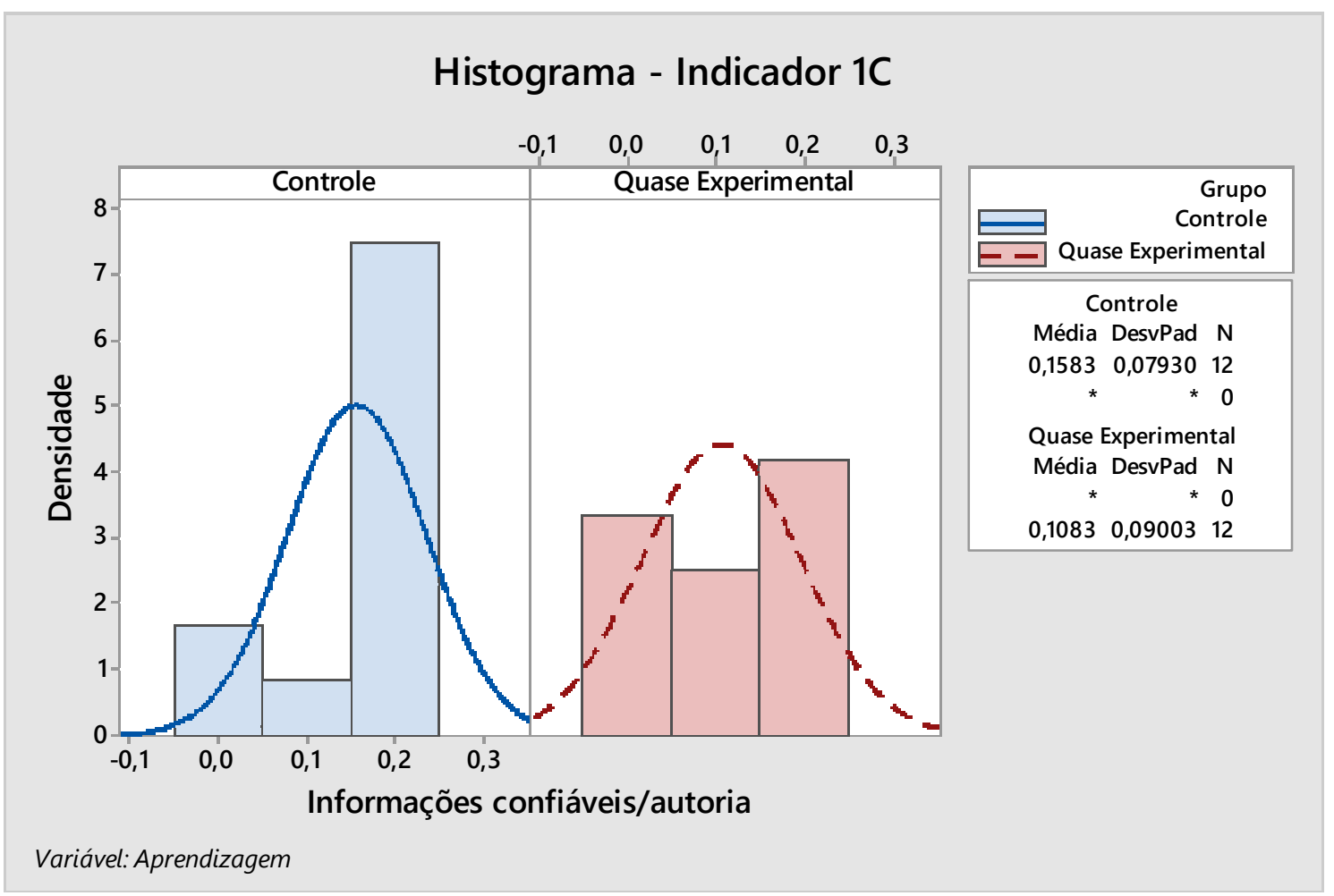

Fonte: Elaboração própria.

O indicador 1C - Informações confiáveis/autoria - mostra que do total de trabalhos entregues, cerca de $65 \%$ dos estudantes do grupo controle e cerca de $35 \%$ do grupo quase experimental obtiveram nota 0,2 . Das notas restantes, cerca de $10 \%$ do grupo controle e cerca de $25 \%$ do grupo quase experimental obteviveram 0,1 no indicador. $15 \%$ do grupo controle e cerca de $30 \%$ do grupo quase experimental não obtiveram nota. Considerando que o valor total da nota do indicador é de 0,2, o grupo controle demonstrou selecionar mais fontes confiáveis no momento de elaboração do trabalho escrito. O grupo obteve melhor desempenho se comparado ao grupo quase experimental, pois mais da metade dos aprendizes alcançaram nota máxima no indicador. 
Figura 21 - Distribuição média das notas - Indicador 1D

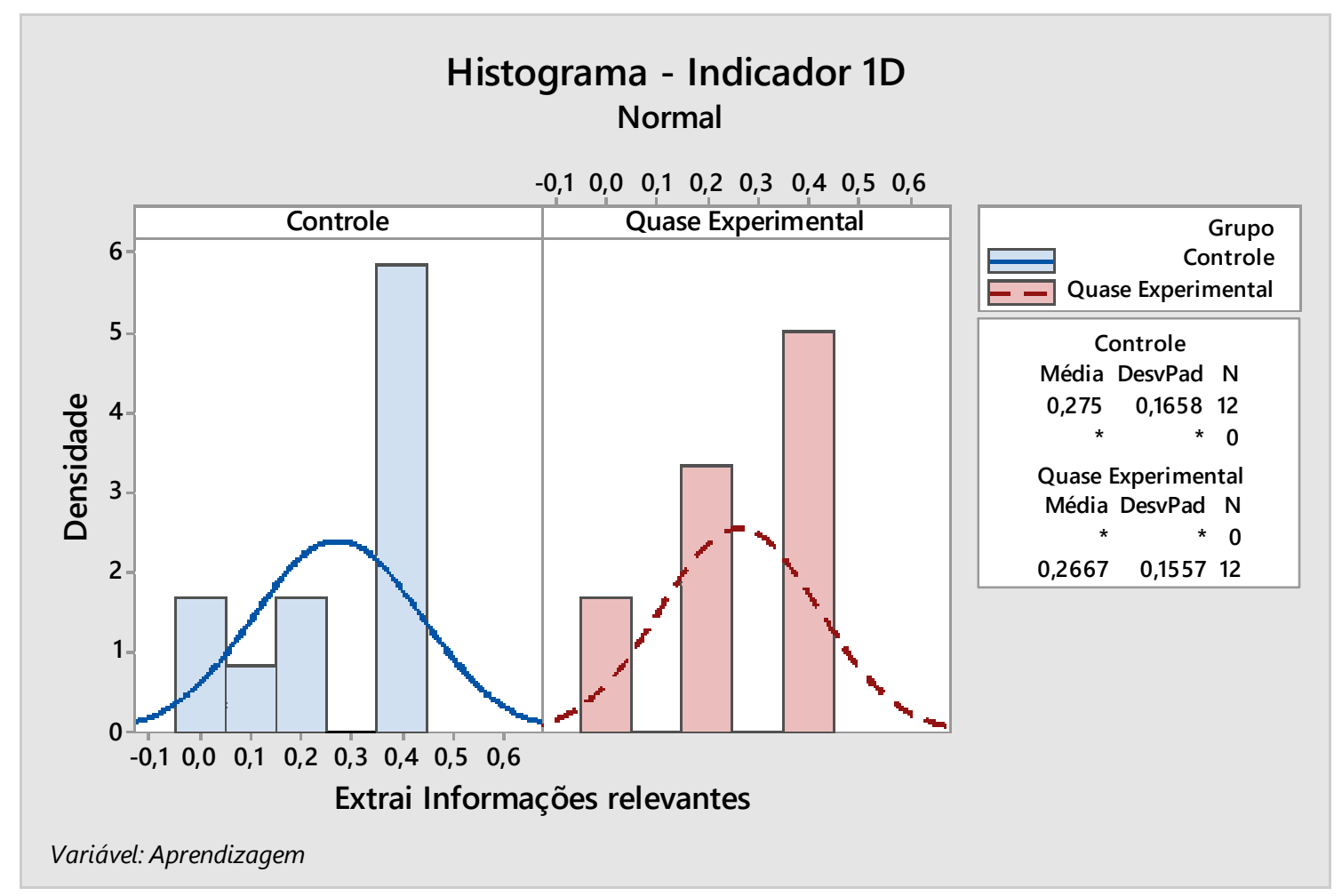

Fonte: Elaboração própria.

O indicador 1D - Extrai informações relevantes - apresenta que do total de trabalhos entregues, cerca de 50\% dos estudantes do grupo controle e cerca de $40 \%$ do grupo quase experimental obtiveram nota 0,4 . Cerca de $15 \%$ do grupo controle e $30 \%$ do grupo quase experimental obteve 0,2 no indicador. Cerca de $10 \%$ do grupo experimental obteve nota 0,1 . Ao final, cerca de $15 \%$ de ambos os grupos não obtiveram nota. Considerando que o valor total da nota do indicador é de 0,4, o grupo controle demonstrou ser capaz de extrair mais informações relevantes que o grupo quase experimental. O grupo obteve desempenho mais satisfatório, pois cerca de metade dos aprendizes atingiu nota máxima no indicador. 
Figura 22 - Distribuição média das notas - Indicador 2A

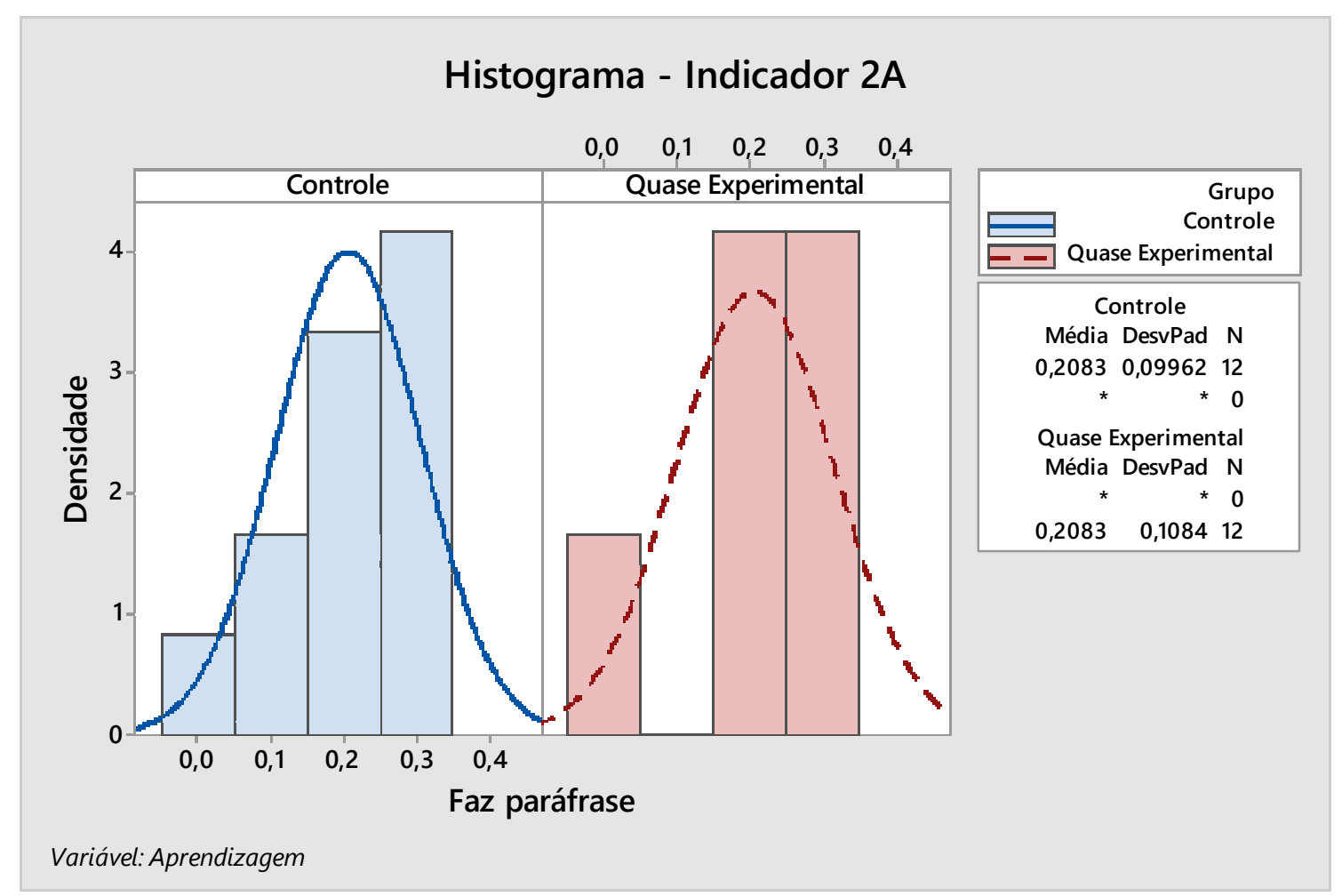

Fonte: Elaboração própria.

O indicador 2A - Faz paráfrase - apresenta que do total de trabalhos entregues, cerca de $35 \%$ de ambos os grupos obtiveram nota 0,3 no indicador. $30 \%$ do grupo controle e cerca de $35 \%$ do grupo quase experimental obteve 0,2 no indicador. Cerca de $15 \%$ do grupo controle obteve nota 0,1 . Ao final, cerca de $10 \%$ do grupo controle e $15 \%$ do grupo quase experimental não obtiveram nota. Considerando que o valor total da nota do indicador é de 0,3 , menos da metade dos estudantes de ambos os grupos atingiram o valor máximo. Isso demonstrou pouco conhecimento na elaboração de paráfrase. 
Figura 23 - Distribuição média das notas - Indicador 2B

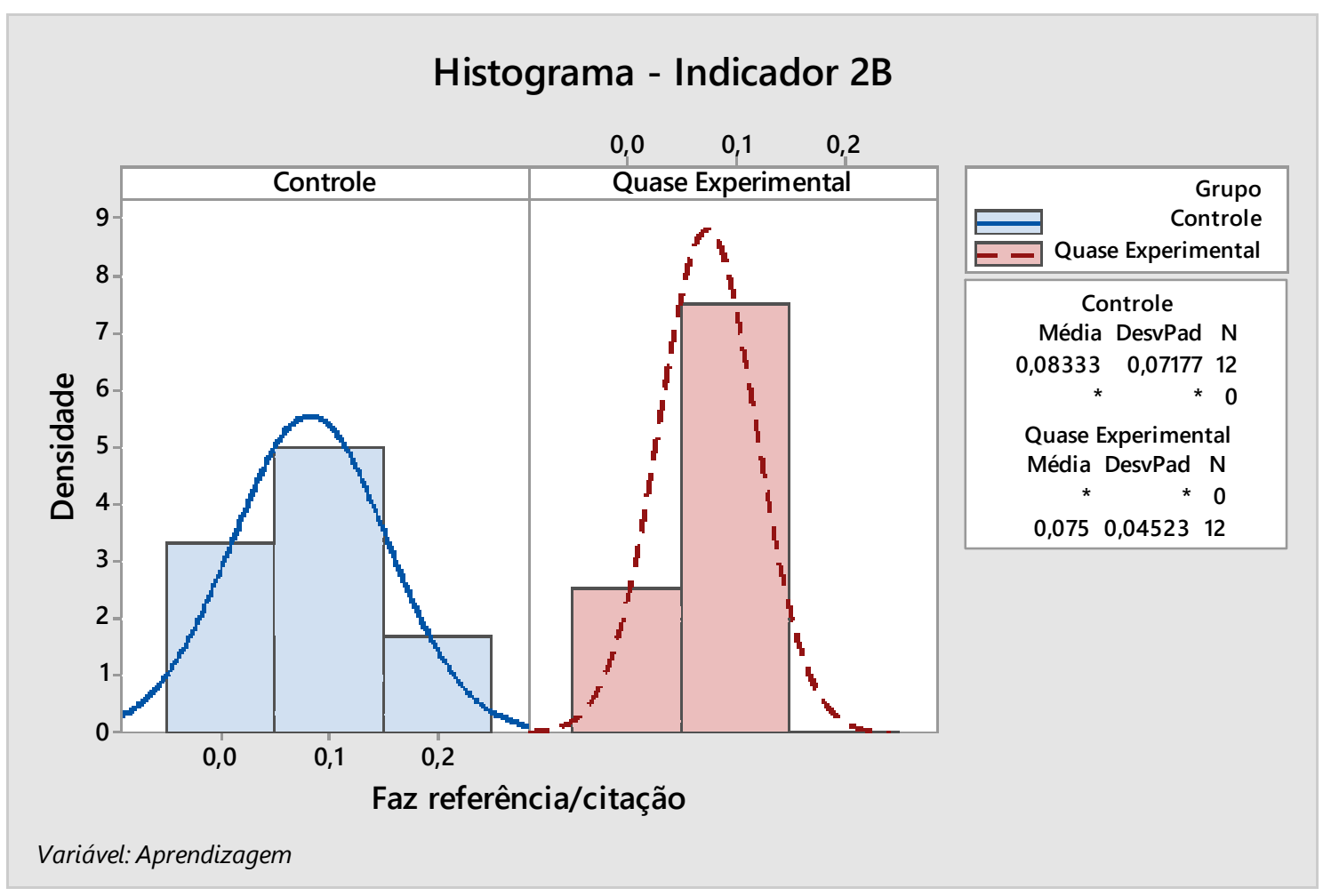

Fonte: Elaboração própria.

O indicador 2B - Faz referência/citação - apresenta que do total de trabalhos entregues, cerca de $40 \%$ do grupo controle e $60 \%$ do grupo quase experimental obtiveram nota 0,1 no indicador. Na segunda opção, 15\% do grupo controle obteve 0,2 no indicador. Ao final, 15\% do grupo controle e $13 \%$ do grupo quase experimental não obtiveram nota. Considerando que o valor total da nota do indicador é de 0,2, o grupo controle demonstrou fazer mais referências ou utilizar mais citações do que o grupo quase experimental. Entretanto, o número de estudantes que atingiu o valor máximo do indicador foi pouco expressivo. 


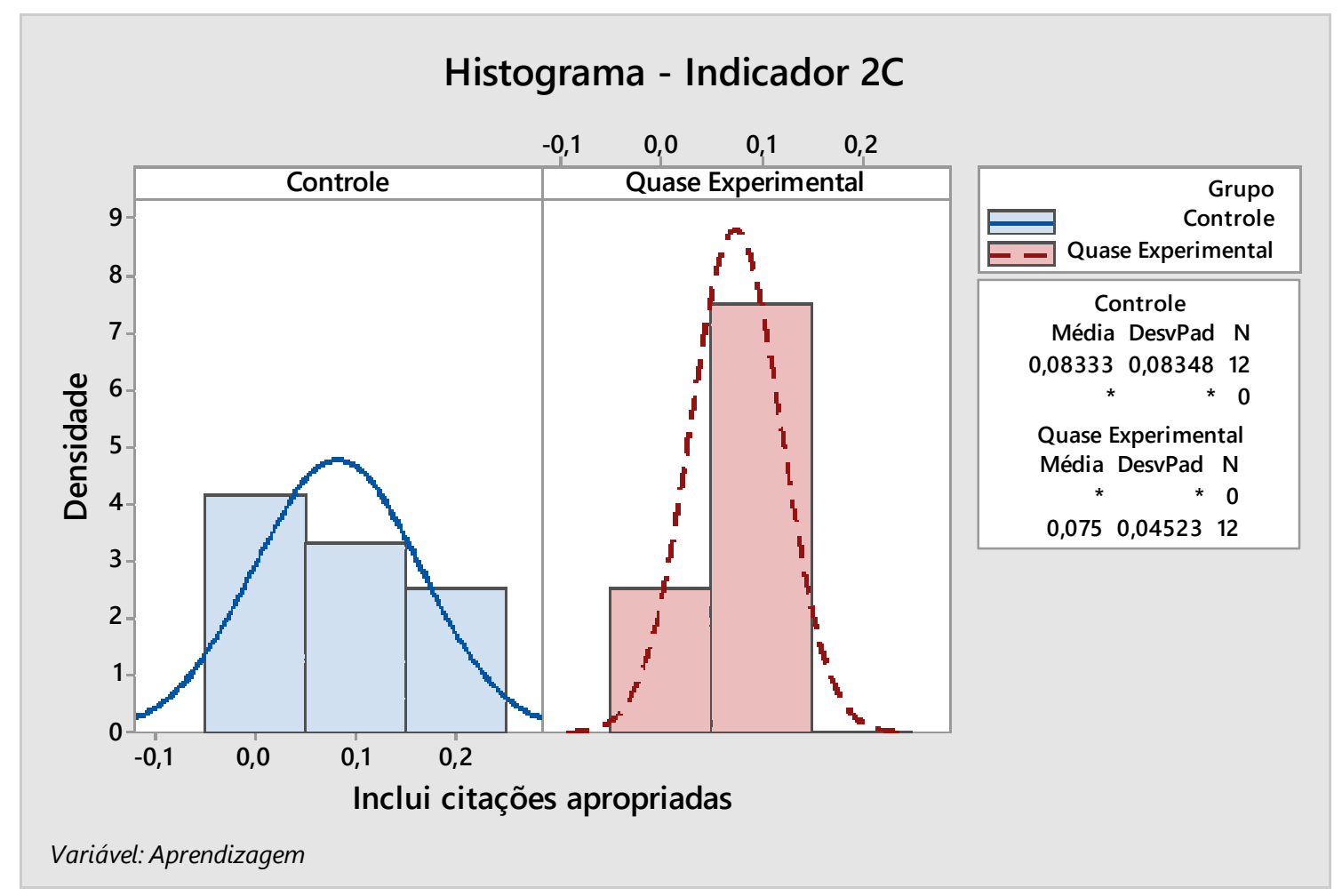

Fonte: Elaboração própria.

O indicador 2C - Inclui citações apropriadas - mostra que do total de trabalhos entregues, cerca de $25 \%$ do grupo controle e $60 \%$ do grupo quase experimental obtiveram nota 0,1 no indicador. Outros $20 \%$ do grupo controle obteve 0,2 no indicador. Ao final, $33 \%$ do grupo controle e $20 \%$ do grupo quase experimental não obtiveram nota. Considerando que o valor total da nota do indicador é de 0,2, o grupo controle demonstrou incluir mais citações corretas que o grupo quase experimental. Entretanto, o número de estudantes que atingiu o valor máximo do indicador foi pouco expressivo. 


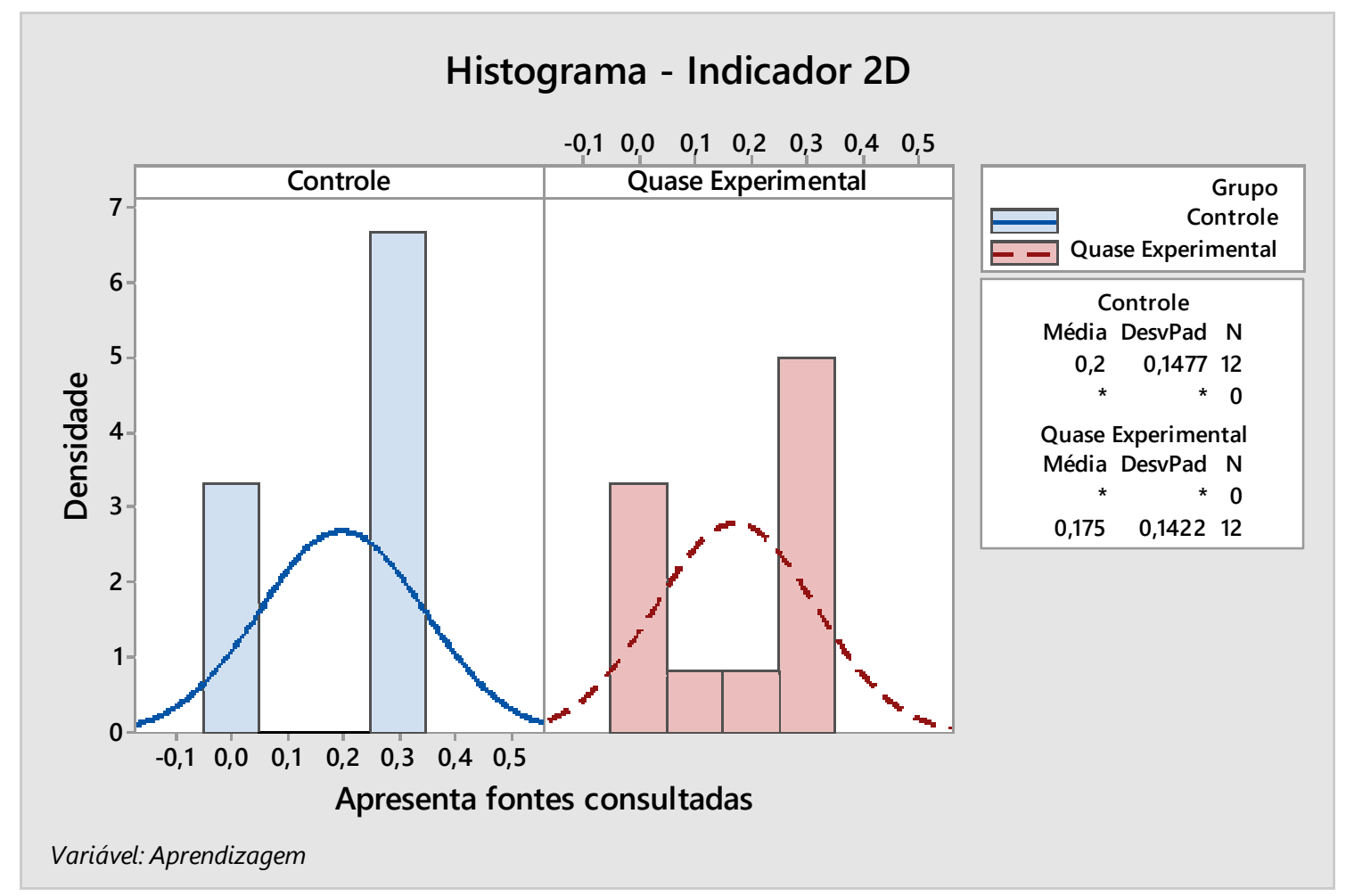

Fonte: Elaboração própria.

O indicador 2D - Apresenta fontes consultadas - mostra que do total de trabalhos entregues, cerca de $55 \%$ do grupo controle e $41 \%$ do grupo quase experimental obtiveram nota 0,3 no indicador. Cerca de $10 \%$ do grupo quase experimental obtiveram nota 0,1 e 0,2 . Ao final, $25 \%$ do grupo controle não obteve nota. Considerando que o valor total da nota do indicador é de 0,3, o grupo controle apresentou mais fontes consultadas que o grupo quase experimental. O grupo obteve desempenho mais satisfatório, pois metade dos aprendizes atingiu nota máxima no indicador. 
Figura 26 - Distribuição média das notas - Indicador 3A

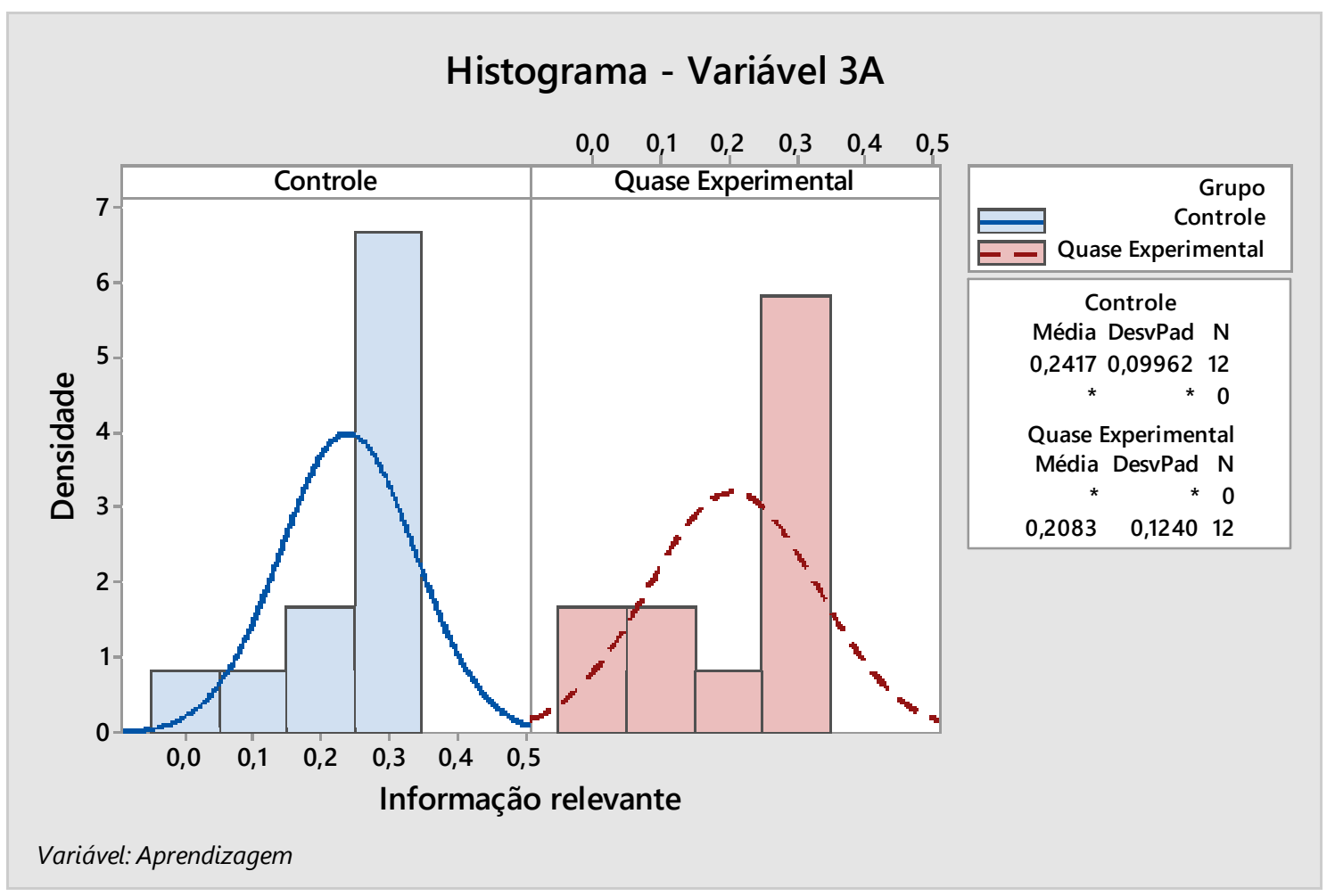

Fonte: Elaboração própria.

O indicador 3A - Informação relevante - mostra que do total de trabaIhos entregues, cerca de $55 \%$ do grupo controle e $50 \%$ do grupo quase experimental obtiveram nota 0,3 no indicador. Cerca de $10 \%$ do grupo quase experimental e $15 \%$ do grupo controle obtiveram nota 0,2 . Outros $15 \%$ do grupo quase experimental e $10 \%$ do grupo controle obtiveram nota 0,1 no indicador. Ao final, $10 \%$ do grupo controle e $15 \%$ do grupo quase experimental não obtiveram nota. Considerando que o valor total da nota do indicador é de 0,3, o grupo controle apresentou mais informações relevantes no trabalho escrito que o grupo quase experimental. O grupo obteve melhor desempenho, pois cerca de metade dos aprendizes alcançou nota máxima no indicador. 
Figura 27 - Distribuição média das notas - Indicador 3B

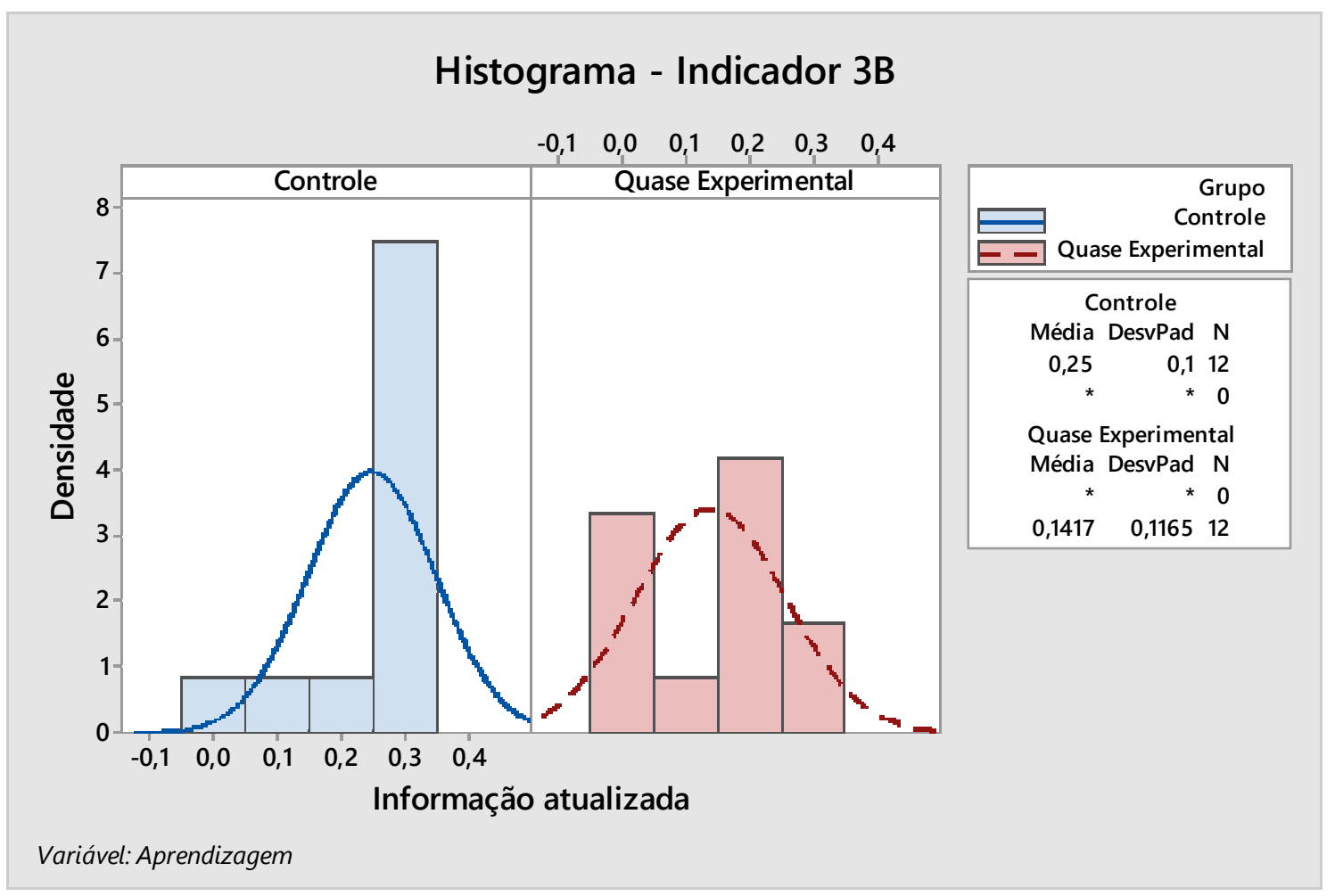

Fonte: Elaboração própria.

O indicador 3B - Informação atualizada - mostra que do total de trabaIhos entregues, cerca de $60 \%$ do grupo controle e $15 \%$ do grupo quase experimental obtiveram nota 0,3 no indicador. Cerca de $10 \%$ do grupo quase experimental e $35 \%$ do grupo controle obtiveram nota 0,2 . Cerca de $10 \%$ de ambos os grupos tiraram nota 0,1 . Ao final, $10 \%$ do grupo controle e $25 \%$ do grupo quase experimental não obtiveram nota. Considerando que o valor total da nota do indicador é de 0,3, o grupo controle apresentou mais informações atualizadas que o grupo quase experimental. $O$ grupo controle obteve desempenho mais satisfatório e mais da metade dos aprendizes atingiram nota máxima no indicador. 
Figura 28 - Distribuição média das notas - Indicador 3C

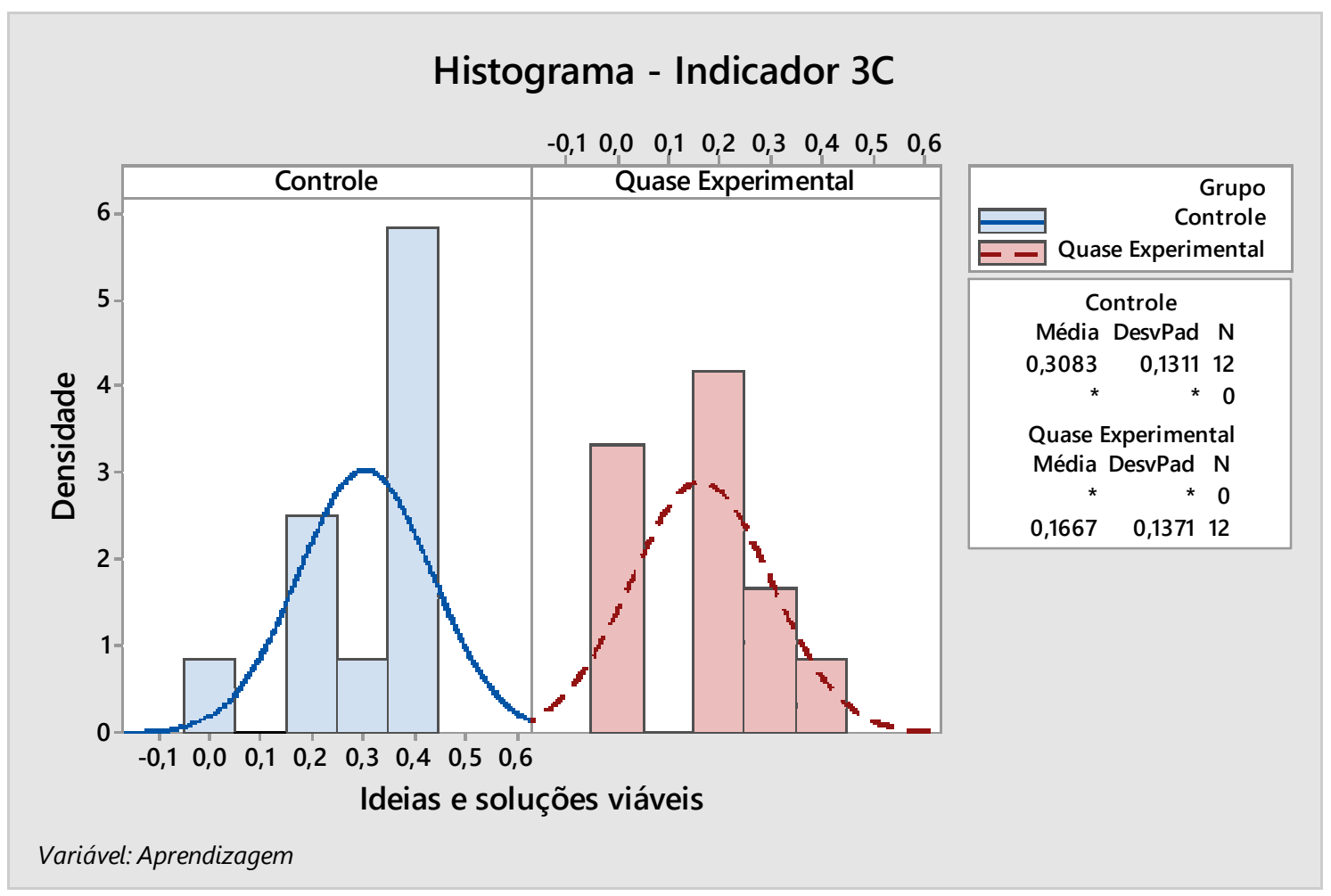

Fonte: Elaboração própria.

O indicador 3C - Ideias e soluções viáveis - apresenta que do total de trabalhos entregues, cerca de $50 \%$ do grupo controle e $10 \%$ do grupo quase experimental obtiveram nota 0,4 no indicador. Na segunda opção, cerca de $15 \%$ do grupo quase experimental e $25 \%$ do grupo controle obtiveram nota 0,3 . Cerca de $30 \%$ do grupo quase experimental e $25 \%$ do grupo controle obtiveram nota 0,2 . Ao final, cerca de $10 \%$ do grupo controle e $30 \%$ do grupo quase experimental não obtiveram nota. Considerando que o valor total da nota do indicador é de 0,4, o grupo controle apresentou trabalho escrito com maior número de ideias e soluções viáveis que o grupo quase experimental. O grupo controle obteve desempenho mais satisfatório e cerca de metade dos aprendizes alcançaram nota máxima no indicador. 
Figura 29 - Distribuição média das notas - Indicador 4A

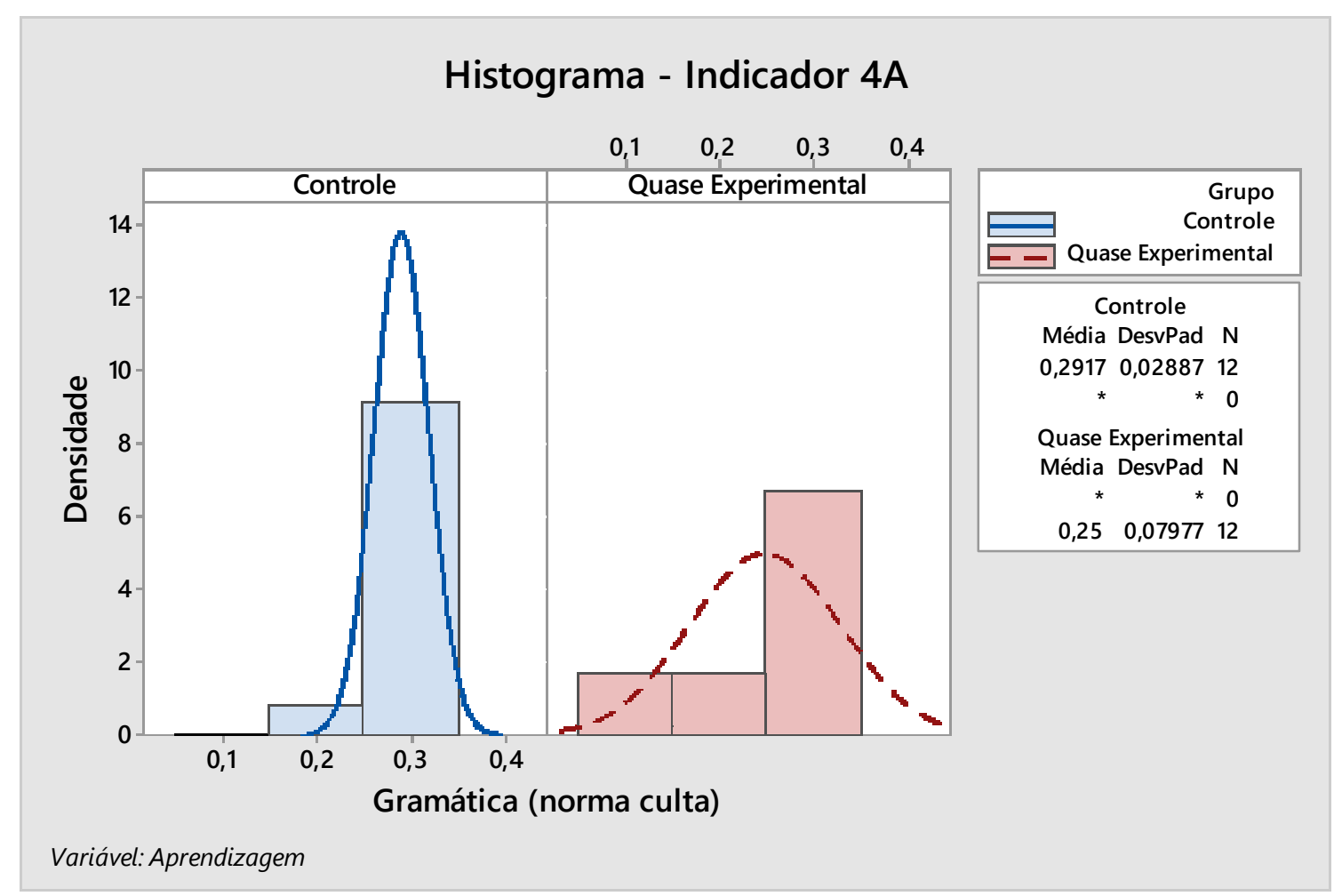

Fonte: Elaboração própria.

O indicador 4A - Gramática - apresenta que do total de trabalhos entregues, cerca de $75 \%$ do grupo controle e $50 \%$ do grupo quase experimental obtiveram nota 0,3 no indicador. Em seguida, $15 \%$ do grupo quase experimental e $10 \%$ do grupo controle obtiveram nota 0,2 . Cerca de $10 \%$ do grupo quase experimental obteve nota 0,1 . Considerando que o valor total da nota do indicador é de 0,3 , o grupo controle teve melhor êxito na utilização da norma culta que o grupo quase experimental. $O$ grupo controle obteve melhor desempenho e mais da metade dos aprendizes atingiram nota máxima no indicador. 
Figura 30 - Distribuição média das notas - Indicador 4B

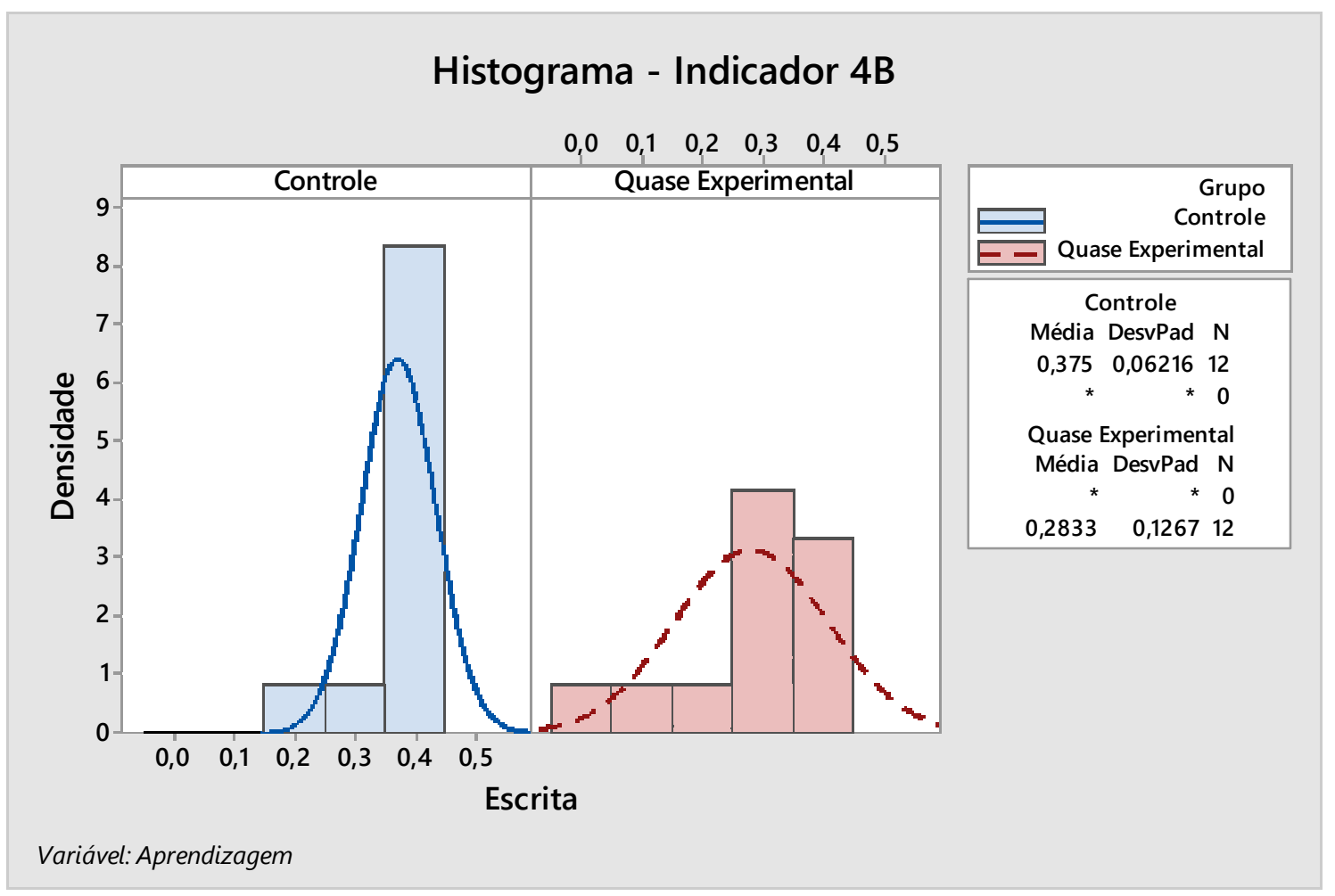

Fonte: Elaboração própria.

O indicador 4B - Escrita - mostra que do total de trabalhos entregues, $65 \%$ do grupo controle e $30 \%$ do grupo quase experimental obtiveram nota 0,4 no indicador. Posteriormente, $33 \%$ do grupo quase experimental e $10 \%$ do grupo controle obtiveram nota 0,3 . Cerca de $10 \%$ de ambos os grupos obtiveram nota 0,2 e 0,1 . Ao final, $10 \%$ do grupo quase experimental não obteve nota. Considerando que o valor total da nota do indicador é de 0,4, o grupo controle apresentou melhor produção escrita que o grupo quase experimental. $O$ grupo obteve melhor desempenho e mais da metade dos aprendizes alcançaram nota máxima no indicador. 
Figura 31 - Distribuição média das notas - Indicador 4C

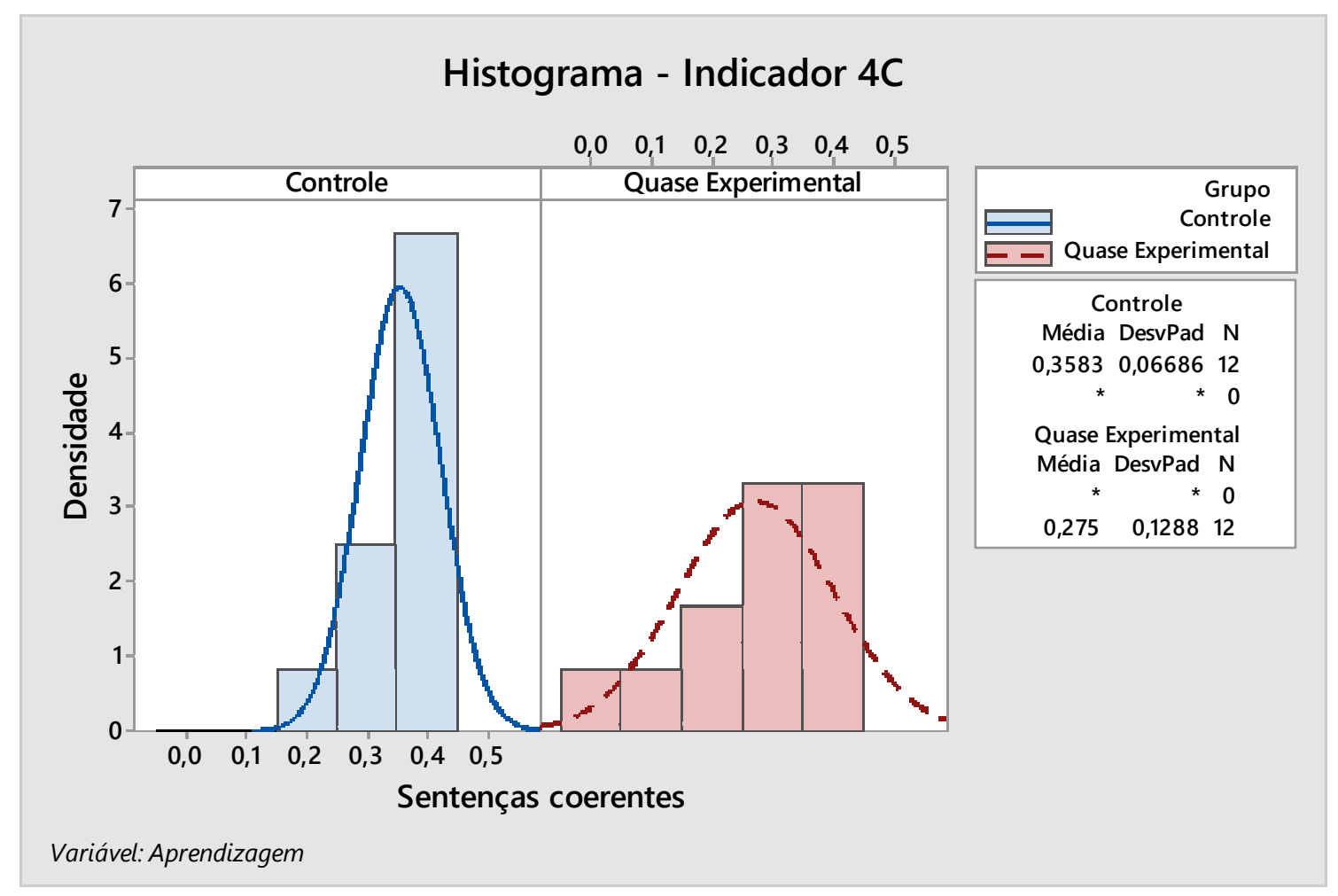

Fonte: Elaboração própria.

O indicador $4 \mathrm{C}$ - Sentenças coerentes - mostra que do total de trabaIhos entregues, $55 \%$ do grupo controle e $25 \%$ do grupo quase experimental obtiveram nota 0,4 no indicador. Em seguida, cerca de $25 \%$ do grupo quase experimental e $18 \%$ do grupo controle obtiveram nota 0,3 . Cerca de $15 \%$ do grupo quase experimental e $10 \%$ do grupo controle obtiveram nota 0,3 . Ao final, $10 \%$ do grupo quase experimental não obteve nota. Considerando que 0 valor total da nota do indicador é de 0,4 , o grupo controle apresentou sentenças mais coerentes que o grupo quase experimental. $\mathrm{O}$ grupo obteve desempenho mais satisfatório e cerca de metade dos aprendizes alcançaram nota máxima no indicador. 
Figura 32 - Distribuição média das notas - Indicador 4D

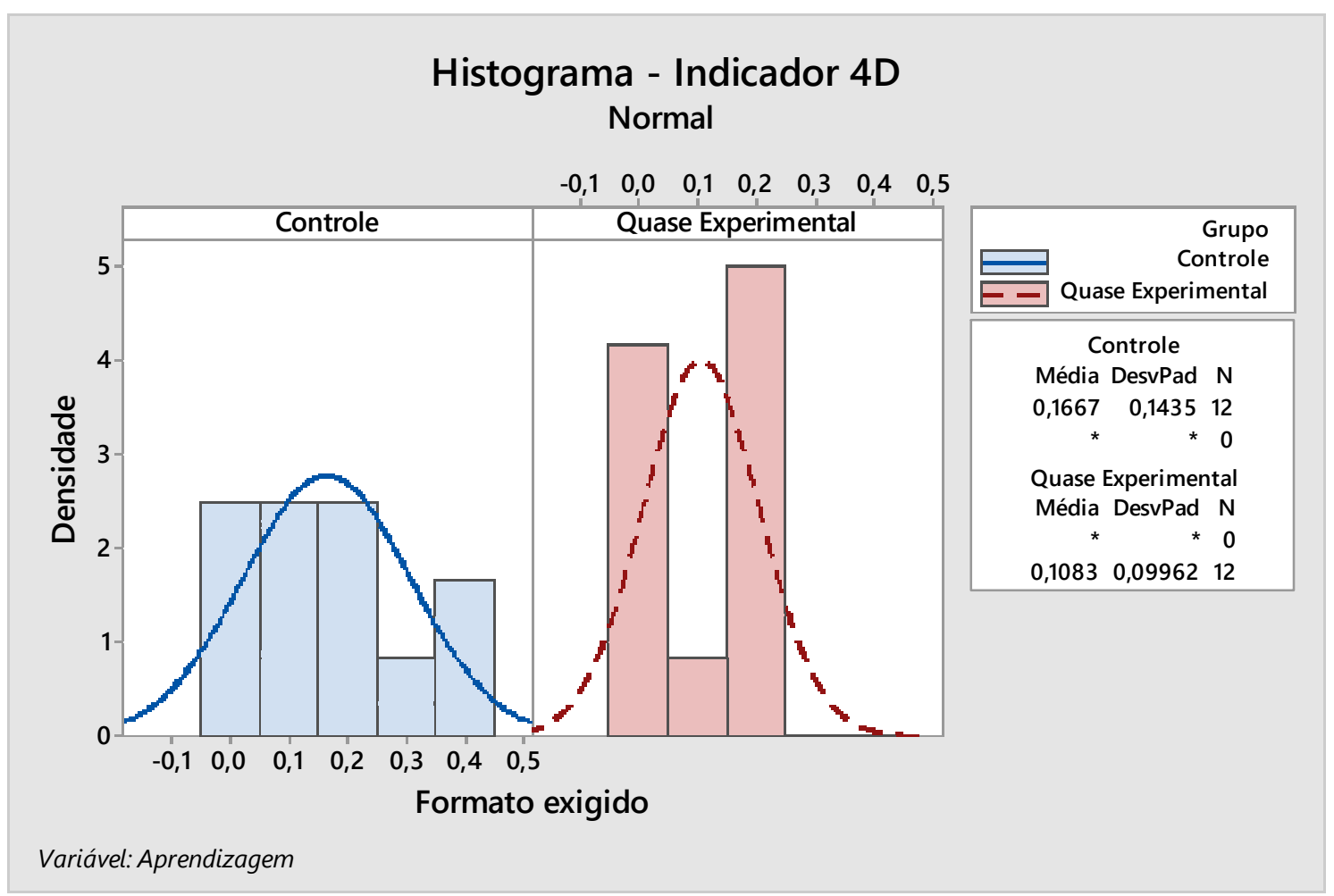

Fonte: Elaboração própria.

O indicador 4D - Formato exigido - demonstra que do total de trabalhos entregues, apenas o grupo controle obteve notas 0,3 e 0,4, cerca de $15 \%$ e $10 \%$ dos estudantes respectivamente. A seguir, $41 \%$ do grupo quase experimental e $20 \%$ do grupo controle obtiveram nota 0,2 . Cerca de $10 \%$ do grupo quase experimental e $20 \%$ do grupo controle obtiveram nota 0,1 . Ao final, cerca de $20 \%$ do grupo controle e $35 \%$ do grupo quase experimental não obtiveram nota. Considerando que o valor total da nota do indicador é de 0,4, os trabalhos apresentados pelo grupo controle atenderam mais adequadamente ao formato exigido. Entretanto, o número de estudantes que atingiram o valor máximo do indicador foi pouco expressivo. Isso demonstrou pouca efetividade na utilização do guia para estruturação de trabalhos escolares.

A relação estabelecida nos gráficos refere-se às notas obtidas em cada indicador e ao número de estudantes. Nesse sentido, observa-se que a quantidade média de alunos que obtiveram nota em pelo menos um dos indicadores é maior no grupo controle. Isso significa que apesar de não terem recebido orientação específica sobre a utilização dos conteúdos de LI, o grupo controle 
apresentou resultados mais satisfatórios em comparação ao grupo quase experimental, conforme dados apresentados na Tabela 1.

\begin{tabular}{|c|c|c|}
\hline Indicador & $\begin{array}{l}\text { Grupo Quase } \\
\text { Experimental }\end{array}$ & Grupo Controle \\
\hline \multicolumn{3}{|c|}{ Média de alunos } \\
\hline $1 \mathrm{~A}$ & 0,09167 & 0,1333 \\
\hline 1B & 0,1 & 0,1333 \\
\hline $1 \mathrm{C}$ & 0,1083 & 0,1583 \\
\hline 1D & 0,2667 & 0,275 \\
\hline $2 \mathrm{~A}$ & 0,2083 & 0,2083 \\
\hline $2 \mathrm{~B}$ & 0,075 & 0,083 \\
\hline $2 \mathrm{C}$ & 0,075 & 0,083 \\
\hline $2 \mathrm{D}$ & 0,175 & 0,2 \\
\hline $3 A$ & 0,2083 & 0,2417 \\
\hline $3 B$ & 0,1417 & 0,25 \\
\hline $3 C$ & 0,1667 & 0,3083 \\
\hline $4 \mathrm{~A}$ & 0,25 & 0,2917 \\
\hline 4B & 0,375 & 0,2833 \\
\hline $4 \mathrm{C}$ & 0,275 & 0,3583 \\
\hline 4D & 0,1083 & 0,1667 \\
\hline Total & 2,62497 & 3,1742 \\
\hline
\end{tabular}

No que diz respeito ao somatório das notas obtidas em cada indicador é possível observar a diferença estabelecida entre ambos os grupos na Figura 33. As notas máxima e mínima também podem ser visualizadas na Figura 34 e Figura 35, respectivamente. 


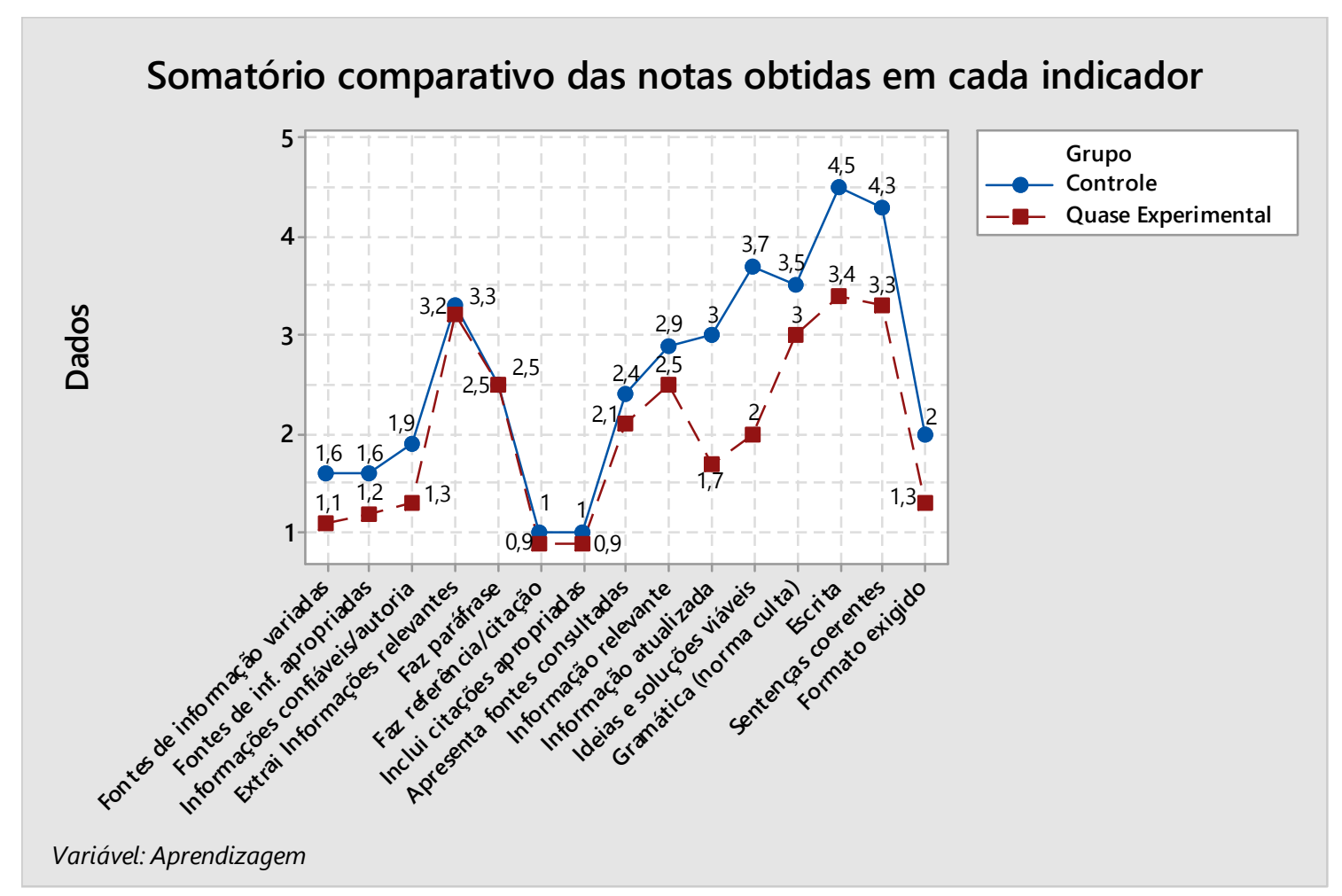

Fonte: Elaboração própria.

No somatório comparativo do total de notas obtidas em cada indicador, percebe-se que o grupo controle apresentou melhor desempenho em comparação ao grupo quase experimental. A maior pontuação pôde ser observada no indicador 4B (escrita), totalizando 4,5 pontos para o grupo controle e 3,4 pontos para o grupo quase experimental. 


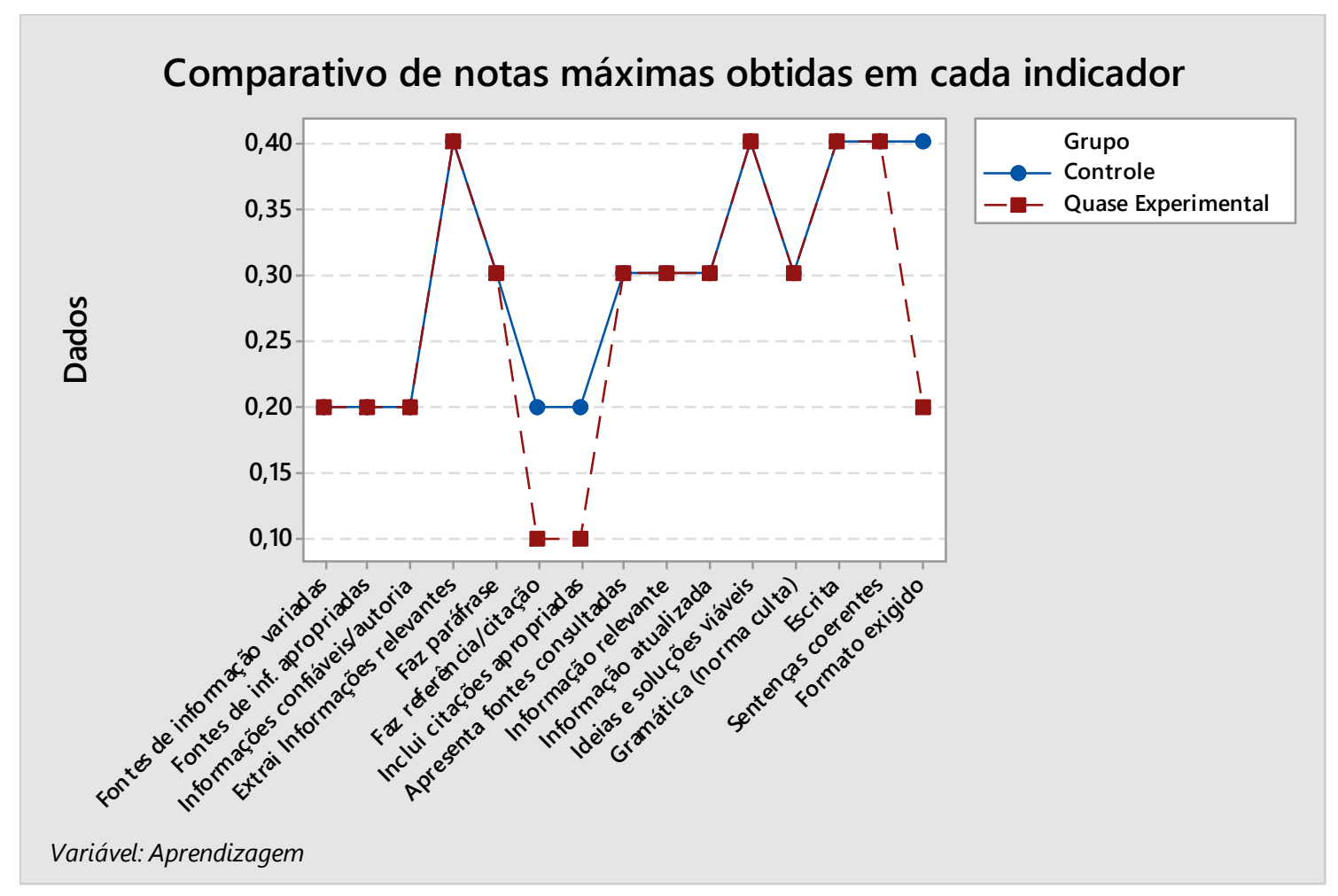

Fonte: Elaboração própria.

No comparativo de notas máximas, os dados obtidos demonstram que apenas o grupo controle conseguiu atingir o valor máximo da nota para cada indicador. O grupo experimental não conseguiu esse resultado nos indicadores 2B (faz referência/citação), 2C (inclui citações apropriadas) e 4D (formato exigido). 


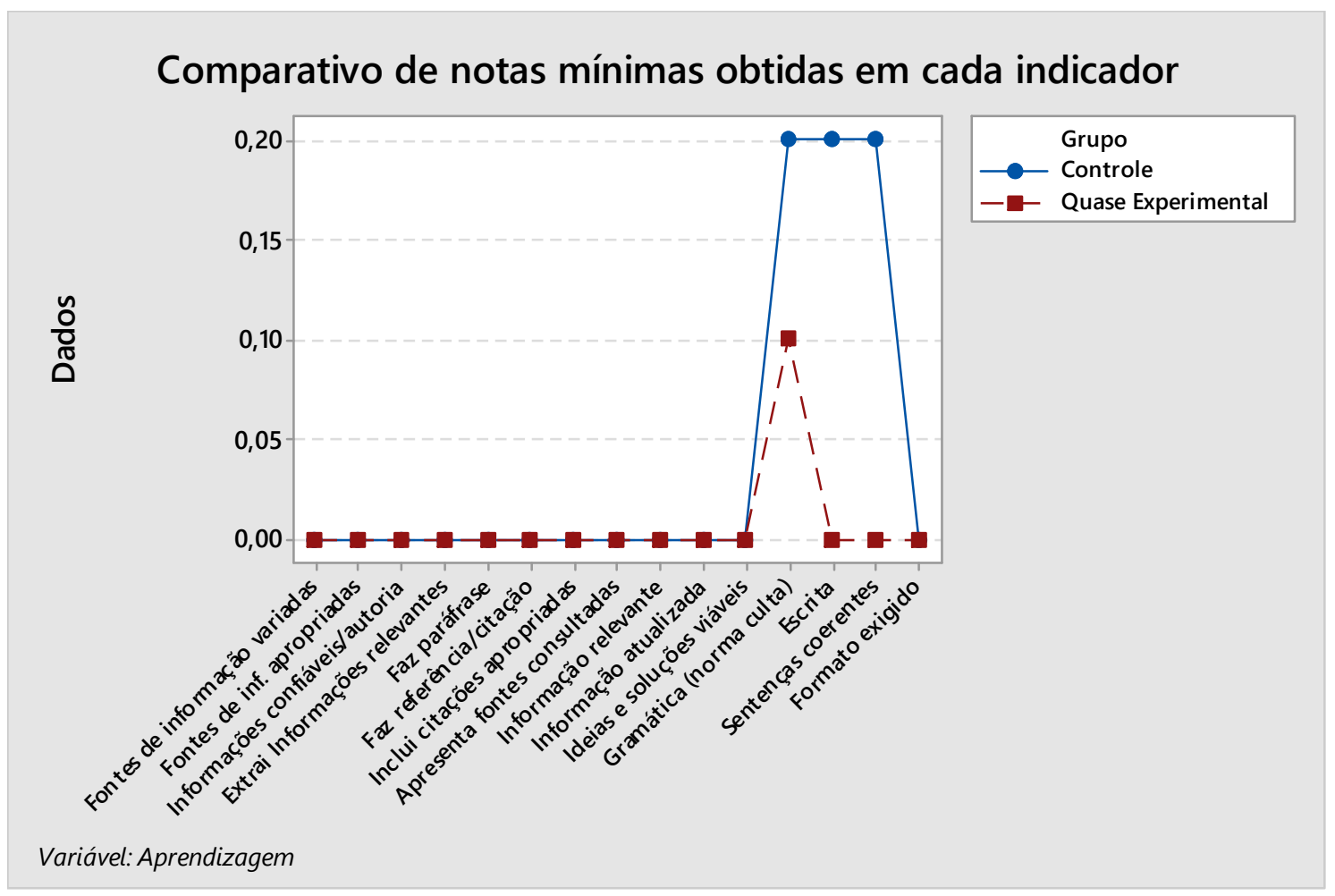

Fonte: Elaboração própria.

No comparativo de notas mínimas, os dados apontam que o índice de notas mínimas obtidas pelo grupo quase experimental foi maior que o grupo controle. Em três dos indicadores avaliados (4A, 4B e 4C), o grupo controle conseguiu manter a nota mínima diferente de zero. $O$ grupo quase experimental conseguiu nota mínima diferente de zero apenas no indicador 4A.

Diante dos dados obtidos, percebeu-se que o grupo quase experimental apresentou notas menores se comparadas ao grupo controle. No que se refere às notas máximas obtidas em cada indicador, a diferença pode ser visualizada principalmente nos indicadores 2B (faz referência/citação), 2C (inclui citações apropriadas) e 4D (formato exigido), conforme Figuras 33 e 34 .

No intuito de analisar se tal diferença de desempenho entre ambos os grupos foi significativa e de aprofundar a análise dos dados obtidos, optou-se pelo planejamento de um experimento fatorial não aleatório, com quantitativo de 24 ensaios (um para cada trabalho entregue), baseado nas notas obtidas nos indicadores. A realização deste experimento não contradiz o método quase experimental definido na metodologia deste estudo. Isso porque a realização do experimento se baseou apenas nas notas obtidas em cada indicador, sendo 
entendida pelo software como simulação de determinada situação produzida por um conjunto específico de dados.

Baseado no modelo teórico da pesquisa, a análise relacionou os fatores "processo de aprendizagem" e "aprendizagem resultante". Para o primeiro fator, foram considerados os termos "aprendizagem mediada" e "aprendizagem não mediada" e para o segundo fator, os termos "aprendizagem A" e "aprendizagem B". Os resultados foram considerados estatisticamente significativos quando os valores "-p", para "processo de aprendizagem" (relacionados na "Tabela de Regressão Fatorial”) foram menores que um $\alpha$ padrão igual a 0,05. Este padrão é definido pelo software Minitab1 $7^{\circledR}$. Os resultados podem ser visualizados (em destaque) no relatório descritivo dos indicadores (Quadros 620).

O Quadro 6 mostra que na Regressão Fatorial: Indicador 1A - os resultados obtidos apresentam o valor de $-p=0,305$, maior portanto que $\alpha=0,05$. Isso implica que o fator "processo de aprendizagem" não apresentou resultado estatisticamente significativo.

Quadro 6 - Relatório descritivo (Indicador 1A)

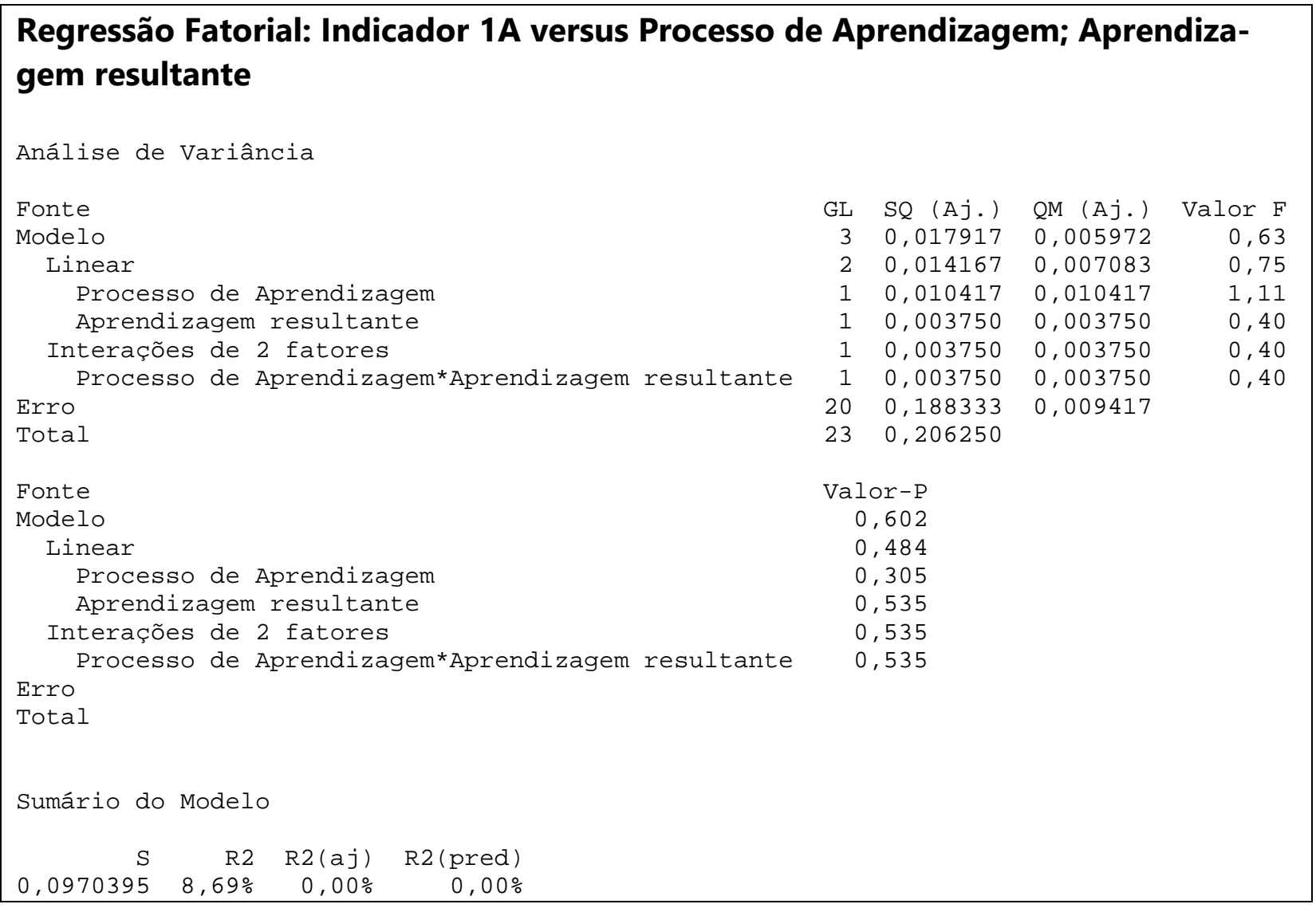




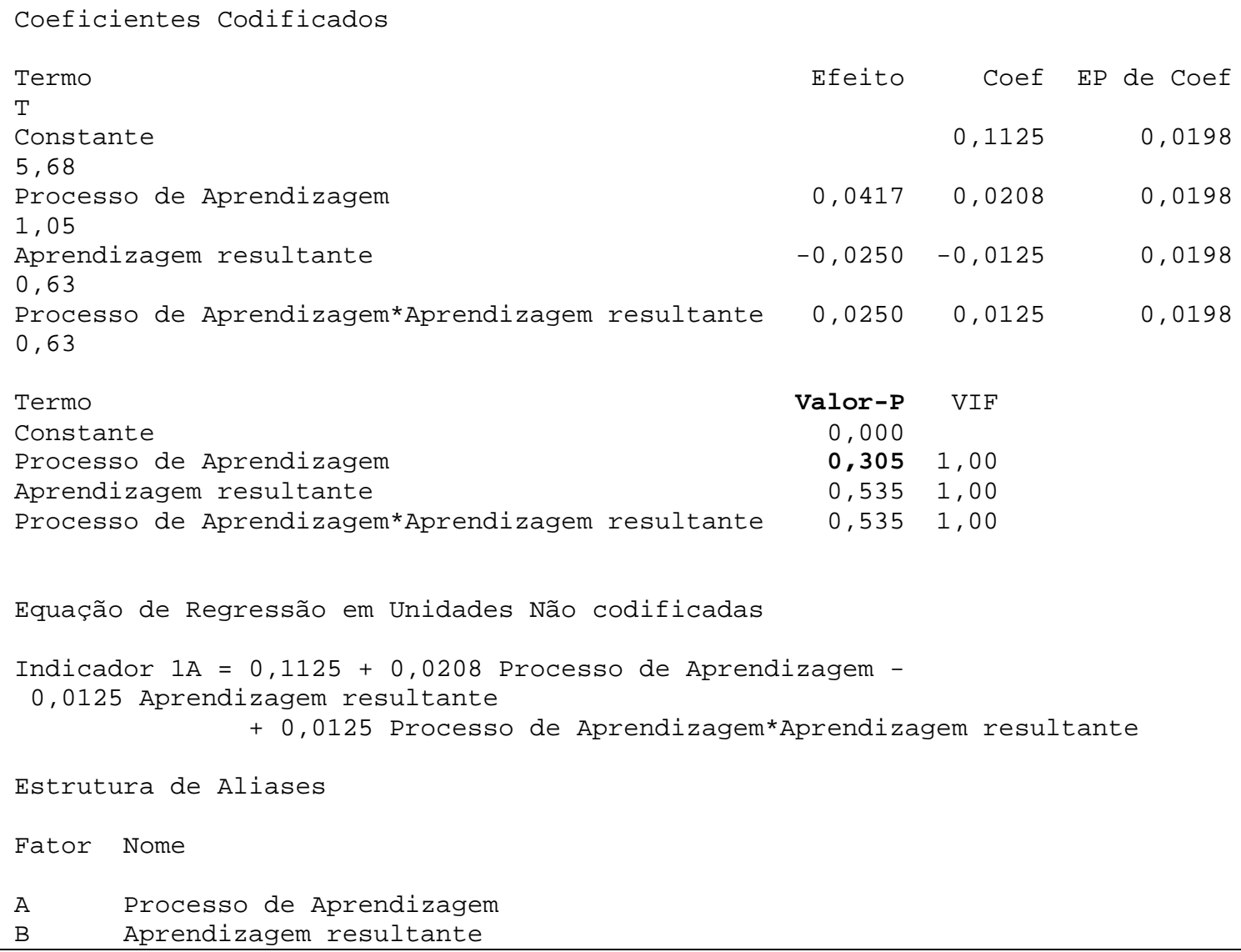

Fonte: Elaboração própria.

O Quadro 7 apresenta que na Regressão Fatorial: Indicador 1B - os resultados obtidos apresentam o valor de $-p=0,391$, maior portanto que $\alpha=0,05$. 0 fator "processo de aprendizagem" não apresentou resultado estatisticamente significativo.

Quadro 7 - Relatório descritivo (Indicador 1B)

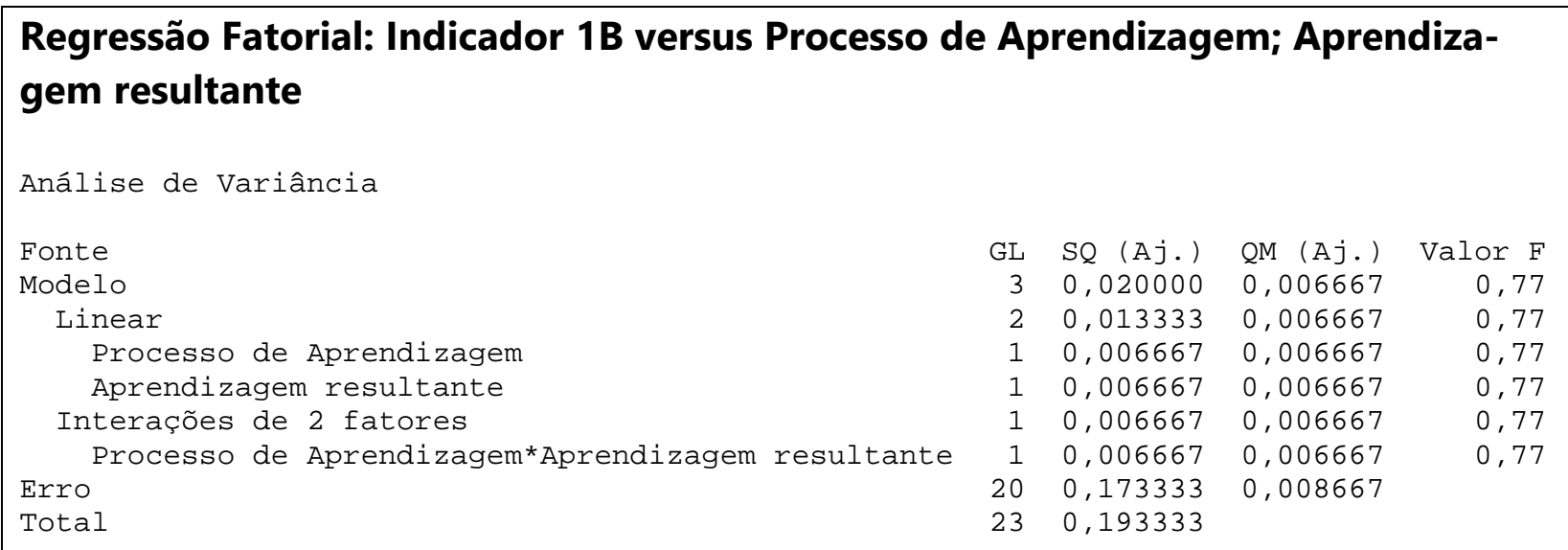

\section{Regressão Fatorial: Indicador 1B versus Processo de Aprendizagem; Aprendiza-} gem resultante

Análise de Variância

Fonte

Modelo

Linear

Processo de Aprendizagem

Aprendizagem resultante

Interações de 2 fatores

Processo de Aprendizagem*Aprendizagem resultante

Erro

Total

$\begin{array}{rrrr}\text { GL } & \text { SQ (Aj.) } & \text { QM }(A j .) & \text { Valor F } \\ 3 & 0,020000 & 0,006667 & 0,77 \\ 2 & 0,013333 & 0,006667 & 0,77 \\ 1 & 0,006667 & 0,006667 & 0,77 \\ 1 & 0,006667 & 0,006667 & 0,77 \\ 1 & 0,006667 & 0,006667 & 0,77 \\ 1 & 0,006667 & 0,006667 & 0,77 \\ 20 & 0,173333 & 0,008667 & \\ 23 & 0,193333 & & \end{array}$




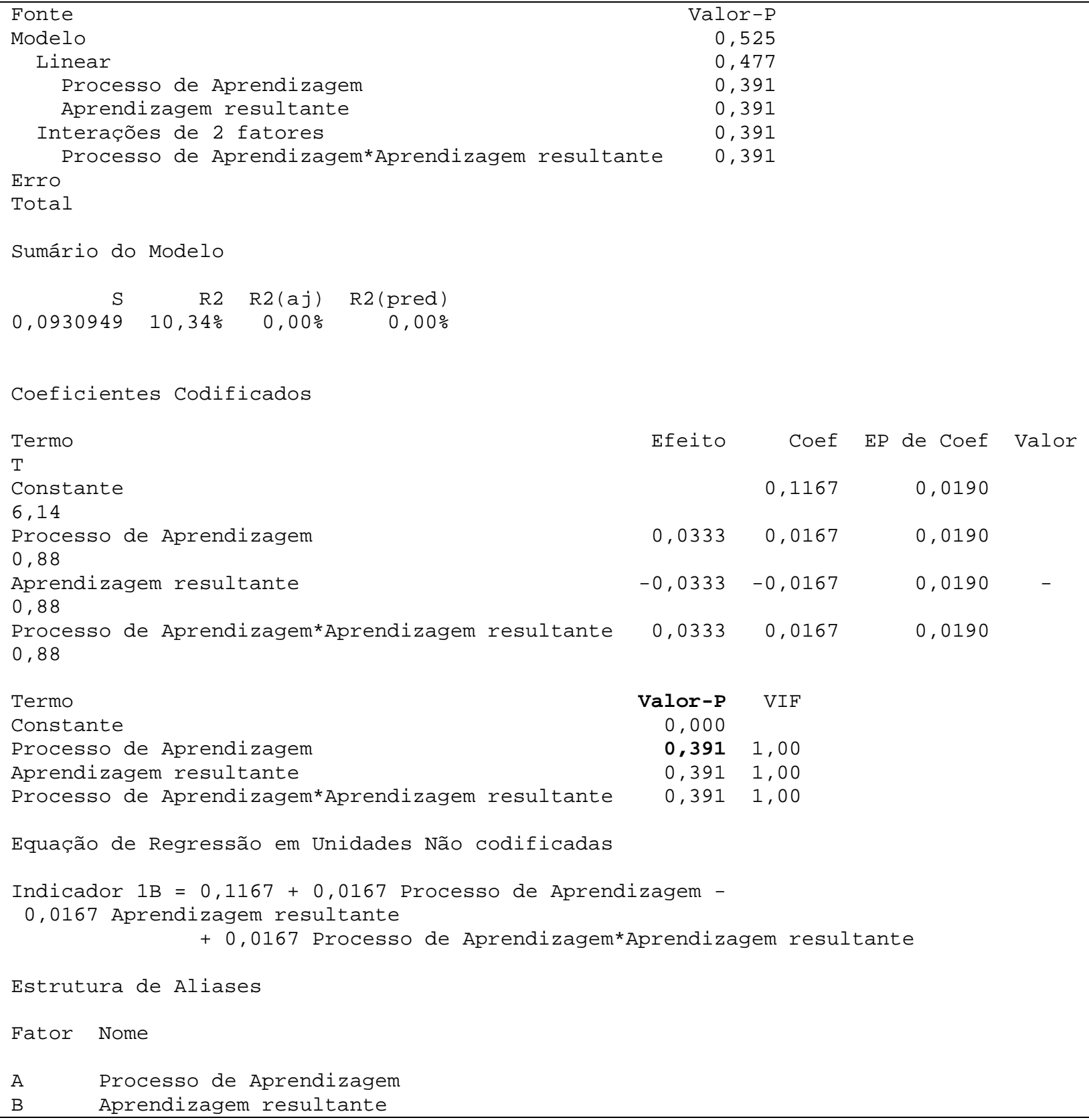

Fonte: Elaboração própria.

Como apresentada no Quadro 8, na Regressão Fatorial: Indicador 1C os resultados obtidos apresentam o valor de $-p=0,154$, maior portanto que $\alpha=0,05$. Assim, o fator "processo de aprendizagem" não apresentou resultado estatisticamente significativo. 


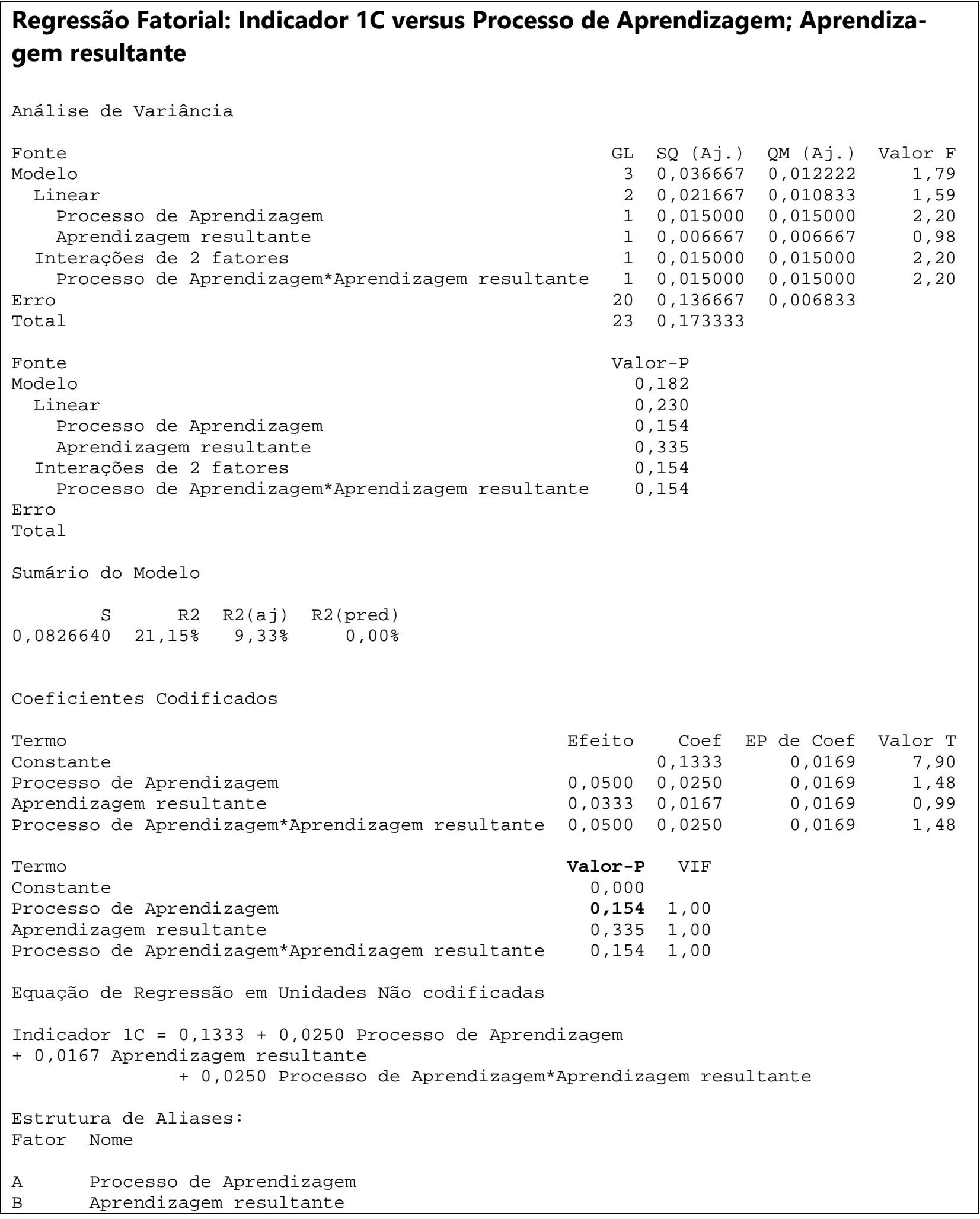

Fonte: Elaboração própria.

O Quadro 9 mostra que na Regressão Fatorial: Indicador 1D - os resultados obtidos apresentam o valor de $-p=0,903$, maior portanto que $\alpha=0,05$. Ou 
seja, o fator "processo de aprendizagem" não apresentou resultado estatisticamente significativo.

Quadro 9 - Relatório descritivo (Indicador 1D)

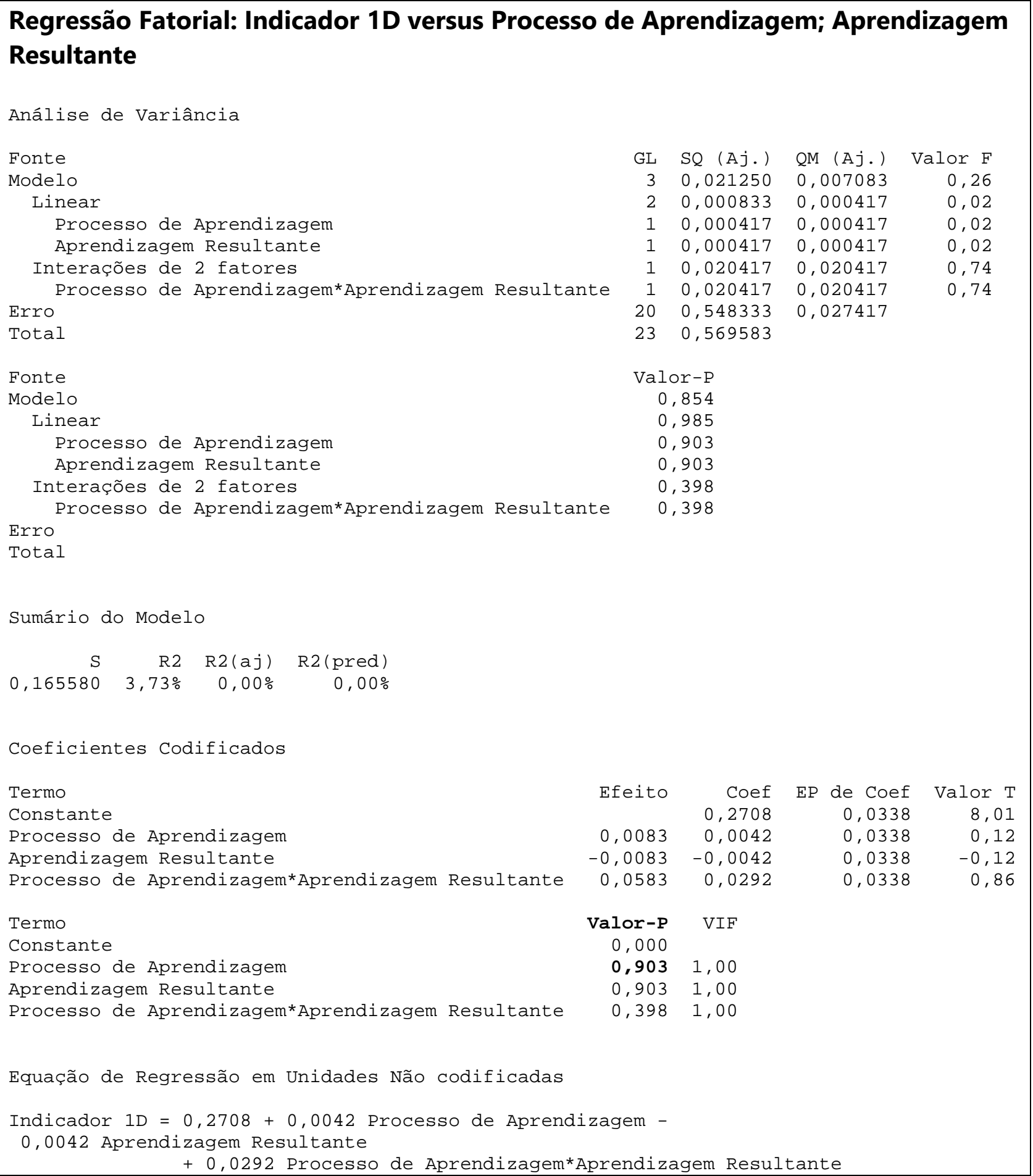

Fonte: Elaboração própria. 
Na Regressão Fatorial: Indicador 2A - os resultados obtidos apresentam 0 valor de $-p=1$, maior portanto que $\alpha=0,05$. Isso implica dizer que o fator "processo de aprendizagem" não apresentou resultado estatisticamente significativo. Os dados são apresentados no Quadro 10.

Quadro 10 - Relatório descritivo (Indicador 2A)

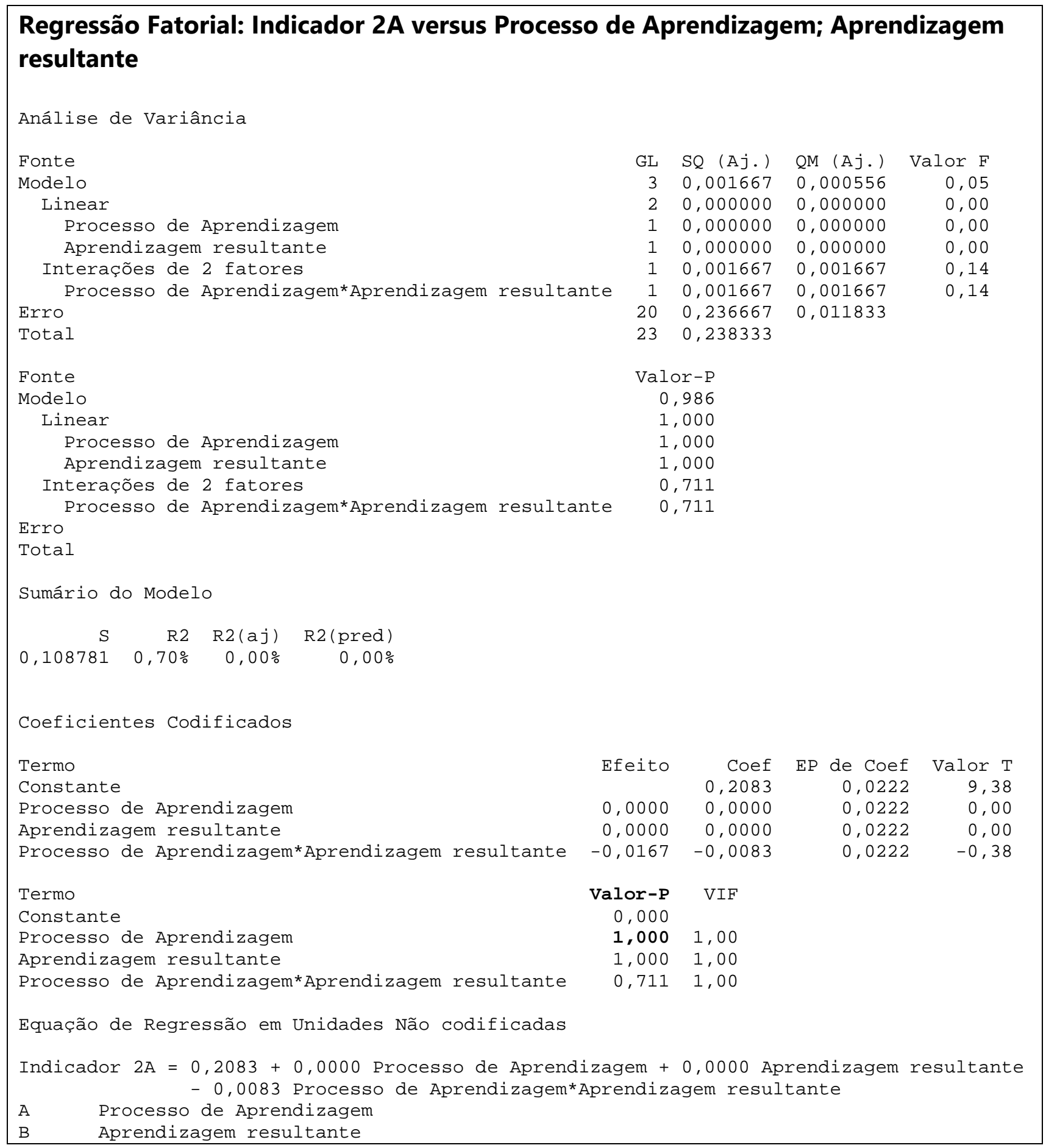

Fonte: Elaboração própria. 
Conforme apresentação no Quadro 11, na Regressão Fatorial: Indicador $2 \mathrm{~B}$ - os resultados obtidos apresentam o valor de $-\mathrm{p}=0,742$, maior portanto que $\alpha=0,05$. Portanto, o fator "processo de aprendizagem" não apresentou resultado estatisticamente significativo.

Quadro 11 - Relatório descritivo (Indicador 2B)

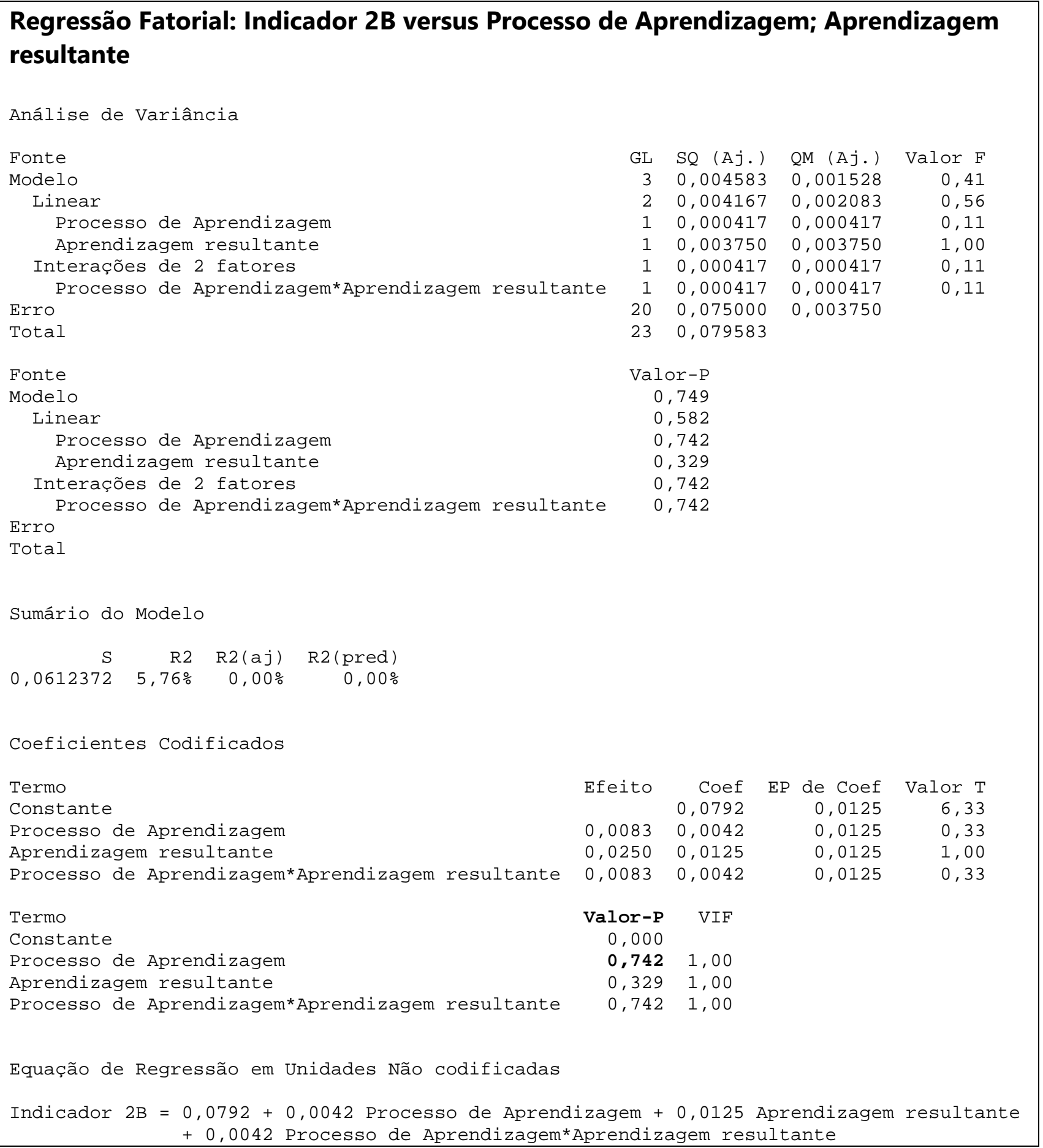

Fonte: Elaboração própria. 
No Quadro 12, na Regressão Fatorial: Indicador $2 \mathrm{C}$ - os resultados obtidos apresentam o valor de $-\mathrm{p}=0,770$, maior portanto que $\alpha=0,05$. Isto é, o fator "processo de aprendizagem" não apresentou resultado estatisticamente significativo.

Quadro 12 - Relatório descritivo (Indicador 2C)

\section{Regressão Fatorial: Indicador 2C versus Processo de Aprendizagem; Aprendizagem resultante}

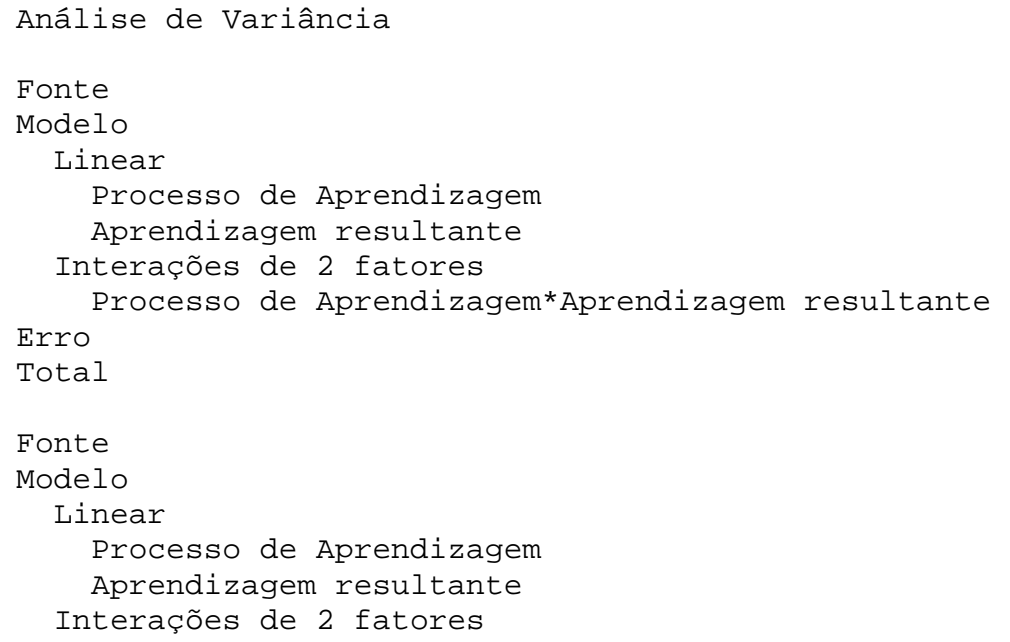

Fonte: Elaboração própria. 
Os dados do Quadro 13 mostram que na Regressão Fatorial: Indicador $2 \mathrm{D}$ - os resultados obtidos apresentam o valor de $-\mathrm{p}=0,685$, maior portanto que $\alpha=0,05$. Desse modo, o fator "processo de aprendizagem" não apresentou resultado estatisticamente significativo.

Quadro 13 - Relatório descritivo (Indicador 2D)

\section{Regressão Fatorial: Indicador 2D versus Processo de Aprendizagem; Aprendizagem resultante}

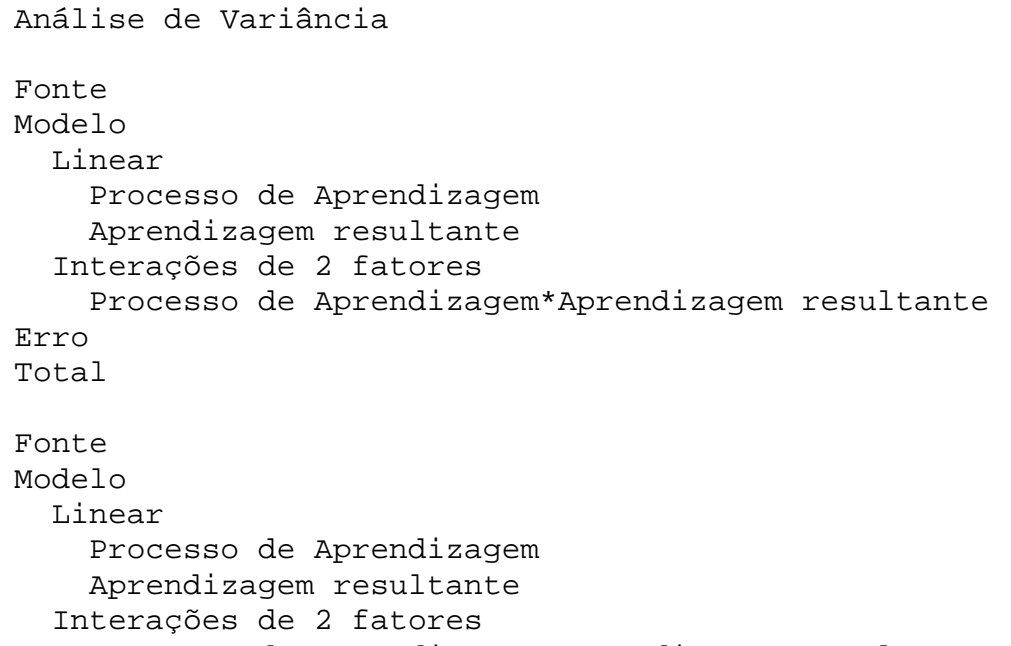

Equação de Regressão em Unidades Não codificadas

Indicador 2D $=0,1875+0,0125$ Processo de Aprendizagem - 0,0208 Aprendizagem resultante $+0,0208$ Processo de Aprendizagem^Aprendizagem resultante 
De acordo com os dados do Quadro 14, na Regressão Fatorial: Indicador $3 \mathrm{~A}$ - os resultados obtidos apresentam o valor de $-\mathrm{p}=0,474$, maior portanto que $\alpha=0,05$. Isso implica dizer que o fator "processo de aprendizagem" não apresentou resultado estatisticamente significativo.

Quadro 14 - Relatório descritivo (Indicador 3A)

\section{Regressão Fatorial: Indicador 3A versus Processo de Aprendizagem; Aprendizagem resultante}

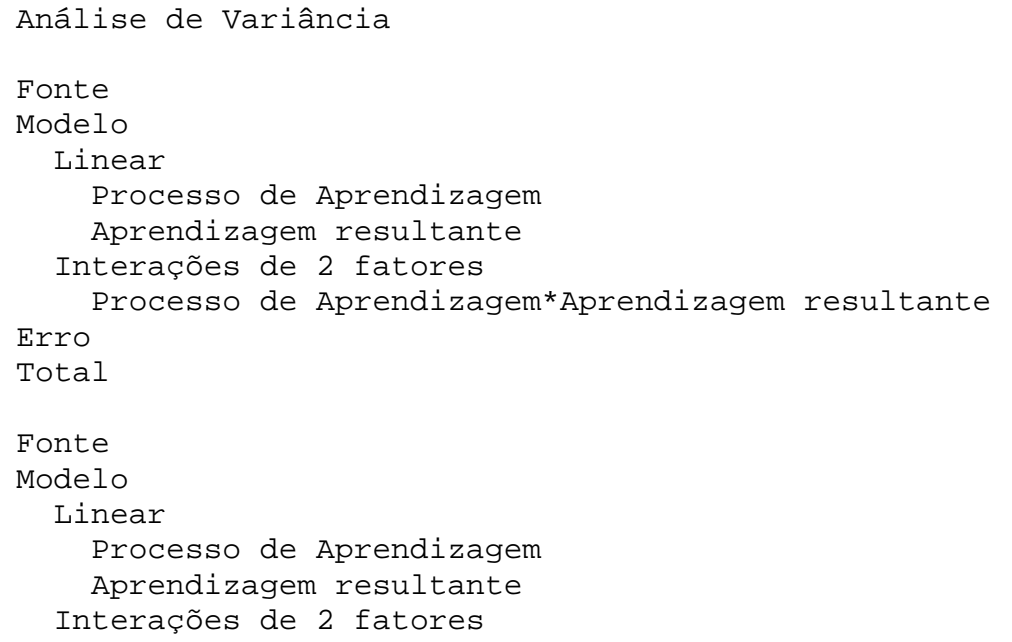
$+0,0333$ Processo de Aprendizagem*Aprendizagem resultante

Fonte: Elaboração própria. 
No Quadro 15, os dados mostram que na Regressão Fatorial: Indicador $3 B$ - os resultados obtidos apresentam o valor de $-p=0,026$, menor portanto que $\alpha=0,05$. Isso implica que o fator "processo de aprendizagem" apresentou resultado estatisticamente significativo.

Quadro 15 - Relatório descritivo (Indicador 3B)

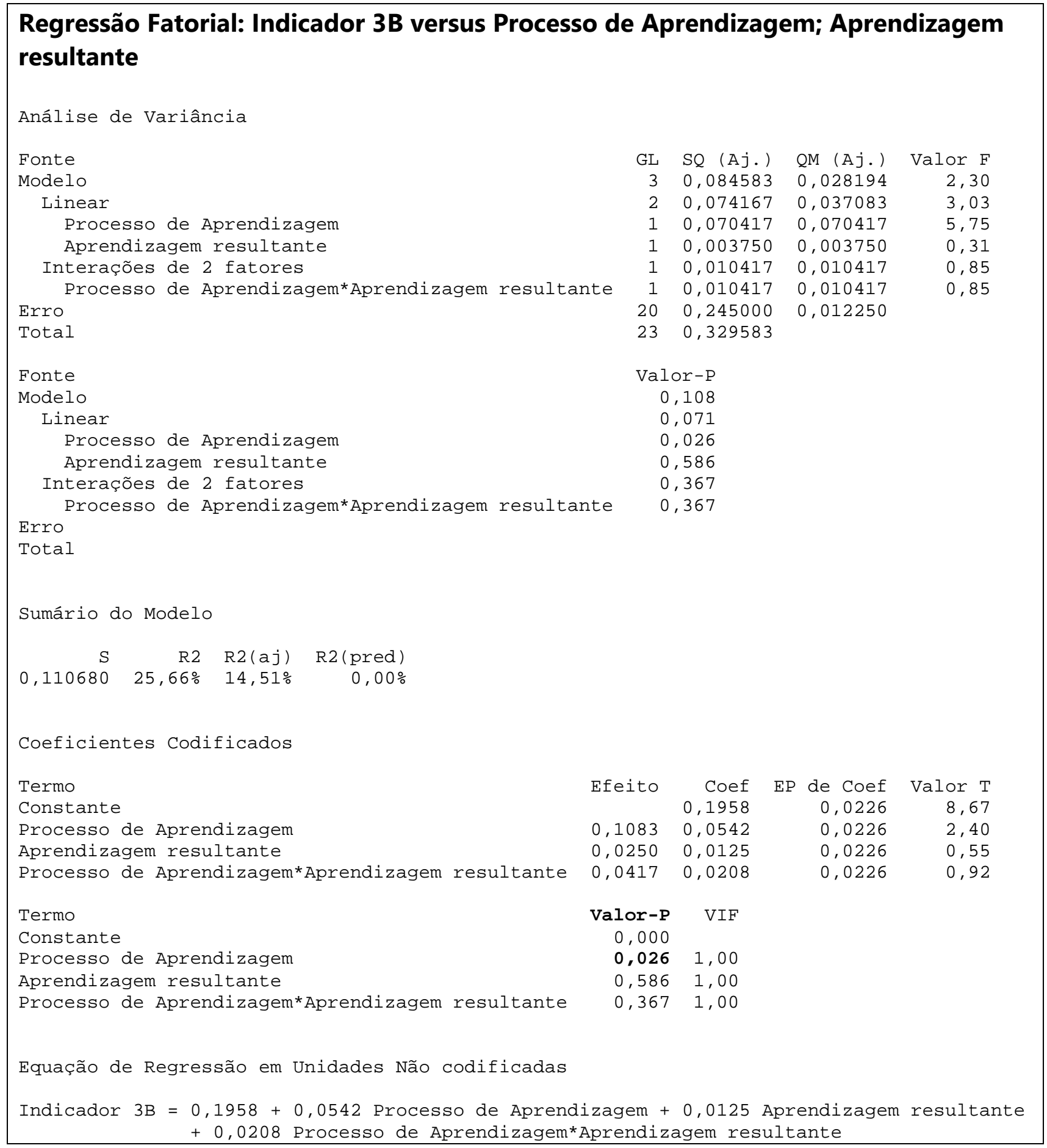

Fonte: Elaboração própria. 
O Quadro 16 mostra que na Regressão Fatorial: Indicador 3C - os resultados obtidos apresentam o valor de $-p=0,018$, menor portanto que $\alpha=0,05$. Assim, o fator "processo de aprendizagem" apresentou resultado estatisticamente significativo.

Quadro 16 - Relatório descritivo (Indicador 3C)

\section{Regressão Fatorial: Indicador 3C versus Processo de Aprendizagem; Aprendizagem resultante}

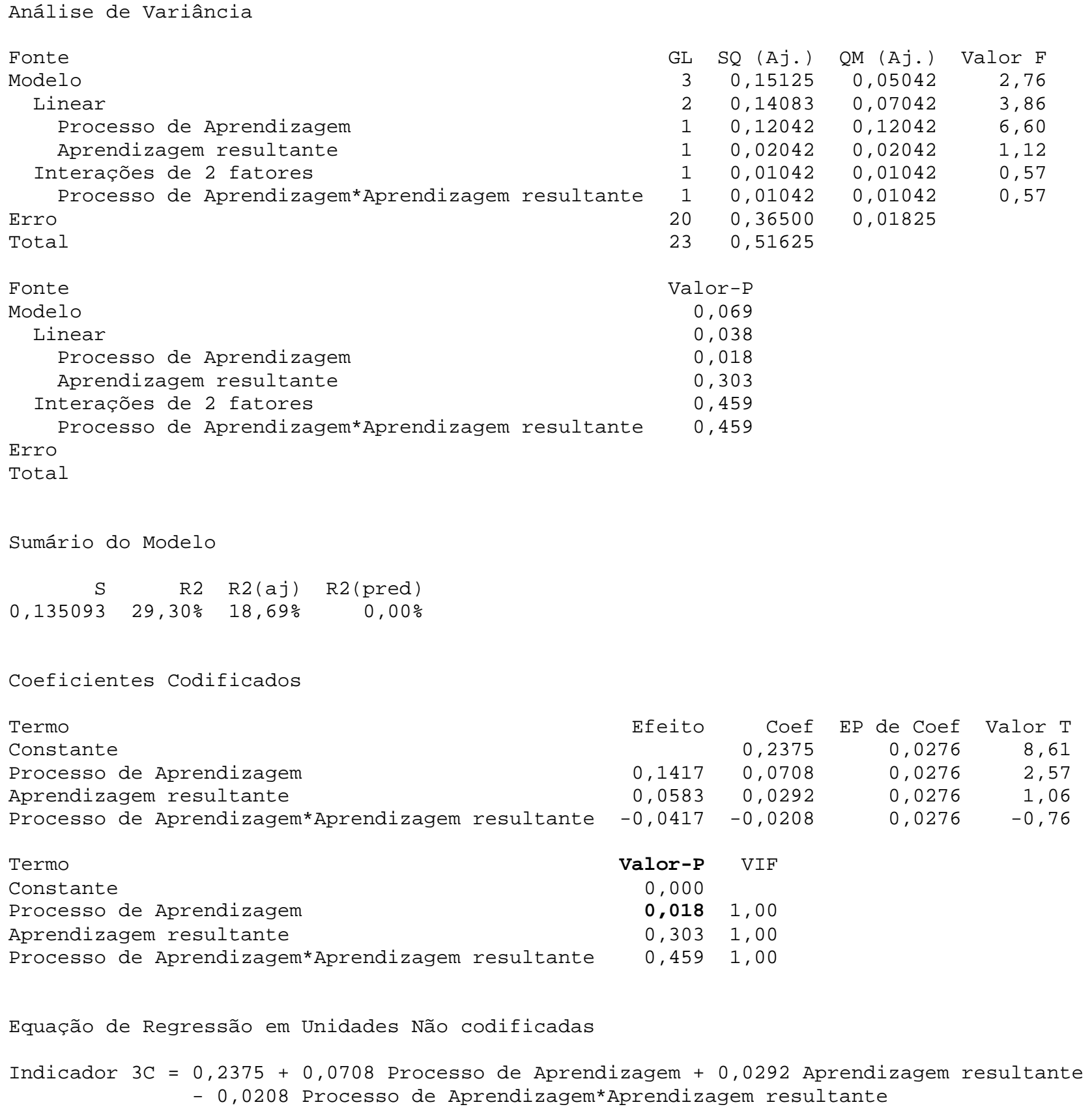

Efeito

0,0583

$-0,0417$

Valor-P

0,000

$0,0181,00$

$0,303 \quad 1,00$

$0,4591,00$

Equação de Regressão em Unidades Não codificadas

Indicador $3 \mathrm{C}=0,2375+0,0708$ Processo de Aprendizagem + 0,0292 Aprendizagem resultante - 0,0208 Processo de Aprendizagem*Aprendizagem resultante 
Conforme dados do Quadro 17, na Regressão Fatorial: Indicador 4A os resultados obtidos apresentam o valor de $-p=0,111$, maior portanto que $\alpha=0,05$. Portanto, o fator "processo de aprendizagem" não apresentou resultado estatisticamente significativo.

Quadro 17 - Relatório descritivo (Indicador 4A)

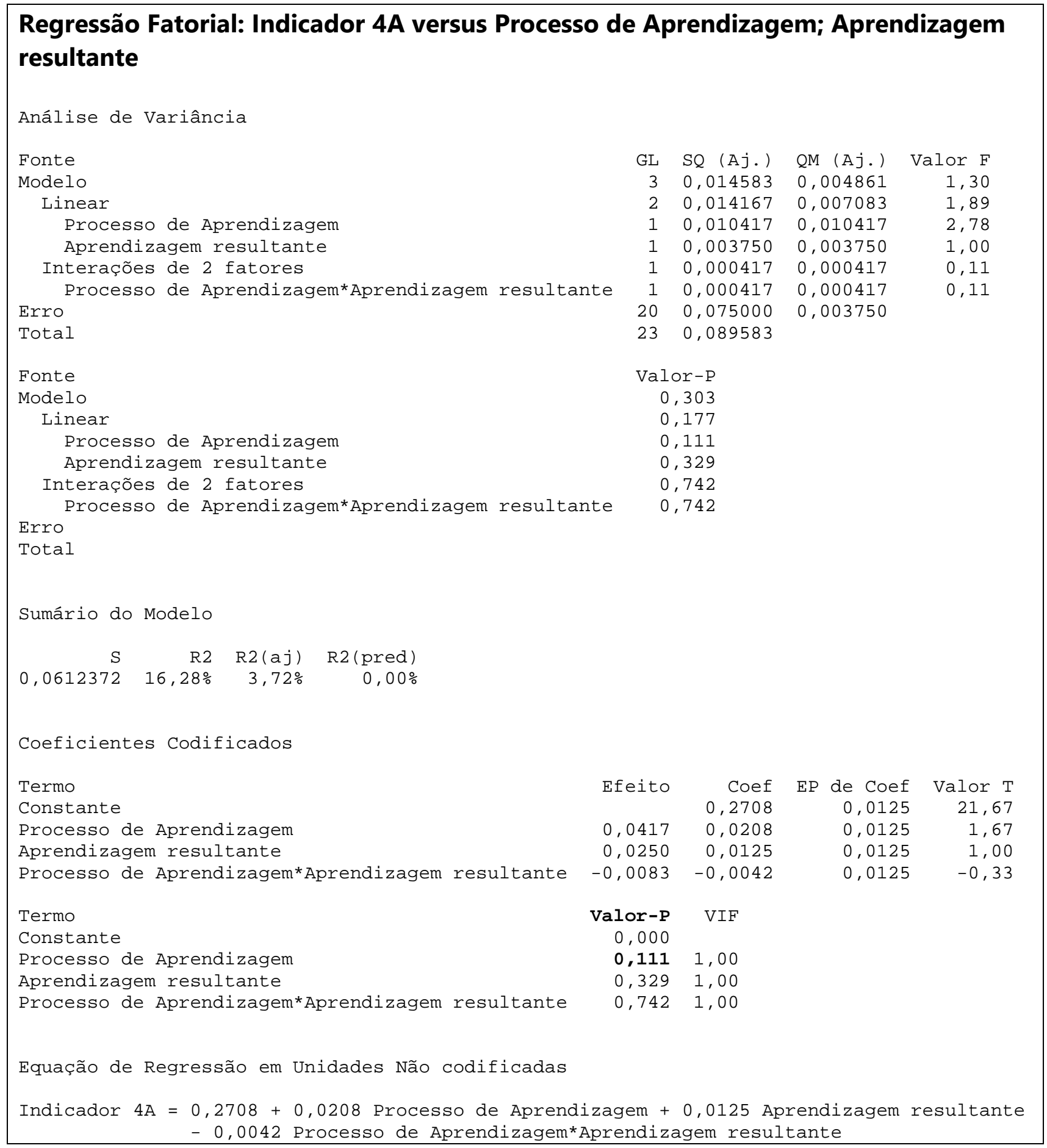

Fonte: Elaboração própria. 
No Quadro 18, na Regressão Fatorial: Indicador 4B - os resultados obtidos apresentam o valor de $-p=0,036$, menor portanto que $\alpha=0,05$. Isso implica dizer que o fator "processo de aprendizagem" apresentou resultado estatisticamente significativo.

Quadro 18 - Relatório descritivo (Indicador 4B)

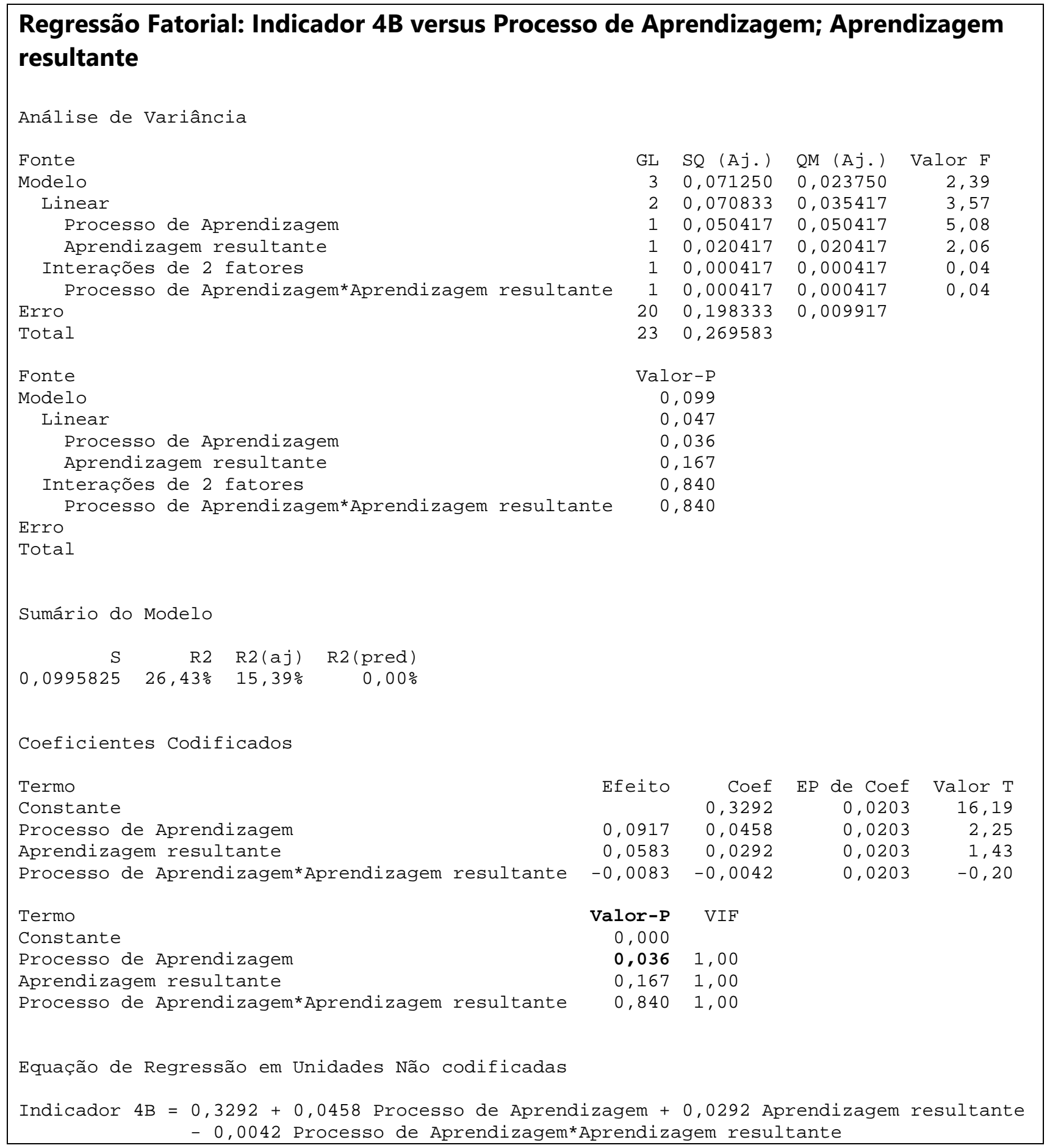

Fonte: Elaboração própria. 
De acordo com o Quadro 19, na Regressão Fatorial: Indicador 4C - os resultados obtidos apresentam o valor de $-\mathrm{p}=0,068$, maior portanto que $\alpha=0,05$. Isso significa que o fator "processo de aprendizagem" não apresentou resultado estatisticamente significativo.

Quadro 19 - Relatório descritivo (Indicador 4C)

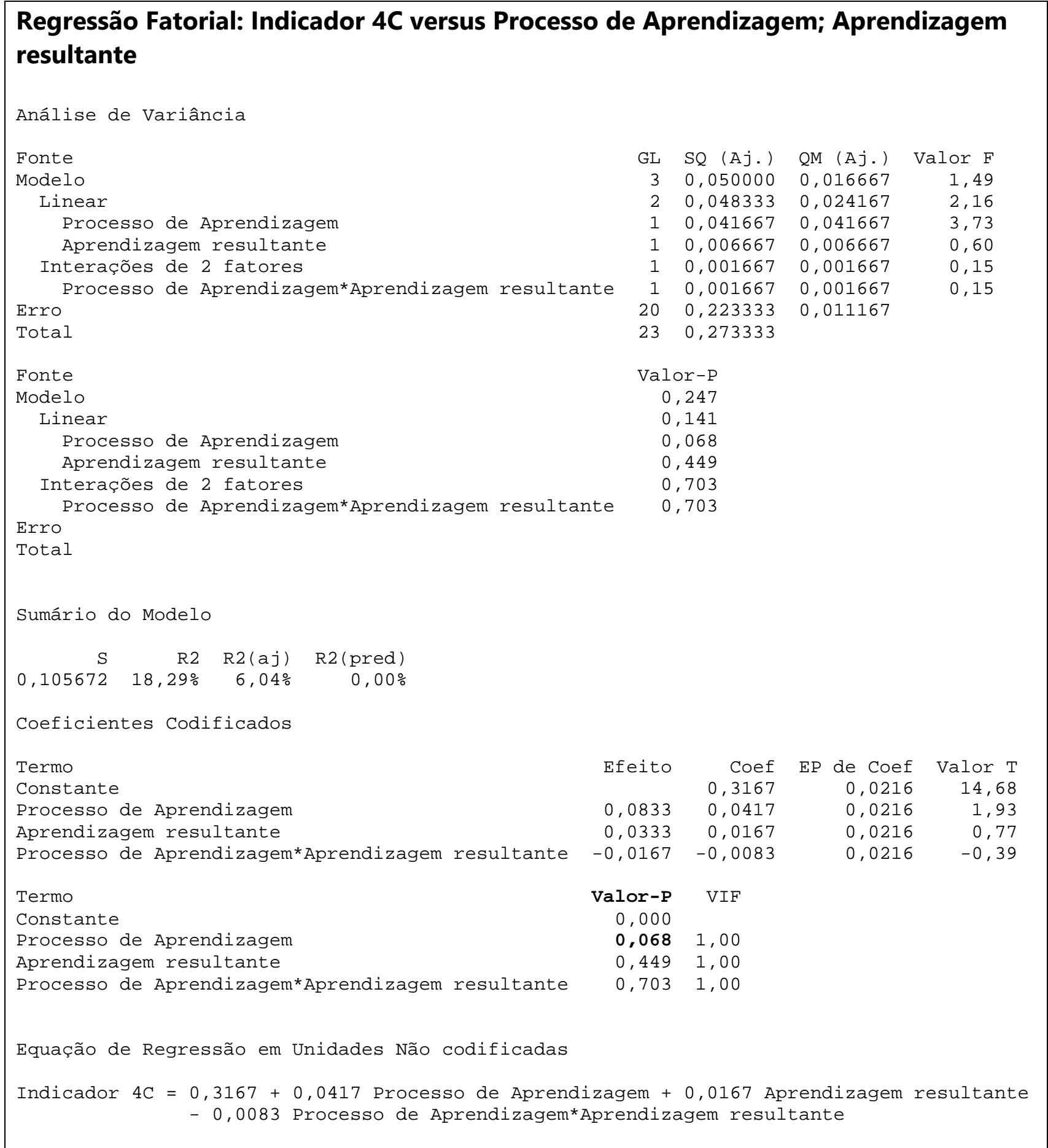

Fonte: Elaboração própria. 
No Quadro 20, na Regressão Fatorial: Indicador 4D - os resultados obtidos apresentam o valor de $-p=0,258$, maior portanto que $\alpha=0,05$. Isso demonstra que o fator "processo de aprendizagem" não apresentou resultado estatisticamente significativo.

Quadro 20 - Relatório descritivo (Indicador 4D)

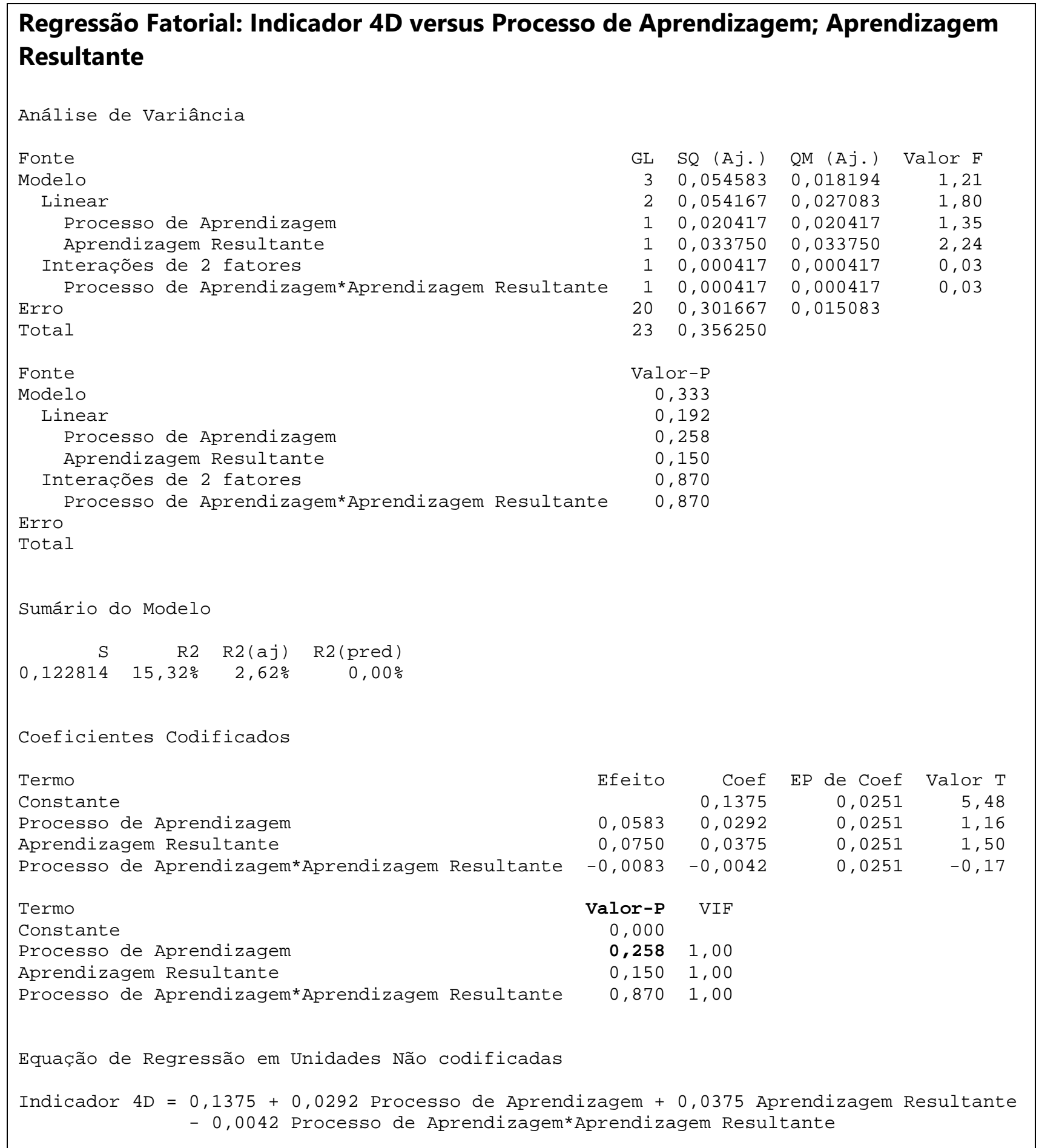


De acordo com os dados obtidos, confirmaram-se efeitos significativos no fator "processo de aprendizagem" nos indicadores 3B (informação atualizada), 3C (ideias e soluções viáveis) e 4B (escrita). Os valores "-p" foram 0,026, 0,018 e 0,036 respectivamente. Isso significa que a diferença de nota entre ambos os grupos, nestes três indicadores, foi considerável. Comparando-se os fatores "aprendizagem mediada" e "aprendizagem não-mediada" (Figura 36), percebe-se que a influência da proposta de ensino de alguns conteúdos de LI em relação à elaboração do trabalho escrito não foi satisfatória.

Figura 36 - Gráfico comparativo (Aprendizagem Mediada x Não Mediada)

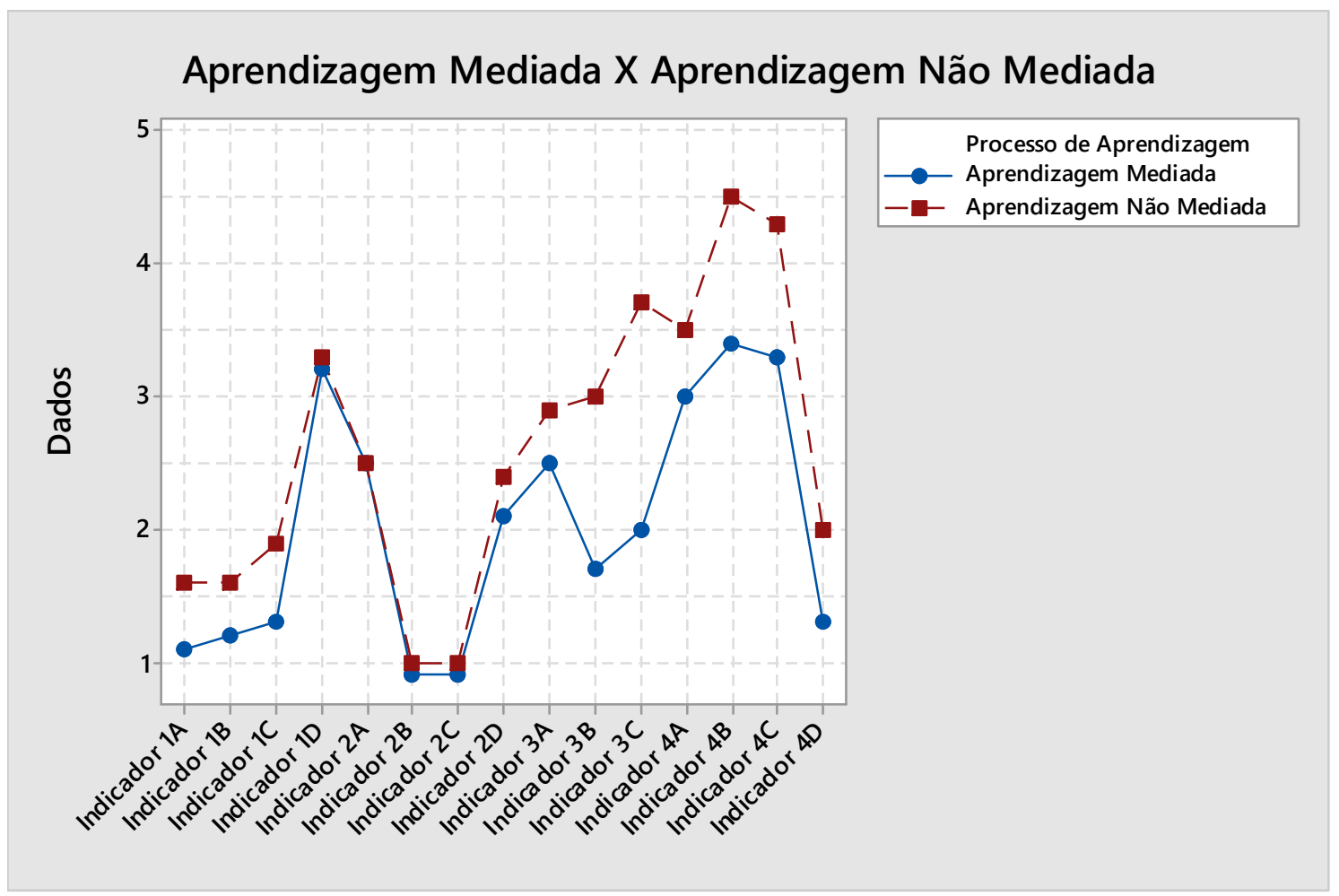

Fonte: Elaboração própria.

Em suma, percebeu-se que a média dos valores referentes a cada indicador foi maior no contexto de "aprendizagem não mediada" em comparação com o contexto de "aprendizagem mediada". 


\subsubsection{Dados qualitativos}

Moraes (1999) explicita que o processo de análise de conteúdo é constituído por cinco etapas: (1) preparação das informações, (2) transformação do conteúdo em unidades, (3) classificação das unidades em categorias, (4) descrição e (5) interpretação.

$\mathrm{Na}$ etapa de preparação, os materiais definidos para análise foram as transcrições das observações em sala, os mapas mentais elaborados, as transcrições das respostas e dos relatórios entregues pelo grupo quase experimental e a entrevista realizada com o professor da disciplina. O material foi codificado como consta no Quadro 21.

Quadro 21 - Quadro de codificação

\begin{tabular}{|l|l|c|}
\hline MATERIAL SELECIONADO & \multicolumn{1}{|c|}{ GRUPO } & CODIFICAÇÃO \\
\hline \multirow{2}{*}{ Observação } & Quase Experimental & OB \\
\cline { 2 - 3 } & Controle & OBC \\
\hline \multirow{2}{*}{ Mapas mentais } & Quase Experimental & MM \\
\cline { 2 - 3 } & Controle & MMC \\
\hline Perguntas & Quase Experimental & PE \\
\hline Relatórios & Quase Experimental & RE \\
\hline Entrevista & Professor & ENT \\
\hline
\end{tabular}

Fonte: Elaboração própria.

Na segunda etapa, o conteúdo do material selecionado foi transformado em unidades de análise, isto é, em palavras ou frases representativas. No caso, foi gerado um código adicional associado aos códigos definidos anteriormente. Para melhor compreensão das unidades de análise, foi necessário estabelecer unidades contextuais que são geralmente mais amplas que as primeiras, proporcionando melhor entendimento (MORAES, 1999). O resultado desta etapa pode ser visualizado no Quadro 22. 


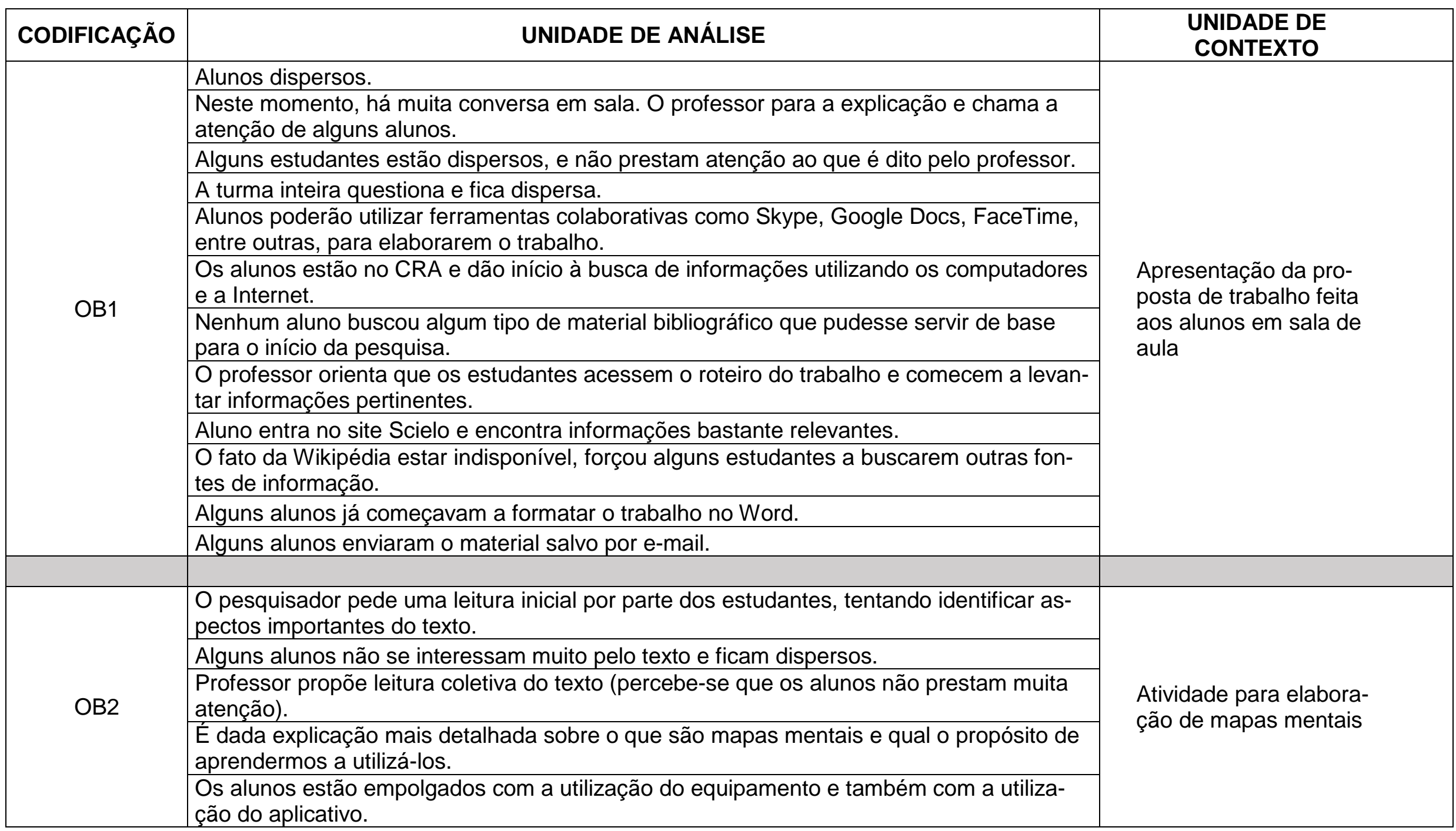




\begin{tabular}{|c|c|c|}
\hline & A temática do mapa foi sobre o conceito de "pesquisa". & \\
\hline \multirow{6}{*}{ OB3 } & 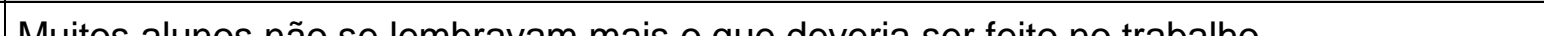 & \multirow{6}{*}{$\begin{array}{l}\text { Aula no laboratório de } \\
\text { informática, para dar } \\
\text { sequência à elaboração } \\
\text { do trabalho }\end{array}$} \\
\hline & $\begin{array}{l}\text { Alguns alunos buscam trocar informações entre eles, buscando compartilhar o que ti- } \\
\text { nham encontrado. }\end{array}$ & \\
\hline & O trabalho já servirá para que os alunos estudem para a prova globalizante. & \\
\hline & Estudantes têm pouca clareza sobre a busca por informações. & \\
\hline & $\begin{array}{l}\text { Percebe-se dificuldades básicas de alguns alunos até mesmo para anexar um arquivo a } \\
\text { ser envido por e-mail. }\end{array}$ & \\
\hline & $\begin{array}{l}\text { Professor passou a questioná-los sobre o andamento do trabalho. Foi uma espécie de } \\
\text { bate-papo, mas poucos alunos falaram. } \\
\text { É dado orientações sobre o roteiro de trabalho, a questão do plágio, o processo de busca } \\
\text { por informaçóes relevantes e sobre a importância do processo de autonomia de cada } \\
\text { estudante na busca por informações. }\end{array}$ & \\
\hline \multirow{9}{*}{ OB4 } & $\begin{array}{l}\text { Alunos parecem não se lembrar mais sobre o que tem que ser feito no trabalho de pes- } \\
\text { quisa. }\end{array}$ & \multirow{9}{*}{$\begin{array}{l}\text { Retorno das aulas e re- } \\
\text { torno das atividades de } \\
\text { busca de informações } \\
\text { realizada na biblioteca } \\
\text { do colégio. }\end{array}$} \\
\hline & $\begin{array}{l}\text { No momento do debate/pesquisa-ação, o professor solicita às duplas de estudantes que } \\
\text { falem um pouco sobre o andamento do trabalho. }\end{array}$ & \\
\hline & $\begin{array}{l}\text { (Aluna) - "A gente tá respondendo primeiro aquelas quatro perguntas, pra depois organi- } \\
\text { zar o trabalho..." }\end{array}$ & \\
\hline & $\begin{array}{l}\text { (Professor) - "Eu me lembro que eu disse que aquelas questões... aqueles objetivos es- } \\
\text { pecíficos não são perguntas, mas são nortes para conduzir o nosso trabalho. Não neces- } \\
\text { sariamente são perguntas a serem respondidas. }\end{array}$ & \\
\hline & $\begin{array}{l}\text { (Professor) - "Vocês têm outra forma de se comunicarem para fazer o trabalho, como é } \\
\text { que vocês estão fazendo?" }\end{array}$ & \\
\hline & (Alunas) - "Eu vou pra casa dela, ela vai pra minha, a gente conversa no Whatzapp..." & \\
\hline & $\begin{array}{l}\text { (Professor) - "Vocês acreditam que ao mesmo tempo que vocês estão fazendo a pesqui- } \\
\text { sa, vocês estão estudando?" }\end{array}$ & \\
\hline & (Alunas) - "Sim!" & \\
\hline & (Aluna) - "Álvaro, é muita coisa... nem minha irmã na UnB faz um trabalho deste tama- & \\
\hline
\end{tabular}




\begin{tabular}{|c|c|c|}
\hline & nho..." & \\
\hline & $\begin{array}{l}\text { (Professor) - "Da gente ir para o campo da pesquisa, não sou eu que estou lá na frente } \\
\text { falando, mas vocês estão pesquisando... a gente vem aqui e discute..." }\end{array}$ & \\
\hline & $\begin{array}{l}\text { (Professor) - "Quais são os aspectos que vocês consideram positivo, ou talvez negativo } \\
\text { nesta proposta?" }\end{array}$ & \\
\hline & $\begin{array}{l}\text { (Aluno) - "Sair da sala de aula, por que na sala de aula é muito entediante. A gente pas- } \\
\text { sa o dia inteiro na sala de aula, só sai para beber..." }\end{array}$ & \\
\hline & $\begin{array}{l}\text { (Professor) - "Como é que tem sido elaborar um trabalho com padrão mais exigente as- } \\
\text { sim, com uma formatação que vocês vão ter que seguir..." }\end{array}$ & \\
\hline & $\begin{array}{l}\text { (Aluna) - "Os trabalhos ficam dentro do padrão... um não tem uma capa mais bonita que } \\
\text { ou outro..." }\end{array}$ & \\
\hline & Aluna também fala da questão do limite de páginas como algo ruim... 10 páginas. & \\
\hline & $\begin{array}{l}\text { (Professor) - "O Murillo está dando dicas de formatação. Tá me ajudando na correção da } \\
\text { formatação de alguns trabalhos". }\end{array}$ & \\
\hline & $\begin{array}{l}\text { (Professor) - "Uma coisa que a gente quer com vocês neste trabalho: é que a gente saia } \\
\text { do esquema do copia e cola. Porque nós estamos acostumados a fazer trabalhos de co- } \\
\text { piar e colar." }\end{array}$ & \\
\hline & $\begin{array}{l}\text { (Professor) - "E o aprendizado não está na formatação... não é isso, mas é o processo } \\
\text { que foi construído pra pesquisar o trabalho. Isso é que é o mais importante." }\end{array}$ & \\
\hline & (Aluna) - "Poxa Álvaro... mas aí é chato, o tema é chato..." & \\
\hline & $\begin{array}{l}\text { (Professor) - "Nós temos que mostrar nosso protagonismo, a nossa autonomia, a nossa } \\
\text { capacidade de fazer as coisas." }\end{array}$ & \\
\hline & Alounc alunos tentam recunerar o roteiro no Portal Maricta demonctrando nouca organi- & \\
\hline & $\begin{array}{l}\text { Alguns alunos tentam recuperar o roteiro no Portal Marista, demonstrando pouca organi- } \\
\text { zação no momento do estudo. }\end{array}$ & \\
\hline & Os estudantes demonstram pouca habilidade para trabalhar com recursos básicos do & Biblioteca: Momento de \\
\hline OB5 & computador (desde editar um texto com fonte específica, até inserir caixa de texto, tabe- & ções/formatação do \\
\hline & Alquns estudantes acabaram perdendo o arquivo principal do trabalho por não terem & trabalho \\
\hline & conseguido salvá-lo em local específico. & \\
\hline
\end{tabular}




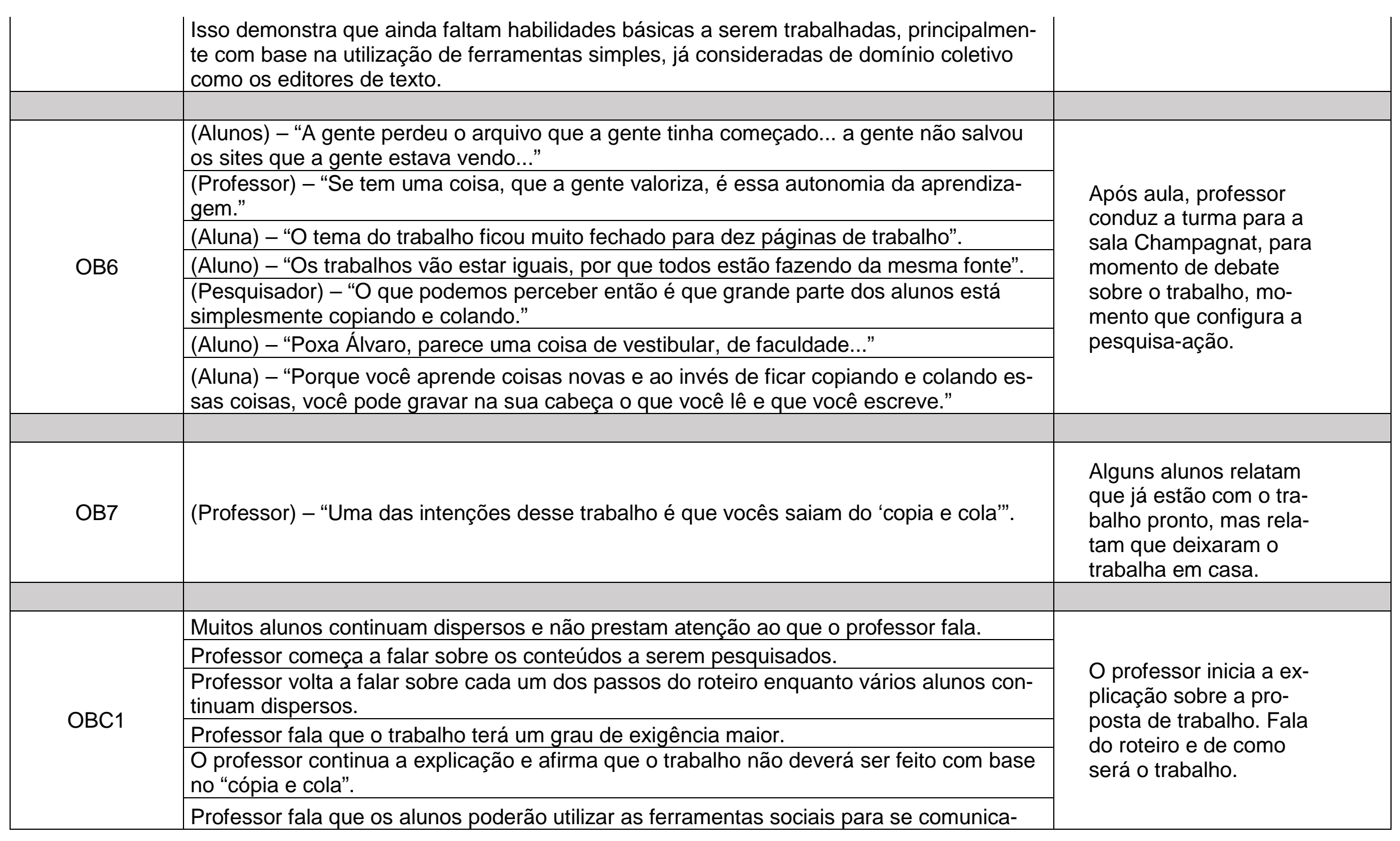




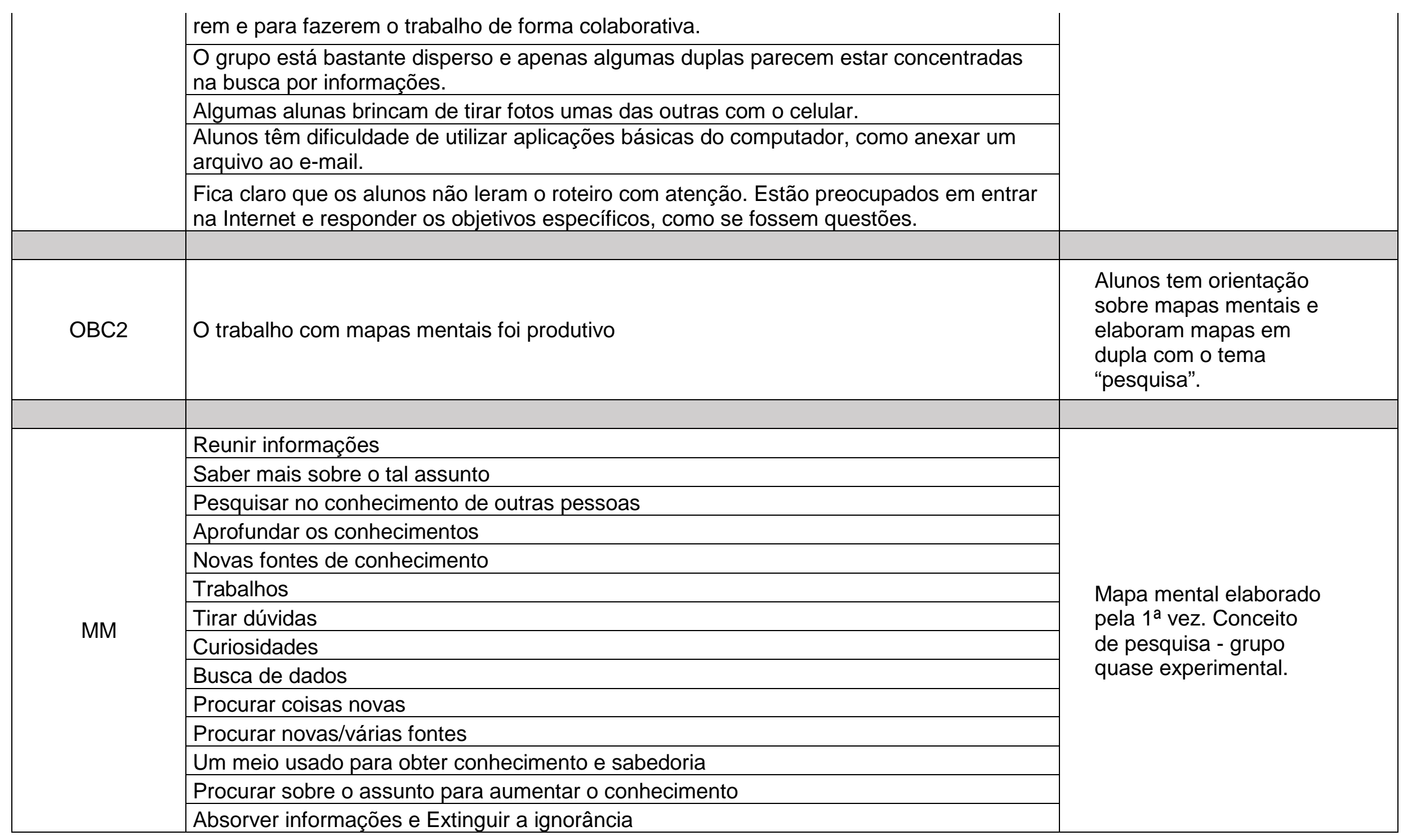


Aprendizagem de assuntos não compreendidos

Busca de argumentos

Aprendizado

Auxílio na compreensão e alfabetização

Aumenta e aprofunda o conhecimento

Saber mais sobre o assunto

Subir notas das provas

Leitura/interpretação/entendimento

Levantamento de dados

Compreensão do conteúdo

Coleta de dados das diferentes fontes de conhecimento

Misturar informações (uma deverá completar a outra)

Ver as diferentes visões sobre o assunto

Inserir a sua visão sobre o conteúdo da pesquisa

Indicação da fonte da pesquisa

Saber mais sobre esse assunto

Ajuda a fazer trabalhos escolares, estudar e fazer provas, testes

Chegar a algumas conclusões

Chegar a algumas respostas

Instrumento de busca de dados

Aprimorar o seu conhecimento e suas respostas

Tornar-se um perito

Ajuda na compreensão da matéria

Novas informações

Estudo/conhecimento geral ou específico

Melhora as notas

Realização pessoal/profissional

Aprimoramento/desenvolvimento no trabalho 


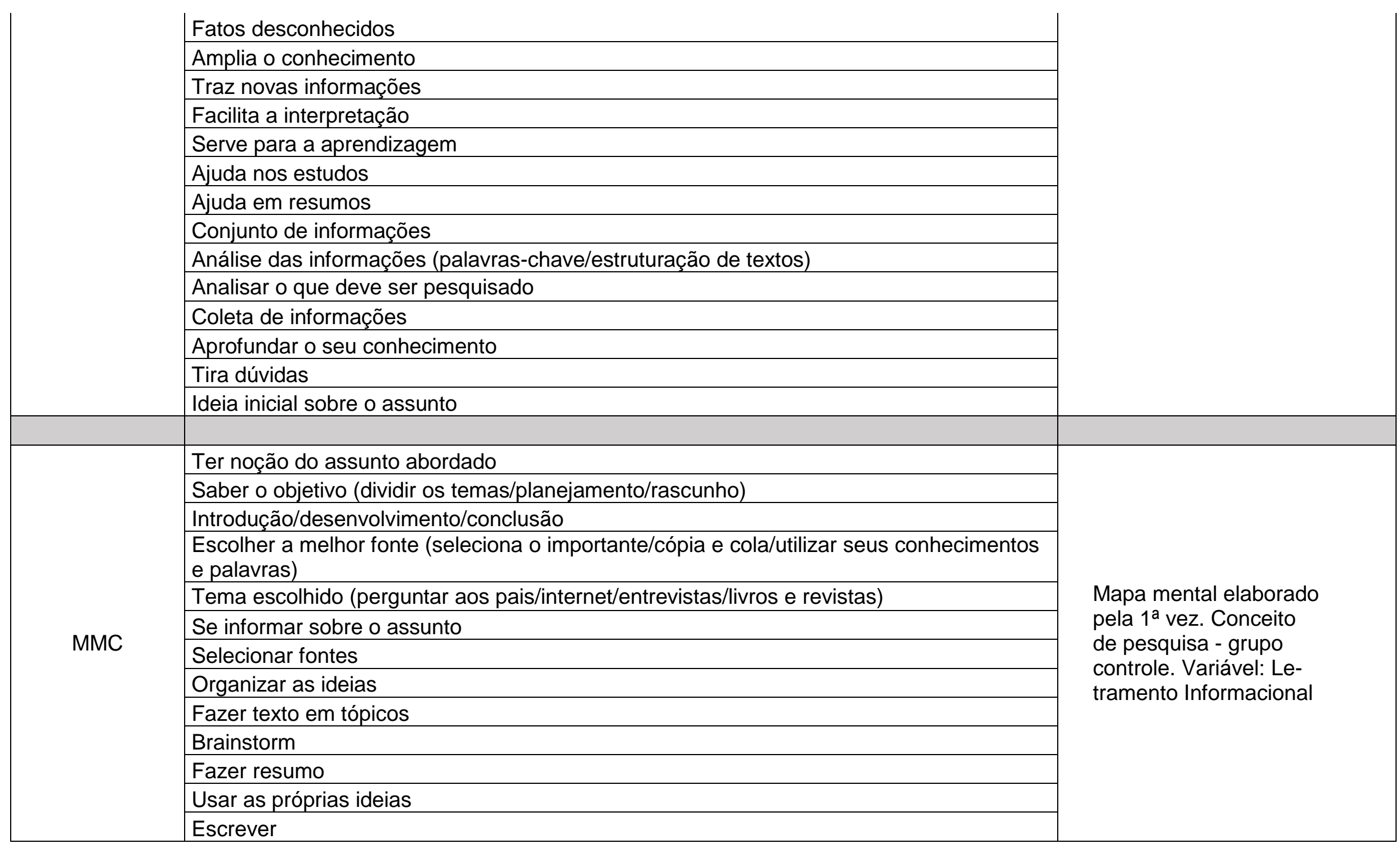




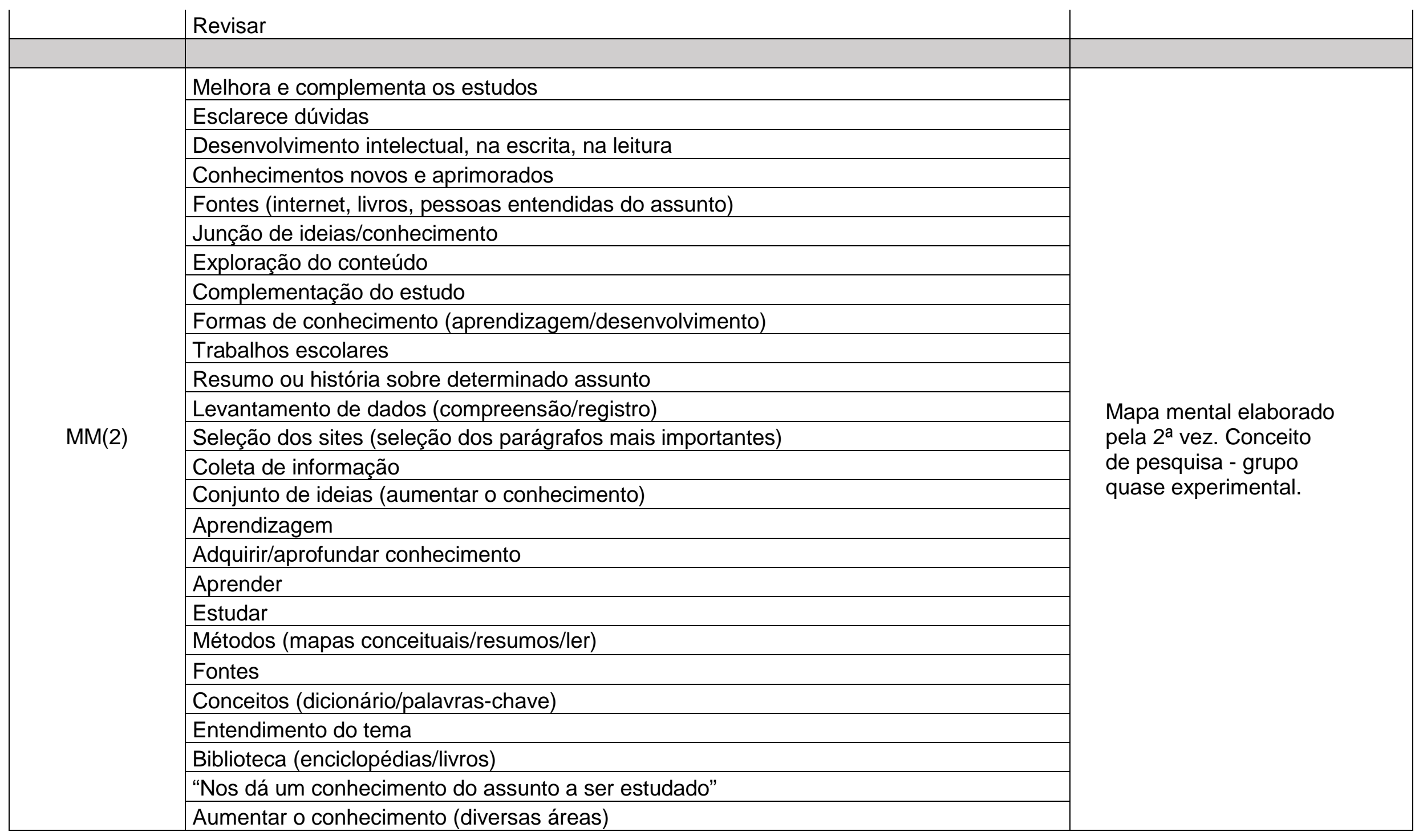




\begin{tabular}{|c|c|c|}
\hline & Lugares para procurar (biblioteca, livros, enciclopédias, internet) & \\
\hline \multirow{15}{*}{ PE1 } & $\begin{array}{l}\text { "Foi um trabalho extenso e complexo, mas que fez com que a gente tivesse que pesqui- } \\
\text { sar mais, consequentemente, aprofundar nosso conhecimento." }\end{array}$ & \multirow{15}{*}{$\begin{array}{l}\text { Respostas dos alunos à } \\
\text { pergunta: O que vocês } \\
\text { observaram } \\
\text { de diferente nesta pro- } \\
\text { posta de atividade? }\end{array}$} \\
\hline & "Um trabalho mais objetivo e trabalhoso, sem o uso do 'copiar e colar"'. & \\
\hline & $\begin{array}{l}\text { "Que foi um trabalho um tanto demorado, porque não tem um tema muito fechado, não } \\
\text { teve nenhum ponto específico". }\end{array}$ & \\
\hline & "Que são muitas páginas para o trabalho e pouco tempo para a primeira vez". & \\
\hline & "Que tinha muita coisa para fazer e que tinha que ser organizado". & \\
\hline & "Nós achamos a atividade mais complexa". & \\
\hline & "A observação dos três Conselhos Religiosos e o que eles têm em comum". & \\
\hline & $\begin{array}{l}\text { "Que são muitas páginas para um trabalho, não muito grande, a proposta é boa para } \\
\text { aprendermos sobre as religiões e outras coisas sobre o mundo religião". }\end{array}$ & \\
\hline & "Exigiram respostas e conceitos mais complexos. O conteúdo é mais complexo". & \\
\hline & "É uma proposta que não tem muitas fontes, mas é um assunto muito interessante". & \\
\hline & "O ecumenismo já é uma coisa diferente, o conceito, a introdução". & \\
\hline & $\begin{array}{l}\text { "Nada, a única diferença perceptível é o tamanho, que faz com que o trabalho fique muito } \\
\text { chato". }\end{array}$ & \\
\hline & "É um trabalho mais complexo que exige mais esforço". & \\
\hline & $\begin{array}{l}\text { "Que o professor nos deu bastante tempo para fazer e que foi realizado no Colégio. Tinha } \\
\text { a proposta de fazer com a ajuda do professor." }\end{array}$ & \\
\hline & "A gente ter um trabalho com um assunto tão aberto, sem temas específicos". & \\
\hline \multirow{6}{*}{ PE2 } & "Sim" & \multirow{6}{*}{$\begin{array}{l}\text { Respostas dos alunos à } \\
\text { pergunta: Na opinião de } \\
\text { vocês, a atividade de } \\
\text { pesquisa, no contexto } \\
\text { escolar, está mais cla- } \\
\text { ra? }\end{array}$} \\
\hline & "Não fez diferença estar no contexto escolar". & \\
\hline & "Não, pois foi mais difícil de fazer e não houve um grande aprendizado". & \\
\hline & "Não" & \\
\hline & "Sim, na nossa opinião, a atividade de pesquisa no contexto escolar está mais clara". & \\
\hline & $\begin{array}{l}\text { "Muito mais, a pesquisa me ajudou a compreender o trabalho e aumentou nosso conhe- } \\
\text { cimento sobre a área trabalhada". }\end{array}$ & \\
\hline
\end{tabular}




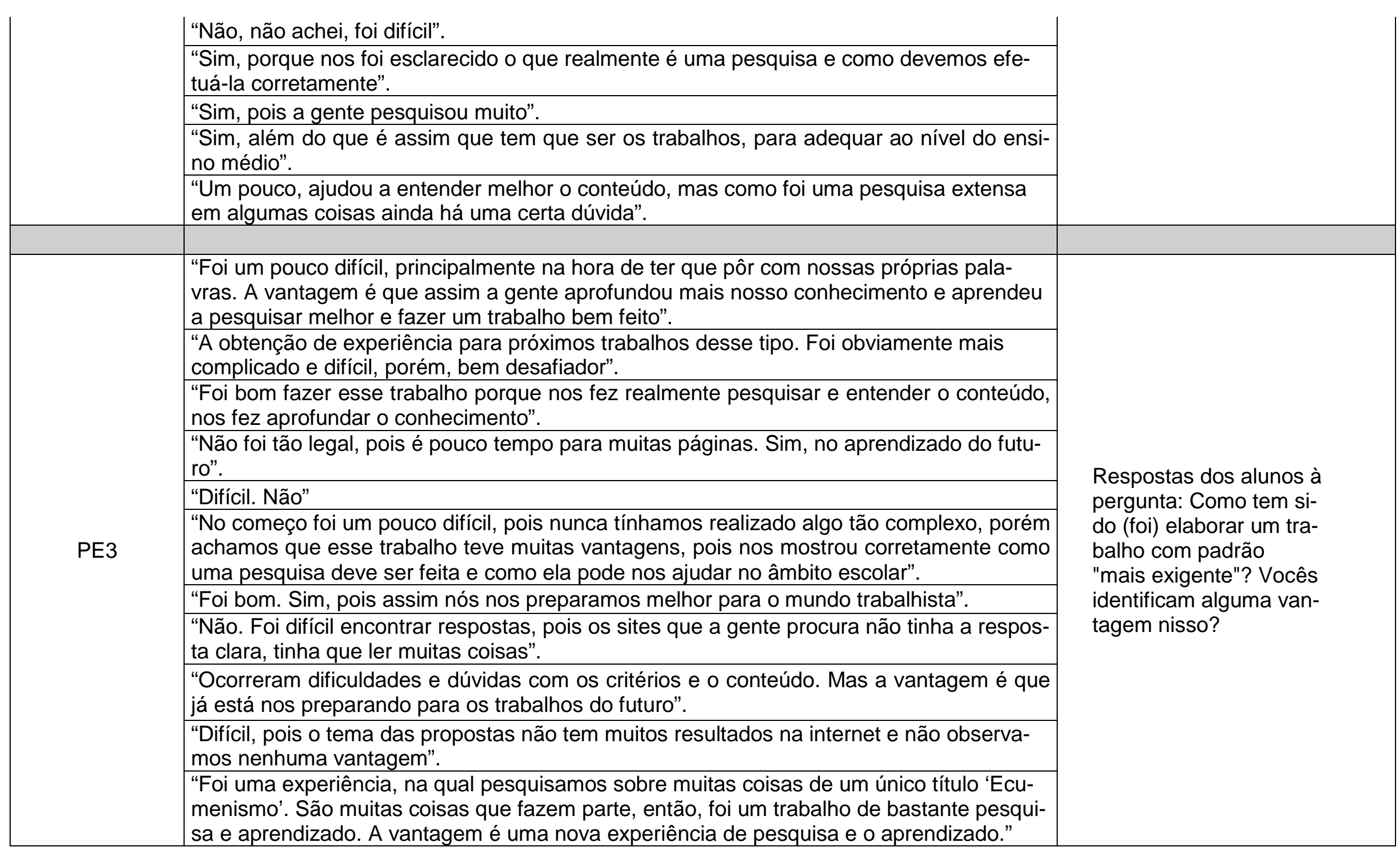




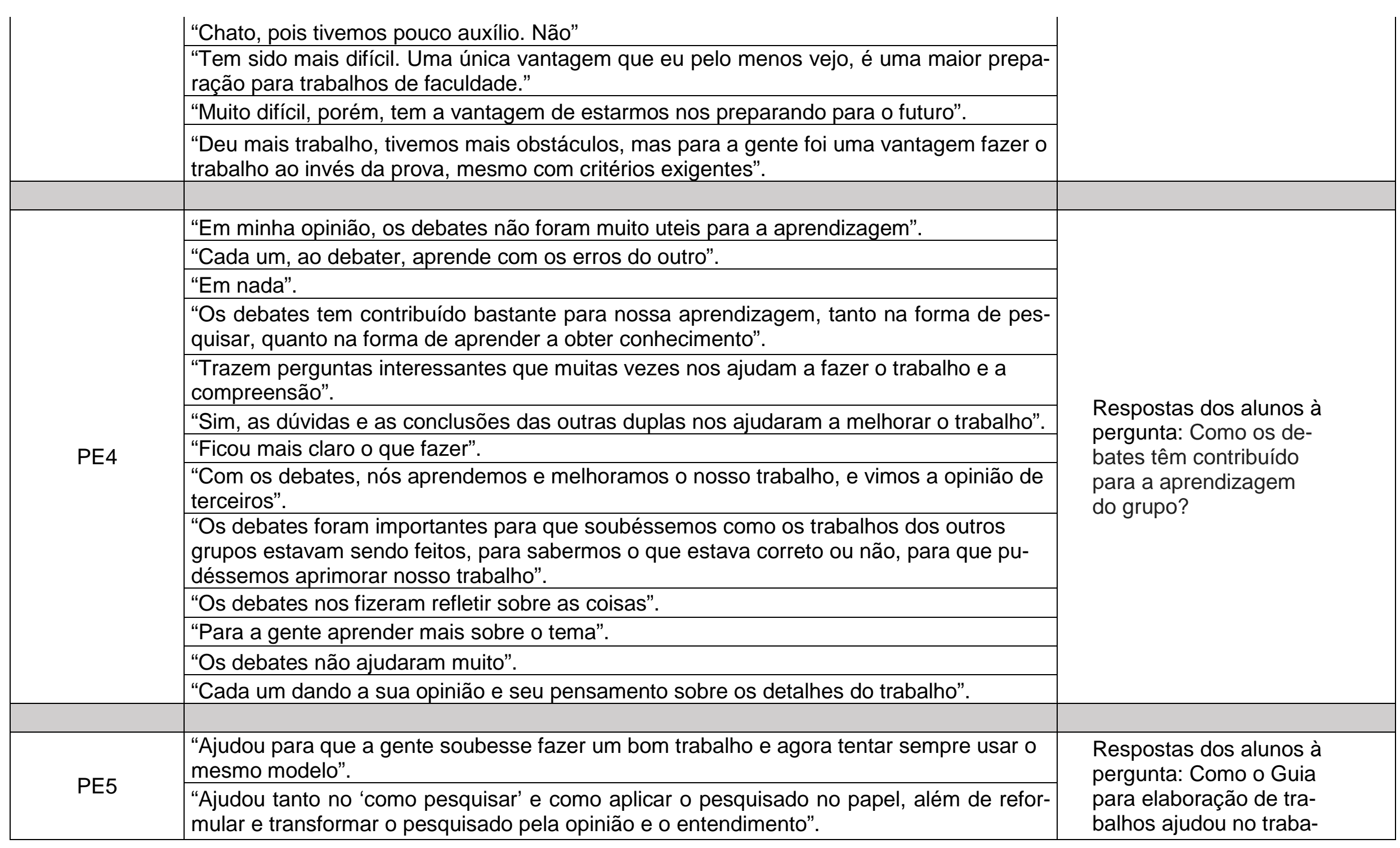




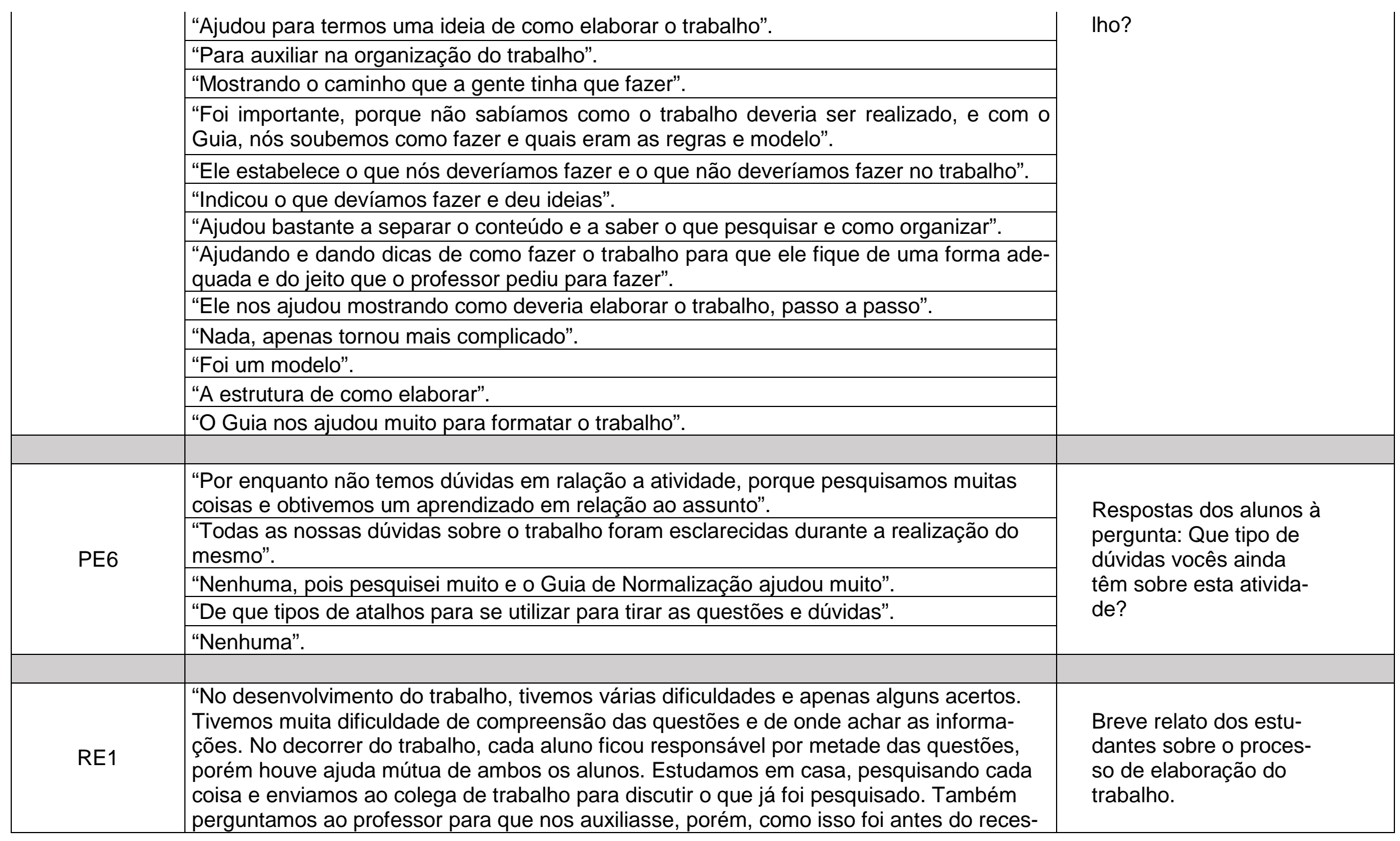




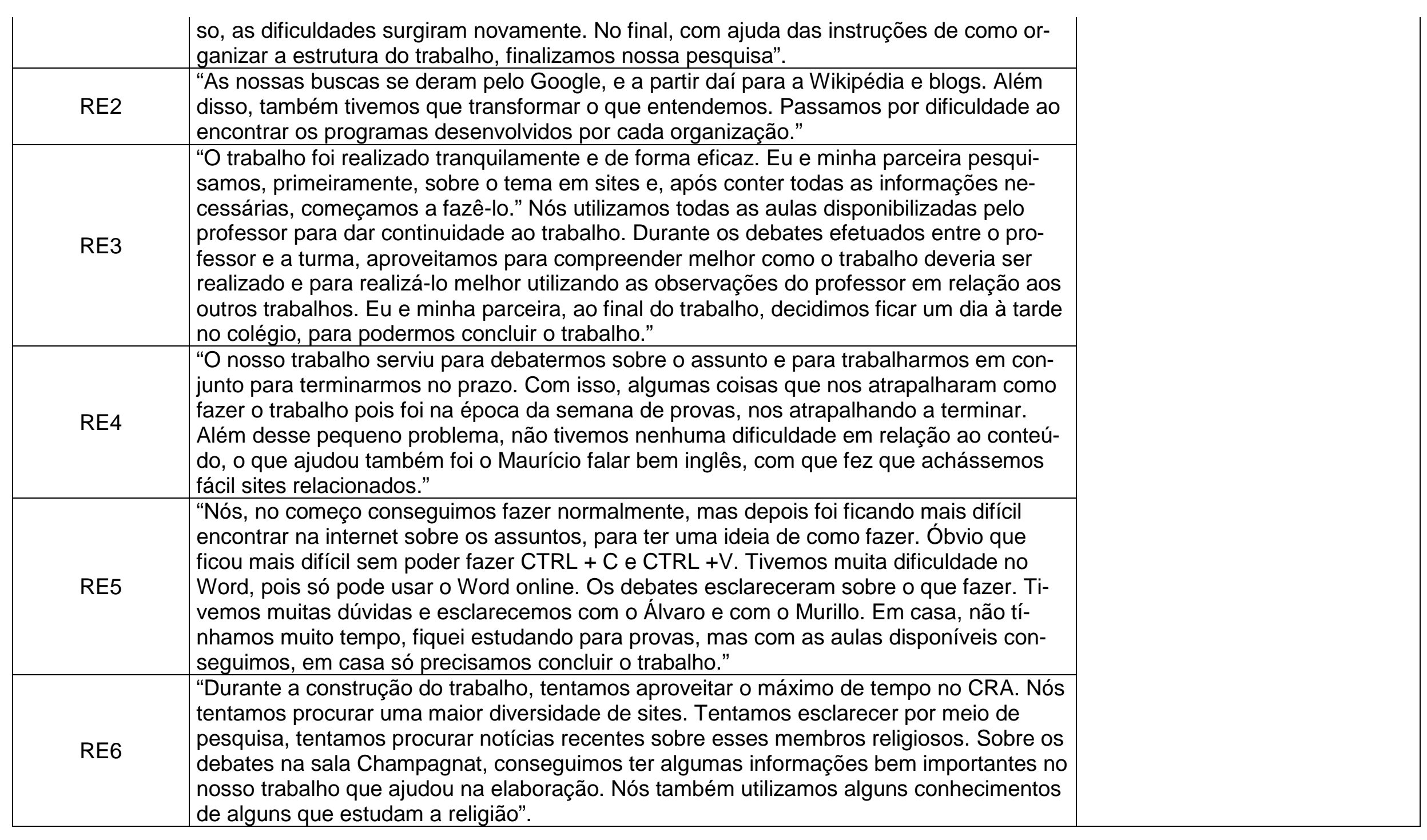




\begin{tabular}{|c|c|}
\hline RE7 & $\begin{array}{l}\text { O tema do trabalho, ecumenismo, é um tema atual e importante, mas acima de tudo } \\
\text { complexo. Foi um dos problemas enfrentados por nós. Para atingir os objetivos do traba- } \\
\text { lho, pesquisamos na internet sobre o assunto, e conseguimos consultar os pontos de } \\
\text { vista de diversas religiões. Com isso, conseguimos concluir que todas as religiões prati- } \\
\text { cam o ecumenismo de uma forma ou de outra. Além disso, a pesquisa nos mostrou a } \\
\text { importância do ecumenismo na vida dos cristãos, a busca da unidade, pois impede que } \\
\text { conflitos sejam proporcionados e confirma o intuito da religião." }\end{array}$ \\
\hline RE8 & $\begin{array}{l}\text { "Nós pesquisamos em vários sites contendo informações necessárias para fazer o traba- } \\
\text { lho. Também discutimos sobre como faríamos o trabalho e comparamos ideias com ou- } \\
\text { tras duplas. Tentamos combinar ideias para efetuar os tópicos para o trabalho. Porém, } \\
\text { com todos esses aspectos, não conseguimos terminar o trabalho". }\end{array}$ \\
\hline RE9 & $\begin{array}{l}\text { "Durante as nossas aulas, o professor disponibilizou tempo para buscar informações, } \\
\text { proporcionou debates, respondeu dúvidas levadas a ele, etc. A busca de informações foi } \\
\text { difícil, pois não existiam muitos sites que favoreciam a busca. Durante os debates, muitas } \\
\text { dúvidas foram respondidas e puderam ser colocadas no trabalho. Ao levarmos dúvidas } \\
\text { ao professor, ele respondeu claramente e nos ajudou. No nosso caso, não houve troca } \\
\text { de informações com os colegas, mas não conseguimos terminar o trabalho em sala, e } \\
\text { então tivemos que terminar em casa". }\end{array}$ \\
\hline RE10 & $\begin{array}{l}\text { "Durante a realização deste trabalho, encontramos várias dificuldades, assim como tive- } \\
\text { mos vários debates sobre o trabalho em geral. Tivemos dificuldade ao pesquisar sobre as } \\
\text { igrejas cristãs em diferentes níveis, porque era um componente do trabalho mais comple- } \\
\text { xo e pelo fato de termos utilizado muitas fontes de pesquisa, para chegarmos ao resulta- } \\
\text { do esperado. O trabalho foi ótimo e feito em dupla." }\end{array}$ \\
\hline RE11 & $\begin{array}{l}\text { "Do início até o final, pois foi um trabalho irritante e desgastante. Foi um trabalho grande, } \\
\text { 'de repente', em vez de fazer um trabalho de uma página ou no máximo duas, vem um } \\
\text { trabalho de oito a 10, e tinha poucas fontes para botar no trabalho. A maioria falava a } \\
\text { mesma coisa, ou falava coisas que não tinham nada a ver com o trabalho ou com o tema. } \\
\text { O que tinha que ver com o tema eram notícias e representantes do CONIC que iam con- } \\
\text { versar com outras religiões. Mas de resto, tudo certo." }\end{array}$ \\
\hline
\end{tabular}




\begin{tabular}{|c|c|c|}
\hline RE12 & $\begin{array}{l}\text { "Fizemos o trabalho por meio de enciclopédias e sites na internet. Confessamos que foi } \\
\text { um trabalho difícil de se fazer, por não saber muito bem do que o assunto se tratava e as } \\
\text { informações que obtivemos eram limitadas. Também foi difícil de elaborar o trabalho em } \\
\text { questões físicas. O modo que o professor nos explicou era complexo e para sermos ho- } \\
\text { nestas, não entendemos qual foi o objetivo desse trabalho. Mas no final demos um jeito e } \\
\text { consequimos estruturar o trabalho e o deixamos razoável e o assunto bem trabalhado." }\end{array}$ & \\
\hline RE13 & $\begin{array}{l}\text { "Tivemos muita dificuldade em achar sites que explicassem com clareza o trabalho. En- } \\
\text { tâs juntamos um pouco de cada coisa. Os acertos foram na hora do desenvolvimen- } \\
\text { to. Cada um resumiu uma parte e juntamos tudo." }\end{array}$ & \\
\hline RE14 & $\begin{array}{l}\text { "Durante o trabalho, nós pesquisamos juntas para ambas aprenderem e entenderem so- } \\
\text { bre todo o assunto e não apenas uma parte, para aprofundarmos o conhecimento. Nós } \\
\text { pesquisamos uma parte na escola e outras em casa, sendo a maioria baseado em sites } \\
\text { específicos na internet." }\end{array}$ & \\
\hline ENT1 & $\begin{array}{l}\text { "É um trabalho que eu não vou dizer pra você que foi fácil, na perspectiva de ter sido pra } \\
\text { mim uma novidade também e pegar um trabalho tanto pra mim quanto para os meninos... } \\
\text { Porque eles estavam acostumados a trabalhar com grupo. E trabalho em grupo, normal- } \\
\text { mente mascara um pouco o trabalho, porque aí você tem um grupo de seis pessoas, vo- } \\
\text { cê tem dois que muitas vezes carregam o trabalho nas costas e os outros quatro levam a } \\
\text { nota. Quando a gente viu a possibilidade de fazer em dupla, eu achei interessante, mes- } \\
\text { mo sabendo que seria um volume muito grande e que o tema também era o mesmo tema } \\
\text { pra todos, e eles também se inquietaram também, acho que por causa disso e o número } \\
\text { de páginas pra alguns incomodava e o formato, tanto que isso fica claro nos questioná- } \\
\text { rios, que eles em um primeiro momento... eles sentem isso. A maior dificuldade é o nú- } \\
\text { mero de páginas que eles tem que produzir." }\end{array}$ & $\begin{array}{l}\text { Entrevista com o pro- } \\
\text { fessor da disciplina } \\
\text { apontando suas im- } \\
\text { pressões sobre a reali- } \\
\text { zação do trabalho. }\end{array}$ \\
\hline
\end{tabular}


"Essas seriam as duas coisas... porque esse, o número de páginas... ele aparece quando você coloca. A formatação, ela vai aparecer depois quando eles se vêm diante da dificuldade. E aí você tem experiências interessantes de meninos que buscaram pessoas próximas... o pai... alguém da família que pudesse ajudá-los... porque a gente pensa muita nessa questão da tecnologia, tal... o uso... e não sei o quê... É bacana isso... A escola acha que a gente está muito atrasado também em relação a algumas coisas. Mas quando se trata de um trabalho como esse, que você precisa de um programa como um Word, um Excel pra trabalhar com planilha... os nossos alunos chegam no $9^{\circ}$ ano e não sabem mexer. E aquilo que eu estava falando pra você hoje pela manhã... Eu não sei se a gente trabalharia com uma espécie de escalonamento, porque também chegar no 9o ano e exigir deles algo que eles não estão habituados a fazer... realmente choca. E aí, os trabaIhos ficam muito mais numa capacidade que eles tem de resumir as coisas e não realmente de ter muitas palavras deles mesmos... da pesquisa."

"É claro que tem uma coisa mais rebuscada de você trazer uma formatação que o Word favorece num trabalho como esse, mas o básico... mesmo o básico eles não sabiam."

"Além disso, eu vi também um aspecto... no meu caso, eu penso que para um aluno de 9응 ano... nós temos alunos excelentes, que são alunos muito autônomos, mas é uma fase também, que autonomia para um trabalho de pesquisa, ela precisa ser melhor conduzida, vamos dizer assim. Não que eu tenha conduzido de maneira ruim, não foi isso... porque eu abri espaço, deixei canais abertos, de e-mail , de tudo, pra gente ficar 'trocando figurinhas', no entanto, eu não obtive isso, esse retorno deles virem até a mim, e perguntarem: 'Álvaro tenho dúvida aqui, como é que faz isso daqui...', entendeu? Alguma coisa nesse sentido."

"É, e aí eu fiquei também me perguntando assim, porque que eles não foram tirar as dúvidas, assim... porque que eles não vieram tirar as dúvidas, se a gente tinha a possibilidade de uma aula aqui e outra aula lá no debate... Eu não entendi assim... em algum momento."

"Então... eles não têm a sensação de que ao fazerem o trabalho, eles estão estudando para a prova. E aí a gente vê relatos de alguns trabalhos de meninos que disseram que ajudaram a fazer a prova parcial. Então assim... eles começaram a entender... alguns começaram a entender que ao pesquisarem, fazerem o trabalho... isso não é um número talvez muito significativo, mas é interessante." 
"Compromete (a enturmação), e eu vejo... tem outro detalhe... que é a questão da própria maturidade dos meninos. Eu estava com um professor ali agora, o Gilberto, corrigindo provas deles. A frase dele: "Não tem jeito, essa turma não tem como...". Então assim, há uma dificuldade ali, que está inserida... uma questão... você tem a turma onde mais tem laudo. São 12, 13, sei lá, 14 meninos com laudo, numa turma de 40 alunos."

"Quando você trabalha, por exemplo, na Secretaria, com meninos assim laudeados, você tem que diminuir o número de alunos por turma. Você não pode trabalhar com um monte de gente com laudo... com a mesma quantidade. Isso também reflete, porque aí você não tem como acompanhar melhor. Eles são colocados também na "massa", coitados. E aí eles também não dão conta de fazer algumas coisas que outros já dão, tranquilamente. $E$ aí o reflexo vai pra nota, vai pra essa falta de autonomia. Quando você passa um trabalho desse... foi uma das turmas que... além de demorar para entregar o trabalho, muitos nem entregaram ainda... duas semanas depois da data de entrega. Não entregaram... e o pior... não só a questão da data, mas tem um outra coisa... a qualidade dos trabalhos. Porque você vai encontrar trabalhos ruins nas outras turmas, mas lá (9ํㅡ) é impressionante.

A única turma que eu até agora, peguei um trabalho e não tive condições de avaliar. Porque ele não tinha absolutamente nada."

"Não foi tão significativa, porque... o resultado não se mostrou. Ou seja, aqueles que são bons, continuam bons. E aí, é claro nessa questão da maturidade. Hoje você tem uma turma, que pra mim... aí é uma questão da própria escola... e aí me revela isso. Porque não é comigo, mas são todos os professores que falam da turma especificamente. Que ela não tem maturidade acadêmica. E os bons que lá estão, não são meninos de liderança, que possam ajudar os colegas a levantar... dar a mão... tomar a frente... não, não conseguem fazer isso."

"Não, ela não entrou né (variável maturidade e número de alunos com laudos). A gente entrou na questão de que era uma turma que tinha dificuldade..."

"Então, o professor, com a carga de trabalho que ele já tem, de prova e tudo mais, ele

não vai querer... se um trabalho desse não estiver dentro da estrutura da escola... o professor não vai se arriscar a fazer um negócio desse."

Fonte: Elaboração própria. 
$\mathrm{Na}$ etapa da categorização, as unidades de análise foram classificadas e agrupadas em categorias (Quadros 23, 24 e 25), considerando semelhanças entre si. Nessa etapa foi possível identificar cada uma das unidades de análise no contexto específico em que ela ocorreu. Apesar do termo "unidade", neste primeiro momento elas estão extensas, apresentando vários trechos, assemelhando-se mais a frases.

Quadro 23 - Definição das Categorias Iniciais

\begin{tabular}{|c|c|}
\hline UNIDADE DE ANÁLISE & CATEGORIA INICIAL \\
\hline Alunos continuavam dispersos. & Interesse pela atividade \\
\hline $\begin{array}{l}\text { Neste momento, há muita conversa em sala. O professor para a explicação e chama a atenção de } \\
\text { alguns alunos. }\end{array}$ & Interesse pela atividade \\
\hline Alguns estudantes estão dispersos, e não prestam atenção ao que é dito pelo professor. & Interesse pela atividade \\
\hline A turma inteira questiona e fica dispersa. & Interesse pela atividade \\
\hline $\begin{array}{l}\text { Alunos poderão utilizar ferramentas colaborativas como Skype, Google Docs, FaceTime, entre ou- } \\
\text { tras, para elaborarem o trabalho. }\end{array}$ & Explicação em sala \\
\hline $\begin{array}{l}\text { Nenhum aluno buscou algum tipo de material bibliográfico que pudesse servir de base para o início } \\
\text { da pesquisa. }\end{array}$ & $\begin{array}{l}\text { Clareza do material apresenta- } \\
\text { do }\end{array}$ \\
\hline $\begin{array}{l}\text { O professor orienta que os estudantes acessem o roteiro do trabalho e comecem a levantar infor- } \\
\text { mações pertinentes. }\end{array}$ & Explicação em sala \\
\hline Aluno entra no site Scielo e encontra informações bastante relevantes. & $\begin{array}{l}\text { Busca por informações relevan- } \\
\text { tes }\end{array}$ \\
\hline Alguns alunos já começavam a formatar o trabalho no Word. & $\begin{array}{l}\text { Registro das informações sele- } \\
\text { cionadas }\end{array}$ \\
\hline Alguns alunos enviaram o material salvo por e-mail. & $\begin{array}{l}\text { Registro das informações sele- } \\
\text { cionadas }\end{array}$ \\
\hline
\end{tabular}


O pesquisador pede uma leitura inicial por parte dos estudantes, tentando identificar aspectos importantes do texto.

Alguns alunos não se interessam muito pelo texto e ficam dispersos.

Professor propõe leitura coletiva do texto (percebe-se que os alunos não prestam muita atenção).

É dada explicação mais detalhada sobre o que são mapas mentais e qual o propósito de apren-

dermos a utilizá-los.

Os alunos estão empolgados com a utilização do equipamento e também com a utilização do aplicativo.

A temática do mapa seria sobre o conceito de "pesquisa".

Muitos alunos não se lembravam mais o que deveria ser feito no trabalho.

Alguns alunos buscam trocar informações entre eles, buscando compartilhar o que tinham encontrado.

O trabalho já servirá para que os alunos estudem para a prova globalizante.

Alguns estudantes têm pouca clareza sobre a busca por informações.

Percebe-se dificuldades básicas de alguns alunos até mesmo para anexar um arquivo a ser envido por e-mail.

Professor passou a questioná-los sobre o andamento do trabalho. Foi uma espécie de bate-papo, mas poucos alunos falaram.

É dado orientações sobre o roteiro de trabalho, a questão do plágio, o processo de busca por informações relevantes e sobre a importância do processo de autonomia de cada estudante na busca por informações.

Alunos parecem não se lembrar mais sobre o que tem que ser feito no trabalho de pesquisa. No momento do debate/pesquisa-ação, o professor solicita às duplas de estudantes que falem um pouco sobre o andamento do trabalho.

(Aluna) - "A gente tá respondendo primeiro aquelas quatro perguntas, pra depois organizar o trabalho..."
Explicação em sala

Interesse pela atividade

Explicação em sala

Explicação em sala

Interesse pela atividade

Explicação em sala

Interesse pela atividade

Troca de informações entre os estudantes

Explicação em sala

Conhecimento prévio

Registro e armazenamento de informações

Participação nas aulas

Explicação em sala

Interesse pela atividade

Participação nas aulas

Participação nas aulas 
(Professor) - "Eu me lembro que eu disse que aquelas questões... aqueles objetivos específicos

não são perguntas, mas são nortes para conduzir o nosso trabalho. Não necessariamente são perguntas a serem respondidas.

(Professor) - "Vocês têm outra forma de se comunicarem para fazer o trabalho, como é que vocês estão fazendo?"

(Alunas) - "Eu vou pra casa dela, ela vai pra minha, a gente conversa no WhatsApp..."

Esclarecimento de dúvidas

Uso de ferramentas colaborativas

Uso de ferramentas colaborati-

(Professor) - "Vocês acreditam que ao mesmo tempo que vocês estão fazendo a pesquisa, vocês estão estudando?"

(Alunas) - "Sim!"

(Aluna) - "Álvaro, é muita coisa... nem minha irmã na UnB faz um trabalho deste tamanho..."

(Professor) - "Da gente ir para o campo da pesquisa, não sou eu que estou lá na frente falando,

mas vocês estão pesquisando... a gente vem aqui e discute..."

(Professor) - "Quais são os aspectos que vocês consideram positivo, ou talvez negativo nesta proposta?"

(Aluno) - "Sair da sala de aula, por que na sala de aula é muito entediante. A gente passa o dia inteiro na sala de aula, só sai para beber..."

(Professor) - "Como é que tem sido elaborar um trabalho com padrão mais exigente assim, como uma formatação que vocês vão ter que seguir..."

(Aluna) - "Os trabalhos ficam dentro do padrão... um não tem uma capa mais bonita que ou outro..."

Aluna também fala da questão do limite de páginas como algo ruim... 10 páginas.

(Professor) - "O Murillo está dando dicas de formatação. Tá me ajudando na correção da formatação de alguns trabalhos".

(Professor) - "Uma coisa que a gente quer com vocês neste trabalho: é que a gente saia do esquema do copia e cola. Porque nós estamos acostumados a fazer trabalhos de copiar e colar." (Professor) - "E o aprendizado não está na formatação... não é isso, mas é o processo que foi construído pra pesquisar o trabalho. Isso é que é o mais importante."

(Aluna) - "Poxa Álvaro... mas aí é chato, o tema é chato..."

(Professor) - "Nós temos que mostrar nosso protagonismo, a nossa autonomia, a nossa capacidade de fazer as coisas." vas

Aprofundamento do conteúdo

Aprofundamento do conteúdo Percepção dos alunos

Esclarecimento de dúvidas

Percepção dos alunos

Percepção dos alunos

Direcionamento do professor

Percepção dos alunos

Percepção dos alunos

Direcionamento do professor

Direcionamento do professor

Direcionamento do professor

Percepção dos alunos

Direcionamento do professor 
Alguns alunos tentam recuperar o roteiro no Portal Marista, demonstrando pouca organização no momento do estudo.

Os estudantes demonstram pouca habilidade para trabalhar com recursos básicos do computador (desde editar um texto com fonte específica, até inserir caixa de texto, tabelas etc.).

Alguns estudantes acabaram perdendo o arquivo principal do trabalho por não terem conseguido salvá-lo em local específico.

Isso demonstra que ainda faltam habilidades básicas a serem trabalhadas, principalmente com base na utilização de ferramentas simples, já consideradas de domínio coletivo como os editores de texto.

(Alunos) - "A gente perdeu o arquivo que a gente tinha começado... a gente não salvou os sites que a gente estava vendo..."

(Professor) - "Se tem uma coisa, que a gente valoriza, é essa autonomia da aprendizagem."

(Aluna) - "O tema do trabalho ficou muito fechado para dez páginas de trabalho".

(Aluno) - "Os trabalhos vão estar iguais, por que todos estão fazendo da mesma fonte".

(Pesquisador) - "O que podemos perceber então é que grande parte dos alunos está simplesmente copiando e colando."

(Aluno) - "Poxa Álvaro, parece uma coisa de vestibular, de faculdade..."

(Aluna) - "Porque você aprende coisas novas e ao invés de ficar copiando e colando essas coisas, você pode gravar na sua cabeça o que você lê e que você escreve."

Concentração no roteiro de estudo

Infraestrutura de informação e comunicação

Registro e armazenamento de informações

Infraestrutura de informação e comunicação

Registro e armazenamento de informações

Direcionamento do professor

Percepção dos alunos

Percepção dos alunos

Esclarecimento de dúvidas

Percepção dos alunos

Percepção dos alunos

(Professor) - "Uma das intenções desse trabalho é que vocês saiam do 'copia e cola"'.

Direcionamento do professor

Muitos alunos continuam dispersos e não prestam atenção ao que o professor fala.

Professor começa a falar sobre os conteúdos a serem pesquisados.

Professor volta a falar sobre cada um dos passos do roteiro enquanto vários alunos continuam dispersos.

Professor fala que o trabalho terá um grau de exigência maior.

Participação nas aulas Explicação em sala

Explicação em sala

Explicação em sala

O professor continua a explicação e afirma que o trabalho não deverá ser feito com base no "cópia

Direcionamento do professor 
e cola".

Professor fala que os alunos poderão utilizar as ferramentas sociais para se comunicarem e para fazerem o trabalho de forma colaborativa.

O grupo está bastante disperso e apenas algumas duplas parecem estar concentradas na busca por informações.

Algumas alunas brincam de tirar fotos umas das outras com o celular.

Alunos têm dificuldade de utilizar aplicações básicas do computador, como anexar um arquivo ao e-mail.

Fica claro que os alunos não leram o roteiro com atenção. Estão preocupados em entrar na Internet e responder os objetivos específicos, como se fossem questões.

Uso de ferramentas colaborativas

Participação nas aulas

Interesse pela atividade

Infraestrutura de informação e comunicação

Infraestrutura de informação e comunicação

O trabalho com mapas mentais foi produtivo

Clareza do material apresentado

\section{Reunir informações}

Saber mais sobre o tal assunto

Pesquisar no conhecimento de outras pessoas

Aprofundar os conhecimentos

Novas fontes de conhecimento

Trabalhos

Tirar dúvidas

Curiosidades

Busca de dados

Procurar coisas novas

Procurar novas/várias fontes

Um meio usado para obter conhecimento e sabedoria

Procurar sobre o assunto para aumentar o conhecimento

Absorver informações e Extinguir a ignorância

Aprendizagem de assuntos não compreendidos

Ideia inicial sobre o assunto

Ideia inicial sobre o assunto

Ideia inicial sobre o assunto Ideia inicial sobre o assunto Ideia inicial sobre o assunto Ideia inicial sobre o assunto Ideia inicial sobre o assunto Ideia inicial sobre o assunto Ideia inicial sobre o assunto Ideia inicial sobre o assunto Ideia inicial sobre o assunto Ideia inicial sobre o assunto Ideia inicial sobre o assunto Ideia inicial sobre o assunto Ideia inicial sobre o assunto 
Auxílio na compreensão e alfabetização

Ideia inicial sobre o assunto

Aumenta e aprofunda o conhecimento

Ideia inicial sobre o assunto

Saber mais sobre o assunto

Subir notas das provas

Leitura/interpretação/entendimento

Levantamento de dados

Compreensão do conteúdo

Coleta de dados das diferentes fontes de conhecimento

Misturar informações (uma deverá completar a outra)

Ver as diferentes visões sobre o assunto

Inserir a sua visão sobre o conteúdo da pesquisa

Indicação da fonte da pesquisa

Saber mais sobre esse assunto

Ajuda a fazer trabalhos escolares, estudar e fazer provas, testes

Ideia inicial sobre o assunto

Ideia inicial sobre o assunto

Ideia inicial sobre o assunto

Ideia inicial sobre o assunto

Ideia inicial sobre o assunto

Ideia inicial sobre o assunto

Ideia inicial sobre o assunto

Ideia inicial sobre o assunto Ideia inicial sobre o assunto

Ideia inicial sobre o assunto

Ideia inicial sobre o assunto Ideia inicial sobre o assunto

Chegar a algumas conclusões

Chegar a algumas respostas

Instrumento de busca de dados

Aprimorar o seu conhecimento e suas respostas

Ideia inicial sobre o assunto

Ideia inicial sobre o assunto

Ideia inicial sobre o assunto Ideia inicial sobre o assunto

\section{Tornar-se um perito}

Ajuda na compreensão da matéria

Novas informações

Estudo/conhecimento geral ou específico

Melhora as notas

Realização pessoal/profissional

Aprimoramento/desenvolvimento no trabalho

Ideia inicial sobre o assunto

Ideia inicial sobre o assunto

Ideia inicial sobre o assunto

Ideia inicial sobre o assunto

Ideia inicial sobre o assunto

Ideia inicial sobre o assunto

Ideia inicial sobre o assunto

Fatos desconhecidos

Ideia inicial sobre o assunto 
Amplia o conhecimento

Ideia inicial sobre o assunto

Traz novas informações

Ideia inicial sobre o assunto

Facilita a interpretação

Ideia inicial sobre o assunto

Serve para a aprendizagem

Ajuda nos estudos

Ajuda em resumos

Conjunto de informações

Análise das informações (palavras-chave/estruturação de textos)

Analisar o que deve ser pesquisado

Coleta de informações

Aprofundar o seu conhecimento

Tira dúvidas

Ideia inicial sobre o assunto

Ideia inicial sobre o assunto

Ideia inicial sobre o assunto

Ideia inicial sobre o assunto

Ideia inicial sobre o assunto

Ideia inicial sobre o assunto

Ideia inicial sobre o assunto

Ideia inicial sobre o assunto

Ideia inicial sobre o assunto

Ideia inicial sobre o assunto

Ideia inicial sobre o assunto

Ter noção do assunto abordado

Saber o objetivo (dividir os temas/planejamento/rascunho)

Introdução/desenvolvimento/conclusão

Escolher a melhor fonte (seleciona o importante/cópia e cola/utilizar seus conhecimentos e pala-

vras)

Tema escolhido (perguntar aos pais/internet/entrevistas/livros e revistas)

Se informar sobre o assunto

Selecionar fontes

Organizar as ideias

Fazer texto em tópicos

Brainstorm

Fazer resumo

Usar as próprias ideias

Escrever

Revisar

Ideia inicial sobre o assunto

Ideia inicial sobre o assunto Ideia inicial sobre o assunto

Ideia inicial sobre o assunto

Ideia inicial sobre o assunto

Ideia inicial sobre o assunto

Ideia inicial sobre o assunto

Ideia inicial sobre o assunto

Ideia inicial sobre o assunto

Ideia inicial sobre o assunto

Ideia inicial sobre o assunto

Ideia inicial sobre o assunto

Ideia inicial sobre o assunto

Ideia inicial sobre o assunto 


\section{Melhora e complementa os estudos}

\section{Esclarece dúvidas}

Desenvolvimento intelectual, na escrita, na leitura

Conhecimentos novos e aprimorados

Fontes (internet, livros, pessoas entendidas do assunto)

Junção de ideias/conhecimento

Exploração do conteúdo

Complementação do estudo

Formas de conhecimento (aprendizagem/desenvolvimento)

Trabalhos escolares

Resumo ou história sobre determinado assunto

Levantamento de dados (compreensão/registro)

Seleção dos sites (seleção dos parágrafos mais importantes)

Coleta de informação

Conjunto de ideias (aumentar o conhecimento)

Aprendizagem
Ideia consolidada sobre o as sunto

Ideia consolidada sobre o as-

sunto

Ideia consolidada sobre o as-

sunto

Ideia consolidada sobre o as-

sunto

Ideia consolidada sobre o as-

sunto

Ideia consolidada sobre o as-

sunto

Ideia consolidada sobre o as-

sunto

Ideia consolidada sobre o as-

sunto

Ideia consolidada sobre o as-

sunto

Ideia consolidada sobre o as-

sunto

Ideia consolidada sobre o as-

sunto

Ideia consolidada sobre o as-

sunto

Ideia consolidada sobre o as-

sunto

Ideia consolidada sobre o as-

sunto

Ideia consolidada sobre o as-

sunto

Ideia consolidada sobre o as- 


\begin{tabular}{|c|c|}
\hline & sunto \\
\hline Adquirir/aprofundar conhecimento & $\begin{array}{l}\text { Ideia consolidada sobre o as- } \\
\text { sunto }\end{array}$ \\
\hline Aprender & $\begin{array}{l}\text { Ideia consolidada sobre o as- } \\
\text { sunto }\end{array}$ \\
\hline Estudar & $\begin{array}{l}\text { Ideia consolidada sobre o as- } \\
\text { sunto }\end{array}$ \\
\hline Métodos (mapas conceituais/resumos/ler) & $\begin{array}{l}\text { Ideia consolidada sobre o as- } \\
\text { sunto }\end{array}$ \\
\hline Fontes & $\begin{array}{l}\text { Ideia consolidada sobre o as- } \\
\text { sunto }\end{array}$ \\
\hline Conceitos (dicionário/palavras-chave) & $\begin{array}{l}\text { Ideia consolidada sobre o as- } \\
\text { sunto }\end{array}$ \\
\hline Entendimento do tema & $\begin{array}{l}\text { Ideia consolidada sobre o as- } \\
\text { sunto }\end{array}$ \\
\hline Biblioteca (enciclopédias/livros) & $\begin{array}{l}\text { Ideia consolidada sobre o as- } \\
\text { sunto }\end{array}$ \\
\hline "Nos dá um conhecimento do assunto a ser estudado" & $\begin{array}{l}\text { Ideia consolidada sobre o as- } \\
\text { sunto }\end{array}$ \\
\hline Aumentar o conhecimento (diversas áreas) & $\begin{array}{l}\text { Ideia consolidada sobre o as- } \\
\text { sunto }\end{array}$ \\
\hline Lugares para procurar (biblioteca, livros, enciclopédias, internet) & $\begin{array}{l}\text { Ideia consolidada sobre o as- } \\
\text { sunto }\end{array}$ \\
\hline $\begin{array}{l}\text { "Foi um trabalho extenso e complexo, mas que fez com que a gente tivesse que pesquisar mais, } \\
\text { consequentemente, aprofundar nosso conhecimento." }\end{array}$ & Percepção dos alunos \\
\hline "Um trabalho mais objetivo e trabalhoso, sem o uso do "copiar e colar". & Percepção dos alunos \\
\hline $\begin{array}{l}\text { "Que foi um trabalho um tanto demorado, porque não tem um tema muito fechado, não teve ne- } \\
\text { nhum ponto específico". }\end{array}$ & Percepção dos alunos \\
\hline "Que são muitas páginas para o trabalho e pouco tempo para a primeira vez". & Percepção dos alunos \\
\hline "Que tinha muita coisa para fazer e que tinha que ser organizado". & Percepção dos alunos \\
\hline
\end{tabular}


"Nós achamos a atividade mais complexa".

"A observação dos três Conselhos Religiosos e o que eles têm em comum".

Percepção dos alunos

"Que são muitas páginas para um trabalho, não muito grande, a proposta é boa para aprendermos sobre as religiões e outras coisas sobre o mundo religião".

"Exigiram respostas e conceitos mais complexos. O conteúdo é mais complexo".

"É uma proposta que não tem muitas fontes, mas é um assunto muito interessante".

"O ecumenismo já é uma coisa diferente, o conceito, a introdução".

"Nada, a única diferença perceptível é o tamanho, que faz com que o trabalho fique muito chato".

"É um trabalho mais complexo que exige mais esforço".

"Que o professor nos deu bastante tempo para fazer e que foi realizado no Colégio. Tinha a pro-

posta de fazer com a ajuda do professor."

"A gente ter um trabalho com um assunto tão aberto, sem temas específicos".

Percepção dos alunos

"Sim"

"Sim"

"Não fez diferença estar no contexto escolar".

"Não, pois foi mais difícil de fazer e não houve um grande aprendizado".

"Não"

"Sim, na nossa opinião, a atividade de pesquisa no contexto escolar está mais clara".

Percepção dos alunos

Percepção dos alunos

Percepção dos alunos

Percepção dos alunos

Percepção dos alunos

Percepção dos alunos

"Muito mais, a pesquisa me ajudou a compreender o trabalho e aumentou nosso conhecimento

sobre a área trabalhada".

"Não, não achei, foi difícil".

"Sim, porque nos foi esclarecido o que realmente é uma pesquisa e como devemos efetuá-la corretamente".

"Sim, pois a gente pesquisou muito".

Percepção dos alunos

Percepção dos alunos

Percepção dos alunos

Percepção dos alunos

Percepção dos alunos

Percepção dos alunos

Percepção dos alunos

"Sim, além do que é assim que tem que ser os trabalhos, para adequar ao nível do ensino médio".

"Um pouco, ajudou a entender melhor o conteúdo, mas como foi uma pesquisa extensa em algu-

mas coisas ainda há uma certa dúvida".

Percepção dos alunos

Percepção dos alunos

Percepção dos alunos

Percepção dos alunos

Percepção dos alunos

Percepção dos alunos 
"Foi um pouco difícil, principalmente na hora de ter que pôr com nossas próprias palavras. A vantagem é que assim a gente aprofundou mais nosso conhecimento e aprendeu a pesquisar melhor e fazer um trabalho bem feito".

"A obtenção de experiência para próximos trabalhos desse tipo. Foi obviamente mais complicado e difícil, porém, bem desafiador".

"Foi bom fazer esse trabalho porque nos fez realmente pesquisar e entender o conteúdo, nos fez aprofundar o conhecimento".

"Não foi tão legal, pois é pouco tempo para muitas páginas. Sim, no aprendizado do futuro".

"Difícil. Não"

"No começo foi um pouco difícil, pois nunca tínhamos realizado algo tão complexo, porém acha-

mos que esse trabalho teve muitas vantagens, pois nos mostrou corretamente como uma pesquisa deve ser feita e como ela pode nos ajudar no âmbito escolar".

"Foi bom. Sim, pois assim nós nos preparamos melhor para o mundo trabalhista".

"Não. Foi difícil encontrar respostas, pois os sites que a gente procura não tinha a resposta clara, tinha que ler muitas coisas".

"Ocorreram dificuldades e dúvidas com os critérios e o conteúdo. Mas a vantagem é que já está nos preparando para os trabalhos do futuro".

"Difícil, pois o tema das propostas não tem muitos resultados na internet e não observamos nenhuma vantagem".

“Foi uma experiência, na qual pesquisamos sobre muitas coisas de um único título 'Ecumenismo'. São muitas coisas que fazem parte, então, foi um trabalho de bastante pesquisa e aprendizado. A vantagem é uma nova experiência de pesquisa e o aprendizado."

"Chato, pois tivemos pouco auxílio. Não"

"Tem sido mais difícil. Uma única vantagem que eu pelo menos vejo, é uma maior preparação para trabalhos de faculdade."

"Muito difícil, porém, tem a vantagem de estarmos nos preparando para o futuro".

"Deu mais trabalho, tivemos mais obstáculos, mas para a gente foi uma vantagem fazer o trabalho ao invés da prova, mesmo com critérios exigentes".

"Em minha opinião, os debates não foram muito uteis para a aprendizagem".

"Cada um, ao debater, aprende com os erros do outro".

\section{Percepção dos alunos}

Percepção dos alunos

Percepção dos alunos

Percepção dos alunos

Percepção dos alunos

Percepção dos alunos

Percepção dos alunos

Percepção dos alunos

Percepção dos alunos

Percepção dos alunos

Percepção dos alunos

Percepção dos alunos

Percepção dos alunos

Percepção dos alunos

Percepção dos alunos

Percepção dos alunos

Percepção dos alunos 
"Em nada".

Percepção dos alunos

"Os debates tem contribuído bastante para nossa aprendizagem, tanto na forma de pesquisar, quanto na forma de aprender a obter conhecimento".

"Trazem perguntas interessantes que muitas vezes nos ajudam a fazer o trabalho e a compreensão".

"Sim, as dúvidas e as conclusões das outras duplas nos ajudaram a melhorar o trabalho".

"Ficou mais claro o que fazer".

"Com os debates, nós aprendemos e melhoramos o nosso trabalho, e vimos a opinião de tercei-

ros".

"Os debates foram importantes para que soubéssemos como os trabalhos dos outros grupos estavam sendo feitos, para sabermos o que estava correto ou não, para que pudéssemos aprimorar nosso trabalho".

"Os debates nos fizeram refletir sobre as coisas".

Percepção dos alunos

"Para a gente aprender mais sobre o tema".

"Os debates não ajudaram muito".

"Cada um dando a sua opinião e seu pensamento sobre os detalhes do trabalho".

Percepção dos alunos

Percepção dos alunos

Percepção dos alunos

Percepção dos alunos

Percepção dos alunos

Percepção dos alunos

Percepção dos alunos

Percepção dos alunos

Percepção dos alunos

"Ajudou para que a gente soubesse fazer um bom trabalho e agora tentar sempre usar o mesmo modelo".

"Ajudou tanto no 'como pesquisar' e como aplicar o pesquisado no papel, além de reformular e transformar o pesquisado pela opinião e o entendimento".

"Ajudou para termos uma ideia de como elaborar o trabalho".

Percepção dos alunos

"Para auxiliar na organização do trabalho".

"Mostrando o caminho que a gente tinha que fazer".

"Foi importante, porque não sabíamos como o trabalho deveria ser realizado, e com o Guia, nós soubemos como fazer e quais eram as regras e modelo".

"Ele estabelece o que nós deveríamos fazer e o que não deveríamos fazer no trabalho".

"Indicou o que devíamos fazer e deu ideias".

"Ajudou bastante a separar o conteúdo e a saber o que pesquisar e como organizar".

Percepção dos alunos

Percepção dos alunos

Percepção dos alunos

Percepção dos alunos

"Ajudando e dando dicas de como fazer o trabalho para que ele fique de uma forma adequada e do Percepção dos alunos 
jeito que o professor pediu para fazer".

"Ele nos ajudou mostrando como deveria elaborar o trabalho, passo a passo".

Percepção dos alunos

"Nada, apenas tornou mais complicado".

Percepção dos alunos

"Foi um modelo".

"A estrutura de como elaborar".

Percepção dos alunos

"O Guia nos ajudou muito para formatar o trabalho".

Percepção dos alunos

Percepção dos alunos

"Por enquanto não temos dúvidas em ralação a atividade, porque pesquisamos muitas coisas e obtivemos um aprendizado em relação ao assunto".

"Todas as nossas dúvidas sobre o trabalho foram esclarecidas durante a realização do mesmo".

"Nenhuma, pois pesquisei muito e o Guia de Normalização ajudou muito".

"De que tipos de atalhos para se utilizar para tirar as questões e dúvidas".

"Nenhuma".

"No desenvolvimento do trabalho, tivemos várias dificuldades e apenas alguns acertos. Tivemos muita dificuldade de compreensão das questões e de onde achar as informações. No decorrer do trabalho, cada aluno ficou responsável por metade das questões, porém houve ajuda mútua de ambos os alunos. Estudamos em casa, pesquisando cada coisa e enviamos ao colega de trabalho para discutir o que já foi pesquisado. Também perguntamos ao professor para que nos auxiliasse, porém, como isso foi antes do recesso, as dificuldades surgiram novamente. No final, com ajuda das instruções de como organizar a estrutura do trabalho, finalizamos nossa pesquisa".

"As nossas buscas se deram pelo Google, e a partir daí para a Wikipédia e blogs. Além disso, também tivemos que transformar o que entendemos. Passamos por dificuldade ao encontrar os programas desenvolvidos por cada organização."

"O trabalho foi realizado tranquilamente e de forma eficaz. Eu e minha parceira pesquisamos, primeiramente, sobre o tema em sites e, após conter todas as informações necessárias, começamos a fazê-lo." Nós utilizamos todas as aulas disponibilizadas pelo professor para dar continuidade ao trabalho. Durante os debates efetuados entre o professor e a turma, aproveitamos para compreender melhor como o trabalho deveria ser realizado e para realizá-lo melhor utilizando as observações do professor em relação aos outros trabalhos. Eu e minha parceira, ao final do trabalho, decidimos ficar um dia à tarde no colégio, para podermos concluir o trabalho."

\section{Experiência}

\section{Experiência}

\section{Experiência}


"O nosso trabalho serviu para debatermos sobre o assunto e para trabalharmos em conjunto para terminarmos no prazo. Com isso, algumas coisas que nos atrapalharam como fazer o trabalho pois foi na época da semana de provas, nos atrapalhando a terminar. Além desse pequeno problema, não tivemos nenhuma dificuldade em relação ao conteúdo, o que ajudou também foi o Maurício falar bem inglês, com que fez que achássemos fácil sites relacionados."

"Nós, no começo conseguimos fazer normalmente, mas depois foi ficando mais difícil encontrar na internet sobre os assuntos, para ter uma ideia de como fazer. Óbvio que ficou mais difícil sem poder fazer $C T R L+C$ e $C T R L+V$. Tivemos muita dificuldade no Word, pois só pode usar o Word online. Os debates esclareceram sobre o que fazer. Tivemos muitas dúvidas e esclarecemos com o Álvaro e com o Murillo. Em casa, não tínhamos muito tempo, fiquei estudando para provas, mas com as aulas disponíveis conseguimos, em casa só precisamos concluir o trabalho."

"Durante a construção do trabalho, tentamos aproveitar o máximo de tempo no CRA. Nós tentamos procurar uma maior diversidade de sites. Tentamos esclarecer por meio de pesquisa, tentamos procurar notícias recentes sobre esses membros religiosos. Sobre os debates na sala Champagnat, conseguimos ter algumas informações bem importantes no nosso trabalho que ajudou na elaboração. Nós também utilizamos alguns conhecimentos de alguns que estudam a religião".

O tema do trabalho, ecumenismo, é um tema atual e importante, mas acima de tudo complexo. Fol um dos problemas enfrentados por nós. Para atingir os objetivos do trabalho, pesquisamos na internet sobre o assunto, e conseguimos consultar os pontos de vista de diversas religiões. Com isso, conseguimos concluir que todas as religiões praticam o ecumenismo de uma forma ou de outra. Além disso, a pesquisa nos mostrou a importância do ecumenismo na vida dos cristãos, a busca da unidade, pois impede que conflitos sejam proporcionados e confirma o intuito da religião." "Nós pesquisamos em vários sites contendo informações necessárias para fazer o trabalho. Também discutimos sobre como faríamos o trabalho e comparamos ideias com outras duplas. Tentamos combinar ideias para efetuar os tópicos para o trabalho. Porém, com todos esses aspectos, não conseguimos terminar o trabalho".

"Durante as nossas aulas, o professor disponibilizou tempo para buscar informações, proporcionou debates, respondeu dúvidas levadas a ele, etc. A busca de informações foi difícil, pois não existiam muitos sites que favoreciam a busca. Durante os debates, muitas dúvidas foram respondidas e puderam ser colocadas no trabalho. Ao levarmos dúvidas ao professor, ele respondeu claramente e nos ajudou. No nosso caso, não houve troca de informações com os colegas, mas não conseguimos terminar o trabalho em sala, e então tivemos que terminar em casa".

\begin{tabular}{|l|} 
Experiência \\
Experiência \\
Experiência \\
Experiência \\
Experiência \\
\hline
\end{tabular}


"Durante a realização deste trabalho, encontramos várias dificuldades, assim como tivemos vários debates sobre o trabalho em geral. Tivemos dificuldade ao pesquisar sobre as igrejas cristãs em diferentes níveis, porque era um componente do trabalho mais complexo e pelo fato de termos utilizado muitas fontes de pesquisa, para chegarmos ao resultado esperado. $\mathrm{O}$ trabalho foi ótimo e feito em dupla."

"Do início até o final, pois foi um trabalho irritante e desgastante. Foi um trabalho grande, 'de repente', em vez de fazer um trabalho de uma página ou no máximo duas, vem um trabalho de oito a 10 , e tinha poucas fontes para botar no trabalho. A maioria falava a mesma coisa, ou falava coisas que não tinham nada a ver com o trabalho ou com o tema. O que tinha que ver com o tema eram notícias e representantes do CONIC que iam conversar com outras religiões. Mas de resto, tudo certo."

"Fizemos o trabalho por meio de enciclopédias e sites na internet. Confessamos que foi um trabaIho difícil de se fazer, por não saber muito bem do que o assunto se tratava e as informações que obtivemos eram limitadas. Também foi difícil de elaborar o trabalho em questões físicas. O modo que o professor nos explicou era complexo e para sermos honestas, não entendemos qual foi o objetivo desse trabalho. Mas no final demos um jeito e conseguimos estruturar o trabalho e o deixamos razoável e o assunto bem trabalhado."

"Tivemos muita dificuldade em achar sites que explicassem com clareza o trabalho. Então, nós juntamos um pouco de cada coisa. Os acertos foram na hora do desenvolvimento. Cada um resumiu uma parte e juntamos tudo."

"Durante o trabalho, nós pesquisamos juntas para ambas aprenderem e entenderem sobre todo o assunto e não apenas uma parte, para aprofundarmos o conhecimento. Nós pesquisamos uma parte na escola e outras em casa, sendo a maioria baseado em sites específicos na internet."

\section{Experiência}

Experiência

"É um trabalho que eu não vou dizer pra você que foi fácil, na perspectiva de ter sido pra mim uma novidade também e pegar um trabalho tanto pra mim quanto para os meninos... Porque eles estavam acostumados a trabalhar com grupo. $E$ trabalho em grupo, normalmente mascara um pouco o trabalho, porque aí você tem um grupo de seis pessoas, você tem dois que muitas vezes carregam o trabalho nas costas e os outros quatro levam a nota. Quando a gente viu a possibilidade de fazer em dupla, eu achei interessante, mesmo sabendo que seria um volume muito grande e que o tema também era o mesmo tema pra todos, e eles também se inquietaram também, acho que por causa disso e o número de páginas pra alguns incomodava e o formato, tanto que isso fica claro nos 
questionários, que eles em um primeiro momento... eles sentem isso. A maior dificuldade é o número de páginas que eles tem que produzir."

"Essas seriam as duas coisas... porque esse, o número de páginas... ele aparece quando você coloca. A formatação, ela vai aparecer depois quando eles se vêm diante da dificuldade. E aí você tem experiências interessantes de meninos que buscaram pessoas próximas... o pai... alguém da família que pudesse ajudá-los... porque a gente pensa muita nessa questão da tecnologia, tal... 0 uso... e não sei o quê... É bacana isso... A escola acha que a gente está muito atrasado também em relação a algumas coisas. Mas quando se trata de um trabalho como esse, que você precisa de um programa como um Word, um Excel pra trabalhar com planilha... os nossos alunos chegam no $9^{\circ}$ ano e não sabem mexer. E aquilo que eu estava falando pra você hoje pela manhã... Eu não sei se a gente trabalharia com uma espécie de escalonamento, porque também chegar no 9ano e exigir deles algo que eles não estão habituados a fazer... realmente choca. E aí, os trabalhos ficam muito mais numa capacidade que eles tem de resumir as coisas e não realmente de ter muitas palavras deles mesmos... da pesquisa."

"É claro que tem uma coisa mais rebuscada de você trazer uma formatação que o Word favorece num trabalho como esse, mas o básico... mesmo o básico eles não sabiam."

"Além disso, eu vi também um aspecto... no meu caso, eu penso que para um aluno de 9aa... nós temos alunos excelentes, que são alunos muito autônomos, mas é uma fase também, que autonomia para um trabalho de pesquisa, ela precisa ser melhor conduzida, vamos dizer assim. Não que eu tenha conduzido de maneira ruim, não foi isso... porque eu abri espaço, deixei canais abertos, de e-mail , de tudo, pra gente ficar 'trocando figurinhas', no entanto, eu não obtive isso, esse retorno deles virem até a mim, e perguntarem: 'Álvaro tenho dúvida aqui, como é que faz isso daqui...', entendeu? Alguma coisa nesse sentido."

"É, e aí eu fiquei também me perguntando assim, porque que eles não foram tirar as dúvidas, assim... porque que eles não vieram tirar as dúvidas, se a gente tinha a possibilidade de uma aula aqui e outra aula lá no debate... Eu não entendi assim... em algum momento."

"Então... eles não têm a sensação de que ao fazerem o trabalho, eles estão estudando para a prova. E aí a gente vê relatos de alguns trabalhos de meninos que disseram que ajudaram a fazer a prova parcial. Então assim... eles começaram a entender... alguns começaram a entender que ao pesquisarem, fazerem o trabalho... isso não é um número talvez muito significativo, mas é interessante."

Percepção do professor

Percepção do professor

Percepção do professor

Percepção do professor

Percepção do professor 
"Compromete (a enturmação), e eu vejo... tem outro detalhe... que é a questão da própria maturidade dos meninos. Eu estava com um professor ali agora, o Gilberto, corrigindo provas deles. A frase dele: "Não tem jeito, essa turma não tem como...". Então assim, há uma dificuldade ali, que está inserida... uma questão... você tem a turma onde mais tem laudo. São 12, 13, sei lá, 14 meninos com laudo, numa turma de 40 alunos."

"Quando você trabalha, por exemplo, na Secretaria, com meninos assim laudeados, você tem que diminuir o número de alunos por turma. Você não pode trabalhar com um monte de gente com laudo... com a mesma quantidade. Isso também reflete, porque aí você não tem como acompanhar melhor. Eles são colocados também na "massa", coitados. E aí eles também não dão conta de fazer algumas coisas que outros já dão, tranquilamente. E aí o reflexo vai pra nota, vai pra essa falta de autonomia. Quando você passa um trabalho desse... foi uma das turmas que... além de demorar para entregar o trabalho, muitos nem entregaram ainda... duas semanas depois da data de entrega. Não entregaram... e o pior... não só a questão da data, mas tem um outra coisa... a qualidade dos trabalhos. Porque você vai encontrar trabalhos ruins nas outras turmas, mas lá (9B) é impressionante. A única turma que eu até agora, peguei um trabalho e não tive condições de avaliar. Porque ele não tinha absolutamente nada."

"Não foi tão significativa, porque... o resultado não se mostrou. Ou seja, aqueles que são bons, continuam bons. E aí, é claro nessa questão da maturidade. Hoje você tem uma turma, que pra mim... aí é uma questão da própria escola... e aí me revela isso. Porque não é comigo, mas são todos os professores que falam da turma especificamente. Que ela não tem maturidade acadêmica. E os bons que lá estão, não são meninos de liderança, que possam ajudar os colegas a levantar... dar a mão... tomar a frente... não, não conseguem fazer isso."

"Não, ela não entrou né (variável maturidade e número de alunos com laudos). A gente entrou na questão de que era uma turma que tinha dificuldade..."

"Então, o professor, com a carga de trabalho que ele já tem, de prova e tudo mais, ele não vai querer... se um trabalho desse não estiver dentro da estrutura da escola... o professor não vai se arriscar a fazer um negócio desse." 
Nessa etapa, pôde-se perceber o aparecimento das primeiras categorias oriundas das unidades de análise. As categorias passam a sintetizar o conteúdo expresso pelas unidades de análise. Para melhor entendimento, as categorias foram subdividas em "iniciais", "intermediárias" e "finais". As categorias iniciais e intermediárias podem ser visualizadas no Quadro 24.

Quadro 24 - Definição das Categorias Intermediárias

\begin{tabular}{|l|l|}
\hline \multicolumn{1}{|c|}{ CATEGORIAS INICIAIS } & CATEGORIAS INTERMEDIÁRIAS \\
\hline Aprofundamento do conteúdo & Mudança de comportamento \\
\hline Busca por informações relevantes & Produtividade \\
\hline Clareza do material apresentado & Orientações de estudo \\
\hline Experiência & Comprometimento \\
\hline Concentração no roteiro de estudo & Produtividade \\
\hline Direcionamento do professor & Orientações de estudo \\
\hline Esclarecimento de dúvidas & Orientações de estudo \\
\hline Explicação em sala & Orientações de estudo \\
\hline Ideia inicial sobre o assunto & Conhecimento prévio \\
\hline Interesse pela atividade & Comprometimento \\
\hline Participação nas aulas & Comprometimento \\
\hline Percepção do professor & Orientações de estudo \\
\hline Percepção dos alunos & Comprometimento \\
\hline $\begin{array}{l}\text { Registro e armazenamento de informa- } \\
\text { çoses }\end{array}$ & Produtividade \\
\hline $\begin{array}{l}\text { Troca de informações entre os estu- } \\
\text { dantes }\end{array}$ & Compartilhamento de informações \\
\hline Uso de ferramentas colaborativas & Trabalho colaborativo \\
\hline $\begin{array}{l}\text { Infraestrutura de informação e comuni- } \\
\text { cação }\end{array}$ & Uso de recursos tecnológicos \\
\hline
\end{tabular}

Fonte: Elaboração própria.

As categorias intermediárias generalizam algumas das categorias iniciais e as agrupam. O propósito mais uma vez foi reduzir o volume de informações que está agregada a uma unidade de análise, tornando-a mais simples, entretanto, ganhando mais representatividade. 
Quadro 25 - Definição das Categorias Finais

\begin{tabular}{|l|l|}
\hline \multicolumn{1}{|c|}{ CATEGORIAS INTERMEDIÁRIAS } & \multicolumn{1}{c|}{ CATEGORIAS FINAIS } \\
\hline Mudança de comportamento & Aprendizagem \\
\hline Produtividade & Letramento Informacional \\
\hline Orientações de estudo & Letramento Informacional \\
\hline Comprometimento & Aprendizagem \\
\hline Conhecimento prévio & Aprendizagem \\
\hline Compartilhamento de informações & Letramento Informacional \\
\hline Trabalho colaborativo & Letramento Informacional \\
\hline Uso de recursos tecnológicos & Letramento Informacional \\
\hline
\end{tabular}

Fonte: Elaboração própria.

A definição das categorias finais (Quadro 25) representa a etapa em que a síntese de informações chegou ao ponto mais relevante. Nesse caso, as categorias obtidas a partir do levantamento de dados qualitativos resultaram nas duas variáveis analisadas no decorrer desse estudo. Essa conversão identificou em que momentos os dados qualitativos retratavam a variável independente ("letramento informacional") e em que momentos representavam a variável dependente ("aprendizagem"). Isso demonstra sincronia entre a etapa quantitativa e qualitativa, permitindo a convergência dos dados obtidos em cada uma destas abordagens na triangulação de dados. A etapa de descrição e interpretação das categorias faz parte do próximo tópico. 


\section{APRESENTAÇÃO E ANÁLISE dOS RESULTADOS}

A apresentação dos dados obtidos nas etapas quantitativa e qualitativa, assim como a análise dos resultados estão diretamente relacionadas aos objetivos específicos desse estudo. Para melhor compreensão, cada análise foi feita conforme objetivo correspondente.

\section{Objetivo: Identificação dos conhecimentos prévios dos estudantes}

A identificação dos conhecimentos prévios dos estudantes, por meio dos mapas mentais, apontou o uso adequado de expressões relacionadas aos conteúdos e habilidades do LI definidos por Gasque (2012). Expressões como "reunir informações", "procurar várias fontes", "leitura", "interpretação", "entendimento", "levantamento de dados", "ver as diferentes visões sobre o assunto", "indicação da fonte da pesquisa", "chegar a algumas conclusões", "fazer resumos", "palavras-chave/estruturação de textos", "coleta de informações", "saber o objetivo (dividir os temas, planejamento, rascunho)", "introdução, desenvolvimento, conclusão", "selecionar fontes", "escrever" e "revisar", demonstram que os estudantes têm noções básicas de como ocorre uma pesquisa científica.

O questionário foi utilizado também para identificar os conhecimentos prévios dos estudantes. Os dados mostraram a preferência em se utilizar a internet para fazer trabalhos escolares. Essa opção relaciona-se, de acordo com Williamson et al. (2007), com a autoconfiança dos jovens. Entretanto, os estudantes apresentam pouca "sofisticação" na busca e uso de informações. Campello et al. (2000) relaciona o uso da internet à independência demonstrada pelos alunos ao navegarem na rede. Fato corroborado por Abreu e Nicolaci-daCosta (2006) ao afirmarem que o uso da rede favorece o "autodidatismo" e, consequentemente, a autonomia do estudante. A preferência pelo uso da rede também pode estar relacionada com a facilidade de acesso, como afirma Gasque (2008). Em estudo realizado com pesquisadores em formação, a autora argumenta que a internet é o primeiro recurso mais utilizado na busca de informações relacionadas à pesquisa. Acrescenta ainda que esse fato parece refletir transformações sociais e pode sinalizar a transição do meio físico (livros 
e bibliotecas) para o meio eletrônico (internet). Isso demonstra impacto significativo na forma de buscar e usar a informação.

Apesar de não ter sido analisado, a prática do plágio também foi identificada nas respostas dos estudantes informadas no questionário. Vale ressaltar que o professor sinalizou a referida prática como algo a ser evitado, conforme observação: "Uma das intenções desse trabalho é que vocês saiam do 'copia e cola'”. Quase metade dos participantes de ambos os grupos afirmou copiar partes do conteúdo sem citar os autores. Esse número ficou mais evidente quando a opção era copiar todo o conteúdo identificado como relevante. As pesquisas de Williamson et al. (2007) identificaram que mesmo os estudantes mais velhos e com mais experiência não conseguiram desenvolver boas práticas para evitar o plágio. Segundo os autores, o plágio é usado pelos estudantes como forma de economizar tempo e por exigir menos esforço. Campello et al. (2000) alertam que apesar de os estudantes mais velhos se preocuparem em elaborar melhor as informações obtidas na internet, o uso da rede não modificou a prática do plágio nas escolas. Isso demonstra pouco avanço na redução de cópias de informações nos trabalhos escolares e aponta dificuldade por parte dos estudantes em realizarem paráfrase, resumos e interpretação crítica do que escrevem.

No que concerne à indicação das fontes consultadas, mais da metade dos estudantes de ambos os grupos costuma informar o material em que retiraram a informação utilizada no trabalho, porém indicando apenas o endereço do site consultado. Em se tratando de formato impresso, os estudantes indicam apenas o título do livro e o nome do autor. Isso demonstra que os estudantes de ensino básico não possuem as competências necessárias de LI (MOKHTAR; MAJID; FOO, 2008).

As dificuldades apontadas pelos estudantes na elaboração do trabalho escrito relacionaram-se, majoritariamente, com a falta de orientação sobre como estruturar o texto. Apesar de o professor da disciplina e do bibliotecário da escola (responsável por esse estudo) terem se colocado à disposição dos estudantes no período de elaboração do trabalho, a consulta aos profissionais foi quase inexistente. Isso fez com que as dificuldades permanecessem. Esse fato também confirma, que apesar das incertezas que os estudantes encontram nos momentos iniciais de busca de informação, muitos deles normalmente não pro- 
curam ajuda de bibliotecários. Geralmente, confiam nos próprios amigos ou na instrução que acreditam ter sobre o assunto (KOVALIK, 2013). Aspecto também confirmado por Campelo et al. (2000) ao afirmarem que nos momentos em que os estudantes precisam de ajuda para usar a internet, pais, mães, irmãos e colegas são mais solicitados do que professores e bibliotecários.

Sobre isso, Gasque e Tescarolo (2010) afirmam que as pessoas agem, muitas vezes, de forma intuitiva quando buscam e usam informação. Williamson et al. (2007) também compartilham dessa visão ao afirmarem que a confiança dos estudantes em buscar informação, muitas vezes, é pouco fundamentada. Para eles, estudantes que tiveram mais contato com professores e bibliotecários foram mais influenciados com informações de qualidade.

Os dados do questionário mostraram que o conteúdo de LI mais utilizado por ambos os grupos relaciona-se à "orientação sobre pesquisa". O grupo quase experimental também apontou a "elaboração de relatórios" como bastante utilizado. Os demais conteúdos foram poucos citados. Por isso, percebe-se que precisam ser reforçados por meio de um acompanhamento mais próximo e de forma mediada para identificar e corrigir lacunas de aprendizagem como afirmam Mokhtar, Majid e Foo (2008). As notas dos indicadores do trabalho escrito demonstraram pouca efetividade na utilização desses conteúdos.

Em suma, observa-se pelos dados que os estudantes possuíam poucos conhecimentos prévios sobre as práticas de pesquisa, apesar de terem noções sobre o processo e as principais fases que constituem uma pesquisa. Isso pode ser explicado pelo fato da pouca valorização de práticas pedagógicas centradas em projetos e pesquisas. Sobre isso, Demo (2002) afirma que aspectos como a prática do professor, o ambiente da escola e da sala de aula, os trabaIhos realizados em grupo, o tempo de aula e a entrega de materiais prontos aos estudantes influenciam diretamente a prática da pesquisa.

Além disso, os professores não se vêm como pesquisadores, em virtude da crença de que pesquisa é algo especial e complexo, feita por gente especial, portanto, o próprio professor não estaria em condições de fazê-la. Assim, os professores não aprendem a pesquisar e, por conseguinte, não sabem ensinar como se faz uma pesquisa. Além disso, a sala de aula clássica, com aulas expositivas, não contribui para o desenvolvimento de pesquisas, pois impede que o estudante participe de forma ativa. $O$ tempo de aula reduzido também é visto 
como dificultador para a implementação de pesquisas no contexto escolar. As aulas precisam ser ampliadas para que as tarefas sejam realizadas com mais participação dos estudantes e maior profundidade. Por fim, entregar todo o material da aula pronto para os alunos, não contribui para o desenvolvimento da pesquisa em sala. É necessário que parte da procura por material seja uma iniciativa do aprendiz, garantindo a prática da investigação (DEMO, 2002).

Outra dificuldade a ser considerada, de acordo com Demo (2002), é o trabalho em equipe (ou em grupos), que muitas vezes, configura-se em perda de tempo ou em exploração de algum colega de sala. O desafio é transformar o trabalho em equipe em algo realmente produtivo, que aprimore a participação conjunta sem esquecer da evolução individual de cada aluno.

Lüdke e Cruz (2005), em estudo sobre a relação entre pesquisa e o professor da educação básica, mostram que as dificuldades de implementação da pesquisa relacionam-se a fatores como condições de trabalho do professor (contrato de trabalho e apoio financeiro), tempo específico para a pesquisa, infraestrutura física para realizar atividades de investigação e a própria visão que o docente tem do conceito de pesquisa. Além disso, a maioria dos professores se ressente da ausência de formação para a pesquisa nos cursos de graduação. Isso tem impacto significativo em sala de aula e confirma a necessidade da formação de professores pesquisadores. Segundo as autoras, para que a pesquisa na educação básica se aproxime da realidade escolar, precisa ser assumida como "atividade orgânica" da escola, isto é, como parte integrante do contexto escolar.

\section{Objetivo: Elaboração e aplicação do roteiro básico do programa de LI para o grupo do quase experimento e do guia de normalização de trabalhos para os estudantes}

Na presente pesquisa foi proposta, inicialmente, a elaboração e aplicação do roteiro básico de LI para o grupo quase experimental, contudo devido ao pouco tempo de aula e a possibilidade de comprometer o desenvolvimento de outros conteúdos da disciplina foram realizadas alterações. A proposta que previa orientações sobre texto científico, elaboração de pesquisa, seleção de material, elaboração de relatórios e citações foi transformada em um guia com 
a estrutura de um trabalho acadêmico. Esse material foi elaborado pelo pesquisador e entregue aos estudantes do grupo quase experimental, que receberam informações pontuais de como utilizá-lo.

Com base nos "conteúdos e habilidades de LI para o 9ำ ano do ensino fundamental", propostos por Gasque (2012), foram consideradas apenas as habilidades de "pesquisa", "citação bibliográfica" e "acompanhamento dos estudos em casa”. Em virtude dessa alteração, foram criados mais dois instrumentos de coleta de dados, quais sejam, relato e questionário de perguntas relacionadas ao processo de elaboração do trabalho escrito, ambos realizados pelos estudantes. Além disso, foram realizados debates com objetivo de esclarecer como ocorre o processo de elaboração da pesquisa.

As dificuldades encontradas em relação à estruturação e à implementação do roteiro básico de LI corroboram os argumentos apresentados por Gasque e Tescarolo (2010). Três das cinco principais dificuldades para consolidar o processo do $\mathrm{LI}$ no modelo educacional vigente puderam ser identificadas nessa pesquisa: a dificuldade de mudar a cultura pedagógica; a concepção de ensinoaprendizagem e a organização do currículo. Apesar de ter havido a abertura por parte do professor, a necessidade de cumprir as exigências do currículo, aplicar instrumentos avaliativos e estruturar outros procedimentos pedagógicos inviabilizou proposta mais aprofundada de se trabalhar com o LI. Tal fato pode ser confirmado por meio do relato do professor:

"O professor, com a carga de trabalho que já tem, de prova e tudo mais, não vai querer... se um trabalho desse não estiver dentro da estrutura da escola... o professor não vai se arriscar a fazer (...)".

Neste sentido, é importante considerar os resultados apresentados por Mokhtar, Majid e Foo (2008), ao afirmarem que as competências do LI não podem ser aprendidas simplesmente por meio de treinamentos rápidos ou transitórios. No caso específico dessa pesquisa, percebeu-se que o tempo para formação dos estudantes foi insuficiente. Com isso, buscou-se realizar uma proposta de orientação e de estímulo à aprendizagem, que abrangeu debates sobre a temática e a estruturação do trabalho. 
Objetivo: Envolvimento dos grupos participantes em processo de resolução de problemas/investigação.

No que se refere ao envolvimento dos grupos em processo de resolução de problemas/investigação, os dados coletados por meio da observação demonstraram a existência de dificuldades apresentadas por partes dos estudantes. Entre elas, pode-se citar: dispersão nas atividades, desorganização com os estudos, dificuldades na organização da informação e com o tema e a proposta do trabalho.

Ainda com base nas dificuldades encontradas, percebeu-se que apesar de terem sido instruídos a buscarem ajuda nos momentos em que precisassem, os estudantes pouco o fizeram, fato que confirma mais uma vez os resultados apresentados por Kovalik (2013). O relato do professor ilustra a questão:

"Eu fiquei me perguntando (...), porque eles não foram tirar as dúvidas, (...) porque não vieram tirar as dúvidas, se a gente tinha a possibilidade de uma aula aqui e outra aula lá no debate... Eu não entendi (...)"; "eu não obtive esse retorno deles virem até mim e perguntarem: 'Professor, tenho dúvida aqui, como é que faz isso daqui...', entendeu?".

Em relação aos resultados apresentados, uma hipótese para explicá-los diz respeito à cultura de aprendizagem. Os estudantes, em geral, estão acostumados a receberem informações prontas, não questionarem e serem mais passivos do que ativos. Ademais, muitos estão preocupados somente com a nota e não com a aprendizagem. Evidentemente isso pode influenciar o comportamento dos estudantes. Tal comportamento também pode ser explicado pela falta de percepção dos estudantes em relação aos próprios processos mentais e ao entendimento de como se aprende. O bom rendimento escolar está associado, em parte, a essa percepção. A capacidade de pensar sobre a própria aprendizagem é definida como "aprendizagem ativa" ou "metacognição" (BRANSFORD; BROWN; COCKING, 2007). Para Boruchovitch (1999), entender como ocorre a própria aprendizagem faz com que o aprendiz monitore constantemente a sua compreensão, o que possibilita demonstrar que não entendeu algo. Isso faz com que o estudante se mantenha em estado de alerta, 
prestando atenção nas aulas, avaliando os resultados em provas e com uma postura proativa na busca e no uso da informação. A mudança da atual cultura de aprendizagem pode estar associada, portanto, à necessidade de se aprender a aprender, que abrange a compreensão da importância da metacognição.

\section{Objetivo: Comparação dos níveis de aprendizagem dos grupos participan- tes do quase experimento.}

A comparação dos níveis de aprendizagem entre os grupos participantes do estudo não apontou melhora no uso dos termos relacionados com a pesquisa, de acordo com a segunda elaboração do mapa mental. Isso ficou evidente com o uso das expressões apresentadas pelos aprendizes do grupo quase experimental, tais como: "fontes, internet, livros, pessoas entendidas no assunto", "resumo ou história sobre determinado assunto", "levantamento de dados", "seleção dos sites", "coleta de informações", "métodos, mapas conceituais, resumos" e "entendimento do tema". Esses termos ao serem comparados com os conteúdos e habilidades do LI, propostos por Gasque (2012), não apresentaram melhora significativa.

Em relação às notas obtidas no trabalho final, os resultados mostraram que a quantidade média de estudantes que obtiveram nota em pelo menos um dos indicadores foi maior no grupo controle do que no grupo quase experimental. Outrossim, o grupo quase experimental apresentou notas menores na avaliação de cada indicador comparadas ao grupo controle. A partir de análise mais detalhada, confirmaram-se efeitos significativos nos indicadores 3B (informação atualizada), 3C (ideias e soluções viáveis) e 4B (escrita). Isso mostra que a diferença de nota entre ambos os grupos nos três indicadores foi considerável.

Mais uma vez, ressalta-se como argumentado anteriormente que o tempo disponível para a aprendizagem deve ser suficiente para que ela ocorra de forma adequada (MOKHTAR; MAJID; FOO, 2008), bem como deve-se considerar que os fatores relacionados à cultura institucional, à concepção de ensinoaprendizagem e à organização curricular (GASQUE; TESCAROLO, 2010) influenciam na implementação das atividades de LI. 
Objetivo: Identificação de como o LI interferiu na aprendizagem dos estudantes.

Os dados referentes à identificação da influência do LI na aprendizagem dos estudantes demonstraram que, na comparação dos fatores "aprendizagem mediada" e "aprendizagem não-mediada", definidas no modelo teórico dessa pesquisa, a proposta de LI direcionada ao grupo quase experimental de alunos do 9 ano do ensino fundamental não foi satisfatória. Assim, a hipótese de pesquisa $H_{1}$, a saber, "A aprendizagem dos estudantes de 9o ano do ensino fundamental está relacionada positivamente com a utilização de técnicas de LI em situação de resolução de problemas/investigação", não foi confirmada.

Entre os fatores que podem ter levado a esse resultado foi possível identificar duas variáveis importantes que não foram consideradas no início do trabalho. A primeira delas foi o aspecto da maturidade dos estudantes e a segunda, o fato de vários participantes do grupo quase experimental apresentarem laudos para problemas como déficit de atenção, como se observa pelo relato do professor:

"E aí, é claro, há essa questão da maturidade. Hoje, você tem uma turma, que pra mim... é uma questão da própria escola... e me revela isso. Isso não é só comigo, mas com todos os professores que falam da turma especificamente. A turma não tem maturidade acadêmica. E os bons que lá estão, não são meninos de liderança, que podem ajudar os colegas a levantar... dar a mão... tomar a frente... não, não conseguem fazer isso."

A segunda variável também foi confirmada com dados do relato do professor:

"Você tem a turma em que há mais laudos. São 12, 13, sei lá, 14 meninos com laudo, numa turma de 40 alunos."

"Quando você trabalha, por exemplo, na Secretaria, com meninos assim laudeados, você diminui o número de alunos por turma. Não se pode trabalhar 
com um monte de gente com laudo... com a mesma quantidade. Isso também reflete, porque você não tem como acompanhar melhor. Eles são colocados também na 'massa', coitados, e não dão conta de fazer algumas coisas que outros já dão, tranquilamente. O reflexo disso ocorre na nota, na falta de autonomia. Quando você passa um trabalho desse... foi uma das turmas que... além de demorar para entregar o trabalho, muitos nem entregaram ainda... duas semanas depois da data de entrega. Não entregaram... e o pior... não só a questão da data, mas tem uma outra coisa... a qualidade dos trabalhos. Você vai encontrar trabalhos ruins nas outras turmas, mas lá [grupo quase experimental] é impressionante. A única turma que eu até agora, peguei um trabalho e não tive condições de avaliar, porque ele não tinha absolutamente nada."

$\mathrm{O}$ aspecto da maturidade pode ser entendido como o comprometimento dos estudantes com a atividade proposta. Apesar de todas as orientações feitas e da disponibilidade do professor e do pesquisador para auxiliar os estudantes, muitos deles não levaram o trabalho a sério. Isso demonstra que o processo de aprendizagem requer do aprendiz mais compromisso e foco nos estudos. Tal fato também pode ser exemplificado com os dados:

"Em minha opinião, os debates não foram muito úteis para a aprendizagem".

"Os debates não ajudaram muito".

Sob o ponto de vista dos estudantes com laudo, apesar de ter sido considerado uma variável importante, é necessário reconhecer que tanto a disciplina escolhida, como a metodologia aplicada para trabalhar com o LI podem não ter sido as mais adequadas, isto é, podem ter impactado os resultados de forma negativa.

Apesar de o grupo quase experimental ter demonstrado baixo desempenho nas habilidades analisadas, observou-se no relato dos estudantes mudança significativa no comportamento em relação à aprendizagem. Isso confirma que a aprendizagem diz respeito às mudanças "no potencial de comportamento", oriundas da experiência (LEFRANÇOIS, 2008). Vale ressaltar que grande 
parte dos estudantes relatou experiências positivas com relação ao processo de pesquisa. Entre elas, podem ser citadas:

"Foi um trabalho extenso e complexo, mas que fez com que a gente tivesse que pesquisar mais, consequentemente, aprofundar nosso conhecimento."

"(...) nos foi esclarecido o que realmente é uma pesquisa e como devemos efetuá-la corretamente".

"Ocorreram dificuldades e dúvidas com os critérios e o conteúdo, mas a vantagem é que já está nos preparando para os trabalhos do futuro".

"Os debates contribuíram bastante para nossa aprendizagem, tanto na forma de pesquisar, quanto na forma de aprender a obter conhecimento".

Mesmo com pouco tempo para aprendizagem de alguns dos conteúdos de LI, ainda assim, as experiências foram significativas para maioria dos estudantes. Estudos como os de Hsieh e Holden (2010) demonstraram que uma única sessão de instrução de LI pode ter efeito positivo para a aprendizagem. Em relação ao significado do processo de pesquisa para os estudantes, a pesquisa realizada por Gasque (2008) mostrou que grande parte dos mestrandos e doutorandos que vivenciou a pesquisa na educação básica avaliou-a como significativa. Contudo, Kovalik (2013) acrescenta que as experiências de pesquisa para serem mais significativas na escola devem estar relacionadas ao uso efetivo da biblioteca. Isto é, os estudantes têm melhor desempenho ao utilizar os recursos da biblioteca para elaboração dos projetos de pesquisa. Nesse sentido, é possível afirmar que experiências envolvendo pesquisa escolar contribuem efetivamente para a aprendizagem. 


\section{CONCLUSÕES E RECOMENDAÇÕES}

Os resultados desse estudo indicaram que a proposta de LI aplicada ao grupo quase experimental não foi satisfatória. Demonstraram também que os estudantes da educação básica, sujeitos da pesquisa, ainda não possuem as competências de LI consideradas necessárias aos estudantes do 9o ano. A hipótese da pesquisa $\mathbf{H}_{1}$ não pôde ser confirmada, visto que a influência da formação de LI na aprendizagem dos estudantes foi pequena. As notas dos estudantes do grupo quase experimental foram inferiores às do grupo controle. Isso pode ter ocorrido em virtude da existência de variáveis não previstas no modelo teórico da pesquisa ou mesmo pela escolha da disciplina e da metodologia de trabalho com o LI. Além disso, um desafio extra ocorrido nesse processo foi o de adequar-se ao padrão formal de sala de aula e propor uma atividade em que os alunos tivessem participação efetiva. Sem a colaboração do professor da disciplina Ensino Religioso, isso certamente não teria sido possível.

Mesmo com resultados pouco satisfatórios em termos de conceitos e procedimentos, percebeu-se que o processo de aprendizagem dos estudantes no que concerne ao comportamento foi alterado positivamente. Os relatos dos estudantes apontam que eles conseguiram superar algumas dificuldades encontradas no início da pesquisa. Isso demonstra que eles obtiveram mais segurança e autonomia em lidar com o processo de pesquisa. Demonstra também, que o trabalho colaborativo pode ter contribuído na mudança de comportamento e consequentemente na melhoria do processo de aprendizagem.

É importante considerar também que a proposta de pesquisa permitiu ao professor da disciplina repensar vários momentos da aula. Em muitos aspectos, o trabalho e a ação em sala foram redirecionados, o que provavelmente favoreceu a aprendizagem dos estudantes. Sair do modelo de aula considerado tradicional contribuiu para uma postura diferente por parte dos aprendizes, 0 que demonstra ser uma ótima estratégia de aprendizagem. Entende-se que tal modelo, caracterizado principalmente por aulas expositivas e de reprodução de conteúdo, não permite que os estudantes avancem na construção do seu próprio conhecimento. Diante disso, entende-se que a proposta de trabalho permitiu avança considerável neste aspecto. 
O fato de o processo de implementação do LI não ter ocorrido de forma adequada requer repensar as práticas tradicionais. Isso porque é necessário reconhecer a forte relação entre o sucesso dos programas de LI e fatores como cultura institucional, concepção de ensino-aprendizagem e organização curricular, como apontados por Gasque e Tescarolo (2010). Tais práticas não devem, entretanto, ser implementadas como treinamentos ou atividades pontuais, ao contrário, para que sejam eficazes e eficientes devem ser realizadas em um período de tempo mais amplo, idealmente, iniciando-se na educação infantil e ocorrendo ao longo do ensino fundamental e médio.

É primordial que se reconheça a necessidade de que o LI seja ensinado e reforçado gradualmente, e que esta prática seja integrada ao currículo escolar favorecendo a mudança da atual cultura de aprendizagem. $O$ uso da pesquisa em sala de aula, com mais frequência, pode garantir ao professor maior segurança e estímulo para implementar essas novas propostas de ensinoaprendizagem. Por sua vez, os estudantes precisam reconhecer que são responsáveis pela própria aprendizagem, ou seja, devem observar e monitorar a própria aprendizagem, mudando a condição de sujeito passivo para ativo e autônomo. Isto, certamente irá assegurar a continuidade da aprendizagem dos estudantes na aplicação das habilidades de LI e contribuirá para que o conceito de aprendizagem ao longo da vida, o aprender a aprender, seja efetivamente incorporado por eles.

Ressalta-se também que a utilização da metodologia dos métodos mistos foi fundamental para se obter uma visão ampla do contexto da pesquisa. Em casos de pesquisas complexas, em que há necessidade de se obter uma visão multifacetada, o uso de várias abordagens, métodos e técnicas propiciam maior qualidade e quantidade dos dados a serem analisados.

Por fim, espera-se que esse estudo contribua como instrumento importante na elaboração de estratégias para se implementar o LI na educação básica. Além disso, recomenda-se que mais pesquisas centradas no impacto dos programas de LI sobre a aprendizagem sejam realizadas. 


\section{REFERÊNCIAS}

ABREU, Rosane de Albuquerque dos Santos; NICOLACI-DA-COSTA, Ana Maria. Mudanças geradas pela internet no cotidiano escolar: as relações dos professores. Paidéia, Riberão Preto, v.16, n. 33, p.193-203, 2006.

AMERICAN LIBRARY ASSOCIATION. Association of College and Research Libraries. Information Literacy Competency Standards for Higher Education. Chicago, 2000. 16p.

BHATT, R.K. Information literacy models and competencies development initiatives in India. 2nd International Conference of Asian Special Libraries. Tokyo, Japan. (2011, Feb.10-12). Disponível em: <http://units.sla.org/chapter/cas/ICoASL-2011\%20Procedings-Day2.htm>. Acesso em: 11 ago. 2014.

BORUCHOVITCH, Evely. Estratégias de aprendizagem e desempenho escolar: considerações para a prática educacional. Psicologia: Reflexão e Crítica, Porto Alegre, v.12, n.2, 1999.

BRANSFORD, John D; BROWN, Ann L.; COCKING, Rodney R. (org.). Como as pessoas aprendem: cérebro, mente, experiência e escola. São Paulo: SENAC, 2007.

BRASIL. Lei 9.394, de 20 de dezembro de 1996. Disponível em: <http://www.planalto.gov.br/ccivil_03/leis//9394.htm>. Acesso em: 13 jul. 2014.

BRASIL. Lei 9.475, de 22 de julho de 1997. Disponível em: <http://www.planalto.gov.br/ccivil_03/Leis/19475.htm>. Acesso em: 5 jul. 2014.

CAMPELLO, Bernardete Santos. Letramento informacional no Brasil: práticas educativas de bibliotecários em escolas de ensino básico. 2009, 209f. Tese (Doutorado em Ciência da Informação) - Universidade Federal de Minas Gerais, Minas Gerais, 2009. 
. O movimento da competência informacional: uma perspectiva para o letramento informacional. Ciência da Informação, Brasília, v.32, n.3, p.28-37, set./dez. 2003.

CAMPELLO, B. et al. A internet na pesquisa escolar: um panorama do uso da web por alunos do ensino fundamental. In: CONGRESSO BRASILEIRO DE BIBLIOTECONMOMIA E DOCUMENTAÇÃO, 19, 2000, Porto Alegre. Anais... Porto Alegre: Associação Rio-Grandense de Bibliotecários, 2000. Disponível em: <http://gebe.eci.ufmg.br/downloads/T029.pdf>. Acesso em: 04 jan. 2015.

CAPURRO, R.; HJORLAND, B. O conceito de informação. Perspectivas em Ciência da Informação, v.12, n.1, p.148-207, jan./abr. 2007.

CLAXTON, Guy. Introdução: aprendendo para a vida. In: O desafio da aprendizagem ao longo da vida. São Paulo: Artmed, 2005. p.13-24.

COHEN, Louis; MANION, Lawrence; MORRISON, Keith. Action reserch. In: Reserch methods in education. $7^{\text {th }}$. London: New York: Routledge, 2011, p.344-361.

CAPURRO, R.; HJORLAND, B. O conceito de informação. Perspectivas em Ciência da Informação, Belo Horizonte, v.12, n.1, p.148-207, jan./abr. 2007.

COUTINHO, Clara Pereira. Aspectos metodológicos da investigação em tecnologia educativa em Portugal (1985-2000). Universidade do Minho. 2006. Disponível em: <http://hdl.handle.net/1822/6497>. Acesso em: 22 mar. 2014.

A influência das teorias cognitivas na investigação em tecnologia educativa: pressupostos teóricos e metodológicos, expectativas e resultados. Revista Portuguesa de Educação, Braga, Portugal, v.21, n.1, p.101-127, 2008.

CUNHA, Murillo Bastos da; CAVALCANTI, Cordélia R. de Oliveira. Dicionário de Biblioteconomia e Arquivologia. Brasília: Briquet de Lemos, 2008. 
CRESWELL, John W. Projeto de pesquisa: métodos qualitativo, quantitativo e misto. Porto Alegre: Artmed, 2010. 296p.

DEMO, PEDRO. O desafio de educar pela pesquisa na educação básica. In: . Educar pela pesquisa. 5.ed. Campinas, SP: Autores Associados, 2002. p.5-38.

DUDZIAK, Elizabeth Adriana. Information literacy: princípios, filosofia e prática. Ciência da Informação, Brasília, v. 32, n. 1, p. 23-35, jan./abr. 2003.

ENGEL, Guido Irineu. Pesquisa-ação. Educar em revista. Curitiba, n.16, p.181-191. 2000.

FREIRE, Gustavo Henrique. Ciência da informação: temática, histórias e fundamentos. Perspectivas em Ciência da Informação, Belo Horizonte, v.11, n.1, jan./abr. 2006.

GASQUE, Kelley Cristine Gonçalves Dias. O pensamento reflexivo na busca e no uso da informação na comunicação científica. 2008, 240p. Tese (Doutorado em Ciência da Informação) - Universidade de Brasília, Brasília, 2008.

Pesquisa, reflexão e aprendizagem. Brasília: FCI/UNB, 2012.

GASQUE, Kelley Cristine Gonçalves Dias; TESCAROLO, Ricardo. Desafios para implementar o letramento informacional na educação básica. Educação em Revista, UFMG, Belo Horizonte, v. 26, n. 1, abr. 2010. Disponível em: $<$ http://www.scielo.br/scielo.php?pid=S0102-46982010000100003\&script=sci_a rttext>. Acesso em: 08 set. 2012.

GASQUE, Kelley Cristine Gonçalves Dias; CUNHA, Marcos Vinícius da. A epistemologia de John Dewey e o letramento informacional. TransInformação, Campinas, 22(2): 139-146, maio/ago. 2010. 
HEPWORTH, Mark e WALTON, Geoff. Teaching Information Literacy for Inquiry-Based Learning. Cambridge: Woodhead Publishing, 2009.

HERNÁNDEZ SAMPIERE, Roberto; FERNÁNDEZ COLLADO, Carlos; BAPTISTA LUCIO, Maria del Pilar. Metodologia de pesquisa. 5.ed. Porto Alegre: Penso, 2013. 623p.

HOUDÉ, Olivier. Aprendizagem. In: Dicionário de educação. Petrópolis, RJ: Vozes, 2011.

HSIEH, Ma Lei; HOLDEN, Hugh A. The effectiveness of a university's singlesession information literacy instruction. Reference Services Review, v. 38, n. 3, p. 458-473, 2010.

KANDEL, Eric. Em busca da memória. São Paulo: Companhia das Letras, 2009.

KOTHARI, C.R. Research methodology: an introduction. In: Research Methodology: methods \& techniques. $2^{\text {th }}$ Revised Edition. New Delhi: New Age International Publishers, (02004. p.1-23.

KOVALIK, Cindy. Information literacy and High school seniors: perceptions of the research process. School Library Reserch, v.16, 2013. Disponível em:< http://www.ala.org/aasl/sites/ala.org.aasl/files/content/aas/pubsandjournals/slr/ vol16/SLR_Information_Literacy_High_School_Seniors_V16.pdf>. Acesso em: 15 jan. 2014.

KUHLTHAU, C. C. Rethinking libraries for the information age school: vital roles in inquiry learning. In: IASL CONFERENCE, 2001, Auckland. Keynote paper... Auckland, 2001. Disponível em: http://www.iaslonline.org/events/conf/keynote-kuhlthau2001.html. Acesso em: 16 jan. 2014.

Como usar a biblioteca na escola: um programa de atividades para o ensino fundamental. Belo Horizonte: Autêntica, 2002. 303p. 
LEFRANÇOIS, Guy R. Teorias da Aprendizagem. São Paulo: Cengage Learning, 2008.

LIMA, Gercina Ângela Borém. Mapa conceitual como ferramenta para organização do conhecimento em sistema de hipertextos e seus aspectos cognitivos. Perspectivas em Ciência da Informação, Belo Horizonte, v.9, n.2, p.134-145, jul./dez. 2004.

LIMBERG, L. Experiencing information seeking and learning: a study of the interaction between two phenomena. Information Research, Borå, v.5, n.1, p.119, oct. 1999.

LÜDKE, Menga; CRUZ, Giseli Barreto. Aproximando universidade e escola de educação básica pela pesquisa. Cadernos de pesquisa, v.35, n.125, p.81109, maio/ago. 2005.

MEIRELES, M. R. G.; CENDÓN, B. V. Aplicação prática dos processos de análise de conteúdo e de análise de citações em artigos relacionados às redes neurais artificiais. Inf. Inf., Londrina, v.15, n.2, p.77-93, jul./dez. 2010.

MOKHTAR, I. A.; MAJID, S.; FOO, S. Information literacy education: applications of mediated learning and multiple intelligences. Library \& Information Science Research, 30 (2008), 195-206. Disponível em: < http://www.ntu.edu.sg/home/sfoo/publications/2008/2008LISR-Publisher.pdf>. Acesso em: 15 jan. 2014.

MORAES, Roque. Análise de conteúdo. Revista Educação, Porto Alegre, v.22, n.37, p.7-32, 1999.

PILETTI, Nelson. Algumas teorias. In: Aprendizagem: teoria e prática. São Paulo: Contexto, 2013. p.15-43. 
PINHEIRO, Lena Vania Ribeiro; LOUREIRO, José Mauro Matheus. Traçados e limites da ciência da informação. Ciência da Informação, Brasília, v.24, n.1, p.1-19, 1995.

POZO, Juan I. Quando nada no animal nos é estranho: da aprendizagem animal à aprendizagem humana. In: Aquisição de conhecimento: quando a carne se faz verbo. Porto Alegre: Artmed, 2004. p.17-38.

ROZADOS, Helen Beatriz Frota. A Ciência da Informação em sua aproximação com as ciências cognitivas. Em questão, Porto Alegre, v.9, n.1, p.79-94, jan./jun. 2003.

SALLEH, M. I. M. [et al.]. Measuring the effect of information literacy on the undergraduates' academic performance in higher education. International Conference on Social Science and Humanity. IACSIT Press, Singapore, vol. 5, p. 506510, 2011. Disponível em:< http://www.ipedr.com/vol5/no2/112-H10267.pdf>. Acesso em: 15 jan. 2014.

SEKARAN, Uma. The research process: step 6: elements of research design. In: Research methods for business: a skill-building approach. $4^{\text {th }}$ ed. New York: John Wiley \& Sons, (02003. p.116-140.

TRIPP, David. Pesquisa-ação: uma introdução metodológica. Educação e Pesquisa, São Paulo, v.31, n.3, p.443-466, set./dez. 2005.

WILLIAMSON, K. [et al.]. Information seeking and use by secondary students: the link between good price and the avoidance of plagiarism. School Library Media Research, v.10, p.1-13, 2007. Disponível em:< http://bilby.unilinc.edu.au/webclient/StreamGate?folder_id=0\&dvs=1391347877 094 503\&usePid1=true\&usePid2=true >. Acesso em: 2 fev. 2014.

WURMAN, Richard S. Ansiedade de informação na era da internet. In: Ansiedade de informação 2: um guia para quem comunica e dá instruções. São Paulo: Editora de Cultura, 2005. p.3-22. 
APÊNDICE 


\section{APÊNDICE A - MODELO DE QUESTIONÁRIO}

Bom dia (Boa tarde):

Este questionário faz parte de um estudo de mestrado que busca analisar a aprendizagem dos estudantes no contexto da educação básica. É composto por perguntas simples e rápidas de serem respondidas. Sua contribuição será de grande valia para a obtenção de dados relevantes para a conclusão da pesquisa. Peço que responda as questões com a maior sinceridade possível. Os números presentes na frente dos itens são apenas para controle.

Grato pela colaboração!

A - Com que frequência você usa a internet para fazer trabalhos escolares? (Marcar apenas uma opção)

( ) 1 Uso a internet em mais de $80 \%$ dos trabalhos solicitados pelos professores.

( ) 2 Uso a internet para fazer metade dos trabalhos solicitados pelos professores.

( ) 3 Uso a internet em menos da metade dos trabalhos solicitados pelos professores.

( ) 4 Não uso a internet (se marcou este item, vá para a questão C).

( ) 5 Outros

B - Se utiliza a internet para fazer trabalhos escritos, que tipo de sites costuma consultar no momento da pesquisa? (Marcar mais de uma opção, se for o caso).

( ) 1 Enciclopédias online (ex. Wikipédia).

( ) 2 Sites governamentais (ex. IBGE).

( ) 3 Sites educacionais (ex. Almanaque Abril).

( ) 4 Sites comerciais (ex. UOL).

( ) 5 Não sei dizer.

C-Que outros recursos, além da internet, utiliza para fazer trabalhos escritos? (Marque os três itens que utiliza com mais frequência)

( ) 1 Livros.

( ) 2 Enciclopédias.

( ) 3 Dicionários.

( ) 4 Almanaques.

( ) 5 Textos de apoio indicados pelo professor.

( ) 6 Outros

D - Ao identificar informações importantes para o trabalho escrito, o que você faz? (Marque apenas uma opção)

( ) 1 Copio todo o conteúdo que preciso.

( ) 2 Copio apenas algumas partes do conteúdo que preciso.

( ) 3 Copio algumas partes e também escrevo o que entendi. 
( ) 4 Não copio nada, apenas escrevo o que entendi sobre o assunto.

E - Você costuma indicar as fontes (fazer citação) que utilizou para a elaboração do trabalho escrito? (Marque Sim ou Não e justifique).

( ) $1 \mathrm{Sim}$

( ) 2 Não (Se a resposta for Não, justifique e vá para a questão G)

Por quê?

$\mathrm{F}$ - Se costuma indicar as fontes, como faz isso no trabalho escrito?

(Material da internet - marcar apenas uma opção)

( ) 1 Indico apenas o site que acessei.

( ) 2 Além do site, indico a data em que acessei o material.

( ) 3 Além do site e da data, também indico o nome do autor do texto que acessei.

(Material impresso - marcar apenas uma opção)

( ) 4 Indico apenas o nome do livro que utilizei.

( ) 5 Além do nome do livro, indico o nome do autor.

( ) 6 Além do nome do livro e do autor, também indico o nome da editora e o ano em que o livro foi publicado.

G - Ao elaborar um trabalho escrito, que tipo de dificuldades você sente? (Marque as duas opções mais importantes para você).

( ) 1 Falta de orientação sobre o conteúdo do trabalho.

( ) 2 Falta de orientação sobre como e onde buscar informações.

( ) 3 Falta de orientação sobre como estruturar o texto.

( ) 4 Falta de orientação sobre como fazer citações.

( ) 5 Não sinto nenhuma dificuldade.

H - Qual ou quais conteúdos abaixo você utiliza para a realização de trabalhos escolares? (Marcar mais de uma opção, se for o caso).

( ) 1 Orientações sobre pesquisa (uso de fontes de informação variadas; divisão do trabalho em introdução, desenvolvimento e conclusão; uso de roteiro de pesquisa; texto relacionando as informações utilizadas).

( ) 2 Elaboração de relatórios (relato das conclusões de uma pesquisa ou trabalho).

( ) 3 Elaboração de resenhas (descrição de um texto, feita com detalhes).

( ) 4 Elaboração de citações (materiais utilizados para elaborar um texto).

( ) 5 Outros

Obrigado por sua participação! 


\section{APÊNDICE B - ROTEIRO DE OBSERVAÇÃO}

\begin{tabular}{|c|c|}
\hline ITENS A CONSIDERAR & DESCRIÇÃO \\
\hline \multirow{3}{*}{ Comprometimento } & Interesse pela atividade \\
\hline & Importância dada ao tema proposto \\
\hline & Participação nas aulas \\
\hline \multirow[t]{2}{*}{ Fontes de informação } & Materiais de consulta \\
\hline & Sites indicados \\
\hline \multirow[t]{2}{*}{ Foco na atividade } & $\begin{array}{l}\text { Alunos se concentram no roteiro de estu- } \\
\text { do }\end{array}$ \\
\hline & $\begin{array}{l}\text { Preocupações dos alunos no momento da } \\
\text { atividade }\end{array}$ \\
\hline \multirow{2}{*}{$\begin{array}{l}\text { Infra-estrutura de informação e comu- } \\
\text { nicação }\end{array}$} & $\begin{array}{l}\text { Recursos tecnológicos existentes (com- } \\
\text { putadores, internet, rede sem fio etc.) }\end{array}$ \\
\hline & Biblioteca com material pertinente \\
\hline \multirow{4}{*}{ Orientações iniciais } & Dúvidas levadas ao professor \\
\hline & Explicação em sala \\
\hline & Esclarecimentos de dúvidas \\
\hline & $\begin{array}{l}\text { Clareza do material apresentado (roteiro } \\
\text { e apresentação) }\end{array}$ \\
\hline \multirow{5}{*}{ Produtividade } & Busca por informações relevantes \\
\hline & Registro das informações selecionadas \\
\hline & Registro de informações \\
\hline & $\begin{array}{l}\text { Uso de dispositivos móveis no momento } \\
\text { da busca por informações }\end{array}$ \\
\hline & $\begin{array}{l}\text { Armazenamento de informações selecio- } \\
\text { nadas (arquivos salvos em pendrive, e- } \\
\text { mail, etc.) }\end{array}$ \\
\hline \multirow{3}{*}{ Trabalho colaborativo } & Troca de informações entre os estudantes \\
\hline & Uso de ferramentas colaborativas \\
\hline & Interação com os colegas \\
\hline
\end{tabular}




\section{APÊNDICE C - ROTEIRO DE AVALIAÇÃO DO TRABALHO}

Selecionar e avaliar fontes de informação

\begin{tabular}{|l|r|r|}
\hline \multicolumn{1}{|c|}{ INDICADOR } & VALOR & NOTA \\
\hline a) Usa fontes de informação variadas & 0,2 & \\
\hline \begin{tabular}{l|r|r|} 
b) Seleciona fontes de informação apropriadas para diferentes necessidades de \\
informação
\end{tabular} & 0,2 & \\
\hline c) Seleciona informações confiáveis e com autoria & 0,2 & \\
\hline d) Capaz de extrair informações relevantes & 0,4 & \\
\hline Subtotal (1) & $\mathbf{1}$ & $\mathbf{0}$ \\
\hline
\end{tabular}

Utilizar as informações e citações

\begin{tabular}{|lr|r|r|}
\hline \multicolumn{1}{|c|}{ INDICADOR } & VALOR & NOTA \\
\hline a) Faz paráfrase (isto é, não copia e cola) & 0,3 & \\
\hline b) Faz referência ou utiliza citações de forma adequada & 0,2 & \\
\hline c) Inclui citações apropriadas & 0,2 & \\
\hline d) Apresenta fontes consultadas & 0,3 & \\
\hline Subtotal (2) & $\mathbf{1}$ & $\mathbf{0}$ \\
\hline
\end{tabular}

Conteúdo

\begin{tabular}{|lr|r|r|}
\hline \multicolumn{1}{|c|}{ INDICADOR } & VALOR & NOTA \\
\hline a) Informação relevante & 0,3 & \\
\hline b) Informação atualizada & 0,3 & \\
\hline c) Ideias e soluções viáveis & 0,4 & \\
\hline Subtotal (3) & $\mathbf{1}$ & $\mathbf{0}$ \\
\hline
\end{tabular}

\section{Apresentação Global}

\begin{tabular}{|l|r|r|}
\hline \multicolumn{1}{|c|}{ INDICADOR } & VALOR & NOTA \\
\hline a) Gramática (usa a norma culta corretamente) & 0,3 & \\
\hline b) Escrita & 0,4 & \\
\hline c) Sentenças coerentes (frases articuladas) & 0,4 & \\
\hline d) Atende ao formato exigido & 0,4 & \\
\hline Subtotal (4) & $\mathbf{1 , 5}$ & $\mathbf{0}$ \\
\hline
\end{tabular}

Entrega dos relatórios

\begin{tabular}{|l|r|r|}
\hline \multicolumn{1}{|c|}{ INDICADOR } & VALOR & NOTA \\
\hline a) Entrega na data estabelecida & 0,5 & \\
\hline Subtotal (5) & $\mathbf{0 , 5}$ & 0 \\
\hline & & \\
\hline Total Geral: Subtotal $\mathbf{1 + 2 + 3 + 4 + 5}$ & $\mathbf{5}$ & $\mathbf{0}$ \\
\hline
\end{tabular}




\section{APÊNDICE D - ROTEIRO DE TRABALHO}

Componente curricular: Ensino Religioso

E, F, G e H

Ano/ turmas: 9ำ Ano A, B, C, D,

Objetivo Geral do Trabalho: Pesquisar a estrutura dos organismos ecumênicos em nível mundial, regional e local.

\section{Objetivos específicos do trabalho:}

1. Identificar quais as tradições (igrejas) cristãs estão presentes nos três níveis (mundial, regional e local) a fim de descobrir qual o grau de envolvimento de cada uma.

2. Citar os programas em comum que pelo diálogo ecumênico as igrejas realizam. (Descrever pelo menos um de cada nível).

3. Analisar as dificuldades para uma maior unidade dos cristãos, elencando os diferentes pontos de vista de cada uma.

4. Descobrir por meio de uma "árvore genealógica" qual o grau de convivência ecumênica que a dupla possui no seu espaço familiar ou de amigos.

\section{Justificativa}

Ao longo do primeiro trimestre, tivemos a oportunidade de analisar a importância da diversidade na qual o Brasil foi formado, além de compreendemos, a partir de uma análise do Censo de 2010, o surgimento de novas tradições e igrejas no território brasileiro. Esses dois fenômenos demonstram que ao longo dos anos o Brasil tem-se afirmado como um país diverso e democrático no âmbito religioso. Esse novo contexto favorece uma luta constante na conquista dos direitos humanos, ou seja, independentemente da opção religiosa, eles devem ser assegurados.

Vimos também que não existe religião melhor do que a outra e que, em se tratando do caminho espiritual escolhido pelas pessoas, não cabe juízo de valores. Ao internalizarmos esses elementos em nossas vidas, temos a possibilidade de compreendermos que nas nossas ações, caso existam, devemos diminuir ou extinguir a intolerância religiosa.

Diante disso, ao longo do segundo trimestre, será feita uma pesquisa que apresentará a estrutura dos organismos ecumênicos em nível mundial, regional e local. O intuito é que ao final da pesquisa compreendamos que tanto o ecumenismo como o diálogo inter-religioso favorecem a unidade na diversidade e principalmente a busca de uma cultura de paz entre os homens.

\section{Avaliação do Trabalho}

1. O trabalho servirá como Avaliação Parcial do Objetivo B2.

2. Poderá ser feito em dupla ou individualmente (as duplas serão escolhidas por sorteio). 
3. O trabalho será apresentado de acordo com as regras da Associação Brasileira de Normas Técnicas (ABNT) (será entregue roteiro básico para consulta).

4. A parte textual do trabalho deverá ter entre 8 e 10 páginas.

5. A pesquisa poderá ser realizada por meio de buscas em sites e/ou consultas em livros.

6. A atividade será dividida em momentos de busca de informações e debates em sala sobre o assunto pesquisado (a participação nas discussões também será avaliada).

7. O trabalho deverá ser entregue dentro do prazo.

\section{Desenvolvimento do Trabalho}

Os estudantes (dupla definida) poderão utilizar, em casa, ferramentas como Skype, FaceTime, Google Docs ou as redes sociais para fazer o trabalho de forma interativa e colaborativa.

\section{Semana de 26 a 30 de maio: Laboratório de Informática ou CRA}

- $1^{a}$ aula - Contextualização e entrega do roteiro

- $\quad 2^{a}$ aula - Início da pesquisa (Será feita observação e aplicação de questionário nas turmas $9^{\circ} \mathrm{B}$ e $9^{\circ} \mathrm{H}$ )

\section{Semana de 2 a 6 de junho: Laboratório de Informática ou CRA}

- $3^{\mathrm{a}}$ aula - Entrega do roteiro base com as normas da ABNT e retomada da pesquisa (Antes da entrega do guia com as orientações da ABNT, os alunos serão instigados a construir um mapa mental sobre o tema "pesquisa", a partir do conhecimento prévio que têm sobre o assunto. Será dado orientações sobre o que é um mapa conceitual e como ele é feito, por meio de texto de apoio ("Mapas conceituais: instrumento para compreensão de textos") e uma pequena apresentação. O mapa será montado a partir da ferramenta SimpleMind+ disponível na Internet.

- $\quad 4^{a}$ aula - Debate sobre o assunto pesquisado (Início da pesquisa-ação. Neste momento, teremos a função de instigar o grupo a pensar sobre sua aprendizagem a partir do tema proposto para a pesquisa (a estrutura dos organismos ecumênicos em nível mundial, regional e local). Os itens que irão nos nortear são: (1) estudar as práticas locais do grupo; (2) envolver indagações individuais ou em equipe; (3) centrar-se no desenvolvimento e na aprendizagem dos participantes; (4) resolver o problema, introduzir uma melhoria ou gerar mudança e (5) exercer liderança em conjunto.)

\section{FÉRIAS}

\section{Semana de 7 a 11 de julho: Laboratório de Informática ou CRA}

- $\quad 5^{\text {a }}$ aula - Retomada da pesquisa (Trabalho direcionado com o 9º $\mathrm{B}$ sobre os conteúdos de uma pesquisa)

- $6^{\text {a }}$ aula - Debate sobre o assunto pesquisado (Continuação da pesquisa-ação com $\left.9^{\circ} \mathrm{B}\right)$ 
Semana de 14 a 18 de julho: Laboratório de Informática ou CRA

- $7^{\text {a }}$ aula - Retomada da pesquisa (Trabalho direcionado com o 9ํㅡ sobre os conteúdos de uma pesquisa)

- $\quad 8^{a}$ aula - Debate sobre o assunto pesquisado (Continuação da pesquisa-ação com 9ํ)

Semana de 21 a 25 de julho: Laboratório de Informática ou CRA

- 9a aula - Retomada da pesquisa (Elaboração de um novo mapa mental com as turmas $9^{\circ} \mathrm{B}$ e $9^{\circ} \mathrm{H}$ )

- $10^{\text {a }}$ aula - Debate sobre o assunto pesquisado (Encerramento da pesquisaação com o 9ํㅗ)

Semana de 28 de julho a 1 de agosto

- Entrega do trabalho 


\section{APÊNDICE E - ENTREVISTA}

\section{Cód. ENT1}

Entrevista Prof. Álvaro Loureiro

Realizada no CRA

Data: $27 / 08 / 2014$

Pesquisador: Na verdade não tem uma pergunta definida mesmo... A ideia é saber a sua percepção... Aquilo que você já vinha me pontuando mesmo... e principalmente perceber se houve algum avanço, se você conseguiu enxergar isso... se o trabalho em si contribuiu para alguma aprendizagem. Lógico que você ainda está analisando as coisas, eu também vou começar a analisar, mas assim... muito da sua percepção.

Professor: Bem, não resta dúvida. Eu penso que assim... a gente começar um pouquinho, talvez, do próprio objetivo do trabalho em si que era mostrar... um a gente já tinha trabalhado um pouco em sala essa questão do ecumenismo e do diálogo inter-religioso. E aí eu gostaria que os meninos aprofundassem um pouco mais nesse assunto, até pra que eles pudessem conhecer as estruturas dos organismos ecumênicos, que você possui hoje na sociedade, tanto em nível mundial, com o Conselho Mundial de Igrejas, em nível local que é o CLAl, considerando aí a América Latina e o Caribe, o Conselho Americano de Igrejas e o CONIC, que é o Conselho Nacional de Igrejas Cristãs do Brasil. Eu queria que eles percebessem com esses conselhos também a dificuldade do porque que algumas religiões, mesmo no âmbito do cristianismo (porque o ecumenismo é o diálogo entre as religiões cristãs), porque há essa dificuldade. Então eles... e aí aproveitando essa oportunidade que você trouxe da questão da própria analise, não é, e aí eu vi que realmente foi muito interessante. É um trabalho que eu não vou dizer pra você que foi fácil, na perspectiva de ter sido pra mim uma novidade também e pegar um trabalho tanto pra mim quanto para os meninos. Porque eles estavam acostumados a trabalhar com grupo. E trabalho em grupo, normalmente mascara um pouco o trabalho, porque aí você tem um grupo de seis pessoas, você tem dois que muitas vezes carregam o trabalho nas costas e os outros quatro levam a nota. Quando a gente viu a possibilidade de fazer em dupla, eu achei interessante, mesmo sabendo que seria um volume muito grande e que o tema também era o mesmo tema pra todos, e eles também se inquietaram também, acho que por causa disso e o número de páginas pra alguns incomodava e o formato, tanto que isso fica claro nos questionários, que eles em um primeiro momento eles sentem isso. A maior dificuldade é o número de páginas que eles tem que produzir. 
Pesquisador: É, em um dos questionários, eu li rapidamente, estava escrito assim "Nós estávamos acostumados a fazer trabalhos de no máximo uma ou duas páginas". Na hora me veio uma reflexão né, a produção escrita não vinha sendo estimulada... Num trabalho de uma página, o menino praticamente só faz síntese, não é? Então, aquilo que você apontou hoje pela manhã de que é necessário um esforço para que este menino escreva mais, ficou muito perceptível né... Eles... o fato de ter essa quantidade de páginas... foi um grande problema pra eles...

Professor: Foi, foi assustador... Eu me lembro que quando a gente falava... $\mathrm{E}$ aí... essas foram as duas coisas: a questão do número de páginas e o rigor, dentro das normas que teria que ser entregue o trabalho. Essas seriam as duas coisas... porque esse, o número de páginas... ele aparece quando você coloca. A formatação, ela vai aparecer depois quando eles se vêm diante da dificuldade. E aí você tem experiências interessantes de meninos que buscaram pessoas próximas... o pai... alguém da família que pudesse ajudá-los... porque a gente pensa muita nessa questão da tecnologia, tal... o uso... e não sei o quê... É bacana isso... A escola acha que a gente está muito atrasado também em relação a algumas coisas. Mas quando se trata de um trabalho como esse, que você precisa de um programa como um Word, um Excel pra trabalhar com planilha... os nossos alunos chegam no 9o ano e não sabem mexer. E aquilo que eu estava falando pra você hoje pela manhã... Eu não sei se a gente trabalharia com uma espécie de escalonamento, porque também chegar no $9^{\circ}$ ano $\mathrm{e}$ exigir deles algo que eles não estão habituados a fazer... realmente choca. $\mathrm{E}$ aí, os trabalhos ficam muito mais numa capacidade que eles tem de resumir as coisas e não realmente de ter muitas palavras deles mesmos... da pesquisa. Então eu tive que relevar alguma coisa nesse sentido, no momento da correção. E aí, também, era trazer coisas relevantes, ou seja, que ele não ficasse só naquilo que eu indiquei. Mas como era um trabalho de pesquisa que eu não precisava falar disso... mas que ele pudesse ir atrás de outras coisas.

Pesquisador: É... eu percebi uma dificuldade também, lendo rapidamente, e até nas conversas que tivemos, ali no debate, enfim, da limitação deles em sempre dizer que entraram naqueles sites... e quase não tinha nada... mas assim, eles ficavam só naquilo, né... isso me chamou a atenção. $E$ aí aquela outra percepção que tivemos... o quanto foi difícil para a grande parte desses meninos usar o Word. Eu fiquei impressionado... eu vi alunos perdendo material porque não sabiam salvar esse material. E aí como eu tinha te dito anteriormente, era uma visão que eu nunca imaginei que nós teríamos desta geração. Uma geração que a gente sempre comenta né... que está muito antenada em relação a tecnologia, mas ficou muito claro que aquilo que é básico, que é da nossa geração... que a gente aprendeu a duras penas também a utilizar né, eles não incorporaram. Eles foram para um outro patamar sem passar por aquilo que a gente hoje consideraria básico. Como é que eu formato no Word, e olha o tanto 
de... E aí, interessante aqueles trabalhos que a fonte está desse tamanho... e eu fico me perguntando: será que foi só para dar o número de páginas ou eles tiveram dificuldade para formatar?

Professor: Não, eu... foi muito interessante você falar isso... que eu peguei alguns trabalhos que não tem "endentação", o parágrafo. E aí eu dizia para os meninos... "mas como é que a gente faz isso no computador..." aí eu disse: sabe aquela tecla TAB que tem lá? (risos) É claro que tem uma coisa mais rebuscada de você trazer uma formatação que o Word favorece num trabalho como esse, mas o básico... mesmo o básico eles não sabiam. Então me chamou a tenção nisso, e a parceria que alguns fizeram com os pais e tal, fazendo esse movimento. Ao mesmo tampo também, eu vi que... tem alguns elementos que são muito importantes. Além disso, eu vi também um aspecto... no meu caso, eu penso que para um aluno de 9a ano... nós temos alunos excelentes, que são alunos muito autônomos, mas é uma fase também, que autonomia para um trabalho de pesquisa, ela precisa ser melhor conduzida, vamos dizer assim. Não que eu tenha conduzido de maneira ruim, não foi isso... porque eu abri espaço, deixei canais abertos, de e-mail , de tudo, pra gente ficar "trocando figurinhas", no entanto, eu não obtive isso, esse retorno deles virem até a mim, e perguntarem: "Álvaro tenho dúvida aqui, como é que faz isso daqui...", entendeu? Alguma coisa nesse sentido.

Pesquisador: Até no meu caso, eu senti assim... na última hora, eles por aqui, me viram... "Ah Murillo, isso aqui...", coisa rápida mesmo assim. Mas a minha visão é que eles, talvez por não terem isso ainda muito claro, não souberam aproveitar essas oportunidades que foram dadas, pra que as dúvidas fossem realmente sanadas... para que no diálogo, juntamente com o professor, mostrando... "olha, a gente já conseguiu fazer isso...".

Professor: É, e aí eu fiquei também me perguntando assim, porque que eles não foram tirar as dúvidas, assim... porque que eles não vieram tirar as dúvidas, se a gente tinha a possibilidade de uma aula aqui e outra aula lá no debate... Eu não entendi assim... em algum momento. Mas vi como positivo que algumas pessoas indicaram que o trabalho... como eles estão muito acostumados a entregar trabalho... e o trabalho é como se fosse algo extraterrestre. Ele vem fora... é dado o conteúdo, mas ele não vai ser da prova. Então eles não têm a sensação de que ao fazerem o trabalho, eles estão estudando para a prova... E aí a gente vê relatos de alguns trabalhos de meninos que disseram que ajudaram a fazer a prova parcial. Então assim... eles começaram a entender... alguns começaram a entender que ao pesquisarem, fazerem o trabalho... isso não é um número talvez muito significativo, mas é interessante. Porque alguém percebe que ao pesquisar, eu estou estudando para a prova. Não é algo estanque, penso que talvez isso seja uma cultura nossa, aqui... não sei se 
da nossa escola ou de qualquer outra escola. Os trabalhos escolares são como que extraterrestres... caem de paraquedas...

Pesquisador: Só pra complementar uma nota...

Professor: Isso... e acabou. Então ele não entra neste esquema de que olha gente, a gente está pesquisando, então isso vai... então você já tá estudando. Algumas pessoas perceberam isso.

Pesquisador: $\mathrm{E}$ que isso, em algum momento também, é retomado... Porque geralmente você faz o trabalho e esquece... Ganha a nota e aquilo fica... Mas o fato de na prova, no nosso caso na Parcial... disso ser retomado e ele perceber que poxa, aquilo que eu fui atrás tá aqui, não ficou fora de propósito.

Professor: Eu quero ver sinais agora na prova Globalizante. Se eles vão trazer alguma coisa que reafirme ainda mais isso. Encontrei alguns ali no corredor e 0 João tava vindo pra cá e disse "Álvaro, vou gabaritar a sua prova de novo". Ele era um dos caras que estava bem empenhado com o trabalho, estava fazendo um trabalho muito bom. Outras meninas do $9^{\circ} \mathrm{G}$ também que foram muito bem agora... o pessoal do $\mathrm{H}$. Então assim, você percebe claramente né? Infelizmente $\circ 9^{\circ} \mathrm{B}$ foi aquela coisa...

Pesquisador: Então, era isso que eu queria trazer para o 9B, que foi o nosso objeto de estudo... Na sua percepção, a questão da enturmação comprometeu muito esta turma?

Professor: Compromete, e eu vejo... tem outro detalhe... que é a questão da própria maturidade dos meninos. Eu estava com um professor ali agora, o Gilberto, corrigindo provas deles. A frase dele: "Não tem jeito, essa turma não tem como...". Então assim, há uma dificuldade ali, que está inserida... uma questão... você tem a turma onde mais tem laudo. São 12, 13, sei lá, 14 meninos com laudo, numa turma de 40 alunos.

Pesquisador: E aí, geralmente com déficit de atenção...

Professor: Isso! Quando você trabalha, por exemplo, na Secretaria, com meninos assim laudeados, você tem que diminuir o número de alunos por turma. Você não pode trabalhar com um monte de gente com laudo... com a mesma 
quantidade. Isso também reflete, porque aí você não tem como acompanhar melhor. Eles são colocados também na "massa", coitados. E aí eles também não dão conta de fazer algumas coisas que outros já dão, tranquilamente. E aí o reflexo vai pra nota, vai pra essa falta de autonomia. Quando você passa um trabalho desse... foi uma das turmas que... além de demorar para entregar o trabalho, muitos nem entregaram ainda... duas semanas depois da data de entrega. Não entregaram... e o pior... não só a questão da data, mas tem um outra coisa... a qualidade dos trabalhos. Porque você vai encontrar trabalhos ruins nas outras turmas, mas lá $\left(9^{\circ} B\right)$ é impressionante. A única turma que eu até agora, peguei um trabalho e não tive condições de avaliar. Porque ele não tinha absolutamente nada.

Pesquisador: Isso me chama atenção também, porque lá atrás né, quando a gente pensou na possibilidade de fazer este trabalho, e fomos definir qual das turmas seria a mais apropriada, o 9B era aquele que estava com mais dificuldade e nós imaginamos que... bom, estando com maior dificuldade, um apoio maior, provavelmente, pode contribuir... né? Ainda não analisamos todas as situações, todas as informações que a gente levantou né, mas pelo que você diz, me parece que a contribuição não foi tão significativa...

Professor: Não foi tão significativa, porque... o resultado não se mostrou. Ou seja, aqueles que são bons, continuam bons. E aí, é claro nessa questão da maturidade. Hoje você tem uma turma, que pra mim... aí é uma questão da própria escola... e aí me revela isso. Porque não é comigo, mas são todos os professores que falam da turma especificamente. Que ela não tem maturidade acadêmica. E os bons que lá estão, não são meninos de liderança, que possam ajudar os colegas a levantar... dar a mão... tomar a frente... não, não conseguem fazer isso.

Pesquisador: Então, a iniciativa... ela pode ter minguado principalmente com relação a questão dos laudos, da maturidade...

Professor: É, esse é um dado pra mim...

Pesquisador: Essa é uma variável, que a princípio, não pensamos em considerar.

Professor: Não, ela não entrou né. A gente entrou na questão de que era uma turma que tinha dificuldade... 
Pesquisador: Sim, até porque não sei se naquele momento... essa quantidade de informações que a gente tem... naquele momento a gente não tinha... talvez.

Professor: Isso... e aí elas foram aparecendo. No decorrer do próprio trabalho elas foram aparecendo.

Pesquisador: É, uma coisa que que também me chamou a atenção, foi a dificuldade que eles tiveram de seguir um roteiro pronto... então... por exemplo, a questão da própria formatação do trabalho... a minha intervenção ali era muito pouca. Principalmente porque eles tinham ali um material auto explicativo...

Professor: Sem considerar que ano passado, nós já tínhamos feito um trabalho assim, só que em grupo.

Pesquisador: Isso foi, inclusive, o que me ajudou a definir a escolha do $9^{\circ}$ ano, porque nós já tínhamos feito um trabalho com o $8^{\circ}$ ano, que provavelmente daria um pouco mais de base... como você tinha pontuado no início... a ideia era de levarmos isso lá para o fundamental e virmos aos poucos... mas pelo menos o 9 ano já tinha tido uma percepção inicial, anterior, sobre pesquisa, sobre trabalho acadêmico... o que é plágio... e a gente tentou retomar isso também, no início da discussão, mas me chamou muita atenção... principalmente vendo os trabalhos, quando você me mostrou... que mesmo com um roteiro, muito bem direcionado ali, auto explicativo, é como se eles não tivessem nem olhado. Eu vi alguns exemplos lá de que parece que eles nem sabiam que existia aquele roteiro.

Professor: E você pode dizer assim: mas é Ensino Religioso. Não, mas a questão não está no componente (curricular), uma que o componente, na instituição (marista), ele tem peso como qualquer outra disciplina.

Pesquisador: Principalmente sendo uma instituição católica.

Professor: Isso! E fora que está lá, na Lei de Diretrizes e Bases, no seu artigo, se eu não me engano, 34 ou 35, que garante o Ensino Religioso na Educação Básica. Ele é garantido na educação básica, do Ensino Fundamental, aí, por exemplo. Até o fundamental do 9o ano ele é garantido por lei. No Ensino Médio, não há mais essa necessidade. As escolas confessionais continuam por serem confessionais. Mas não que haja uma necessidade legal mais. Mas a legalida- 
de, ela está para garantir até o $9^{\circ}$ ano. O Estado não garante, porque ele não tem estrutura pra isso... ele não consegue fazer o Ensino Religioso desse jeito. Então assim, não está no componente. Porque a gente vê claramente que os alunos que tem o cuidado com qualquer outra... vai ter também com o Ensino Religioso. Ele não faz uma diferenciação... e fica até melhor, que por exemplo, essa quantidade de pontos, que nós demos também para o trabalho... Outra coisa que eu acho que chamou a atenção deles agora foi a devolutiva do trabaIho. Porque quando você coloca numa folha de rosto aquilo que você avaliou, tirou pontos e tudo mais... Não sei também, aí agora... coloco uma outra coisa... talvez um viés pra gente refletir... é que se talvez nós tivéssemos aqueles elementos antes, entregue junto com o roteiro, para eles saberem o que seria avaliado, se teríamos uma coisa diferente. Poderíamos tornar diferente, porque no fundo eles sabiam como seria avaliado o trabalho como um todo. E talvez não daqueles critérios que nós colocamos na tabela.

Pesquisador: Infelizmente agora nós ficamos levantando hipóteses... mas enfim... Agora uma das questões que eu também tenho pensado é se nós conseguiríamos fazer esse trabalho numa outra disciplina que não tenha esse mesmo tipo de abertura. Porque na verdade, eu só consegui fazer esse trabalho, porque eu percebi... primeiro, logicamente com a sua parceria, o seu interesse em querer fazer... mas também entendendo que o Ensino Religioso permite um pouco mais...

Professor: Eu acho que independe... por exemplo: eu vi agora... O Gilberto estava trabalhando II Guerra, e eu fiquei pensando... os meninos vieram falar comigo: "poxa professor, eu gostei tanto do assunto que eu vi filme, eu vi não sei o que...". Então eu vejo, que se você falar da II Guerra Mundial, ou os elementos que foram aparecendo... porque nós trabalhamos em sala, um texto de uma comunidade ecumênica que surge logo após a II Guerra Mundial, que é a comunidade de Taisé... Então você teria na História, e talvez fazendo uma interdisciplinaridade com Ensino Religioso, a própria Língua Portuguesa e tudo mais... você conseguiria fazer isso. Eu acredito que em outros componentes, nós conseguiríamos fazer isso também. Isso vai depender muito do professor, porque não é uma coisa muito fácil, eu coloco pra você. A correção, ela é árdua, e a gente não ganha pra isso. Pra essa quantidade de horário que eu tenho dispendido para corrigir esses trabalhos.

Pesquisador: É, a gente percebe que há uma melhoria... pelo menos é essa a proposta, mas ao mesmo tempo, o desgaste para o professor é muito grande. E aí talvez uma alternativa fosse um trabalho interdisciplinar... 
Professor: Isso! Que aí, você conseguiria dividir e diluir o peso. Porque como você tem, no meu caso, oito turmas, o trabalho em dupla, cada turma com 40, você tinha 20 trabalhos, com no mínimo oito ou 10 páginas você calcula isso daí. Pra você fazer retornos, e tudo mais, pontualmente... não é um trabalho muito simples. Então, o professor, com a carga de trabalho que ele já tem, de prova e tudo mais, ele não vai querer... se um trabalho desse não estiver dentro da estrutura da escola... o professor não vai se arriscar a fazer um negócio desse.

Pesquisador: Agora, pra gente finalizar, você acha que foi algo que realmente valorizou o seu conteúdo...

Professor: Com certeza! Não tenho dúvida! Por mais que tenham aparecido trabalhos assim... ainda da dinâmica deles... pelas considerações finais dos trabalhos que eles conseguiram, pegar e tal... Que eles estão apropriados do conceito, e tudo... Da dinâmica de coisas que eles não imaginavam que existia... estruturas ecumênicas, então quando eles veêm uma reportagem, por exemplo, do Papa Francisco visitando o Oriente Médio, ele tem condições, ele tem elementos para fazer uma reflexão sobre aquilo ali, ele sabe por onde caminha o diálogo inter-religioso, o que é o ecumenismo, ou seja, pra mim, particularmente, valeu muito. 
APÊNDICE F - OBSERVAÇÕES

CÓD.: OB E OBC

TRANSCRIÇÃO DAS OBSERVAÇÕES EM SALA

\begin{tabular}{|c|c|c|c|}
\hline CÓD. & $\begin{array}{l}\text { DATA/ } \\
\text { HORÁ }\end{array}$ & GRUPO & OBSERVAÇÕES \\
\hline OB1 & $\begin{array}{l}27 / 5(7: 20) \\
\text { Aulas } 1 \text { e } 2\end{array}$ & $\begin{array}{l}\text { Expe- } \\
\text { rimen- } \\
\text { tal } \\
\left(9^{\circ} \mathrm{B}\right)\end{array}$ & $\begin{array}{l}\text { Após sinal (música), o professor já está em sala } \\
\text { com grande parte dos alunos. Alguns poucos } \\
\text { ainda entram na sala. Sentado, o professor pas- } \\
\text { sa as notas da "tarefa de sala" para o "controle } \\
\text { individual de avaliação" (tabela com todas as no- } \\
\text { tas dos alunos). Logo em seguida é tocada outra } \\
\text { música, significando que todos os alunos já de- } \\
\text { vem estar em sala. Neste momento, é passado } \\
\text { na Tv em sala, um slide show, com fotos de es- } \\
\text { tudantes que participaram da Olimpíada Marista } \\
\text { de Conhecimento - Português e Inglês. Após o } \\
\text { término, indagado sobre o posicionamento de } \\
\text { alguns estudantes em sala, o professor fala so- } \\
\text { bre o mapa de sala (organização de cada um dos } \\
\text { alunos em sala) e diz que não houve alteração. A } \\
\text { aula tem início com o professor lendo uma pe- } \\
\text { quena reflexão ("sorria"), de um livro chamado } \\
\text { "Sorria um pouco mais". Após esse momento, o } \\
\text { professor passa as orientações iniciais e apre- } \\
\text { senta o pesquisador Murillo Macedo à turma. O } \\
\text { pesquisador toma a palavra, e rapidamente se } \\
\text { apresenta aos alunos, falando da participação do } \\
\text { grupo em pesquisa realizada para o Programa de } \\
\text { Pós-Graduação da Faculdade de Ciência da In- } \\
\text { formação da Universidade de Brasília. O pesqui- } \\
\text { sador relata que estará com a turma como ob- } \\
\text { servador participante, insto é, que contribuirá pa- }\end{array}$ \\
\hline
\end{tabular}




\begin{tabular}{|l|l|l|}
\hline & $\begin{array}{l}\text { ra o andamento do processo. Os estudantes ob- } \\
\text { servam com atenção. Não foi feito nenhum ques- } \\
\text { tionamento a respeito. Logo em seguida, o pro- } \\
\text { fessor sinaliza que alguns alunos ainda devem } \\
\text { algum tipo de atividade. Uma delas é a tarefa de } \\
\text { casa sobre o assunto "diálogo inter-religioso". } \\
\text { Muitos alunos questionam que não houve tarefa. } \\
\text { O professor entretanto mostra que tinha passado } \\
\text { sim. Cerca de } 20 \text { min depois do início da aula } \\
\text { (7h38min), o professor dá início as explicações } \\
\text { sobre o trabalho proposto, um dos focos desta } \\
\text { pesquisa. A apresentação dos slides é feita via } \\
\text { TV. Apesar da mudança de assunto, alguns alu- } \\
\text { nos continuavam dispersos falando sobre a ativi- } \\
\text { dade que o professor cobrou anteriormente. O } \\
\text { professor tenta retomar o assunto, falando bre- } \\
\text { vemente sobre os conteúdos discutidos em sala } \\
\text { anteriormente (conteúdos que dariam embasa- } \\
\text { mento para o trabalho). Alguns alunos continuam } \\
\text { a questionar a cobrança da tarefa de casa. No- } \\
\text { vamente o professor para a aula e logo após re- } \\
\text { toma o assunto principal. Faz uma explanação } \\
\text { sobre liberdade e intolerância religiosa. Aborda a } \\
\text { estrutura dos organismos ecumênicos e retoma a } \\
\text { explicação de como será o trabalho. Neste mo- } \\
\text { mento, há muita conversa em sala. O professor } \\
\text { para a explicação e chama a atenção de alguns } \\
\text { alunos. Após a retomada do assunto, uma das } \\
\text { alunas interrompe e diz ao professor: "Vamos } \\
\text { para o CRA logo!". (CRA é a biblioteca do Colé- } \\
\text { gio, conhecida como Centro de Recursos de } \\
\text { Aprendizagem). O professor diz que "ainda não" } \\
\text { e passa para a apresentação dos objetivos gerais }\end{array}$ \\
\end{tabular}




\begin{tabular}{|l|l|l|}
\hline & $\begin{array}{l}\text { e específicos do trabalho. Alguns estudantes es- } \\
\text { tão dispersos, e não prestam atenção ao que é } \\
\text { dito pelo professor. O professor passa a explicar } \\
\text { o roteiro do trabalho, indicando o assunto que } \\
\text { será foco da pesquisa. Nesse momento, um dos } \\
\text { estudantes pergunta "o que é convivência ecu- } \\
\text { mênica". O professor passa a explicar. Após ex- } \\
\text { plicação, o professor diz como o trabalho será } \\
\text { avaliado e define que o mesmo poderá ser indivi- } \\
\text { dual ou em dupla. OBS: O professor permitiu que } \\
\text { os alunos escolhessem as duplas que iriam tra- } \\
\text { balhar por afinidade. Isso aconteceu, porque em } \\
\text { trabalho anterior, o professor é que tinha definido } \\
\text { os grupos de trabalho. Dessa vez, os alunos é } \\
\text { que fariam a escolha. A escolha por duplas, tam- } \\
\text { bém foi motivada pelo fato de que em grupos } \\
\text { grandes, poucos alunos acabavam produzindo, } \\
\text { enquanto o restante acaba se "escorando" nos } \\
\text { outros. O trabalho em dupla, exige que ambos } \\
\text { tenham um nível de produtividade parecido, o } \\
\text { que pode proporcionar um maior aproveitamento } \\
\text { do conteúdo por parte dos estudantes. O profes- } \\
\text { sor indica também o tamanho do trabalho a ser } \\
\text { entregue, sinalizando que o mesmo deverá ter } \\
\text { entre oito e 10 páginas. Neste momento, a turma } \\
\text { inteira questiona e fica dispersa. O professor } \\
\text { busca contê-los. Acrescenta que os alunos pode- } \\
\text { rão utilizar ferramentas colaborativas como } \\
\text { Skype, Google Docs, FaceTime, entre outras, } \\
\text { para elaborarem o trabalho. Neste momento os } \\
\text { alunos demonstraram interesse, focando um } \\
\text { pouco mais no que o professor dizia. Esse as- } \\
\text { pecto parece tê-los deixado interessados. Após }\end{array}$ \\
\hline
\end{tabular}




\begin{tabular}{|l|l|l|}
\hline & $\begin{array}{l}\text { explicação geral do trabalho, o professor dá início } \\
\text { à formação das duplas. A representante de turma } \\
\text { ajuda anotando o nome dos estudantes que farão } \\
\text { o trabalho em dupla ou sozinhos (7h58min). Nes- } \\
\text { te momento os alunos ficam dispersos, saindo } \\
\text { dos seus lugares. O professor pede atenção. Lo- } \\
\text { go em seguida, o pesquisador toma a palavra } \\
\text { novamente e fala na importância de se ter foco } \\
\text { na elaboração de um trabalho desta natureza. } \\
\text { Além disso, fala da entrega de um questionário } \\
\text { (item integrante da pesquisa) que será entregue } \\
\text { logo mais a cada estudante para que respondam. } \\
\text { Logo em seguida, os alunos voltam a se disper- } \\
\text { sar para a formação das duplas. Professor pede } \\
\text { que se organizem para podermos sair para o } \\
\text { CRA (as aulas da disciplina de Ensino Religioso } \\
\text { são duplas). Dá início à chamada e logo em se- } \\
\text { guida os alunos saem rapidamente para o espa- } \\
\text { ço da biblioteca. (8h15min) Os alunos estão no } \\
\text { CRA e dão início à busca de informações utili- } \\
\text { zando os computadores e a Internet. Um dos fa- } \\
\text { tos observados, é que apesar de estarem em } \\
\text { uma biblioteca, nenhum deles buscou algum tipo } \\
\text { de material bibliográfico que pudesse servir de } \\
\text { base para o início da pesquisa. Todos foram } \\
\text { imediatamente para as cabines de estudo e co- } \\
\text { meçaram a utilizar os computadores. O professor } \\
\text { orienta que os estudantes acessem o roteiro do } \\
\text { trabalho e comecem a levantar informações per- } \\
\text { tinentes. Alguns alunos ainda parecem dispersos. } \\
\text { Uma das duplas brinca com o programa Google } \\
\text { Earth. Ao todo são 39 alunos. Apenas uma aluna } \\
\text { optou por fazer o trabalho sozinha. Em virtude de }\end{array}$ \\
\hline
\end{tabular}




\begin{tabular}{|l|l|l|}
\hline & $\begin{array}{l}\text { ajustes na rede da escola, o site da Wikipédia } \\
\text { está indisponível. Muitos alunos questionam e } \\
\text { neste momento, o pesquisador os instrui a bus- } \\
\text { car outros sites que também abordam o assunto. } \\
\text { Um aluno entra no site Scielo e encontra infor- } \\
\text { mações bastante relevantes. Imediatamente, o } \\
\text { pesquisador informa ao professor, que fica con- } \\
\text { tente com o que vê. O fato da Wikipédia estar } \\
\text { indisponível, forçou alguns estudantes a busca- } \\
\text { rem outras fontes de informação. Isto foi visto } \\
\text { como positivo pelo pesquisador. Apesar de ainda } \\
\text { não terem pesquisado o suficiente para encontra- } \\
\text { rem um volume interessante de informações a } \\
\text { serem analisadas, alguns alunos já começavam } \\
\text { a formatar o trabalho no Word. (8h35min) 20min } \\
\text { antes do término da aula, os alunos são convida- } \\
\text { dos a responderem o questionário. A opção por } \\
\text { ter aplicado depois do início da pesquisa nos } \\
\text { computadores, foi feita para que as perguntas } \\
\text { não influenciassem a postura dos alunos no mo- } \\
\text { mento da busca por informações. Os estudantes } \\
\text { foram convidados a se sentarem afastados uns } \\
\text { dos outros. Apesar da distância, observou-se que } \\
\text { houve comunicação entre alguns alunos, não } \\
\text { estando certo se isso acarretou interferência nas } \\
\text { respostas. A média de tempo de resolução foi de } \\
\text { cerca de 4min. Após responderem o questioná- } \\
\text { rio, alguns alunos voltaram para o computador e } \\
\text { enviaram o material salvo por e-mail. Algumas } \\
\text { alunas iniciam a montagem do trabalho em ar- } \\
\text { quivo do Power Point. A aula é finalizada as } \\
\text { 8h55min e os estudantes saem do CRA em dire- } \\
\text { ção à sala de aula. O pesquisador conversa com }\end{array}$ \\
& \\
&
\end{tabular}




\begin{tabular}{|l|l|l|l|}
\hline & & $\begin{array}{l}\text { o professor e elogia alguns estudantes. A turma } \\
\text { pareceu ter um pouco mais de foco na segunda } \\
\text { aula. }\end{array}$ \\
\hline OBC1 & $28 / 5$ & $\begin{array}{l}\text { Con- } \\
\text { trole } \\
\left(9^{\circ} \mathrm{H}\right)\end{array}$ & $\begin{array}{l}\text { 10h17min Retorno do recreio. Os estudantes es- } \\
\text { tão agitados. O professor prepara a apresenta- } \\
\text { ção enquanto algumas alunas cantam uma músi- } \\
\text { ca em inglês. O professor inicia a explicação so- } \\
\text { bre a proposta de trabalho. Fala do roteiro e de } \\
\text { como será o trabalho. Muitos alunos continuam } \\
\text { dispersos e não prestam atenção ao que o pro- } \\
\text { fessor fala. Professor mostra alguns jornais com } \\
\text { notícias sobre o Papa, que estão relacionadas } \\
\text { com a temática da pesquisa. O professor apre- } \\
\text { senta os objetivos geral e específicos da ativida- } \\
\text { de e começa a falar sobre os conteúdos a serem } \\
\text { pesquisados. O primeiro deles é o CONIC, sigla } \\
\text { para Conselho Nacional de Igrejas Cristãs. O } \\
\text { professor volta a falar sobre cada um dos passos } \\
\text { do roteiro enquanto vários alunos continuam dis- } \\
\text { persos. Uma das alunas se incomoda com o ba- } \\
\text { rulho e grita "gente!" (10h28min). Professor fala } \\
\text { que o trabalho terá um grau de exigência maior e } \\
\text { faz a turma se recordar que no ano passado eles } \\
\text { já tinham passado por experiência parecida, ten- } \\
\text { do que elaborar um trabalho diferenciado. Uma } \\
\text { das alunas diz que aquele trabalho tinha sido } \\
\text { "horrível", provavelmente se referindo ao formato } \\
\text { exigido. O professor continua a explicação e } \\
\text { afirma que o trabalho não deverá ser feito com } \\
\text { base no "cópia e cola". Professor fala que os alu- } \\
\text { nos poderão utilizar as ferramentas sociais para } \\
\text { se comunicar e para fazer o trabalho de forma }\end{array}$ \\
\hline
\end{tabular}




\begin{tabular}{|c|c|c|c|}
\hline & & & $\begin{array}{l}\text { colaborativa. Neste momento, o pesquisador é } \\
\text { apresentado à turma e fala sobre a participação } \\
\text { dos alunos na sua pesquisa. Após as explica- } \\
\text { ções, os alunos são orientados a formarem as } \\
\text { duplas e a se dirigirem para o CRA, para inicia- } \\
\text { rem a pesquisa. Chegando ao CRA, o pesquisa- } \\
\text { dor orienta os alunos a lerem o roteiro do traba- } \\
\text { lho que está disponível nos computadores e a } \\
\text { iniciar a busca por informações. Alguns alunos } \\
\text { ainda parecem perdidos sobre o que tem que ser } \\
\text { feito. O grupo está bastante disperso e apenas } \\
\text { algumas duplas parecem estar concentradas na } \\
\text { busca por informações. Em uma cabine, seis } \\
\text { alunas brincam e tiram fotos umas das outras } \\
\text { com o celular. O pesquisador observa que alguns } \\
\text { alunos têm dificuldade de utilizar aplicações bá- } \\
\text { sicas do computador, como anexar um arquivo } \\
\text { ao e-mail. Essa dificuldade já tinha sido observa- } \\
\text { da no grupo quase experimental. Ao todo, estão } \\
\text { presentes } 32 \text { alunos de um total de } 40 \text {. As } \\
11 \text { h42min os alunos começam a voltar para sala. } \\
\text { Houve pouco aproveitamento da aula com pou- } \\
\text { cas buscas efetivas. Ao final da atividade, pro- } \\
\text { fessor e pesquisador trocam impressões sobre a } \\
\text { atividade. Fica claro que os alunos não leram o } \\
\text { roteiro com atenção. Estão preocupados em en- } \\
\text { trar na Internet e responder os objetivos específi- } \\
\text { cos, como se fossem questões. }\end{array}$ \\
\hline OB2 & $\begin{array}{l}3 / 6 \\
\text { (Aulas } 3 \text { e } \\
4)\end{array}$ & $\begin{array}{l}\text { Expe- } \\
\text { rimen- } \\
\text { tal } \\
\left(9^{\circ} \mathrm{B}\right)\end{array}$ & $\begin{array}{l}\text { Realização da Pesquisa. Identificação dos co- } \\
\text { nhecimentos prévios dos alunos por meio da ela- } \\
\text { boração de mapas mentais. O pesquisador dá as } \\
\text { orientações de como será a atividade. Apresenta } \\
\text { aos alunos o conceito de mapa mental e diz que }\end{array}$ \\
\hline
\end{tabular}




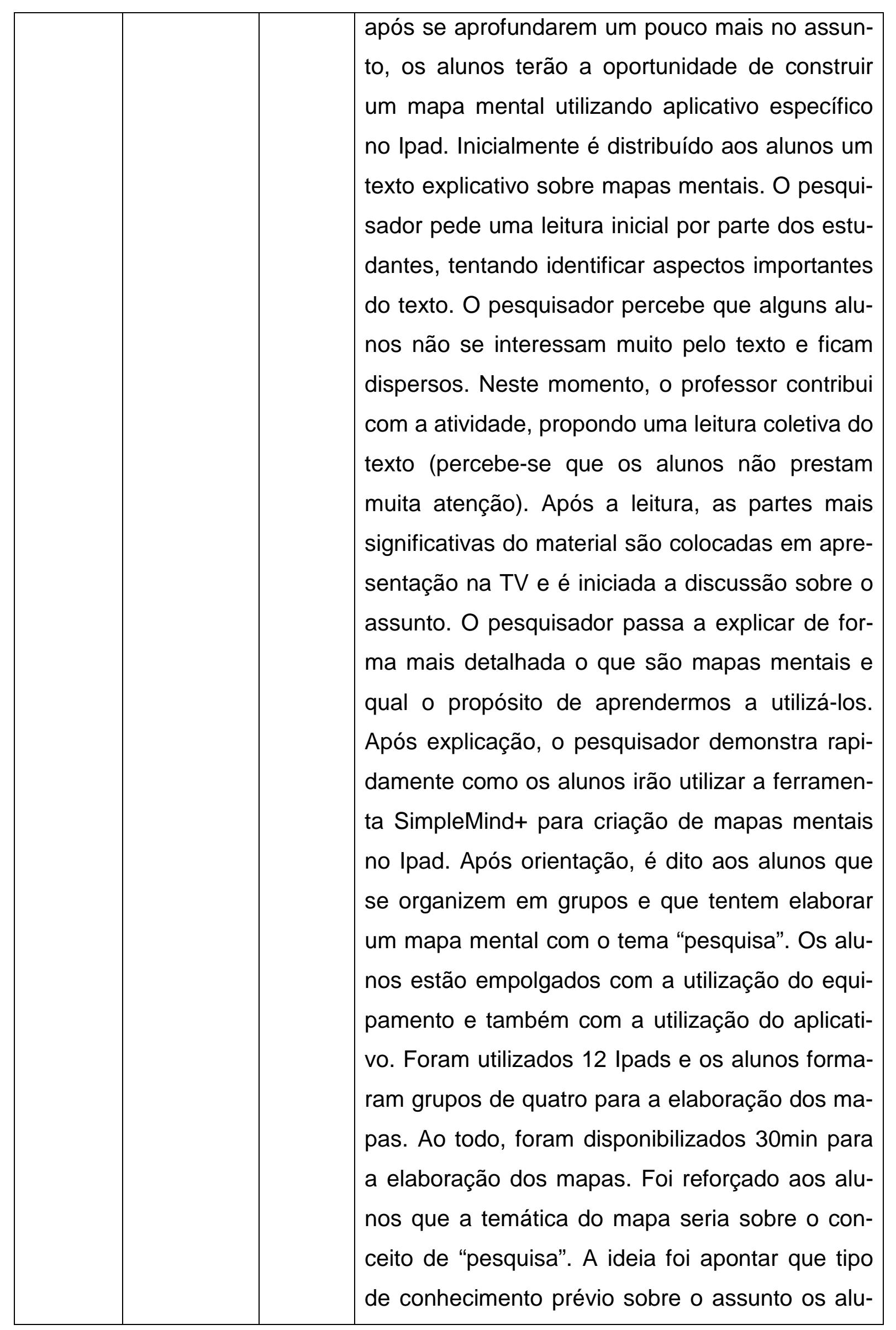




\begin{tabular}{|c|c|c|c|}
\hline & & & $\begin{array}{l}\text { nos tinham. Após a elaboração dos mapas, os } \\
\text { Ipads foram recolhidos (no momento da ativida- } \\
\text { de, foi ativada a função "modo guiado" no Ipad, } \\
\text { para que os alunos não tivessem acesso a outros } \\
\text { aplicativos ou funcionalidades do equipamento. } \\
\text { Isso possibilitou que eles se mantivessem com } \\
\text { foco na atividade). Após o término, os Ipads fo- } \\
\text { ram recolhidos e os mapas elaborados pelos alu- } \\
\text { nos foram transferidos para um computador, via } \\
\text { programa específico. }\end{array}$ \\
\hline OBC2 & $4 / 6$ & $\begin{array}{l}\text { Con- } \\
\text { trole } \\
9 \text { o } \mathrm{H}\end{array}$ & $\begin{array}{l}\text { Alunos foram visitar o Maristão e por isso não } \\
\text { houve aula. }\end{array}$ \\
\hline OB3 & $\begin{array}{l}10 / 6 \\
\text { (7h23min) } \\
\text { Aulas } 5 \text { e } 6\end{array}$ & $\begin{array}{l}\text { Expe- } \\
\text { rimen- } \\
\text { tal } \\
\left(9^{\circ} \mathrm{B}\right)\end{array}$ & $\begin{array}{l}\text { Início da aula em sala. Os alunos estão agitados } \\
\text { e o professor faz a chamada. Professor inicia a } \\
\text { atividade falando de uma reportagem que ele } \\
\text { escutara na rádio logo cedo. A reportagem falava } \\
\text { sobre a importância de se ter sonhos e de fazer } \\
\text { coisas interessantes. Mais uma vez, o professor } \\
\text { lê um pequeno trecho do livro "Comece o seu dia } \\
\text { feliz". Após leitura, o professor inicia a atividade } \\
\text { explicando como será a atividade e de que hoje a } \\
\text { turma irá para o Laboratório de Informática. As } \\
7 \text { h37min a turma sai e se dirige ao laboratório. } \\
\text { Após se organizarem nas duplas na frente dos } \\
\text { computadores, o pesquisador percebe que mui- } \\
\text { tos alunos não se lembravam mais o que deveria } \\
\text { ser feito no trabalho. Novamente precisam aces- } \\
\text { sar o Portal Marista para baixar o roteiro. O pes- } \\
\text { quisador percebeu que nenhum grupo guardou o } \\
\text { roteiro em um pendrive ou mesmo salvou no e- } \\
\text { mail para ficar de fácil acesso. Os que precisa- } \\
\text { vam consultar novamente sempre tinham que }\end{array}$ \\
\hline
\end{tabular}




\begin{tabular}{|l|l|}
\hline & $\begin{array}{l}\text { acessar o Portal do Marista, perdendo tempo até } \\
\text { localizar o roteiro no link da disciplina. O profes- } \\
\text { sor e o pesquisador passam pelos grupos dando } \\
\text { orientações. O pesquisador percebe que alguns } \\
\text { alunos buscam trocar informações entre eles, } \\
\text { buscando compartilhar o que tinham encontrado. } \\
\text { Vários alunos parecem ter dúvidas ainda sobre o } \\
\text { trabalho. Neste momento, o professor diz para a } \\
\text { turma que resolveu dar um peso maior para o } \\
\text { trabalho. A nota será maior, valendo 5,0 pontos. } \\
\text { Nesse sentido, afirma que o trabalho já servirá } \\
\text { para que os alunos estudem para a prova globa- } \\
\text { lizante. O pesquisador percebe que alguns estu- } \\
\text { dantes tem pouca clareza sobre a busca por in- } \\
\text { formações. Muitos não indicam o site pesquisa- } \\
\text { do, e tampouco organizam as informações en- } \\
\text { contradas para serem analisadas depois. Mais } \\
\text { uma vez o pesquisador percebe dificuldades bá- } \\
\text { sicas de alguns alunos até mesmo para anexar } \\
\text { um arquivo a ser envido por e-mail. Após a aula } \\
\text { destinada para a busca de informações, os alu- } \\
\text { nos fizeram uma roda dentro do laboratório e o } \\
\text { professor passou a questioná-los sobre o anda- } \\
\text { mento do trabalho. Foi uma espécie de bate- } \\
\text { papo, mas poucos alunos falaram. Neste mo- } \\
\text { mento, o pesquisador pede a palavra e fala sobre } \\
\text { o roteiro de trabalho, sobre a questão do plágio, } \\
\text { o processo de busca por informações relevantes } \\
\text { e sobre a importância do processo de autonomia } \\
\text { de cada estudante na busca por informações. O } \\
\text { professor aproveita o assunto e tentar reforçar a } \\
\text { questão da autonomia. A aula é finalizada e os } \\
\text { alunos são informados que a próxima aula acon- }\end{array}$ \\
\hline
\end{tabular}




\begin{tabular}{|c|c|c|c|}
\hline & & & $\begin{array}{l}\text { tecerá no retorno das aulas após as férias esco- } \\
\text { lares (em virtude da Copa do Mundo, as férias } \\
\text { foram antecipadas para o mês de junho). }\end{array}$ \\
\hline OBC3 & $11 / 6$ & $\begin{array}{l}\text { Con- } \\
\text { trole } \\
\left(9^{\circ} \mathrm{H}\right)\end{array}$ & $\begin{array}{l}\text { Sala de aula. Penúltimo dia de aula, apenas } 8 \\
\text { alunos aparecem para assistir as aulas. Apesar } \\
\text { da pouca quantidade, o pesquisador realiza o } \\
\text { trabalho sobre mapas mentais, no intuito de não } \\
\text { comprometer o cronograma da pesquisa. Fala } \\
\text { rapidamente sobre o que é um mapa mental e } \\
\text { mostra aos alunos o aplicativo SimpleMind+, so- } \\
\text { licitando que eles construam em duplas um mo- } \\
\text { delo de mapa que represente o entendimento de } \\
\text { cada um com relação a temática "pesquisa". O } \\
\text { trabalho foi produtivo e ao final, os mapas elabo- } \\
\text { rados foram transferidos para um computador, } \\
\text { para análise posterior. }\end{array}$ \\
\hline OB4 & $\begin{array}{l}8 / 7 \\
\text { Aulas } 7 \text { e } 8\end{array}$ & $\begin{array}{l}\text { Expe- } \\
\text { rimen- } \\
\text { tal } \\
\left(9^{\circ} \mathrm{B}\right)\end{array}$ & $\begin{array}{l}\text { CRA: Retorno das atividades de busca de infor- } \\
\text { mações após as férias. Alunos parecem não se } \\
\text { lembrar mais sobre o que tem que ser feito no } \\
\text { trabalho de pesquisa. Alguns relatam que o tra- } \\
\text { balho está sendo feito em casa. O professor ten- } \\
\text { ta retomar grupo a grupo o foco do trabalho. No } \\
\text { momento do debate/pesquisa-ação, o professor } \\
\text { solicita às duplas de estudantes que falem um } \\
\text { pouco sobre o andamento do trabalho. Em gra- } \\
\text { vação realizada, o professor inicia dizendo: } \\
\text { (Professor) - "Clara e Júlia, o que que vocês já } \\
\text { fizeram até agora? Como é que vocês caminha- } \\
\text { ram, o que que vocês já pesquisaram, o que que } \\
\text { vocês podem falar pra gente" } \\
\text { (Alunas) - "A gente já pesquisou sobre o CLAI, } \\
\text { não, não, CONIC, e tá começando a pesquisar } \\
\text { sobre o CLAl." }\end{array}$ \\
\hline
\end{tabular}




\begin{tabular}{|l|l|}
\hline $\mid$ & (Professor) - "Além desses organismos ecumê- \\
& nicos, tem algo, por exemplo, que chamou a ten- \\
ção de vocês durante a pesquisa, que vocês gos- \\
tariam de partilhar com a gente?" \\
(Alunos) - Risos \\
(Alunas) - "Não" \\
(Professor) - "Não!" \\
(Alunos) - Murmuro na sala \\
(Professor) - "Manu, você ficou sozinha hoje, a \\
Ana Tereza não está aí. Em que pé que está o \\
trabalho de vocês? O que que vocês já fizeram? \\
O que que você pode partilhar conosco sobre o \\
que vocês já viram, como é que vocês estão fa- \\
zendo, se vocês... Qual foi a estrutura que vocês \\
criaram em dupla, pra realizar esta atividade? \\
(Aluna) - "A gente tá respondendo primeiro aque- \\
las quatro perguntas, pra depois organizar o tra- \\
balho..." \\
(Professor) - "Eu me lembro que eu disse que \\
aquelas questões... aqueles objetivos específicos \\
não são perguntas, mas são nortes para conduzir \\
o nosso trabalho. Não necessariamente são per- \\
guntas a serem respondidas. Isso tá claro pra \\
vocês? Tem alguma dificuldade até agora, que \\
vocês estão achando mais complicado, mas difí- \\
cil especificamente, está tranquilo? \\
(Aluna) - na gravação não fica claro o que ela \\
disse, mas o fato de o professor ter partido para \\
outra dupla dá indício que ela respondeu que \\
estava tudo tranquilo. Alguns alunos respondem \\
ao fundo: "mais ou menos". \\
(Professor) - "Catarina e Laís, e aí meninas?" \\
(Alunas) - "A gente pesquisou os órgãos, o co- \\
\hline
\end{tabular}




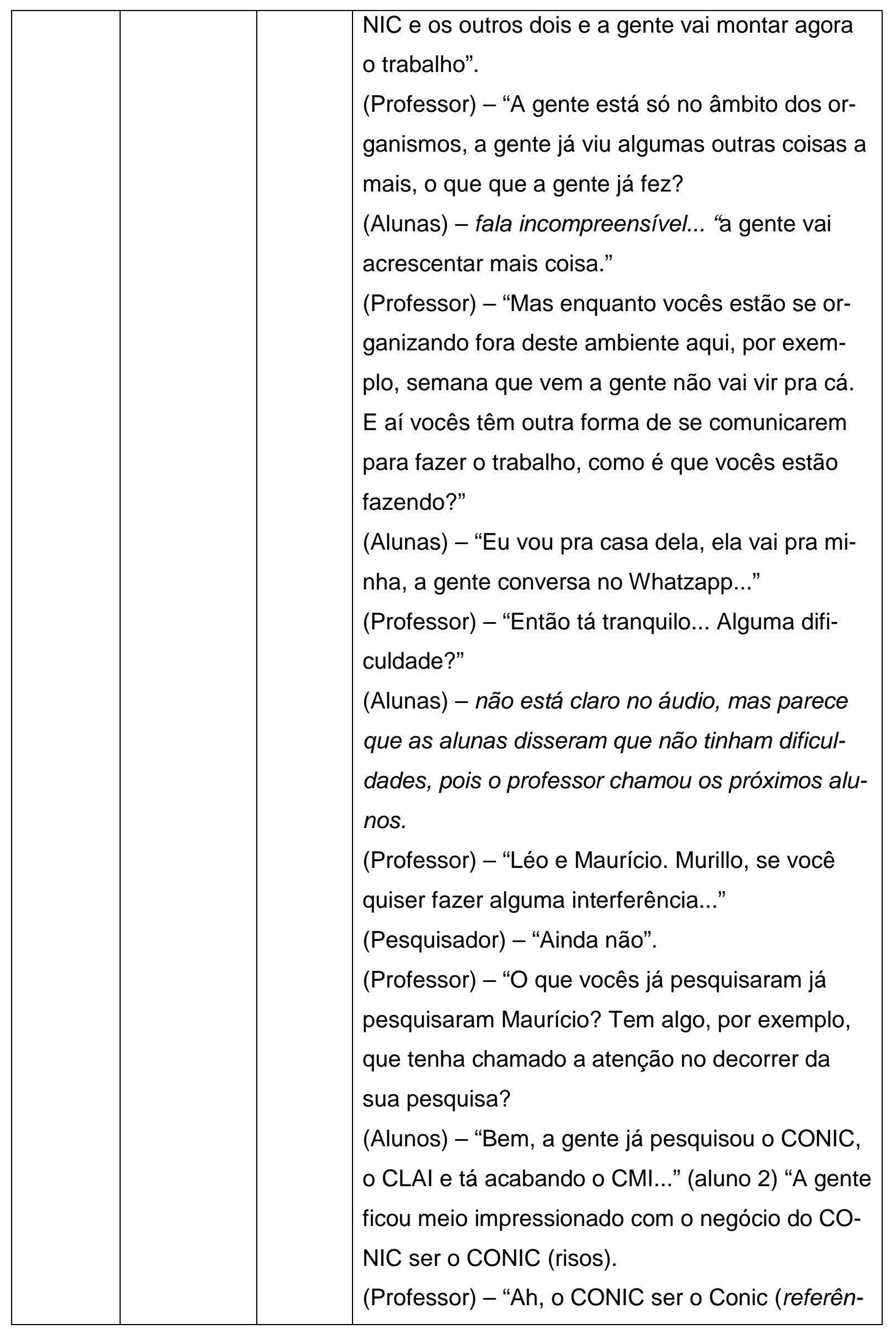




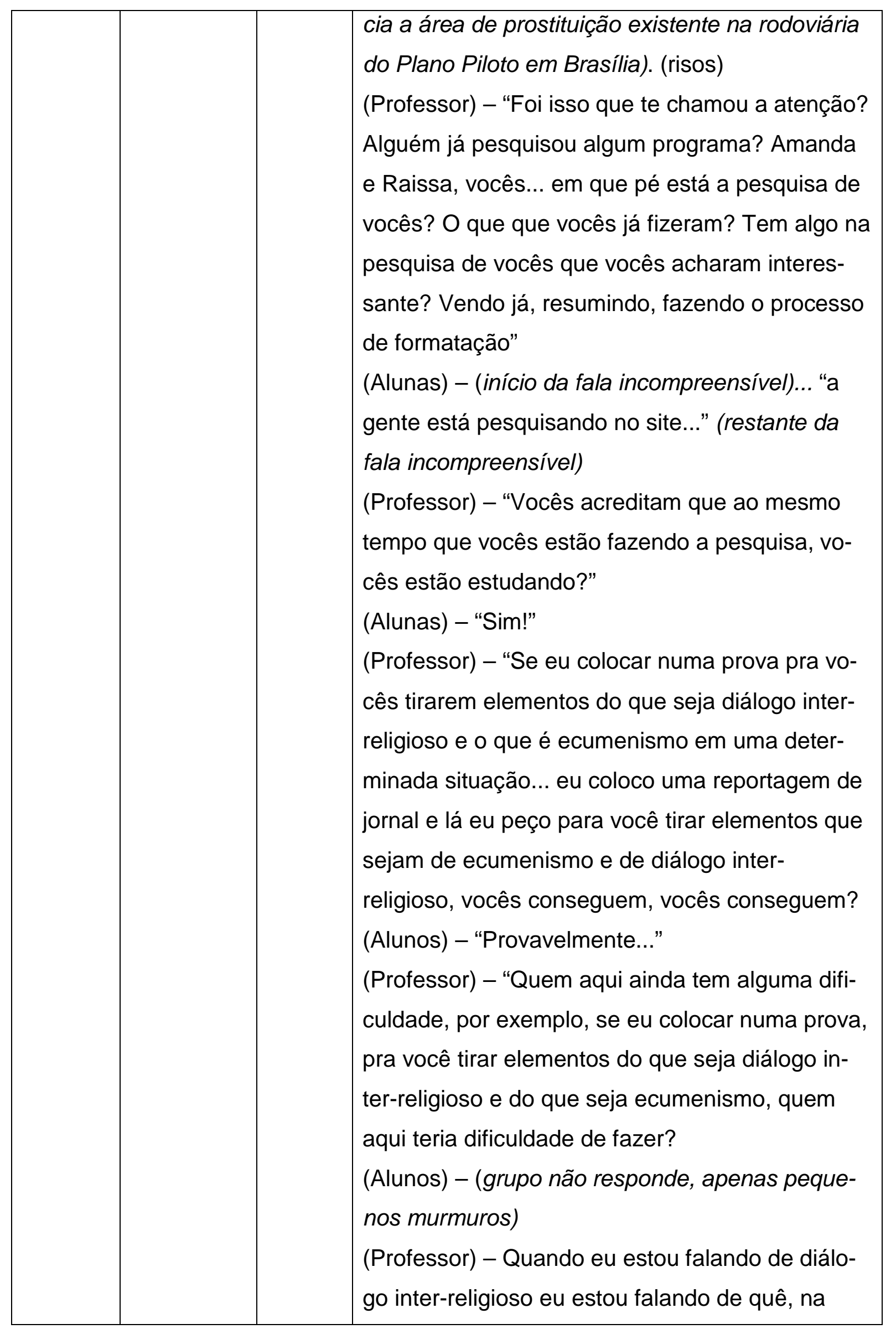




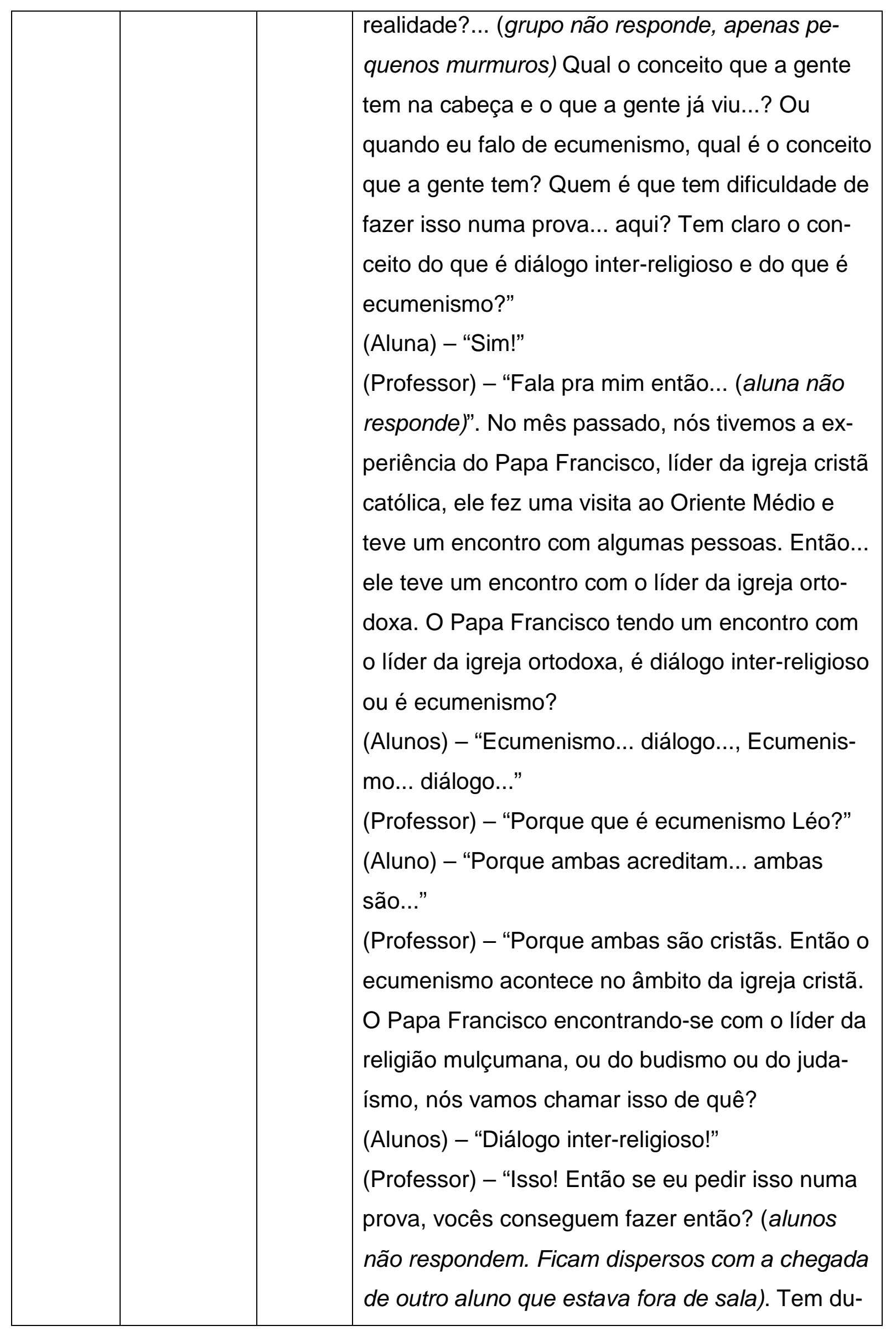




\begin{tabular}{|l|l|}
\hline & $\begin{array}{l}\text { as folhinhas que eu vou entregar pra vocês pre- } \\
\text { encherem depois que eu vou dar nota pra vocês. } \\
\text { Umas são umas perguntas e a outra é para vo- } \\
\text { cês dizerem como é que este trabalho... como é } \\
\text { que vocês estão pesquisando, o jeito de fazer, } \\
\text { quais são as dificuldades que vocês encontraram } \\
\text { ou que vocês estão encontrando... Quero só que } \\
\text { vocês escrevam isto. Aqui vai ter escrito na reali- } \\
\text { dade, o que que vocês vão ter que fazer. Então é } \\
\text { um pra dupla. Depois vocês colocam direitinho. } \\
\text { Isso aqui eu vou dar ponto pra vocês. E a outra } \\
\text { são cinco perguntinhas, sete na realidade, e a } \\
\text { primeira eu vou começar... perguntar pra vocês } \\
\text { aqui agora. O que que vocês observaram de dife- } \\
\text { rente nesta proposta de atividade, da gente vir } \\
\text { para o CRA... A Helena está ali reclamando... ela } \\
\text { disse assim: 'Álvaro, é muita coisa... nem minha } \\
\text { irmã na UnB faz um trabalho deste tamanho.... } \\
\text { Helena, você poderia partilhar com a gente o que } \\
\text { você observa de diferente nesta proposta desta } \\
\text { atividade? } \\
\text { (Aluna) - “Como assim?” } \\
\text { (Professor) - Da gente ir para o campo da pes- } \\
\text { quisa, não sou eu que estou lá na frente falando, } \\
\text { mas vocês estão pesquisando... a gente vem } \\
\text { aqui e discute... Eu queria que você falasse um } \\
\text { pouquinho. } \\
\text { (Aluna) - Fala! (aluna 2) Eu não, o professor per- } \\
\text { guntou pra você... (aluna não responde... há um } \\
\text { certo burburinho na sala) } \\
\text { (Professor) - “Outra pessoa então, quem gostaria } \\
\text { de falar? O que observa de diferente nesta pro- } \\
\text { posta de atividade, desta maneira? Quais são os }\end{array}$ \\
\hline
\end{tabular}




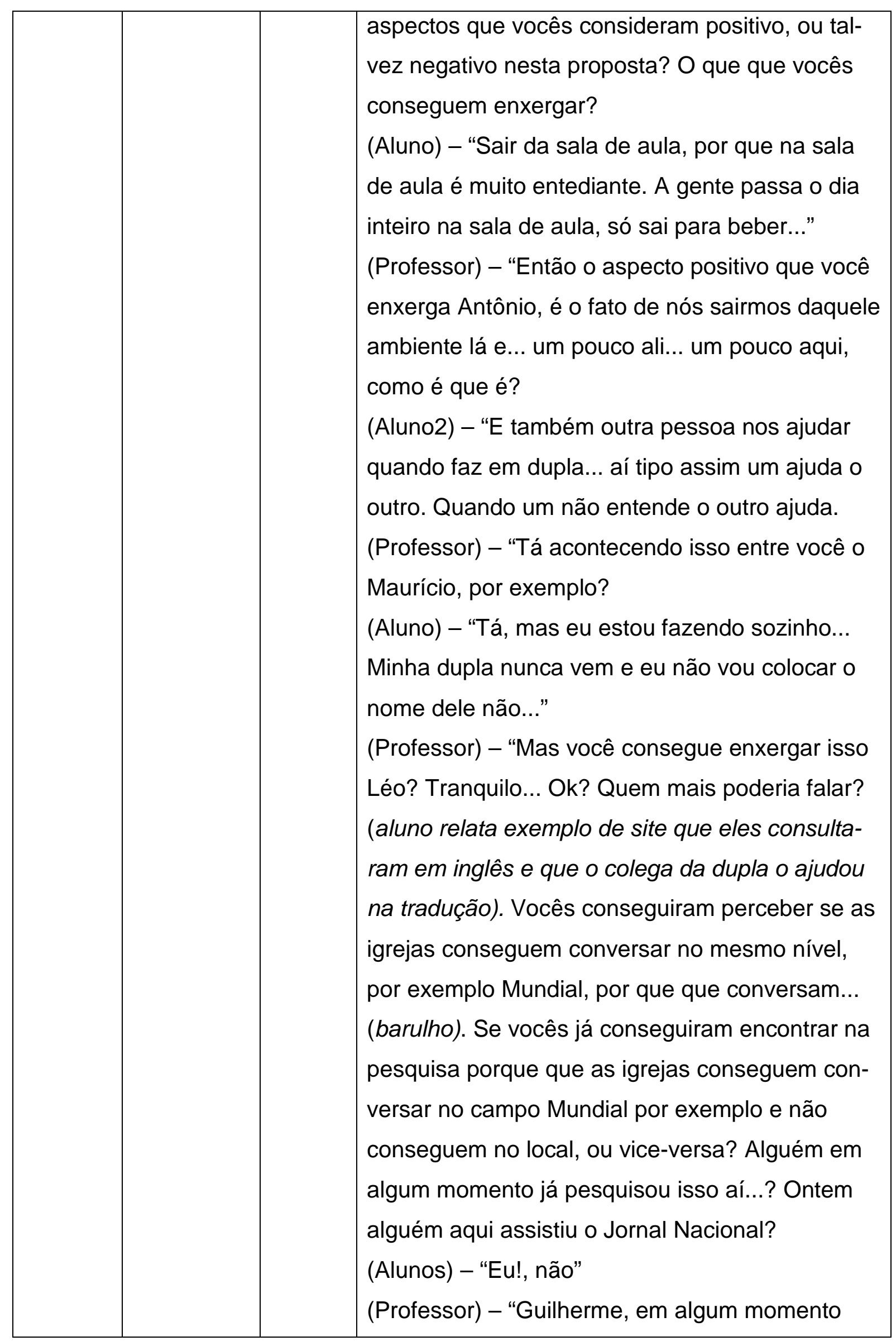




\begin{tabular}{|l|l|}
\hline & $\begin{array}{l}\text { você viu lá uma matéria, bem rapidamente, que } \\
\text { falava sobre este assunto que nós estamos dis- } \\
\text { cutindo aqui?" } \\
\text { (Aluno) - "Não, tem uma parte que parei de } \\
\text { ver..." } \\
\text { (Professor) - "Ontem apareceu no Jornal Nacio- } \\
\text { nal que a Igreja Anglicana autorizou a ordenação } \\
\text { de mulheres bispos. As mulheres podem ser bis- } \\
\text { pos, você viu isso? Porque a 10 anos atrás ela já } \\
\text { tinha autorizado as mulheres serem padres. E } \\
\text { agora ela traz essa proposta para as mulheres } \\
\text { serem bispas. Então assim... é uma igreja cristã, } \\
\text { onde a mulher tem um papel fundamental, onde } \\
\text { a mulher pode celebrar... Nós só temos a figura } \\
\text { masculina. Aqui você vai ter a presença do femi- } \\
\text { nino, a presença de uma mulher à frente, tanto } \\
\text { como padre como bispo. Então, pra Igreja Católi- } \\
\text { ca, isso não é possível, não é permitido. Isso é } \\
\text { uma dificuldade de conversar, de dialogar. Esse } \\
\text { é um elemento: porque que a gente tem aqueles } \\
\text { objetivos específicos... Quais são as dificulda- } \\
\text { des? Essa é uma dificuldade. Porque o papel das } \\
\text { mulheres em algumas igrejas, ainda é um papel } \\
\text { muito serviçal. A mulher é só para o serviço, e } \\
\text { não para presidir uma celebração. Entenderam? } \\
\text { O que a gente está discutindo aqui, provavelmen- } \\
\text { te esteja no jornal de hoje, algum jornal impresso. } \\
\text { (Professor) - “Uma outra perguntinha aqui... é... } \\
\text { Como é que tem sido Tamara, pra você, depois a } \\
\text { Massoni, queria que vocês me respondessem, } \\
\text { como é que tem sido elaborar um trabalho com } \\
\text { padrão mais exigente assim, como uma formata- } \\
\text { ção que vocês vão ter que seguir... Vocês identi- }\end{array}$ \\
& \\
&
\end{tabular}




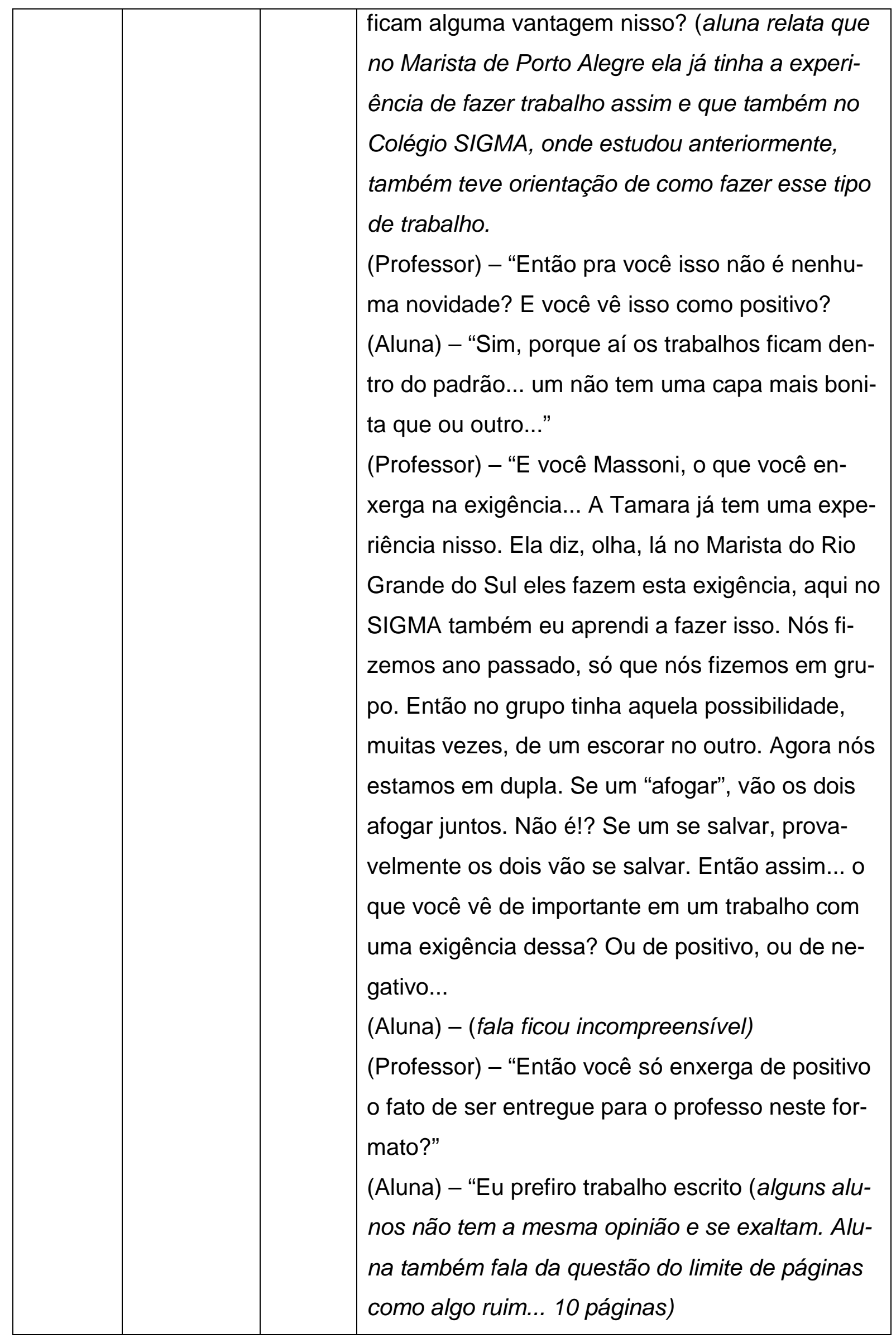




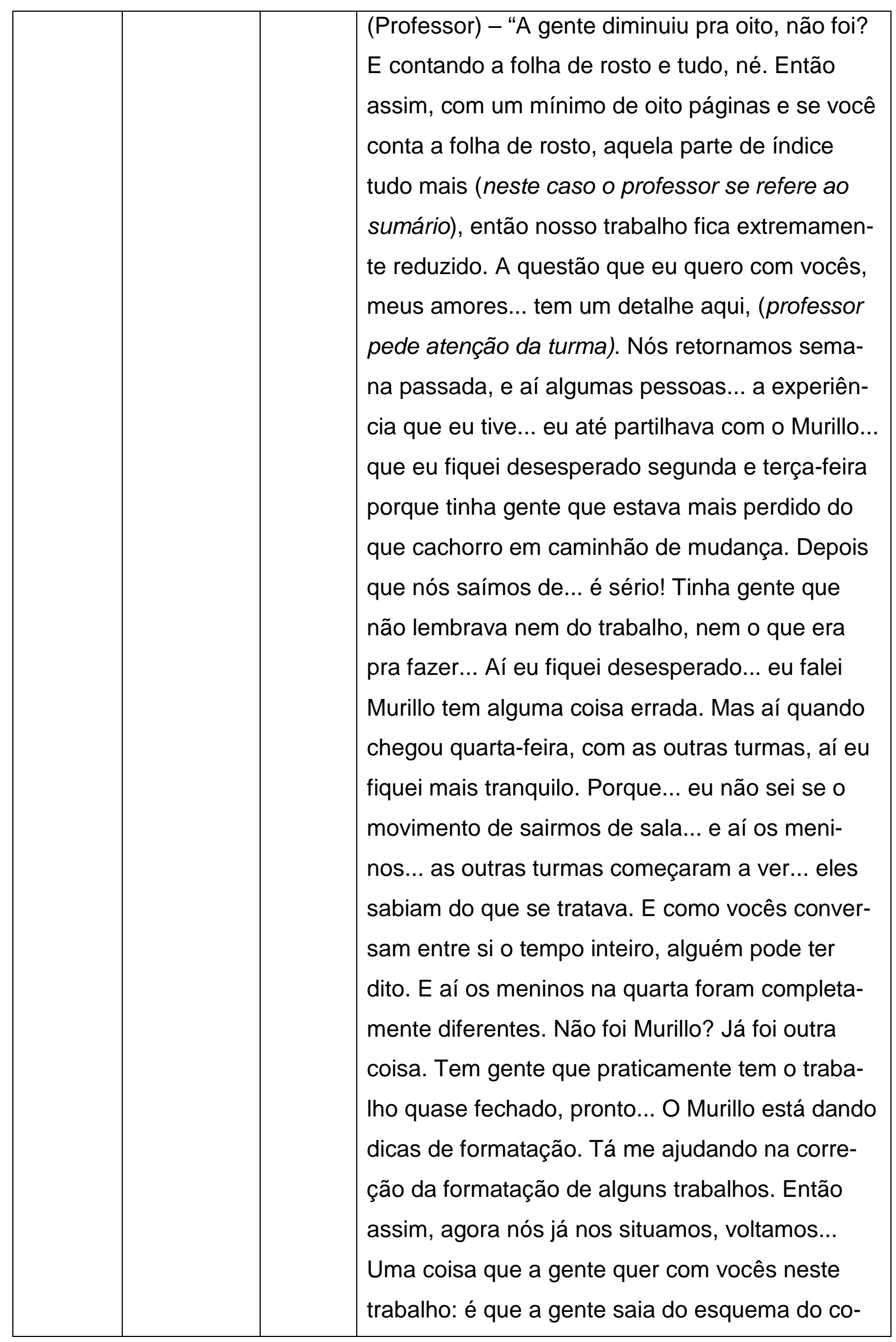




\begin{tabular}{|l|l|l|}
\hline $\mid$ & $\begin{array}{l}\text { pia e cola. Porque nós estamos acostumados a } \\
\text { fazer trabalhos de copiar e colar. E isso a gente } \\
\text { não quer. Porque oh, eu falo pra vocês... e eu } \\
\text { falo de cadeira porque pra mim também é: escre- } \\
\text { ver não é fácil. Falar é fácil. Falar é muito fácil. } \\
\text { Mas quando você vai colocar no papel alguma } \\
\text { coisa... e ainda mais quando você pesquisa e } \\
\text { que você tem que resumir e tudo mais... é muito } \\
\text { mais difícil. Não é fácil. Agora, se você aprende } \\
\text { como a Tamara colocou ali... a entregar os seus } \\
\text { trabalhos de maneira mais exigente... não é por- } \\
\text { que o professor pediu, mas é porque eu vou en- } \\
\text { tregar o meu trabalho assim. Eu vou entregar o } \\
\text { meu trabalho e vou dar uma exigência pra ele. } \\
\text { Aí, com certeza, a gente também aprende. Não } \\
\text { tenho dúvida disso. E o aprendizado não está na } \\
\text { formatação. Não se tem que ficar no centro, o } \\
\text { número à direita, tem que ter referência... não é } \\
\text { isso, mas é o processo que foi construído pra } \\
\text { pesquisar o trabalho. Isso é que é o mais impor- } \\
\text { tante. É isso que a gente deve pensar. } \\
\text { (Pesquisador) - "Bom, como o Álvaro disse, o } \\
\text { processo é que interessa pra o professor, não é? } \\
\text { Não é aquilo de fato que vocês vão entregar. E é } \\
\text { por isso que ele vai passar pra vocês, a solicita- } \\
\text { ção de vocês elaborarem um pequeno relatório e } \\
\text { responderem algumas perguntas. Primeiro, que o } \\
\text { Álvaro percebeu: tem muita gente aqui, que está } \\
\text { se descuidando, e que provavelmente não vai } \\
\text { conseguir uma nota interessante. Pensando nis- } \\
\text { so, a gente elaborou dois outros instrumentos, } \\
\text { principalmente para ajudá-los a obterem um pou- } \\
\text { co mais de nota. Então as sete perguntinhas que }\end{array}$ \\
\\
\hline
\end{tabular}




\begin{tabular}{|l|l|l|}
\hline $\mid$ & $\begin{array}{l}\text { o Álvaro vai passar depois, por exemplo, vale } \\
\text { meio ponto. E um pequeno relatório que vocês } \\
\text { também vão responder... e aí esse relatório é pra } \\
\text { que: O Álvaro precisa saber como foi esse pro- } \\
\text { cesso de escrita desse trabalho. Então ele quer } \\
\text { saber se vocês se reuniram em casa, se vocês } \\
\text { só estudaram aqui no CRA, se vocês só utiliza- } \\
\text { ram a internet. É pra escrever mesmo. É um rela- } \\
\text { to, prestem atenção! É um relato de como foi a } \\
\text { experiência de realizar este trabalho. Inclusive } \\
\text { dizendo, olha, as minhas dificuldades foram es- } \\
\text { sas. Esse relatório também vai valer meio ponto. } \\
\text { Então percebam o seguinte, quem ainda não se } \\
\text { dedicou o suficiente, precisa, mais do que nunca, } \\
\text { aproveitar essa oportunidade que o Álvaro vai } \\
\text { dar, pra ganhar pelo menos um ponto. E aqueles } \\
\text { que se dedicaram muito, pensem da seguinte } \\
\text { forma: vocês terão um ponto adicional. Então } \\
\text { assim, percebam que é algo a mais que o pro- } \\
\text { fessor está querendo dar pra vocês que estão se } \\
\text { dedicando. Então, a próxima atividade que tem } \\
\text { depois que vocês terminarem o trabalho será } \\
\text { responder essas perguntas e escrever esse pe- } \\
\text { queno relatório. E não se enganem, isso não é } \\
\text { brincadeira. Vocês de fato terão que fazer. Tem } \\
\text { muita gente aqui que quando a gente olha, não } \\
\text { começaram ainda a fazer o trabalho. } \\
\text { (Professor) - "Alguém quer falar alguma coisa...? } \\
\text { (pequena pausa) Oh, eu sei... teve uma aluna } \\
\text { que falou assim: 'poxa Álvaro... mas aí é chato, o } \\
\text { tema é chato, não sei mais o que...' Oh, deixa eu } \\
\text { falar uma coisa para vocês: na vida a gente não } \\
\text { faz apenas aquilo que gosta. Eu gostaria muito }\end{array}$ \\
\end{tabular}




\begin{tabular}{|c|c|c|c|}
\hline & & & $\begin{array}{l}\text { de tá fazendo só aquilo que eu gosto particular- } \\
\text { mente, mas na vida não é assim. A gente faz coi- } \\
\text { sas, muitas vezes, que nós não gostamos, certo? } \\
\text { Não nos atrai, não é interessante. Mas nem por } \\
\text { isso, eu vou deixar de me comprometer com } \\
\text { aquilo que faz parte do meu processo acadêmi- } \\
\text { co, da minha formação. Então assim, não fiquem } \\
\text { chateados porque o tema é ruim, por que é difícil, } \\
\text { porque muitas vezes a gente se depara diante de } \\
\text { uma situação e aí ao invés da gente ir pra cima } \\
\text { dela, a gente faz é ficar mais é... reprimido, retra- } \\
\text { ído. E aí nós temos que mostrar nosso protago- } \\
\text { nismo, a nossa autonomia, a nossa capacidade } \\
\text { de fazer as coisas. Então eu acredito que um } \\
\text { trabalho como esse também, ele proporciona } \\
\text { isso. Ok? Tá bom? Foi bom estar com vocês. }\end{array}$ \\
\hline OBC4 & $9 / 7$ & $\begin{array}{l}\text { Con- } \\
\text { trole } \\
\left(9^{\circ} \mathrm{H}\right)\end{array}$ & $\begin{array}{l}\text { CRA: Retorno das atividades de busca de infor- } \\
\text { mações após as férias. Alunos parecem não se } \\
\text { lembrar mais sobre o que tem que ser feito no } \\
\text { trabalho de pesquisa. Alguns relatam que o tra- } \\
\text { balho está sendo feito em casa. O professor ten- } \\
\text { ta retomar grupo a grupo o foco do trabalho. }\end{array}$ \\
\hline OB5 & $\begin{array}{l}15 / 7(7: 40) \\
\text { Aulas } 9 \text { e } \\
10\end{array}$ & 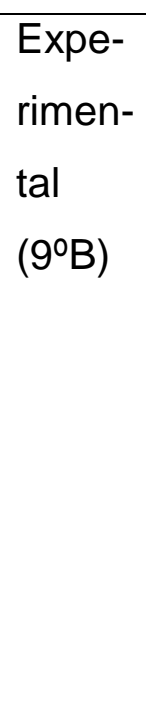 & $\begin{array}{l}\text { CRA: (Momento de busca de informa- } \\
\text { ções/formatação do trabalho). Alunos ainda dis- } \\
\text { persos. Algumas duplas montam o trabalho no } \\
\text { PowerPoint. Apesar de terem recebido a infor- } \\
\text { mação de que o trabalho deverá ser entregue em } \\
\text { Word, alguns alunos preferem colocar em modo } \\
\text { de apresentação primeiro (isso pode implicar em } \\
\text { perda de tempo). Alguns alunos tentam recuperar } \\
\text { o roteiro no Portal Marista, demonstrando pouca } \\
\text { organização no momento do estudo. Professor }\end{array}$ \\
\hline
\end{tabular}




\begin{tabular}{|c|c|c|c|}
\hline & & & $\begin{array}{l}\text { passa nas cabines tirando eventuais dúvidas. } \\
\text { Pelo observado, muitos alunos apresentam vá- } \\
\text { rias dúvidas. O pesquisador ajuda duas alunas } \\
\text { que já esboçam o trabalho no formato solicitado, } \\
\text { com base no guia. Uma curiosidade observada } \\
\text { pelo pesquisador, é que os estudantes demons- } \\
\text { tram pouca habilidade para trabalhar com recur- } \\
\text { sos básicos do computador. Desde editar um } \\
\text { texto com fonte específica, até inserir caixa de } \\
\text { texto, tabelas etc. Alguns estudantes acabaram } \\
\text { perdendo o arquivo principal do trabalho por não } \\
\text { terem conseguido salvá-lo em local específico. O } \\
\text { pesquisador não imaginou que os alunos fossem } \\
\text { demonstrar esse tipo de dificuldade. Isso de- } \\
\text { monstra que ainda faltam habilidades básicas a } \\
\text { serem trabalhadas, principalmente com base na } \\
\text { utilização de ferramentas simples, já considera- } \\
\text { das de domínio coletivo como os editores de tex- } \\
\text { to. O pesquisador também observa muita disper- } \\
\text { são e perda de tempo dos estudantes. Segundo } \\
\text { o professor, a enturmação (montagem das tur- } \\
\text { mas) realizada pela escola, acabou comprome- } \\
\text { tendo o comportamento da turma, já que colocou } \\
\text { juntos muitos alunos considerados inquietos. }\end{array}$ \\
\hline OB6 & $\begin{array}{l}22 / 7 \\
\text { Aulas } 11 \text { e } \\
12\end{array}$ & $\begin{array}{l}\text { Expe- } \\
\text { rimen- } \\
\text { tal } \\
\left(9^{\circ} \mathrm{B}\right)\end{array}$ & $\begin{array}{l}\text { Após aula, professor conduz a turma para a sala } \\
\text { Champagnat, para momento de debate sobre o } \\
\text { trabalho, momento que configura a pesquisa- } \\
\text { ação. } \\
\text { Professor: "A gente não tem que ficar agora aca- } \\
\text { nhado, né... de nos colocar. É esse o momento. } \\
\text { Até por que a gente pensa que... o professor tem } \\
\text { uma ideia na cabeça, e ele toca. Então assim... } \\
\text { Só que necessariamente, aí é a parte de vocês }\end{array}$ \\
\hline
\end{tabular}




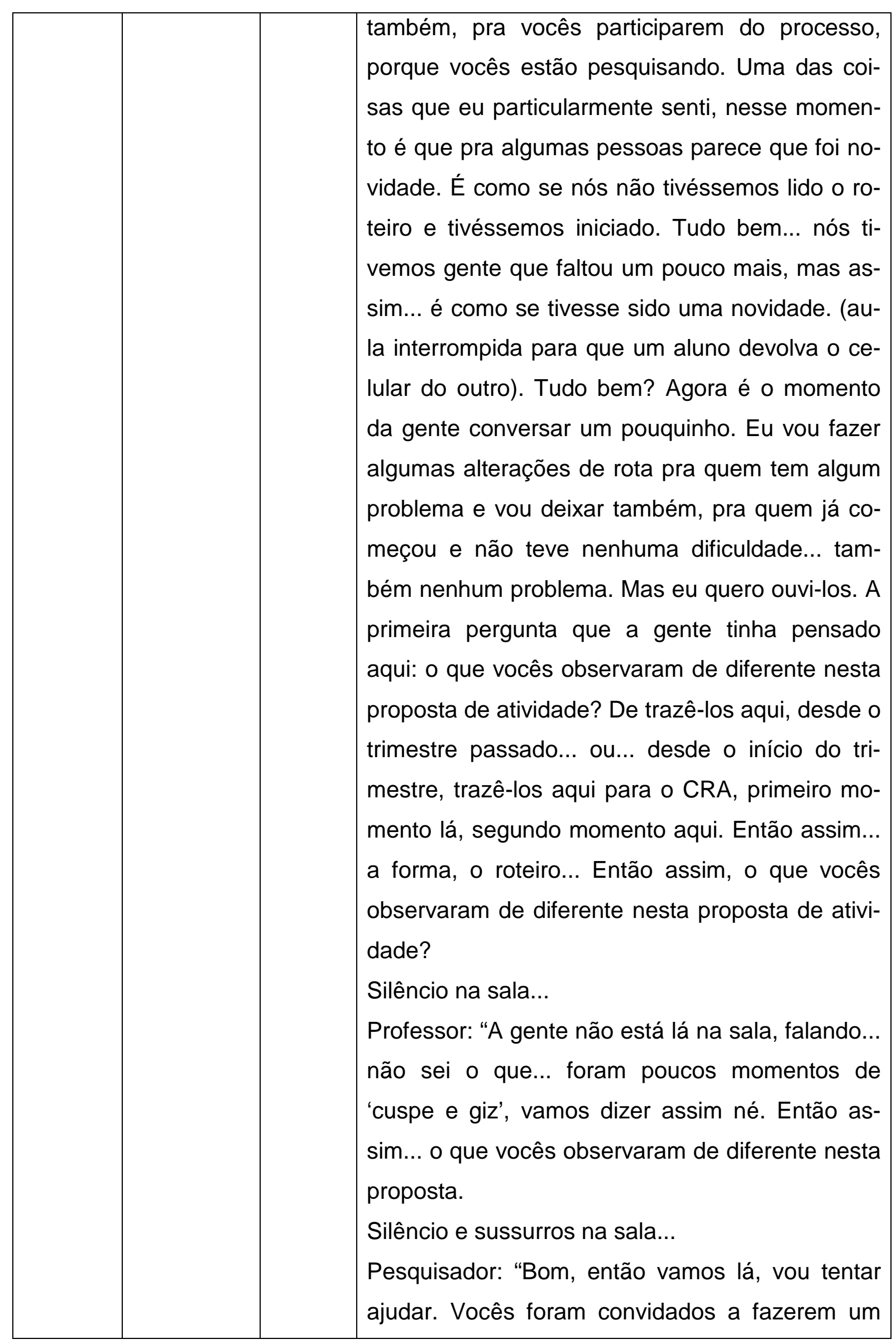




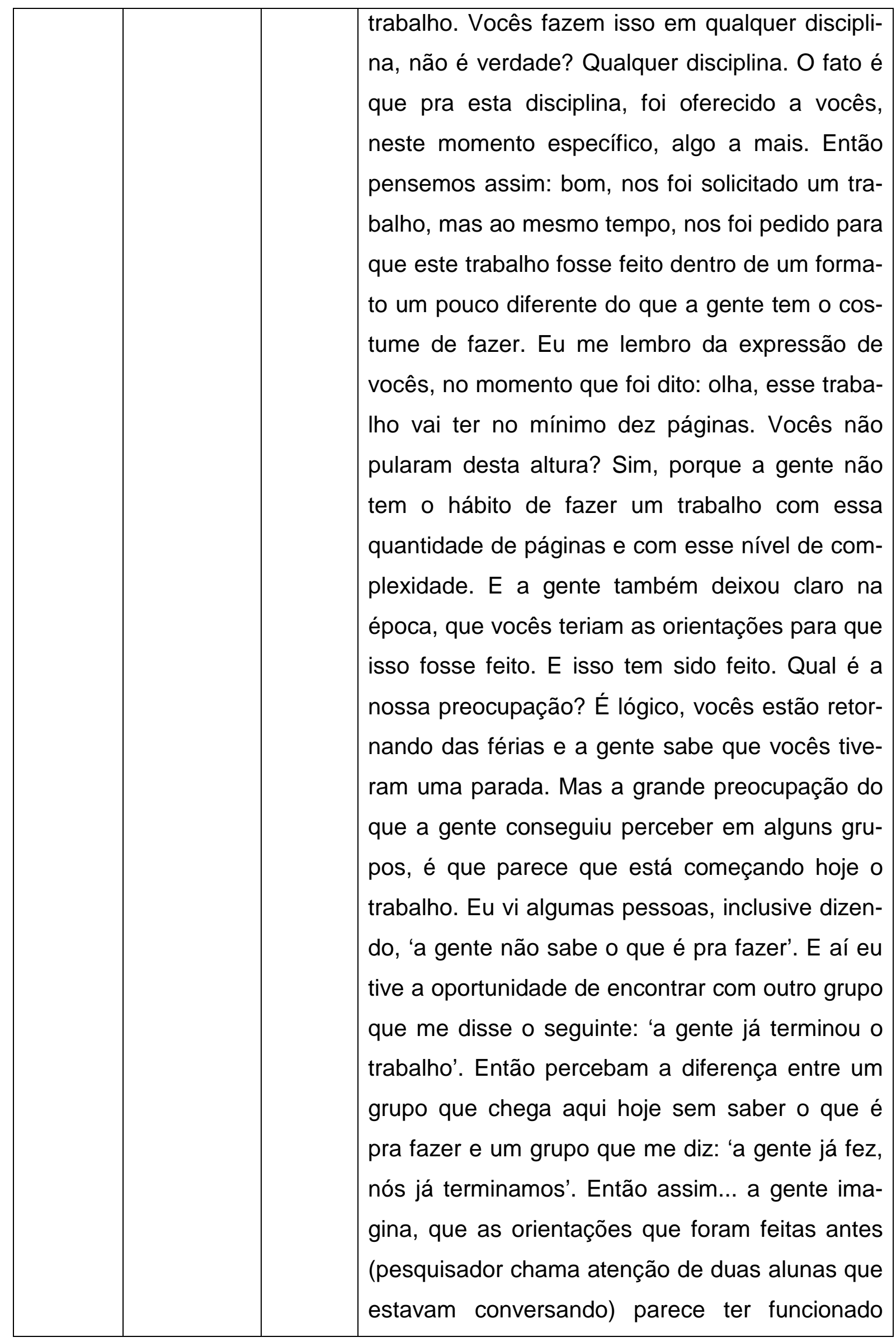




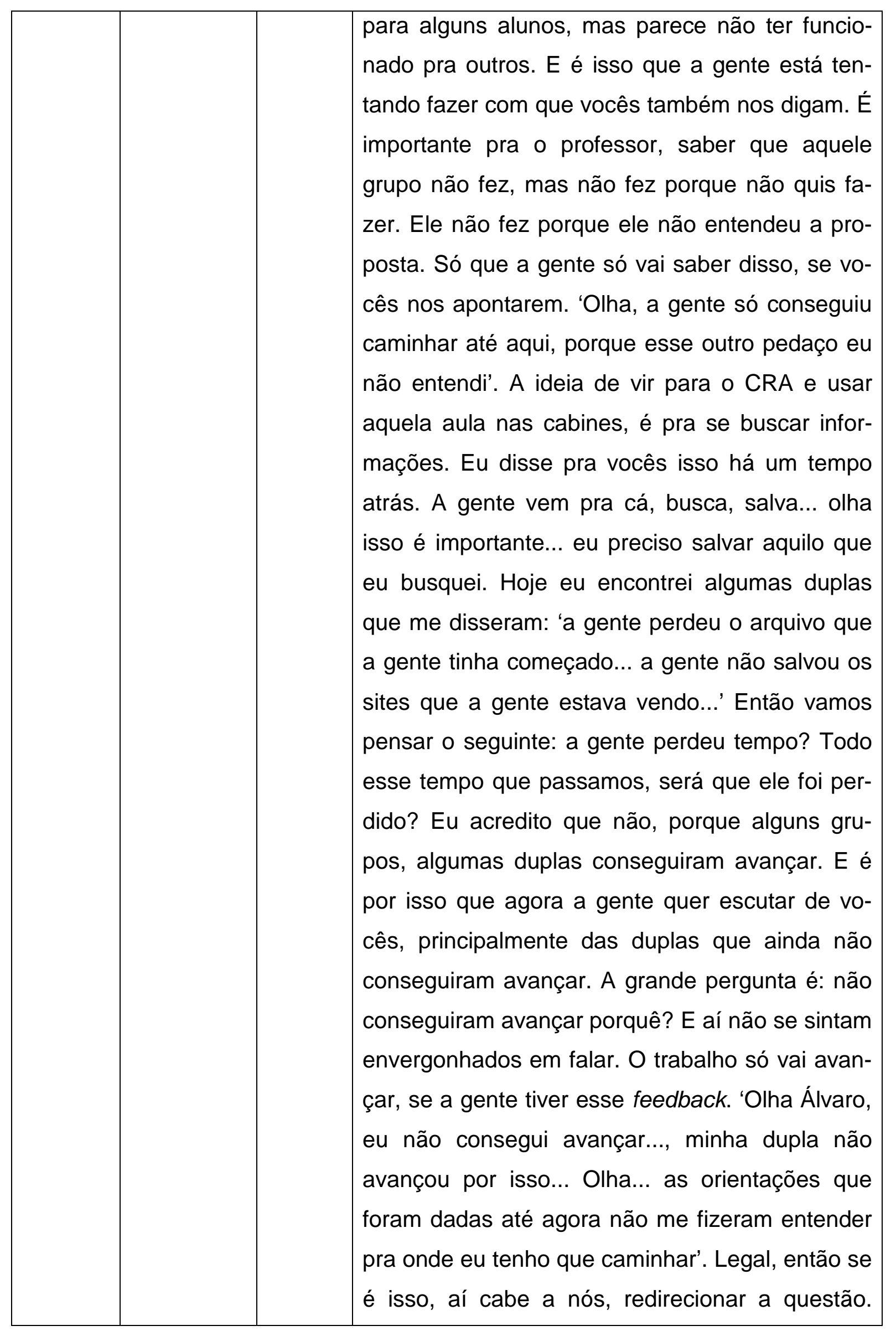




\begin{tabular}{|l|l|l|}
\hline & $\begin{array}{l}\text { Mas, se vocês não nos trouxerem aquilo que está } \\
\text { incomodando, no final das contas, vocês serão } \\
\text { prejudicados. Porquê? Porque o Álvaro precisa } \\
\text { deste trabalho pronto. E aí é uma relação de tro- } \\
\text { ca: ele precisa do trabalho, vocês vão precisar da } \\
\text { nota também. Só que o que a gente realmente } \\
\text { precisa é outra coisa. É que vocês aprendam o } \\
\text { conteúdo que está sendo colocado. Então qual a } \\
\text { ideia desses momentos de debate? É que a gen- } \\
\text { te aqui consiga mostrar, inclusive para os nossos } \\
\text { colegas que eu estudei em casa o conteúdo e é } \\
\text { por isso que eu estou conseguindo falar. E tam- } \\
\text { bém pra dizer: 'olha, eu ainda não entendi a pro- } \\
\text { posta, porque mesmo estudando, eu não estou } \\
\text { conseguindo avançar'. Esse momento aqui, ele é } \\
\text { diferente. Vocês não tem um momento de debate } \\
\text { desses em todas as disciplinas. E o momento de } \\
\text { debate é pra dizer : 'como é que anda o meu tra- } \\
\text { balho?'. Nós não temos esses momentos... então } \\
\text { quando o Álvaro faz essa primeira pergunta 'o } \\
\text { que que vocês estão observando de diferente } \\
\text { nesta atividade?'. Pra mim, esta é uma das coi- } \\
\text { sas diferentes. Vocês estão tendo a oportunidade } \\
\text { de falar sobre o processo do aprendizado que } \\
\text { vocês estão tendo sobre um determinado tema. } \\
\text { Aí eu jogo uma outra questão e queria que vocês } \\
\text { tentassem responder: 'o conteúdo que foi solici- } \\
\text { tado, é muito difícil?' Aquilo que foi proposto... tá } \\
\text { sendo muito difícil pra fazer. } \\
\text { Alunos: "Não... sim...” } \\
\text { Pesquisador: Então vamos lá: o grupo que me } \\
\text { disse hoje que terminou o trabalho... e aí sem } \\
\text { constrangimento... que terminou o trabalho é }\end{array}$ \\
\hline
\end{tabular}




\begin{tabular}{|l|l|l|}
\hline & $\begin{array}{l}\text { porque usou as férias para estudar... Tem gente } \\
\text { que preferiu se divertir... não tem problema ne- } \\
\text { nhum... Mas, o grupo que conseguiu avançar, } \\
\text { entendeu a proposta como algo muito complica- } \\
\text { do? Porque... o grupo que já conseguiu termi- } \\
\text { nar... ele pode apontar para o grupo que ainda } \\
\text { tem dificuldade, que caminho ele seguiu... e isso } \\
\text { é muito positivo. } \\
\text { Professor: "Tem gente em outras turmas que } \\
\text { também já fecharam o trabalho. Por exemplo, } \\
\text { ontem aqui do 9oG, tem gente que praticamente } \\
\text { fechou o trabalho... e tem gente que não. Então } \\
\text { assim... isso que eu quero também entender. } \\
\text { Porque eu não quero que alguns fiquem no meio } \\
\text { do caminho e outros avancem. Então... o pro- } \\
\text { blema pode estar comigo também... então a gen- } \\
\text { te precisa avaliar isso. Nós estamos tendo essa } \\
\text { oportunidade de fazermos estes processos. Se } \\
\text { tem uma coisa, que a gente valoriza, é essa au- } \\
\text { tonomia da aprendizagem. Porque ai não faz } \\
\text { sentido, se vocês... tem aluno que por exemplo... } \\
\text { não precisa nem do professor... e tem aluno que } \\
\text { precisa do professor pra fazer esta mediação. } \\
\text { Então esse é o momento da gente discutir sobe } \\
\text { isso. Então se os meninos puderem vir aqui para } \\
\text { dizer 'fizemos o caminho e tal.... Tá certo? Quem } \\
\text { vai dizer se o caminho que eles fizeram está cer- } \\
\text { to sou eu, na avaliação. Mas eles já fizeram o } \\
\text { caminho, então pode vir aqui, pode falar de onde } \\
\text { tiver, como é que fizeram... colocar um pouqui- } \\
\text { nho sobre o processo. } \\
\text { Pesquisador: "Ai antes de vocês começarem, é } \\
\text { dizer o seguinte: quando o Álvaro pede pra vocês }\end{array}$ \\
\end{tabular}




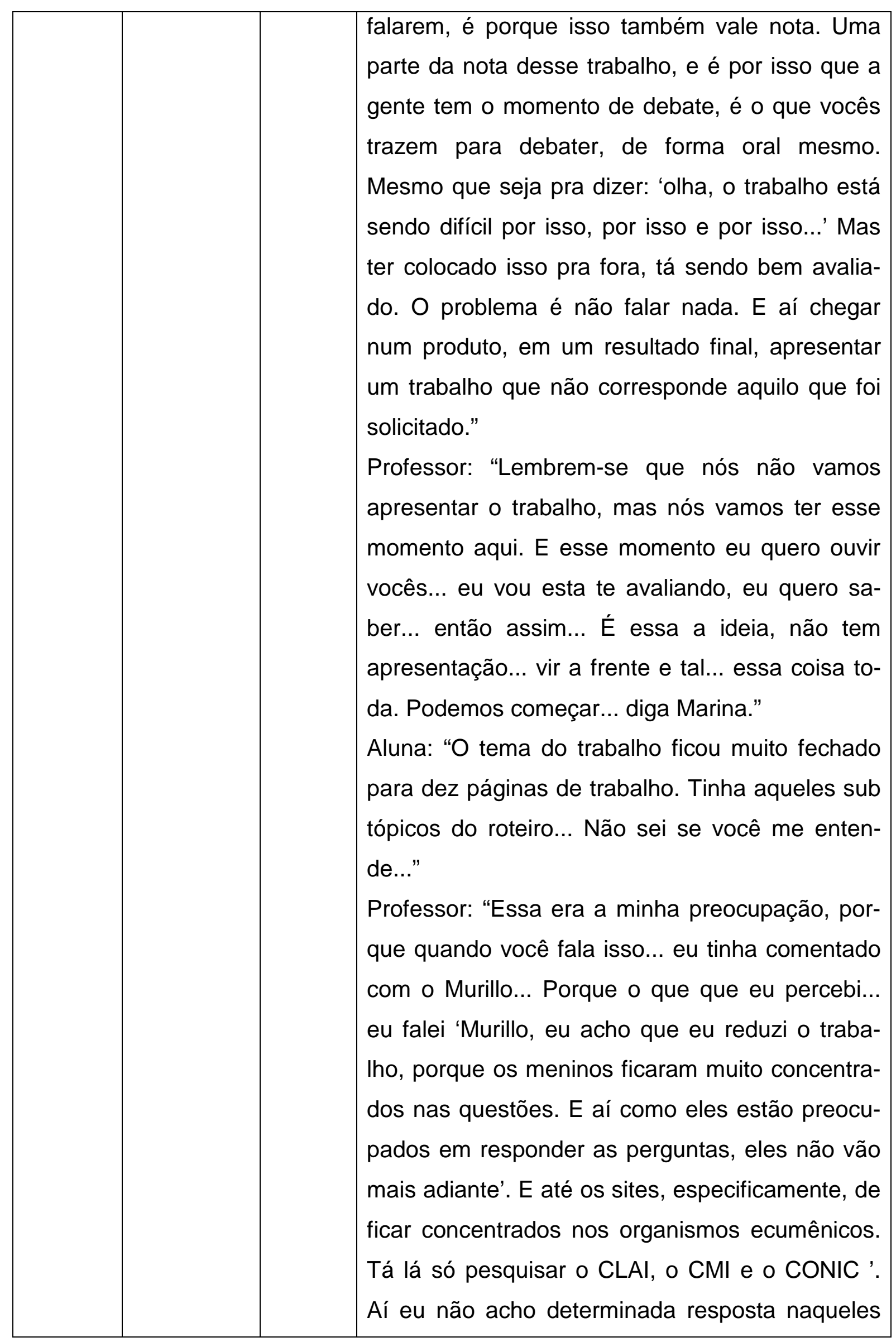




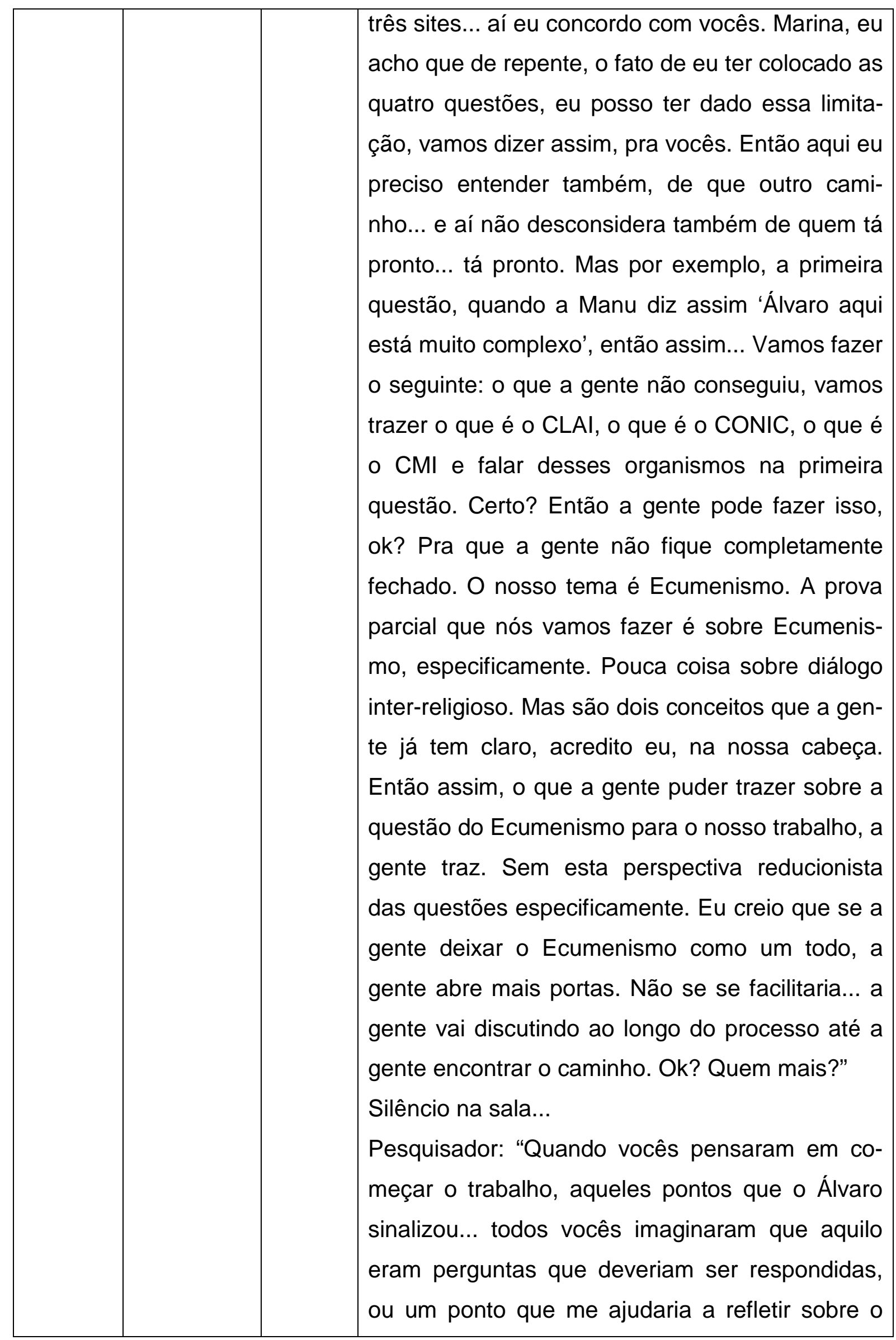




\begin{tabular}{|l|l|}
\hline & $\begin{array}{l}\text { assunto para guiar aquilo que eu teria que buscar } \\
\text { para aí sim começar a escrever? Eu pergunto } \\
\text { isso porque, eu vi alguns alunos fazendo o se- } \\
\text { guinte: pegava ou o objetivo que o professor ti- } \\
\text { nha colocado, ou a proposta que o Álvaro tinha } \\
\text { colocado, copiava inteira no Google e mandava } \\
\text { buscar. Isso me fez refletir o seguinte: 'os alu- } \\
\text { nos... parte dos alunos está achando que isso é } \\
\text { uma pergunta pra ser respondida'. Na verdade, a } \\
\text { proposta de ter colocado alguns questionamen- } \\
\text { tos ali, foi justamente para ajudar vocês a refleti- } \\
\text { rem sobre o assunto. A reflexão sobre o assunto } \\
\text { é que é o trabalho. Não existe uma pergunta a } \\
\text { ser respondida. A proposta do trabalho é que } \\
\text { vocês tragam a reflexão sobre aqueles pontos. } \\
\text { Quando nossa colega diz que a proposta estava } \\
\text { muito fechada... é difícil escrever dez páginas } \\
\text { com uma coisa que parece fechada. Mas ao } \\
\text { mesmo tempo, se eu entender que aqueles pon- } \\
\text { tos, me servem apenas de reflexão, aí eu não } \\
\text { tenho mais uma proposta fechada. Eu tenho a } \\
\text { possibilidade de abrir um leque e de trazer isso } \\
\text { para o trabalho. Mas foi fundamental que a cole- } \\
\text { ga de vocês apresentasse as primeiras indaga- } \\
\text { ções. Agora, a gente precisa de mais instrumen- } \\
\text { tos para que o Álvaro perceba se é necessário } \\
\text { fazer alguma mudança ou ajuste. Ou então, va- } \\
\text { mos encarar que se um grupo conseguiu, isso } \\
\text { quer dizer que todos deveriam ter conseguido? } \\
\text { Sim, ou não?" } \\
\text { Aluno: "Não, porque um grupo pode ser menos } \\
\text { desenvolvido que o outro (risos)". } \\
\text { Pesquisador: "Eu não diria 'menos desenvolvi- }\end{array}$ \\
\hline
\end{tabular}




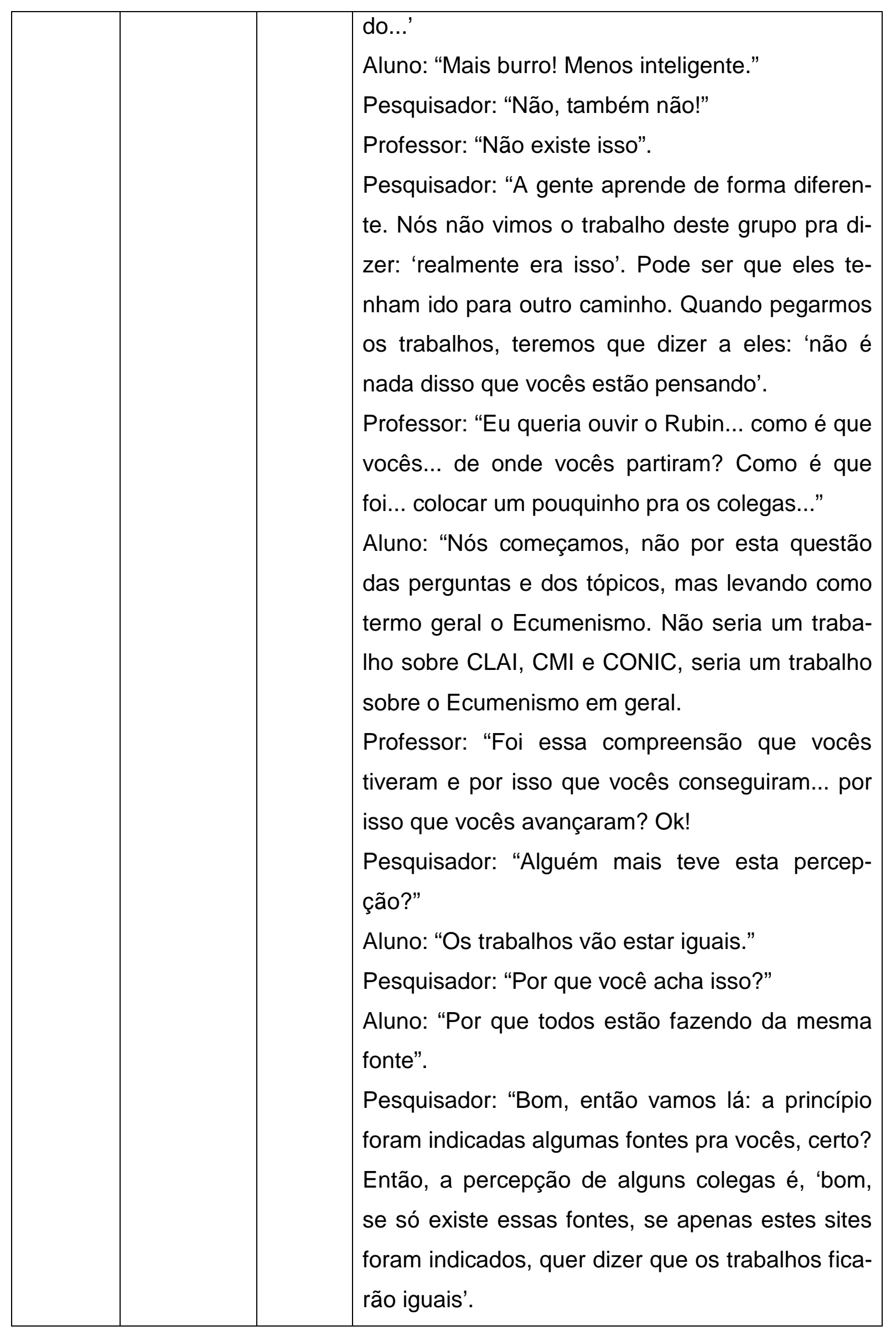




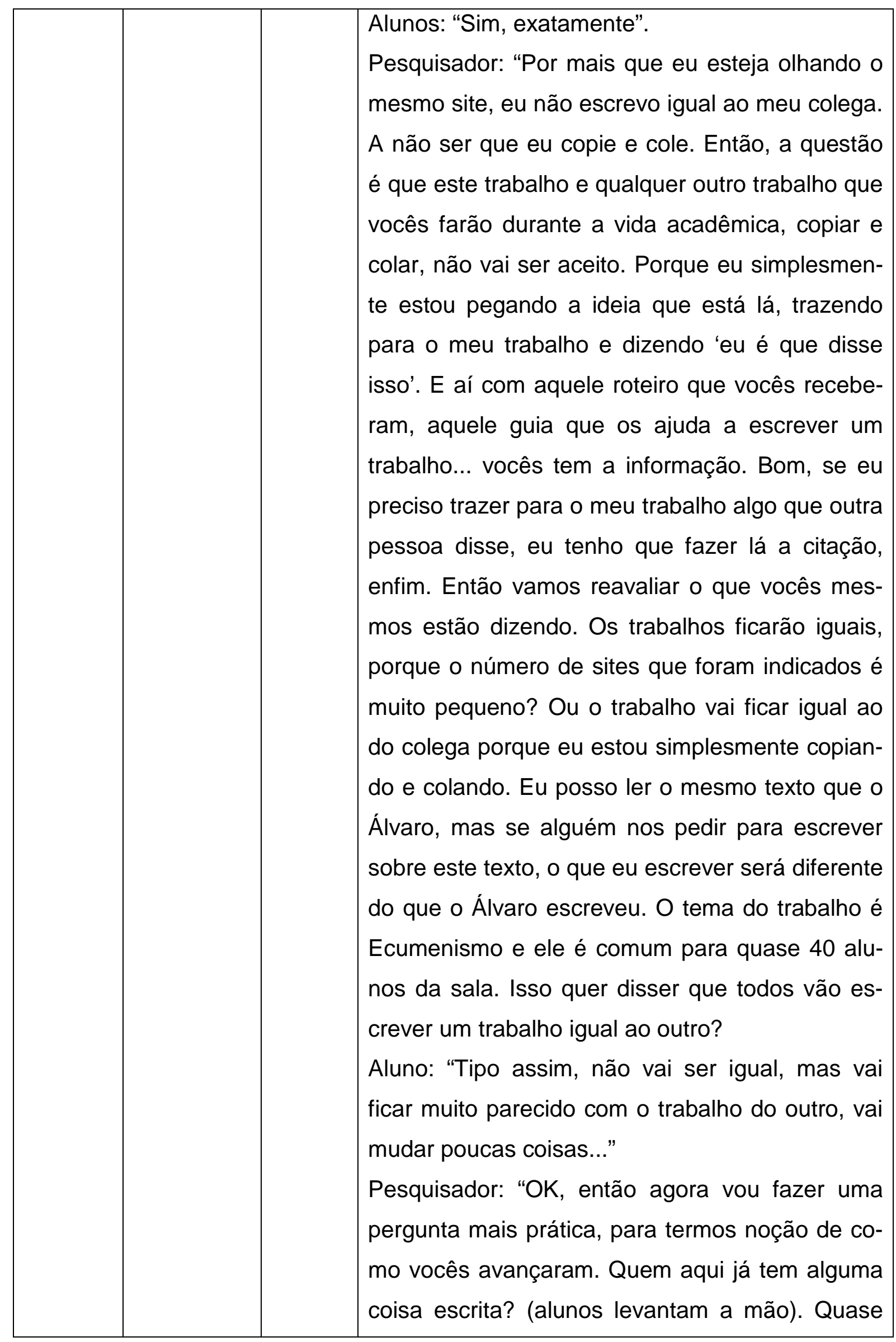




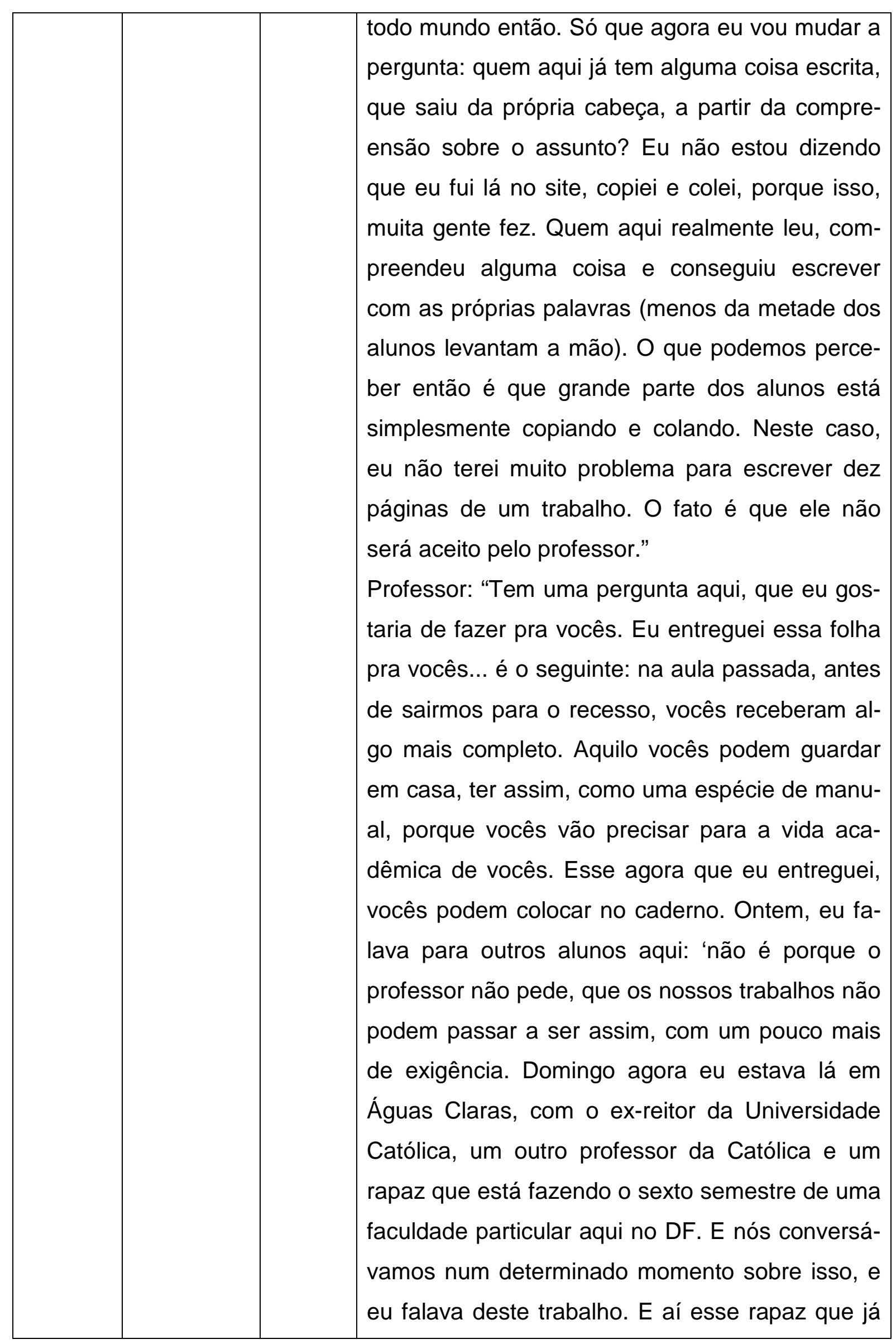




\begin{tabular}{|l|l|}
\hline & $\begin{array}{l}\text { está a três anos na faculdade me disse o seguin- } \\
\text { te: 'tem aluno lá na faculdade, que não sabe fa- } \\
\text { zer isso aí'. } \\
\text { Aluno: “Que é isso velho!" } \\
\text { Professor: "Sexto semestre! É claro que a gente } \\
\text { entende, por exemplo a angústia que o Gustavo } \\
\text { trouxe, quando ele fala assim: 'puxa Álvaro, pa- } \\
\text { rece uma coisa de vestibular, de faculdade, não } \\
\text { sei mais o que...' E é por isso que eu queria fazer } \\
\text { esta pergunta aqui pra vocês: como é que tem } \\
\text { sido elaborar um trabalho, com um padrão mais } \\
\text { exigente? Vocês identificam alguma vantagem } \\
\text { nisso? É vantajoso, a gente fazer um trabalho } \\
\text { que há uma exigência maior? Como é que a gen- } \\
\text { te enxerga isso? } \\
\text { Aluna: “Sim”. } \\
\text { Pesquisador: "Pra você que disse 'sim', sim por- } \\
\text { que? } \\
\text { Aluna: "Porque você aprende coisas novas e ao } \\
\text { invés de ficar copiando e colando essas coisas, } \\
\text { você pode gravar na sua cabeça o que você lê e } \\
\text { que você escreve. } \\
\text { Pesquisador: "Você acha que você aprende mais } \\
\text { com isso?" } \\
\text { Aluna: “Sim". } \\
\text { Pesquisador: "Bom, esta é a visão de uma colega } \\
\text { de vocês, mas a pergunta é curiosa. Isso porque, } \\
\text { se o aluno perceber que... bom, se eu tenho algo } \\
\text { mais exigente... se a escola está me pedindo al- } \\
\text { go mais trabalhoso, mais exigente, e eu, pelo } \\
\text { menos de acordo com a percepção que a colega } \\
\text { acabou de trazer, aprendo melhor, será que isso } \\
\text { é vantajoso pra vocês? Então vamos pensar: a }\end{array}$ \\
\end{tabular}




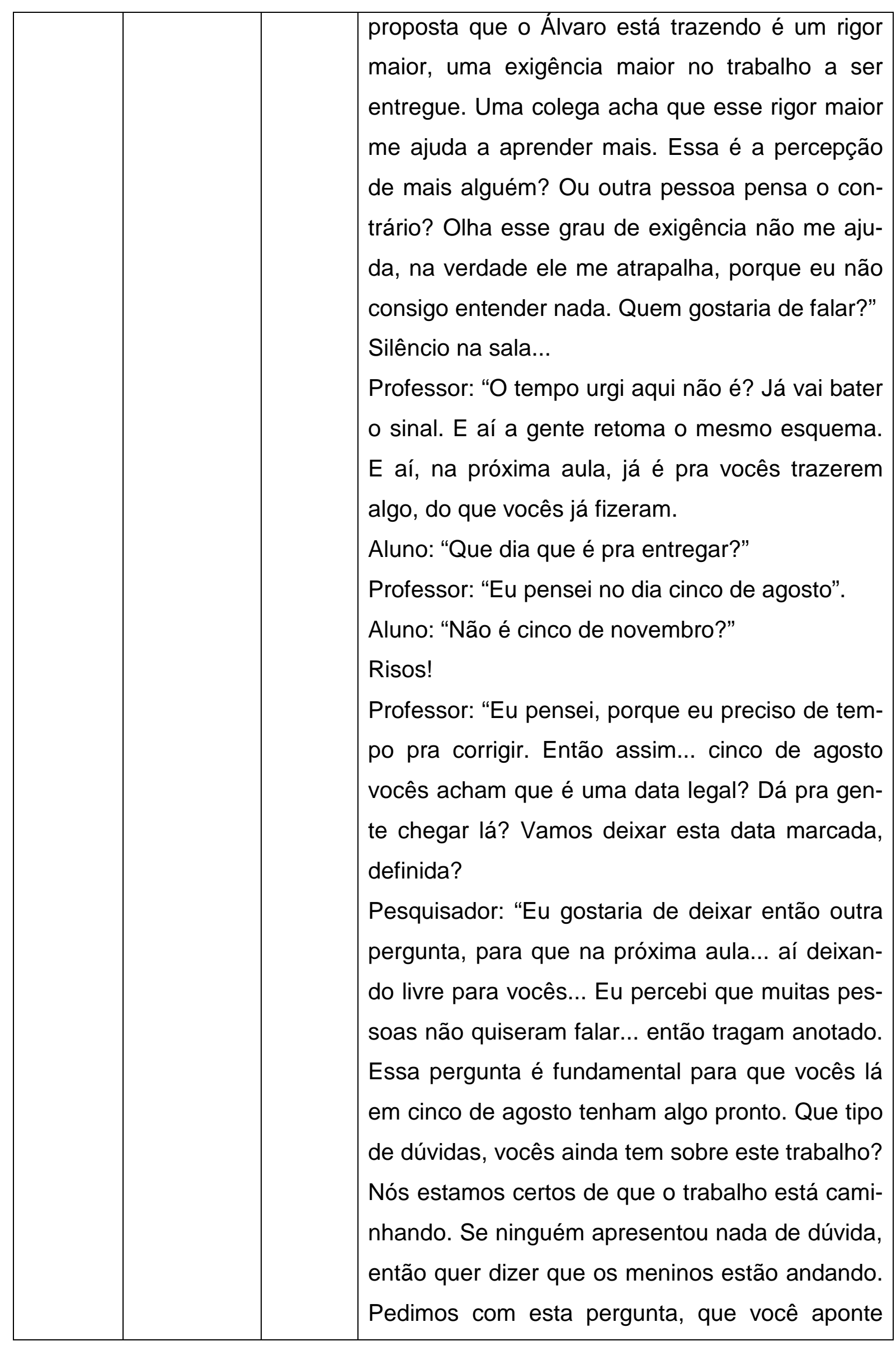




\begin{tabular}{|c|c|c|c|}
\hline & & & $\begin{array}{l}\text { para o professor, de forma clara, que tipo de dú- } \\
\text { vidas vocês ainda tem. Tragam por escrito, man- } \\
\text { dem e-mail... } \\
\text { Aluno: "Minha dupla nunca vem... e aí, como é } \\
\text { que eu faço? Coloco o nome dele no trabalho ou } \\
\text { não?" } \\
\text { Pesquisador: "O que você acha? Alguém que } \\
\text { não está contribuindo com o trabalho... aí uma } \\
\text { questão de deixar a amizade de lado... se o cole- } \\
\text { ga não fez nada no trabalho, você acha que é } \\
\text { válido colocar o nome dele só porque ele é seu } \\
\text { amigo? } \\
\text { Aluno: "Não, não..." } \\
\text { Professor encerra a aula e sai com os alunos. }\end{array}$ \\
\hline OB7 & $\begin{array}{l}29 / 7(8 \mathrm{~h}) \\
\text { Aulas } 13 \mathrm{e} \\
14\end{array}$ & 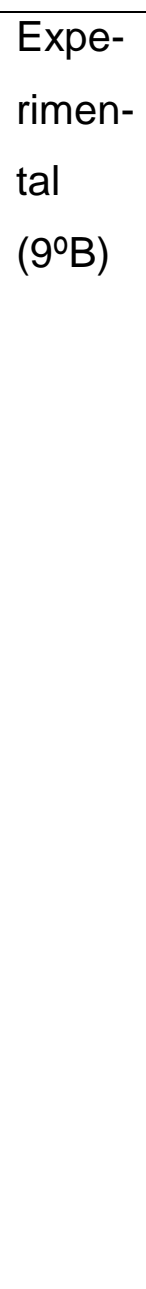 & $\begin{array}{l}\text { CRA: Alguns alunos relatam que já estão com o } \\
\text { trabalho pronto. O pesquisador pede então para } \\
\text { que o trabalho seja mostrado, para que as dúvi- } \\
\text { das sobre a formatação sejam sanadas, mas } \\
\text { neste momento os alunos relatam que deixaram } \\
\text { o trabalha em casa. } \\
\text { Professor: "Esse conceito de diálogo inter- } \\
\text { religioso e ecumenismo está claro pra vocês? } \\
\text { Está claro? Sexta-feira, se eu pedir na prova pra } \\
\text { vocês... vou colocar um artigo de jornal e vou } \\
\text { pedir pra vocês naquele artigo, tirar elementos } \\
\text { que sejam de ecumenismo e de diálogo inter- } \\
\text { religioso, vocês conseguem fazer sem dificulda- } \\
\text { de?" } \\
\text { Alunos: "Sim, tranquilo." } \\
\text { Professor: "Se eu disser pra vocês... no mês de } \\
\text { maio, o líder da igreja católica esteve reunido... } \\
\text { (barulho na turma). No final do mês de maio, vo- }\end{array}$ \\
\hline
\end{tabular}




\begin{tabular}{|l|l|}
\hline & $\begin{array}{l}\text { cês devem ter acompanhado tanto do meio tele- } \\
\text { visivo quanto impresso, que o líder da igreja cató- } \\
\text { lica esteve no Oriente Médio antes desse conflito } \\
\text { agora... que está instalado novamente entre ju- } \\
\text { deus e palestinos. E ele teve alguns encontros } \\
\text { com algumas pessoas... Se eu pedir para que } \\
\text { você... se eu perguntar pra vocês: o encontro do } \\
\text { líder da igreja católica com o líder do judaísmo e } \\
\text { do islamismo é ecumenismo ou diálogo inter- } \\
\text { religioso?" } \\
\text { Alunos: "Diálogo inter-religioso." } \\
\text { Professor: "Porquê?" } \\
\text { Alunos: "São religiões diferentes." } \\
\text { Professor: "Seria ecumenismo se fosse o quê?" } \\
\text { Aluno: “Só entre igrejas cristãs." } \\
\text { Professor: "lgrejas cristãs, não necessariamente } \\
\text { católicas. Mas a Católica com a Anglicana, com a } \\
\text { Ortodoxa, com a Luterana, com a Presbiteriana, } \\
\text { isso é ecumenismo. Tá certo?" } \\
\text { O professor continua sua aula sobre a temática } \\
\text { do ecumenismo e retoma com a questão da ela- } \\
\text { boração do trabalho ao final. } \\
\text { Professor: "Atenção: tem duas duplas, não, tem } \\
\text { três duplas que já terminaram... Então... vocês } \\
\text { (duplas que terminaram), terça-feira, já vão trazer } \\
\text { o trabalho pronto, certo? Dentro daquele formato, } \\
\text { bonitinho. Outra dupla parece que vai concluir o } \\
\text { trabalho hoje também. Então... essas quatro du- } \\
\text { plas já ficaram prontos. Os outros se não concluí- } \\
\text { rem até terça-feira tragam impresso o que vocês } \\
\text { já pesquisaram. O fato de vocês trazerem eu vou } \\
\text { contar como tarefa de casa também, certo? En- } \\
\text { tão o que vocês já pesquisaram. Porque aí a }\end{array}$ \\
\hline
\end{tabular}




\begin{tabular}{|l|l|l|}
\hline & $\begin{array}{l}\text { gente vai promover um pouco um debate... Não é } \\
\text { pra chegar aqui e dizer assim: 'Álvaro, o nosso } \\
\text { trabalho, a gente mandou por e-mail e aí a fulana } \\
\text { colocou no pendrive, e aí o pendrive estragou, o } \\
\text { pendrive sumiu, o cachorro comeu.... Não vale } \\
\text { catástrofes desse tipo. Não vale... é trazer aquilo } \\
\text { que já produzimos. Tem umas novas composi- } \\
\text { ções aí... só pra gente saber se houve alguma } \\
\text { mudança. Atenção!" } \\
\text { Professor checa os nomes das duplas para saber } \\
\text { se houve alguma modificação. } \\
\text { Professor: "O Alberto saiu... você foi pra qual du- } \\
\text { pla?" Gente... uma dupla veio falar comigo por- } \\
\text { que... uma das intenções desse trabalho é que } \\
\text { vocês saiam do 'copia e cola'. Não quero 'copia e } \\
\text { cola'. Tá certo? E aí tem uma dupla que está com } \\
\text { dificuldade de escrever... na hora de resumir... } \\
\text { Então assim, a gente tem que fazer um esforço. } \\
\text { Porque se eu colocar na internet lá, e ver que } \\
\text { você copiou... que está do mesmo jeito, eu vou } \\
\text { tirar ponto de você. Tá certo? Então nada de 'co- } \\
\text { pia e cola'." } \\
\text { Professor finaliza a aula. }\end{array}$ \\
\hline
\end{tabular}




\section{APÊNDICE G - ESTRUTURA DE UM TRABALHO ACADÊMICO}

\section{INTRODUÇÃO}

A elaboração de trabalhos acadêmicos normalizados é uma prática bastante comum nas faculdades e universidades brasileiras, mas quase inexistente na educação básica. Tal fato tem colaborado para que muitos estudantes encontrem dificuldades no ensino superior. Muitos deles sequer ouviram falar da Associação Brasileira de Normas Técnicas (ABNT), desconhecendo a existência de normas e padrões. Tal desconhecimento, muitas vezes, favorece a prática do plágio ${ }^{15}$ e cria barreiras para a prática da pesquisa.

A proposta deste manual introdutório é garantir ao aluno marista a possibilidade de antecipar e facilitar o aprendizado de tais normas, contribuindo para a padronização dos trabalhos escritos, elaborados no Colégio Marista de Brasília. Acredita-se que tal padronização traga contribuições também ao trabalho dos professores, no sentido de tornar a prática da pesquisa em sala de aula mais efetiva.

Este manual foi elaborado de acordo com os padrões definidos pela ABNT e não pretende esgotar o assunto. Está composto de informações básicas, consideradas essenciais para a construção de um trabalho e foi adaptado para a realidade dos alunos do Colégio Marista de Brasília. É uma fonte de consulta, sendo recomendado que faça parte do material de trabalho do professor.

15 "Apresentação feita por alguém, como de sua própria autoria, de trabalho, obra intelectual etc. produzido por outrem". (HOUAISS, 2001) 


\section{DEFINIÇÕES}

\subsection{SUMÁRIO}

Sumário é a enumeração das principais divisões de um trabalho ou documento. Deve vir sempre no início (geralmente logo após a Folha de Rosto ${ }^{16}$ ) e traz a ordem exata de todas as partes ou capítulos que compõem o trabalho. É apresentado ainda com numeração sequencial (1, 2, 3...) e por suas subdivisões (1, 2, 2.1, 2.2, 2.1.1,3...) quando for o caso, e com o número da página respectivo à frente (MENDONÇA; ROCHA; GOMES, 2005).

\section{2 ÍNDICE}

Índices são frequentemente confundidos com sumários. São mais utilizados em trabalhos acadêmicos e têm como principais características sempre vir ao final do documento e serem apresentados em ordem alfabética. Podem ser tanto de "palavras, frases ou expressões técnicas" (MENDONÇA; ROCHA; GOMES, 2005) e remetem a uma determinada parte do texto (o número da página deverá estar indicado na frente dos termos).

Exemplo de um índice alfabético:

Índice Alfabético

Apresentação gráfica, 159

Artigos de jornal, 139

Bibliografia, 123

Capa, 12

${ }^{16}$ O termo "Folha de Rosto" será definido no item 3.1. 
Citações, 115

Direitos autorais, 167

Documentos eletrônicos, 130

\subsection{REFERÊNCIAS}

O termo refere-se a todas as fontes de pesquisa utilizadas, efetivamente, para a elaboração de um trabalho. São fontes que, necessariamente, foram citadas, ao longo do texto, contribuindo para o enriquecimento do trabalho. As referências devem ser apresentadas em ordem alfabética ao final do trabalho.

Obs: A expressão REFERÊNCIAS BIBLIOGRÁFICAS vem sendo cada vez menos utilizada. Com o advento da internet e a possibilidade de se fazer pesquisas em documentos eletrônicos, o termo "bibliográfico" passou a não ser mais apropriado (o prefixo "biblio" ou "biblos" em grego, quer dizer "livro"). Sendo assim, a expressão mais adequada a ser utilizada para referenciar os documentos utilizados na elaboração de um trabalho é apenas REFERÊNCIAS.

\subsection{CITAÇÕES}

Uma citação ocorre quando o autor de um texto extrai um determinado trecho ou ideia de outra publicação, com o intuito de enriquecer o trabalho. As citações podem ser diretas (transcrição literal do trecho consultado) ou indiretas (interpretação do trecho consultado). Em caso de citações diretas de até três linhas, o trecho deverá vir entre aspas. Para citações longas (mais de três linhas), o trecho citado deverá ser transcrito em parágrafo independente, em itálico, com fonte menor e recuo de página maior que o restante do texto.

Para fazer uma citação, é necessário apontar o último sobrenome do(s) autor(es) e apontar a data da obra consultada entre parênteses. A indicação do número da pá- 
gina de onde a citação foi retirada é opcional (caso opte por colocar a página, faça isso em todas as citações).

\section{Ex.: Citação Direta}

Quando se faz uso de citações, é necessário indicar, no texto, os documentos de onde as informações foram retiradas. Todos os documentos citados [...] devem ser indicados na lista de referências apresentada ao final do trabalho (MENDONÇA; ROCHA; GOMES, 2005, p.34).

\section{Ex.: Citação Indireta}

Segundo Curty e Cruz (2001, p.34), citação é "a menção, no texto, de uma informação extraída de outra fonte".

\subsection{BIBLIOGRAFIA}

O termo refere-se a uma lista de documentos que tratam do assunto abordado no trabalho, mas que não foram utilizados na sua elaboração. São materiais que ampliam o conhecimento sobre o assunto abordado, mas que não foram utilizados para a confecção do trabalho. Recomenda-se que o termo seja utilizado, apenas quando se tem a pretensão de indicar ao leitor uma fonte alternativa de informações para aprofundamento do assunto pesquisado. Uma bibliografia sobre a obra de Machado de Assis, por exemplo, é uma listagem de vários outros documentos (eletrônicos ou não) que tratam sobre a obra do autor. A lista de bibliografias é apresentada em ordem alfabética. 


\section{ESTRUTURA DE UM TRABALHO}

\subsection{FOLHA DE ROSTO}

Parte do documento que inclui o maior número de informações referentes ao trabalho, deve conter os seguintes itens:

- Autoria (em caso de mais de um autor, os nomes deverão vir um embaixo do outro em ordem alfabética);

- Título do trabalho (em destaque e fonte maior);

- Disciplina e instituição ao qual o trabalho é apresentado;

- Nome do professor responsável pela disciplina;

- Série e turma;

- Cidade, mês e ano de execução do trabalho.

EX:

FERNANDO HENRIQUE CASTRO

GLAUBER ROCHA DA SILVA

\section{A POLUIÇÃO DO LAGO PARANOÁ}

Trabalho de Ciências apresentado à professora Suely Figueira do $6^{\circ}$ ano $\mathrm{C}$.

Colégio Marista de Brasília

BRASÍLIA

Abril/2014 


\subsection{SUMÁRIO}

O Sumário traz a relação exata de todas as partes ou capítulos que compõem o trabalho, da forma em que eles aparecem no texto. Deverá vir sempre no início do documento e apontar o número das páginas correspondentes.

Em caso de mais de uma seção para os capítulos (Primária, Secundária ou Terciária), seguir a recomendação abaixo:

- PRIMEIRA SEÇÃo (Primária) - Caixa Alta (todas as letras maiúsculas) e em negrito;

- SEGUNDA SEÇÃO (Secundária) - Caixa Alta sem negrito;

- Terceira Seção (Terciária) - Caixa Baixa (apenas iniciais maiúsculas) e em negrito.

Ex.

\section{SUMÁRIO}

1 INTRODUÇÃO

2 O BIG BANG_ 3

2.1 AS GALÁXIAS _ 4

2.2 O SISTEMA SOLAR 5

2.2.1 O Sol 6

2.3 A VIA LÁCTEA 7

2.4 OS PLANETAS 8

$\begin{array}{lll}2.5 \text { PLANETA TERRA__ } & 10\end{array}$

3 CONSIDERAÇÕES FINAIS__ 12

REFERÊNCIAS__ 13

ANEXOS 
Obs: No Sumário, apenas os elementos textuais (Introdução, Desenvolvimento e Considerações Finais) serão numerados. Elementos pré-textuais (antes da Introdução) e pós-textuais (depois das Considerações Finais) não têm numeração.

\subsection{INTRODUÇÃO}

A Introdução de um trabalho deve trazer informações resumidas sobre ele. Deve deixar claro o tema que será abordado, como a pesquisa foi elaborada (busca a sites, pesquisa bibliográfica) e que objetivos pretende alcançar.

\subsection{DESENVOLVIMENTO}

Refere-se à etapa mais longa do trabalho. Pode ser dividido em várias partes ou capítulos, de acordo com o assunto abordado. Os títulos dos capítulos devem ser apresentados obedecendo às seções PRIMÁRIA, SECUNDÁRIA e Terciária. Recomenda-se que os capítulos indicados pela seção primária sejam iniciados em páginas separadas, mesmo que o item anterior não tenha utilizado toda a página.

EX.:
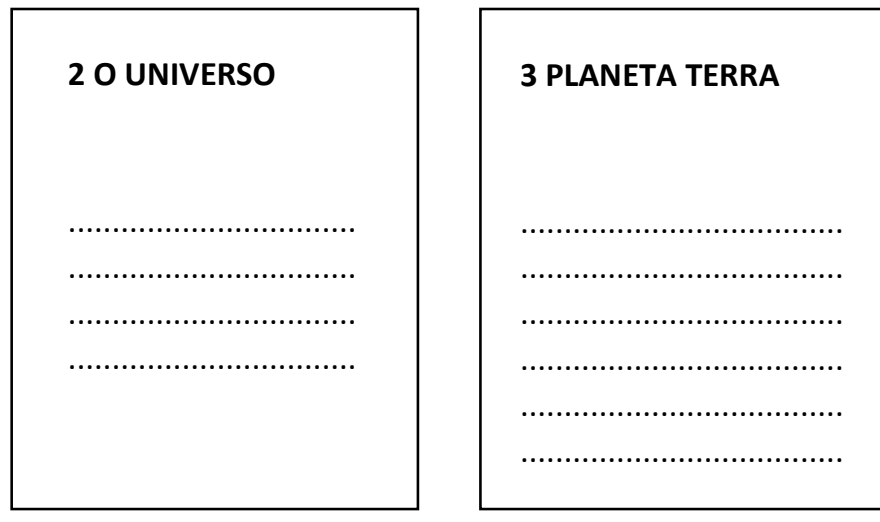


\subsection{CONSIDERAÇÕES FINAIS}

Nas Considerações Finais, o autor e/ou autores deverão apresentar a síntese dos resultados do trabalho e dar suas impressões sobre o estudo feito. Geralmente, as "Considerações Finais" são substituídas pela "Conclusão", mas nesse caso, optou-se por não utilizar este termo.

\subsection{REFERÊNCIAS}

Assim como especificado no item 2.3, são as fontes utilizadas efetivamente em uma pesquisa. Para que sejam registradas como referências, as fontes devem ter sido citadas (com o uso de CITAÇÕES) no decorrer do trabalho.

\subsection{ANEXOS}

Anexos são acréscimos feitos ao trabalho com o intuito de enriquecê-lo com informações adicionais, elaborados por outros autores. Geralmente são postos em anexo conteúdos que não poderiam ser inseridos no corpo do trabalho como cópias, encartes, imagens não digitalizadas, etc.

Para se acrescentar algum tipo de anexo a uma pesquisa, ele precisa ter sido mencionado no texto.

Ex.: As crateras lunares (fotos em ANEXO) foram produzidas pelo choque constante de meteoritos.

Em caso de gráficos ou figuras que ocupem toda uma página, recomenda-se a criação de mais de um anexo. 
Ex.: Os indicadores da economia, no primeiro semestre de 2011 (ANEXO 1 Gráfico 1), apontam inflação superior ao mesmo período do ano anterior.
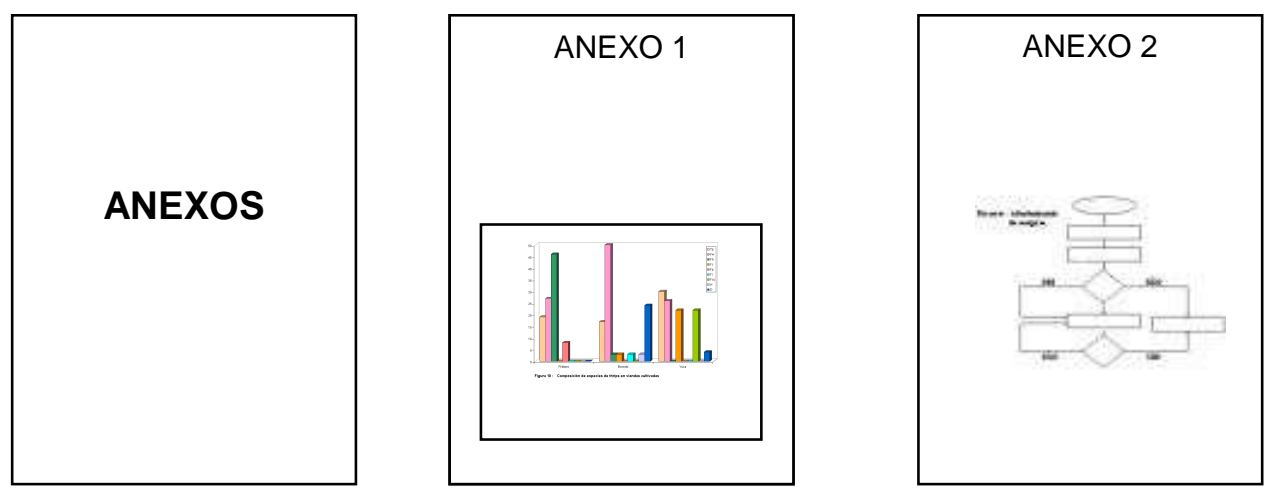

Em caso de várias ilustrações em um único anexo, registram-se as imagens em separado. OBS: Caso as imagens ou gráficos estejam em formato eletrônico, poderão ser inseridos no corpo do trabalho, sem necessidade de anexo.

Ex.: A destruição das matas ciliares (ANEXOS - Fig.1) é um dos grandes riscos para a manutenção das nascentes dos rios.

Ex:
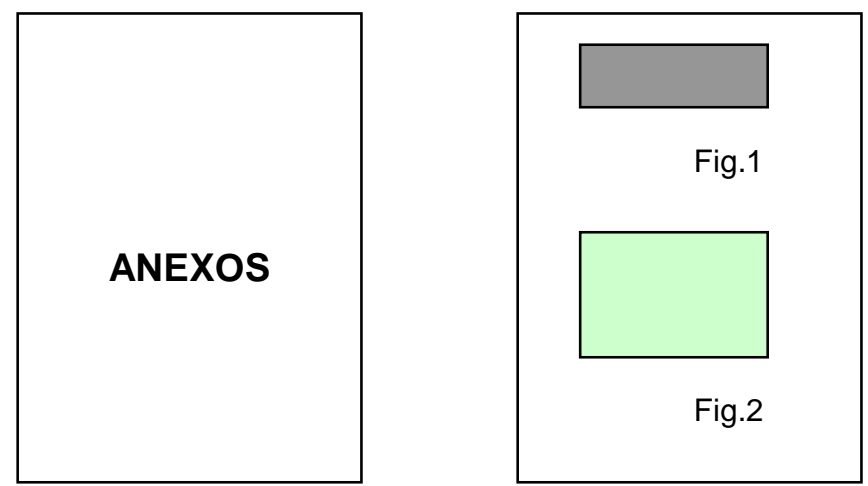


\section{COMO FAZER REFERÊNCIAS?}

4.1 LIVRO NO TODO

\subsubsection{Um autor}

ÚLTIMO SOBRENOME DO AUTOR, Outros nomes. Título do livro: subtítulo. Local de Publicação: Editora, Ano de publicação. Número de páginas.

Ex.:

SOARES, Jurandir. Iugoslávia: guerra civil e desintegração. São Paulo: Novo Século, 1999. 120p.

\subsubsection{Dois autores}

ÚLTIMO SOBRENOME DO 1 AUTOR, Outros nomes; ÚLTIMO SOBRENOME DO ㅜำ AUTOR, Outros nomes. Título do livro: subtítulo. Local de Publicação: Editora, Ano de publicação. Número de páginas.

Ex.:

BRIGADÃO, Clóvis; RODRIGUES, Gilberto. Globalização a olho nu: o mundo conectado. São Paulo: Moderna, 1998. 135p.

\subsubsection{Três autores}

ÚLTIMO SOBRENOME DO 1ำAUTOR, Outros nomes; ÚLTIMO SOBRENOME DO $2^{\circ}$ AUTOR, Outros nomes; ÚLTIMO SOBRENOME DO 3ำ AUTOR, Outros nomes. Título do livro: subtítulo. Local de Publicação: Editora, Ano de publicação. Número de páginas. 
Ex:

BRIGADÃO, Clóvis; RODRIGUES, Gilberto; SANTOS, Milton. Globalização.

São Paulo: Moderna, 1998. 220p.

\subsubsection{Mais de três autores}

ÚLTIMO SOBRENOME DO 1ATOR, Outros nomes. et al. Título. Local de Publicação: Editora, Ano de publicação. Número de páginas.

Expressão latina
que significa "e
outros".

Ex:

MAGNOLI, Demétrio. et al. Visões do mundo. São Paulo: Moderna, 1998. 150p.

4.2 CAPÍTULO DE LIVRO

\subsubsection{Um autor}

ÚLTIMO SOBRENOME DO AUTOR DO CAPÍTULO, Outros nomes. Título do capítulo. In: ÚlTIMO SOBRENOME DO AUTOR DO LIVRO, Outros nomes. Título do livro: subtítulo. Local de Publicação: Editora, Ano de publicação. Número do intervalo das páginas.

Ex:

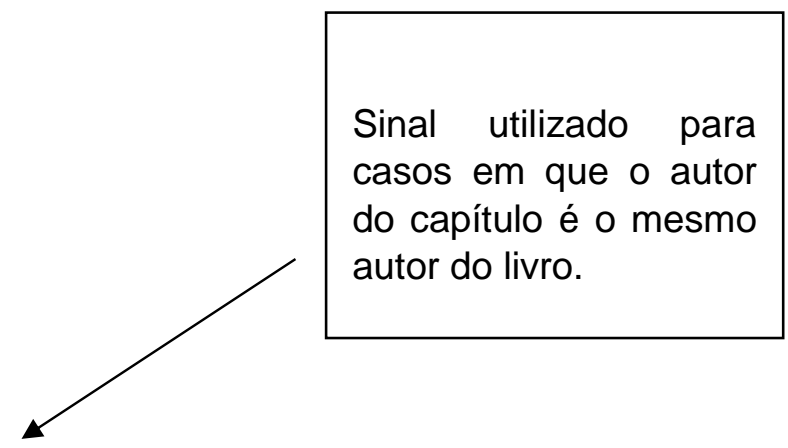

SOARES, Jurandir. Estruturação econômica. In: lugoslávia: guerra civil e desintegração. São Paulo: Novo Século, 1999. p. 35-44. 


\subsubsection{Com autoria}

ULTIMO SOBRENOME DO AUTOR, Outros nomes. Título do artigo. Disponível em: $<$ endereço do site $>$. Acesso em: Data de acesso.

Ex::

FONSECA, Leonardo. Refugiados do oriente. Disponível em: <http://www.refugiados.org.br>. Acesso em: 25 ago. 2003.

\subsubsection{Sem autoria}

TÍTULO do artigo (primeira palavra do título em maiúsculo). Disponível em: <endereço do site>. Acesso em: Data de acesso.

Ex:

IUGOSLÁVIA destruída. Disponível em:

<http://www.wikpedia.iugoslavia.arquivo\&texto.html> Acesso em: 15 jun. 2005.

OBS: As Referências deverão vir em ordem alfabética.

EX:

BRIGADÃO, Clóvis; RODRIGUES, Gilberto. Globalização a olho nu: o mundo conectado. São Paulo: Moderna, 1998. 135p.

FONSECA, Leonardo. Refugiados do oriente. Disponível em: <http://www.refugiados.org.br>. Acesso em: 25 ago. 2003.

MAGNOLI, Demétrio. et al. Visões do mundo. São Paulo: Moderna, 1998. 150p. 


\subsubsection{Imagem}

ÚLTIMO SOBRENOME DO AUTOR, Outros nomes. Título (quando não existir, atribuir um nome ou fazer a indicação [Sem título]). Data (quando não souber, indicar com o termo [s.d.] ou quando não tiver certeza indicar [2013?]). Especificação do suporte.

Ex: Com autoria

SALGADO, S. Menina sem terra. 1996. 1 fotografia, color. Disponível em: $<$ http://caminhosdojornalismo.wordpress.com/fotojornalismo/fotojornalistas-emdestaque-2/sebastiao-salgado/>. Acesso em: 08 maio 2013.

Ex. Sem autoria e sem data

Praia. [s.d.]. 1 fotografia, color. Disponível em:

<http://superimagensblog.blogspot.com.br/>. Acesso em: 08 maio 2013.

EX. Com data provável

Deserto. [2009?]. 1 fotografia, color. Disponível em:

<http://superimagensblog.blogspot.com.br/>. Acesso em: 08 maio 2013.

\subsection{PERIÓDICOS}

\subsubsection{Artigo de Revista}

AUTOR DO ARTIGO. Título do artigo: subtítulo. Título do periódico, local de publicação, número do volume ou ano, número do fascículo, páginas inicial-final, data.

Ex:

TEIXEIRA, Duda. A razão pede socorro. Veja, São Paulo, ano 44, n. 39, p.96-100. 


\subsubsection{Artigo de Jornal}

SOBRENOME, Nome do autor do artigo. Título do artigo: subtítulo. Título do jornal, local de publicação, dia, mês e ano. Nome do caderno, seção ou suplemento, páginas inicial-final.

Ex:

LUNA, Thais de. Lembranças em pedaços. Correio Braziliense, Brasília, 29 set. 2011. Ciência, p.28.

\subsection{LETRAS DE MÚSICA}

SOBRENOME, Nome do Compositor(es). Título da música (ou faixa de gravação). Seguidos da expressão In: SOBRENOME, Nome do Intérprete. Título do álbum. Local: Gravadora, ano. No final da referência, deve-se informar o tipo de suporte do documento (CD, Web etc.) e a faixa musical (quando for o caso).

Ex. CD:

CAYMMI, Dorival; GUINLE, Carlos. Não tem solução. In: SANTIAGO, Emilio. Aquarela brasileira. Rio de Janeiro: Som Livre, 1992. 1 CD. Faixa 2.

EX. WEB:

VELOSO, Caetano. Sampa. Disponível em: http://letras.terra.com.br/caetanoveloso/41670/. Acesso em: 15 abr. 2013.

\section{6 FILMES EM DVD}

TÍTULO (apenas primeira parte em caixa alta). Direção: Nome do diretor. Produção: Nome do produtor. Local: Produtora, data. Especificação do suporte (tempo de duração). 
Ex:

BLADE Runner. Direção: Ridley Scott. Produção: Michael Deeley. Los Angeles: Warner Brothers, 1991. 1 DVD (117 min). 


\section{FORMATAÇÃO DO TRABALHO}

Para a formatação do produto da pesquisa, serão utilizados os seguintes padrões:

- Papel - A-4 (folha branca ou reciclada);

- Texto - deverá ser digitado com entrelinhas 1,5;

- Citações diretas - deverão ser digitadas com entrelinhas simples e com recuo maior que o do parágrafo tradicional $(4 \mathrm{~cm})$;

- Fonte - será utilizada a Arial ou Times New Roman tamanho 12 para o texto e 10 para as citações;

- Margens - Margem superior do papel $2 \mathrm{~cm}$, inferior $2 \mathrm{~cm}$, esquerda 3 $\mathrm{cm}$ e direita $2 \mathrm{~cm}$;

- Número de páginas - Deverá aparecer na margem superior direita.

Apesar de todas as folhas serem contadas a partir da Folha de Rosto, o número da página só deverá aparecer a partir da Introdução. 


\section{REFERÊNCIAS}

ASSOCIAÇÃO BRASILEIRA DE NORMAS TÉCNICAS. NBR 6023 - Informação e documentação: referências: elaboração. Rio de Janeiro, 2002, 24p.

BIBLIOTECA DO IPPUR/UFRJ: normalizando documentos. Disponível em:< http://bibliotecadoippur.blogspot.com.br/>. Acesso em: 5 dez. 2014.

CURTY, Marlene Gonçalves; CRUZ, Anamaria da Costa. Guia para apresentação de trabalhos acadêmicos, dissertações e teses. Maringá: Dental Press, 2001.104p.

HOUAISS, Antônio. Dicionário Houais da língua portuguesa. Rio de Janeiro: Objetiva, 2001.

MENDONÇA, Leda Moreira Nunes; ROCHA, Cláudia Regina Ribeiro; GOMES, Suely Henrique de Aquino. Guia para apresentação de trabalhos acadêmicos na UFG. Goiânia: Universidade Federal de Goiás, Pró-Reitoria de Pesquisa e PósGraduação, 2004. 48p. 
ANEXOS 


\title{
MAPAS CONCEITUAIS: INSTRUMENTOS PARA A COMPREENSÃO DE TEXTOS
}

\author{
Waldyr Azevedo Junior
}

Uma figura vale mil palavras... mas como dizer isto em uma figura?

\begin{abstract}
Nesta parte do curso vamos apresentar algo ao mesmo tempo muito antigo e muito novo: um modo de representar idéias graficamente. Neste sentido, os mapas conceituais são um modo de representação que tem diversos propósitos, embora tenha uma estrutura particular, adequada a uma grande diversidade de assuntos. Eles complementam e enriquecem outras técnicas de leitura de textos, como as técnicas de resumo já apresentadas a você. Tão logo você tenha aprendido esta técnica, poderá aplicá-la ao estudo do material pedagógico deste curso, com proveito.
\end{abstract}

Deste modo, prezado Cursista, procuraremos atingir os seguintes objetivos:

- Aprender o que são mapas conceituais, para que servem, como fazê-los e como utilizá-los em diversos contextos.

- Indicar onde obter uma ferramenta automática gratuita de mapas conceituais na Internet.

- Professor da Universidade Federal de Juiz de Fora. 


\section{O QUE SÃO E COMO FAZER MAPAS CONCEITUAIS}

Prezado Cursista, gostaria de iniciar o assunto definindo o que são mapas conceituais. Em seus termos mais essenciais, mapas conceituais são representaçōes gráficas do conhecimento organizado. O conhecimento organizado é composto por uma estrutura de proposiçōes; estas sāo afirmaçōes compostas por conceitos e palavras de ligaçāo.

Parece confuso? São muitos conhecimentos novos somente nas linhas acima? Vamos ver se podemos representar graficamente o que já foi dito. Veja a Figura 1.

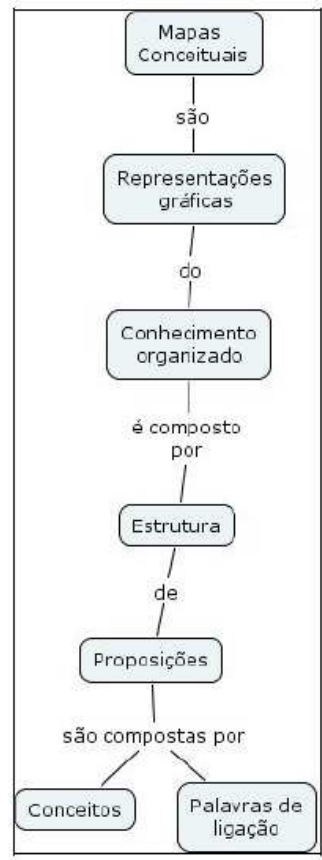

Figura 1 - Primeiro exemplo de mapa conceitual

Veja se agora o primeiro parágrafo não ficou mais compreensível. Claro que ainda restam dúvidas. Mas já fica mais fácil ver, pela representação gráfica, o que queríamos dizer. Temos um conjunto de conceitos, tais como "mapas conceituais", "representaçōes gráficas", "estrutura", "proposições", os quais colocamos nas "caixinhas" e eles são ligados pelas "palavras de ligaçāo", tais como: "sāo", "do", "é composto por" etc. Percebemos que as frases ficam mais facilmente verificáveis, pois podemos ver seus componentes. Esse conjunto de conceitos interligados forma uma estrutura. 
Vamos esclarecer mais um termo que aparece na definição de mapas conceituais. O que são conceitos, afinal? Conceitos são regularidades que percebemos no mundo - seja em objetos, seja em acontecimentos. Eles se expressam por termos conceituais ou nomes. Por exemplo, "a borboleta de asas azuis da prancha de surfe do filho da prima da vizinha da minha irmã que mora no México". Este conjunto de palavras é um "termo conceitual", porque designa um objeto muito bem definido. Se conhecêssemos a borboleta apontada pelo termo conceitual acima, poderíamos designá-la mais simplesmente com seu nome científico, digamos, "Myscelia orsis". Seriam dois termos conceituais que apontariam para o mesmo objeto e designariam, portanto, o mesmo conceito. Vamos acrescentar esses novos conhecimentos ao nosso mapa conceitual.

Como já aprendemos algo sobre mapas conceituais, vamos acrescentar os conhecimentos obtidos no parágrafo acima ao mapa da Figura 1. O mapa vai ficar como mostra a Figura 2.

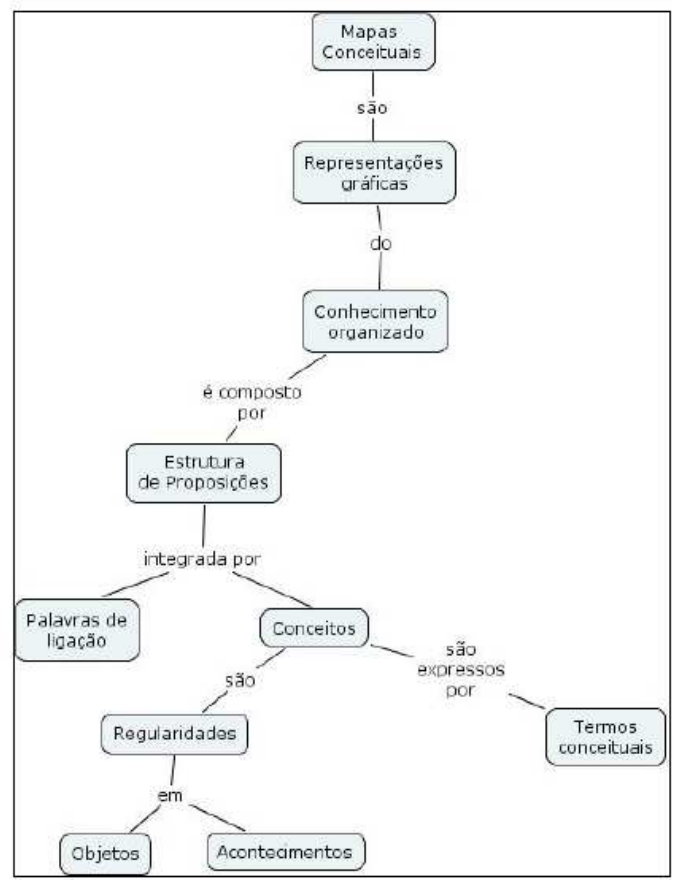

Figura 2 - Continuaçẫo do $1^{\circ}$ exemplo de mapa conceitual

Podemos depreender dos dois exemplos acima que nem tudo o que consta do texto é posto no mapa conceitual. O mapa conceitual exige uma seleção de conceitos, daqueles que são julgados os mais importantes, de modo a resumir as idéias principais. Neste sentido, ele é não apenas uma representaçāo do conhecimento organizado, mas é também uma 
simplificação. Neste contexto, ele pode servir a dois objetivos: a) o de compreensão de um texto, ao nos levar a determinar os principais conceitos do texto e sua interligação; b) uma vez feito o mapa conceitual de um texto, servir de um resumo dele.

Resumindo, o mapa conceitual exige uma seleção de conceitos de um texto. Ele é uma simplificação deste. Por outro lado, nem toda representação gráfica do conhecimento pode ser considerada um mapa conceitual. Nos mapas conceituais, os conceitos são basicamente representados de um modo que vai do conceito mais geral para o mais específico, ou do mais abrangente para o menos abrangente.

Tecnicamente, chama-se esta representação gráfica de "representação hierárquica" ou "hierarquia".

Assim, em nosso exemplo da Figura 1, a primeira proposição - "Mapas conceituais" são "representações gráficas do conhecimento organizado" - é uma relação do conceito "Mapas conceituais" com seu conceito mais geral, "representaçöes gráficas do conhecimento organizado", através da forma verbal "são". Ou seja, existem "representações gráficas do conhecimento organizado" que não são "mapas conceituais". A segunda proposição da Figura 1 - o "conhecimento organizado" é composto por "estrutura de proposiçōes" - é um outro tipo de relação: a relação "todo/parte". O conceito "Estrutura de proposições" é parte do conceito "conhecimento organizado". Os conceitos mais inclusivos ou mais gerais são colocados no alto da representação gráfica. O mapa é lido essencialmente de cima para baixo, começando com o assunto que escolhemos estudar; no nosso caso, o assunto é "mapas conceituais".

Pelo que pudemos observar nas Figuras 1 e 2, o mapa conceitual tem grande impacto visual. A representação gráfica bidimensional explicita os conceitos de um modo fácil de ver o que figuramos mentalmente. Ao explicitarmos os conceitos de nossa fala através das representações gráficas do "mapa conceitual", fica mais fácil, tanto para nós quanto para um interlocutor, entender o que está sendo dito.

Tudo isto que dissemos pode ser acrescentado ao mapa conceitual inicial, produzindo o mapa da Figura 3. 


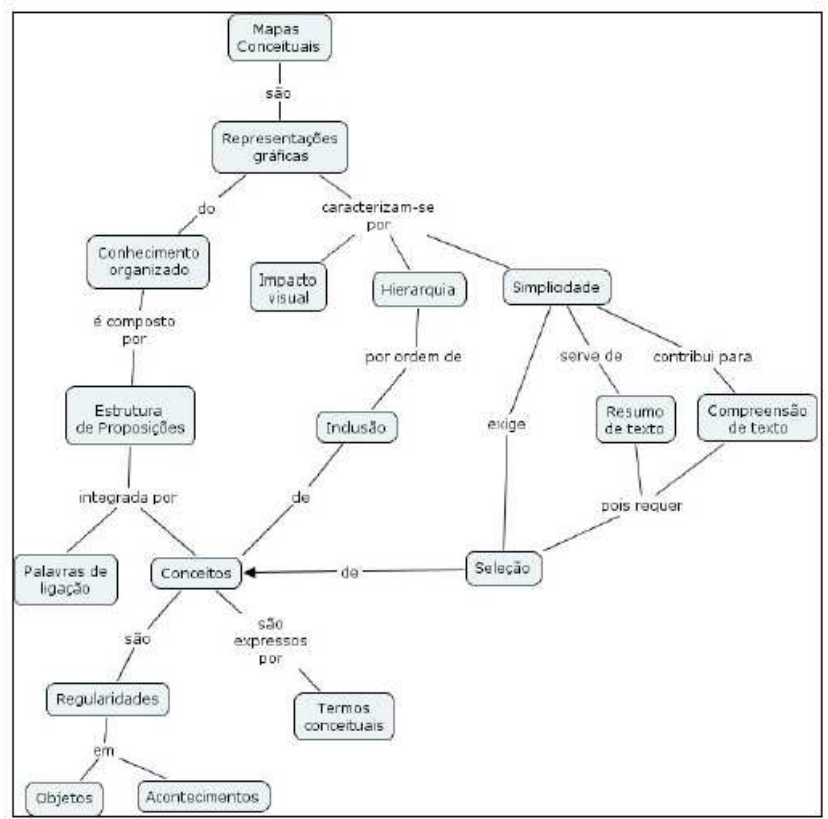

Figura 3 - Continuação do mapa conceitual inicial

Mas os mapas que foram feitos parecem não ser amostras válidas de um verdadeiro trabalho de "mapeamento" de um texto. Você, caro Cursista, pode dizer que eu já sabia a "resposta certa" e que, na prática, as coisas podem não correr de um modo tão fácil. Somos obrigados a concordar com você. Para começar, o texto dado é muito curto, embora complexo para um não conhecedor desses assuntos aqui tratados. Foi válido, mas sua execução pode ter sido enganadoramente fácil. Entāo, como se faz um mapa conceitual na prática?

\section{PRÁTICA DA EXECUÇÃO DOS MAPAS CONCEITUAIS}

Na prática, e considerando apenas o contexto acima explicitado, o de compreendermos um texto dado, não sabemos nem quais são os conceitos mais importantes nem a ligação que existe entre eles. Este é um ponto de pesquisa. Tendo acesso a um texto, o primeiro passo é o de identificar os conceitos principais. Porém, para um texto novo, podemos não saber quais são os conceitos mais importantes. A solução para este problema é a de ler o texto, anotando todos os conceitos que pareçam relevantes.

Como também não sabemos a disposição relativa dos conceitos na estrutura conceitual, que ainda vai ser montada, uma boa idéia é a de anotar os conceitos em cartões de cartolina ou em papeizinhos coloridos - desses que em papelarias são vendidos em blocos com um 
faixa de cola que permite colá-los em papel ou em paredes. Esta escrita em cartōes é fundamental para a prática, pois facilita muito o deslocamento físico do conceito, na montagem do mapa conceitual. Usamos uma folha grande de papel pardo sobre a qual fazemos uma primeira tentativa de disposição dos conceitos escritos nos cartōes. As frases de ligação nâo precisam ser escritas inicialmente. Basta lermos os cartōes e falarmos para nós mesmos as frases de ligação.

Talvez tenhamos de fazer várias tentativas até termos uma disposição satisfatória dos conceitos. Porém, quando julgarmos que a disposiçāo dos conceitos, mais as frases de ligação fazem sentido, colamos os cartões com fita adesiva na folha de papel pardo, desenhamos as ligaçōes entre os conceitos, nesta mesma folha, com uma caneta tipo "Pilot" e escrevemos as frases de ligação nos locais apropriados. Vamos fazer um mapa conceitual deste tópico? Ele está representado na Figura 4.

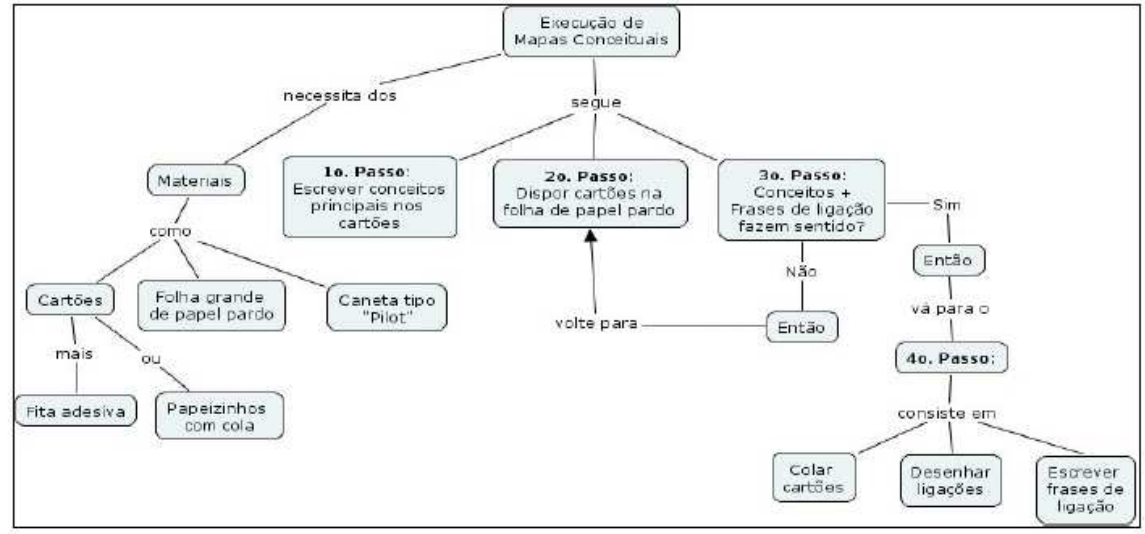

Figura 4 - Execução de mapas conceituais

Depois de terminado, o mapa conceitual deve ser armazenado. Podemos guardá-lo da maneira como foi feito, embora isto não seja muito prático. Ocupa muito espaço. O melhor a fazer é transcrevê-lo numa folha de papel de tamanho adequado ou fotografá-lo. Hoje em dia, está ficando muito barato ter câmeras fotográficas digitais, de modo que fica prático tirar uma fotografia e armazená-la posteriormente em meio magnético, como CDs ou no disco rígido de um computador digital.

Para saber mais: programas de computador para executar mapas conceituais

Podemos também utilizar um programa automático de computador, como o que foi utilizado para fazer os mapas conceituais deste texto.

Existe um programa de computador chamado Cmap Tools, gratuito, e que pode ser localizado na Internet. Basta você acessar o site http://cmap.ihmc.us/ e fazer o "download" do programa para sua máquina. 
Muito bem, agora você já sabe como construir um mapa conceitual num contexto muito específico, o de um indivíduo interpretando um texto. Mas você pode perguntar: "Muito bem, todo esse trabalho somente para isso? Será que vale o esforço?". Como você verá, este é um instrumento valioso para uma função muito importante em nosso contexto educacional: precisamente o de compreensão e interpretação de textos.

Os mapas conceituais têm sido usados com sucesso em muitas situações de trabalho em grupo. Não apenas na escola, mas também na indústria e nas organizações governamentais. Entretanto, vamos aqui desenvolver apenas as aplicaçöes na escola.

\section{UTILIZAÇÃO DE MAPAS CONCEITUAIS NO CONTEXTO EDUCACIONAL}

Bem, prezado Cursista, o que dissemos acima já mostra que a construção de mapas conceituais pode ser um importante instrumento para você, pessoalmente, compreender e interpretar textos. É um primeiro ganho. Além disso, você também pode utilizá-lo para esboçar os itens principais de um escrito que você tenha de fazer. Um roteiro do seu texto. É claro que existem outras técnicas; porém, a dos mapas conceituais permite que você mostre a interligação entre as diversas partes com mais facilidade. Neste sentido, temos aí uma segunda utilização dos mapas conceituais.

Como vimos, a identificação dos conceitos, o entendimento do vocabulário usado neles e a disposição especial deles, assim como o ato de relacioná-los, facilitam muito a compreensão de um texto, qualquer que ele seja. Desta maneira, você acabou de adquirir um novo instrumento para auxiliar a compreensão e a redação de textos. Não é pouco. Mas temos mais aplicaçōes para mapas conceituais.

Os exemplos de construção de mapas conceituais acima desenvolvidos podem ter parecido um exercício solitário, de cada leitor com um texto dado. Nada mais enganador. Como afirmam vários especialistas em educação, a mera leitura de um texto é uma espécie de diálogo do leitor com o autor do texto. Durante a leitura fazemos perguntas, discordamos, concordamos... Ao final do texto, pode acontecer que o autor se antecipe a nossas dúvidas e as responda. Pode ser que não. De qualquer modo, há uma interação; embora o autor não esteja presente para nos responder. Esta "deficiência" é suprida quando dialogamos efetivamente com outra pessoa e quando tentamos negociar um sentido comum para nosso discurso. Essa interação nos trabalhos em grupo é uma grande necessidade educacional em nossos dias. Hoje em dia, ficou claro que ninguém trabalha sozinho. Sempre precisaremos conversar com outras pessoas, agir em equipe, saber se o que estamos dizendo foi recebido de modo claro pelos nossos colegas. E precisamente neste contexto, o do trabalho em grupo, que se revela uma outra grande aplicabilidade dos mapas conceituais. 


\subsection{Aprendizagem significativa}

O desenvolvimento de mapas conceituais está ligado à aprendizagem significativa. Sob uma perspectiva ampla, a utilização de mapas conceituais na educação combina com um modelo de educação que é centrado no aluno e não no professor; que favorece o desenvolvimento de competências e não a repetição memorizada de informaçōes pelo aluno e que visa a um desenvolvimento de todas as dimensões da pessoa, não apenas as intelectuais.

Aprendizagem significativa é aquela em que uma nova informação relaciona-se com um aspecto relevante da estrutura de conhecimento já existente de uma pessoa. Esses aspectos relevantes preexistentes são conceitos relevantes para o aluno. Especialistas no assunto afirmam que as informaçōes são armazenadas no cérebro humano numa forma de hierarquia conceitual, na qual os conceitos mais específicos são ligados a conceitos mais gerais, ou mais inclusivos. Esta teoria permite que o professor, tendo em mente os novos conceitos a introduzir numa dada experiência educacional, possa fazer uma avaliação diagnóstica dos conceitos preexistentes nos alunos de uma turma e, assim, preencher as lacunas observadas, antes de avançar. Novamente, podemos afirmar que os mapas conceituais são um instrumento de fácil utilização para o diagnóstico.

Ao ter de elaborar um mapa conceitual, mesmo individualmente, o esforço está centrado no aluno. Este é desafiado a fazer seu trabalho. Deve interagir com uma informação nova e compreendê-la, isto é, integrá-la à sua estrutura cognitiva. Este tipo de aprendizagem pressupōe uma descoberta e uma compreensão do mundo e a incorporação dele a si mesmo.

O uso de mapas conceituais favorece o desenvolvimento de todas as dimensões da pessoa. Isto ocorre porque: em primeiro lugar, o aluno é o protagonista do processo de ensinoaprendizagem. A atenção e a aceitação que se dá a suas contribuições e o aumento em seu sucesso no processo de aprendizagem aumentam sua auto-estima. Em segundo lugar, o uso dos mapas conceituais na negociação de significados em grupo melhora as habilidades sociais desse aluno e desenvolve atitudes de trabalho em equipe, o que é muito importante.

Em qualquer situação em grupo em que seja necessário estabelecer um consenso sobre um determinado assunto, a utilização de mapas conceituais tem se revelado um auxílio valioso. Os conceitos de qualquer participante do grupo podem ser tornados visíveis através de sua escrita em cartōes, de modo que os outros participantes possam considerar se tinham pensado em algo semelhante - e então teríamos um sinônimo - podendo concordar com a idéia; ou verificar de modo fácil que não tinham pensado naquilo. Diante disso, o novo conceito enriqueceria o grupo. Todos podem, assim propor conceitos que, ao final, de um modo ou de outro, serão refletidos no mapa conceitual do grupo.

Neste exato momento de exposição posso ver seu rosto, meu prezado Cursista. Um rosto de alguém que fala que as coisas estão ficando confusas de novo ou que, pelo menos, pensa isso. Se estivéssemos numa situação presencial, você estaria de braço levantado para fazer perguntas em busca de esclarecimento. Vamos tentar nos antecipar a algumas perguntas e resumir num mapa conceitual os novos conceitos vistos até agora. Não todos, como já dissemos, mas apenas os considerados mais importantes no contexto deste curso. Veja o mapa conceitual mostrado na Figura 5 . Como você pode verificar, é um resumo dos usos dos mapas conceituais, vistos até agora. 


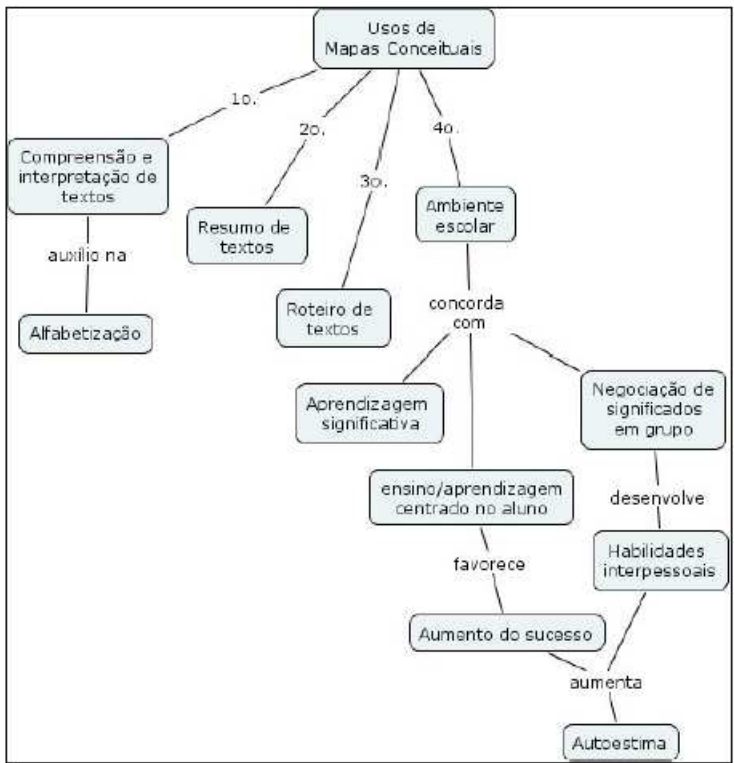

Figura 5 - Usos de mapas conceituais

\title{
3.2 Mapas conceituais como instrumentos privilegiados de um processo participativo de ensino- aprendizagem
}

\begin{abstract}
Vamos pensar um pouco mais sobre o ponto que tocamos acima: os mapas conceituais são instrumentos privilegiados de negociaçāo de consenso em grupos. Vistos desta perspectiva, os mapas conceituais permitem o desenvolvimento de atitudes de compromisso pessoal do indivíduo com o trabalho e facilitam a relação com os seus colegas, num processo que envolve a participação de todos de modo ativo e criativo.
\end{abstract}

Desta maneira, o uso de mapas conceituais em sala de aula é essencialmente participativo, porque põe em prática duas características que definem a participação:

- o compromisso com o próprio trabalho, do qual depende o trabalho do grupo; e

- a cooperação, que está implícita no processo social de aprendizagem, em razão de o indivíduo estar comprometido numa tarefa em comum com colegas.

Esse processo participativo é perfeitamente compatível com a aprendizagem significativa porque: 
- sua prática obriga o aluno a envolver-se na tarefa;

- sua realização traz consigo a explicitação dos conteúdos das experiências cognitivas anteriores dos alunos; $e$

- o resultado é aberto, o que favorece a iniciativa pessoal.

Resumindo, os mapas conceituais tanto podem ser vistos como instrumentos de uma aprendizagem significativa quanto de um processo participativo de ensino-aprendizagem. São duas óticas do mesmo assunto. Ou seja, é uma boa idéia para uso como estratégia de ensino-aprendizagem. Vamos acrescentar isto à Figura 5 ? $\mathrm{O}$ resultado pode ser visto na Figura 5a.

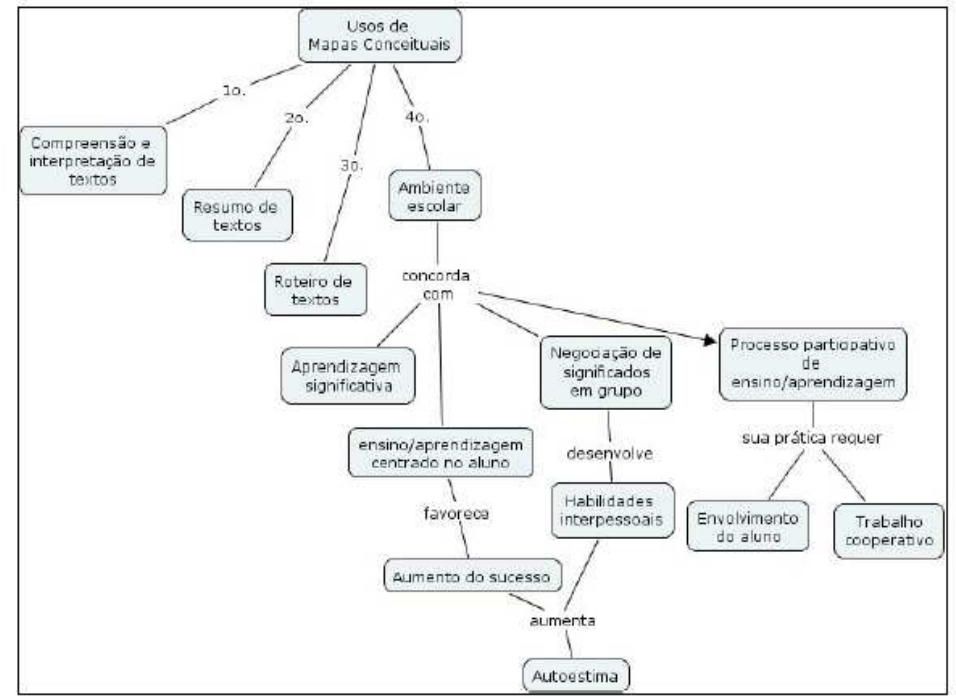

Figura 5a - Usos de mapas conceituais (continuaçâo)

Bem, o que dissemos aqui extrapolou muito o que diz o título: "Mapas conceituais como instrumentos para a compreensão e a interpretaçăo de textos". Você, meu caro Cursista, deve ter concluído logo que o que foi dito aqui se aplica ao processo de ensinoaprendizagem como um todo, desde os primeiros anos do ensino fundamental até a pósgraduação. E não se aplica somente à interpretaçāo de textos, mas também, e de modo privilegiado, à obtenção de significados consensuais num grupo de participantes. 
A experiência mostra que, comumente, os alunos costumam captar a técnica com facilidade, além de descobrirem seu valor em relação à compreensão, assimilação e retenção das idéias básicas do texto. Além disso, a técnica facilita a retenção das informações a longo prazo, pois esta é facilitada quando: a) são reduzidos o número de elementos a recordar; b) esses elementos são agrupados; c) a informação é recebida através da vista.

Voltemos, agora, nossa atenção para o roteiro representado na Figura 4. Utilizamos o artifício de designar cada passo com um ordinal: $1^{\circ}$ Passo, $2^{\circ}$ Passo... Você deve ter pensado: "Esse roteiro aqui não ficou muito claro". Eu teria de concordar com você. Pois acabamos de encontrar um contexto no qual os mapas conceituais não se encaixam confortavelmente. Para a descrição de processos, foram elaboradas outras representações, como o fluxograma. Os fluxogramas descrevem, por exemplo, fluxos de matéria, de energia, de informação, de produtos, de dinheiro. Diagramas de causa-efeito também são importantes em diversas disciplinas e não se enquadram como tipos de mapas conceituais. Portanto, os mapas conceituais devem ser complementados por outros tipos de representação do conhecimento organizado, que sejam melhor adequados aos tópicos em questão. Resumindo, vamos deixar as coisas como estão e esperar que o roteiro, descrito nos passos da Figura 4 acima, esteja claro.

Prezado Cursista, você talvez já esteja satisfeito com os usos de mapas conceituais vistos até agora. Mas há outros usos de mapas conceituais no contexto escolar que não podemos omitir. São os usos no planejamento e na avaliação de ensino. Pelo fato de este domínio ser vasto e diversificado, faremos apenas algumas observaçöes sobre ele, mostrando onde podemos aplicar os mapas conceituais.

O processo educativo é um processo intencional, ou seja, visa resultados desejados e antecipados. Neste sentido, projetamos o processo educativo, que começa com o perfil do aluno que desejamos formar. Obtemos recursos tais como prédios, salas de aula com equipamentos diversos, professores qualificados, administradores diversos, bibliotecas, laboratórios, computadores... E pomos tudo a funcionar. Depois de algum tempo, precisamos saber se o que está acontecendo na escola corresponde ao que foi planejado. Caso não esteja, precisamos saber a razão e providenciar medidas corretivas para que o processo, nos períodos previstos, forme os alunos como foi desejado. É comum se falar de modo superficial que a educação deve ser de "qualidade". Então, poderíamos caracterizar a avaliação como a determinação do grau em que os objetivos educacionais estão sendo atingidos no cotidiano da escola. Avalia-se para tomar medidas corretivas, caso os objetivos não estejam sendo atingidos de modo satisfatório.

Dentro de uma perspectiva de avaliação contínua do processo de ensino/aprendizagem, os mapas conceituais podem ser um bom instrumento para o professor julgar se um aluno compreendeu determinados conceitos de sua matéria e, mais ainda, onde ele não compreendeu. O próprio aluno, ao tentar construir um mapa conceitual de qualquer assunto que seja, pode mais facilmente descobrir quais conceitos não estão ligados com os restantes. Este aluno, assim, poderá posteriormente procurar conhecer, seja com os colegas, seja com o professor, os significados destes conceitos, os quais podem também ser muito importantes. 
Daquilo que falamos sobre a importância dos mapas conceituais na obtenção de um consenso de entendimento de um assunto em um grupo de pessoas, meu caro Cursista, você pode deduzir que eles também são aplicáveis ao próprio planejamento do ensino, desde o planejamento da Escola como um todo até cada disciplina e cada aula em particular. E essa sua dedução é amplamente apoiada pela prática do uso de mapas conceituais. Dessa forma, se o Diretor de sua escola ou algum professor seu não conhecer a técnica dos mapas conceituais, você pode chamar a atenção deles para esse recurso valioso de planejamento.

Finalizando...

E, aqui, interrompemos nosso percurso. Somente para recapitulação dele, começamos por definir, entender o que são e como fazer mapas conceituais. Vimos não apenas a lógica de execução como também os materiais facilmente acessíveis que permitem sua construção. Foram apresentadas diversas funções dos mapas conceituais: como resumo de um tema, como instrumento de compreensão de um tema ou texto, como se fosse uma aplicação individual. Estendemos a aplicação para uso em grupos, que podem utilizá-los para negociar um consenso de significado sobre um tema. Indicamos que os mapas conceituais também podem ser utilizados com sucesso em diversas situações de planejamento, em particular do planejamento do ensino.

Este olhar retrospectivo nos indica que caminhamos bastante. Que temos uma ferramenta útil em diversos contextos - tanto pessoais quanto de grupos - e, em particular, no contexto escolar.

\section{Para este texto consultamos:}

CAÑAS, A. J. et al. CMAPTOOLS: a knowledge modeling and sharing environment. proc. of the first int. conference on concept mapping. Pamplona, Spain, 2004. Disponível em: http://cmc.inmc.us/papers/cmc2004-283.pdf . Acesso em: 12 jul. 2008.

DAHLBERG, I. Uma teoria para o interconcept: teoria analítica do conceito voltada para o refe-rente. Publicado originalmente na revista International Classification, v. 5, n. 3, p. 142151, 1978. Disponível em: dataware.nce.ufrj.br:8080/dataware/seminarios/ 2002/fisico/seminariosInternos/dataware.nce.ufrj.br:8080/dataware/seminarios/2002/fisico/se minariosInternos/2002/Teoria\%20do\%20Conceito.doc . Acesso em: 27 jun. 2008.

MOREIRA, M. A.; BUCHWEITZ, B. Mapas conceituais: instrumentos didáticos, de avaliação e de análise de currículo. São Paulo: Ed. Moraes, 1987.

ONTORIA, A. et al. Mapas conceptuales: una tecnica para aprender. Ed. 6. Madrid, España: Narcea, S. A. de Ediciones, 1996.

UNIVERSIDADE FEDERAL DO RIO GRANDE DO SUL. Mapas conceituais. Disponível em: http://penta2.ufrgs.br/edutools/mapasconceituais/. Acesso em: 12 jul. 2008.

\section{Mas a conversa continua...}

Para você perceber como a idéia de mapas está presente em nossa vida, sugiro a leitura do texto "Mapas" de Rubem Alves. O autor nos mostra, numa leitura bastante agradável, que a construção de mapas "talvez seja nosso primeiro impulso de aprendizagem da vida", pois eles existem como realidades virtuais, muito antes de existirem no papel ou no computador.

Sugiro também que você experimente fazer um mapa conceitual utilizando as ferramentas do CmapTools. Esse programa também pode ser "baixado" pelo site http://baixaki.ig.com.br/download/CmapTools.htm. Aventure-se! 
ANEXO 2 - MAPAS MENTAIS: GRUPO QUASE EXPERIMENTAL (1 ${ }^{a}$ ELABORAÇÃO)
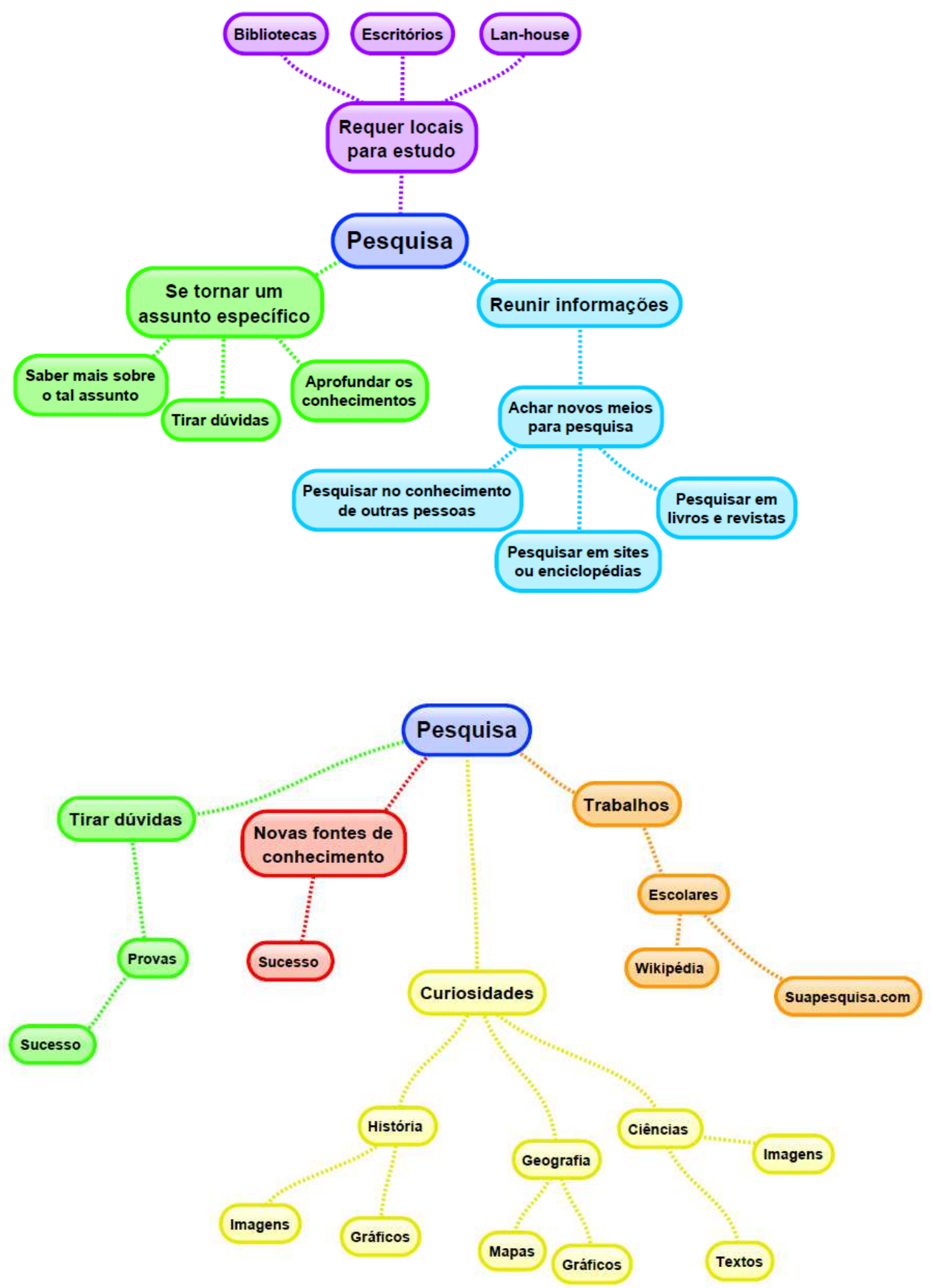

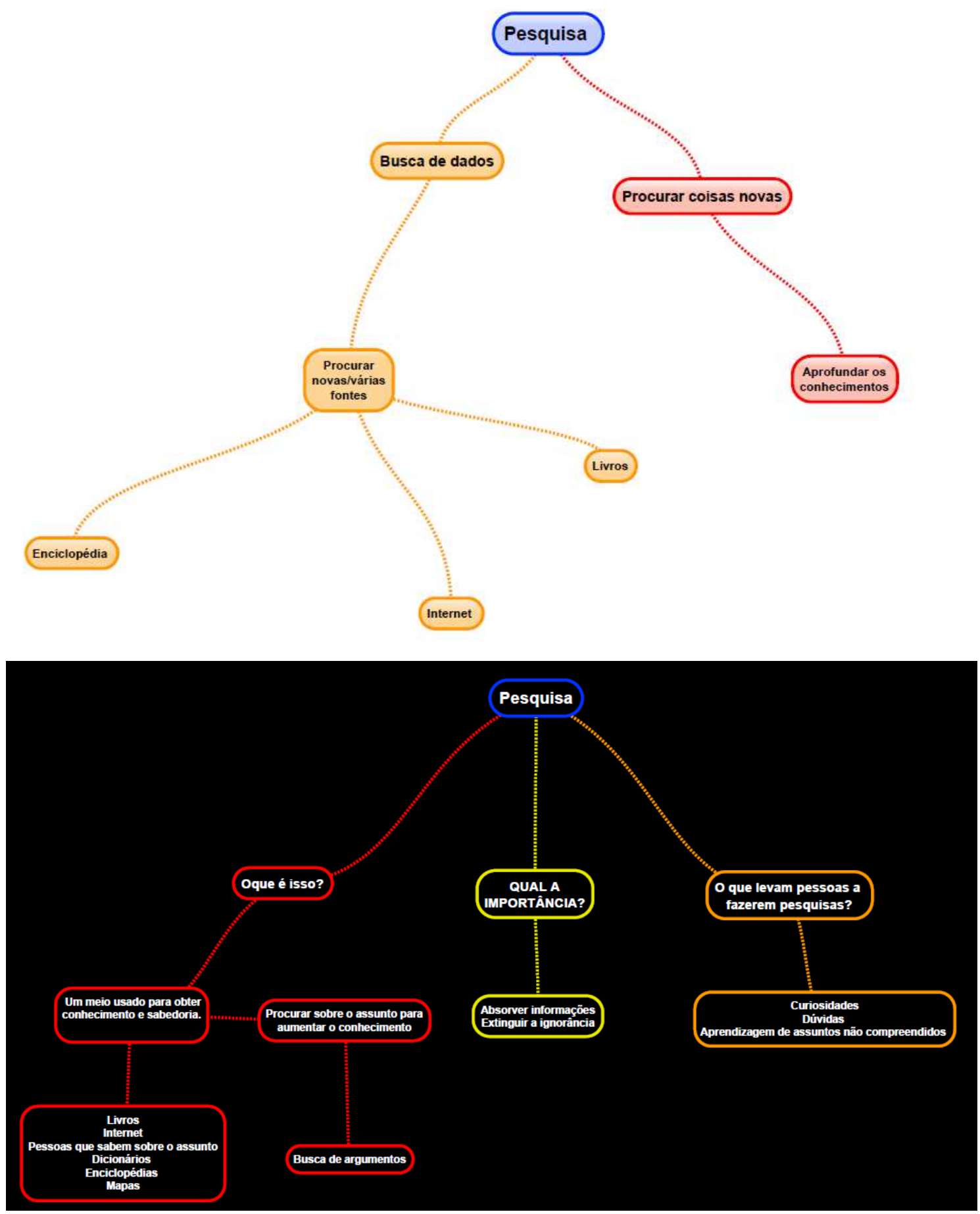

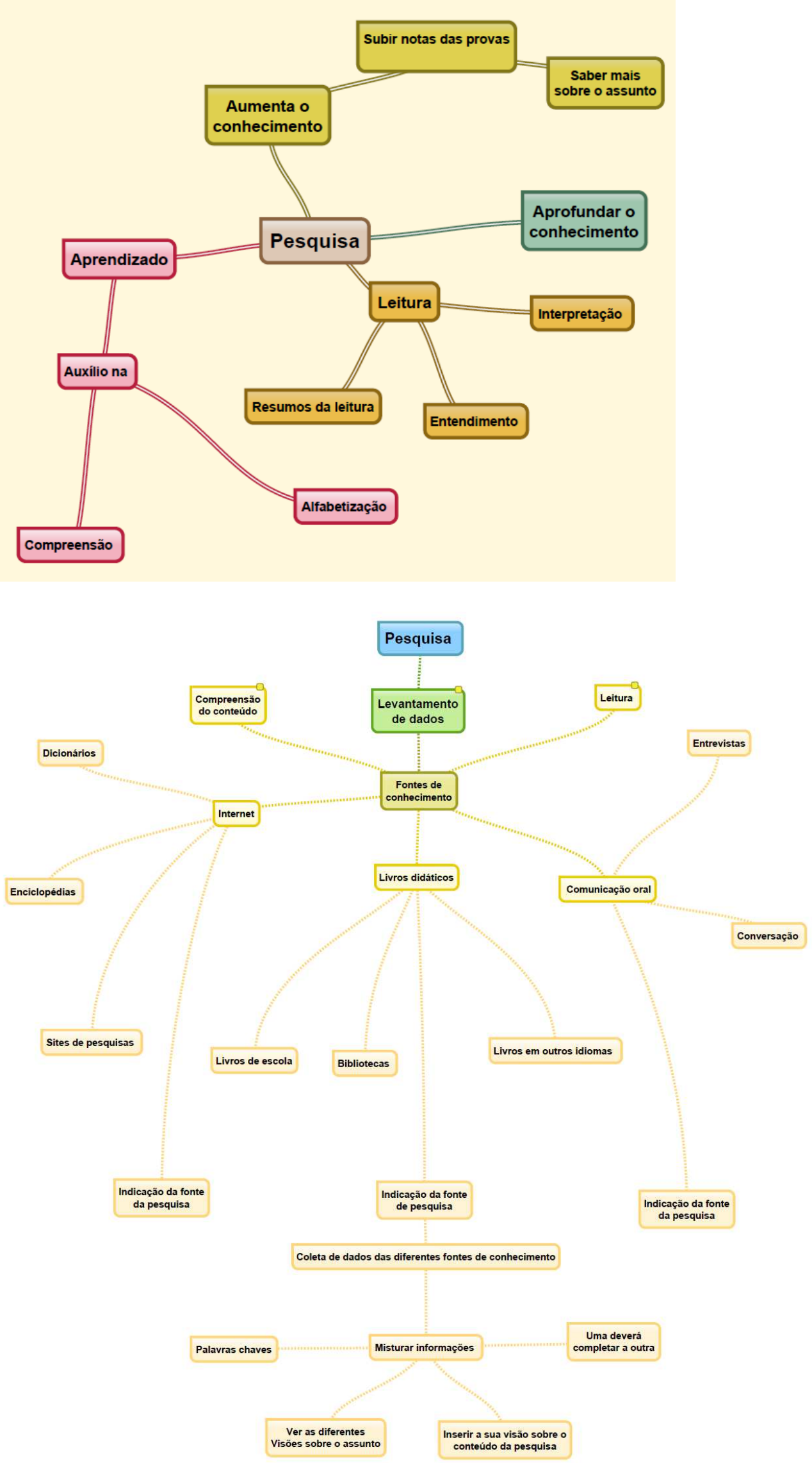

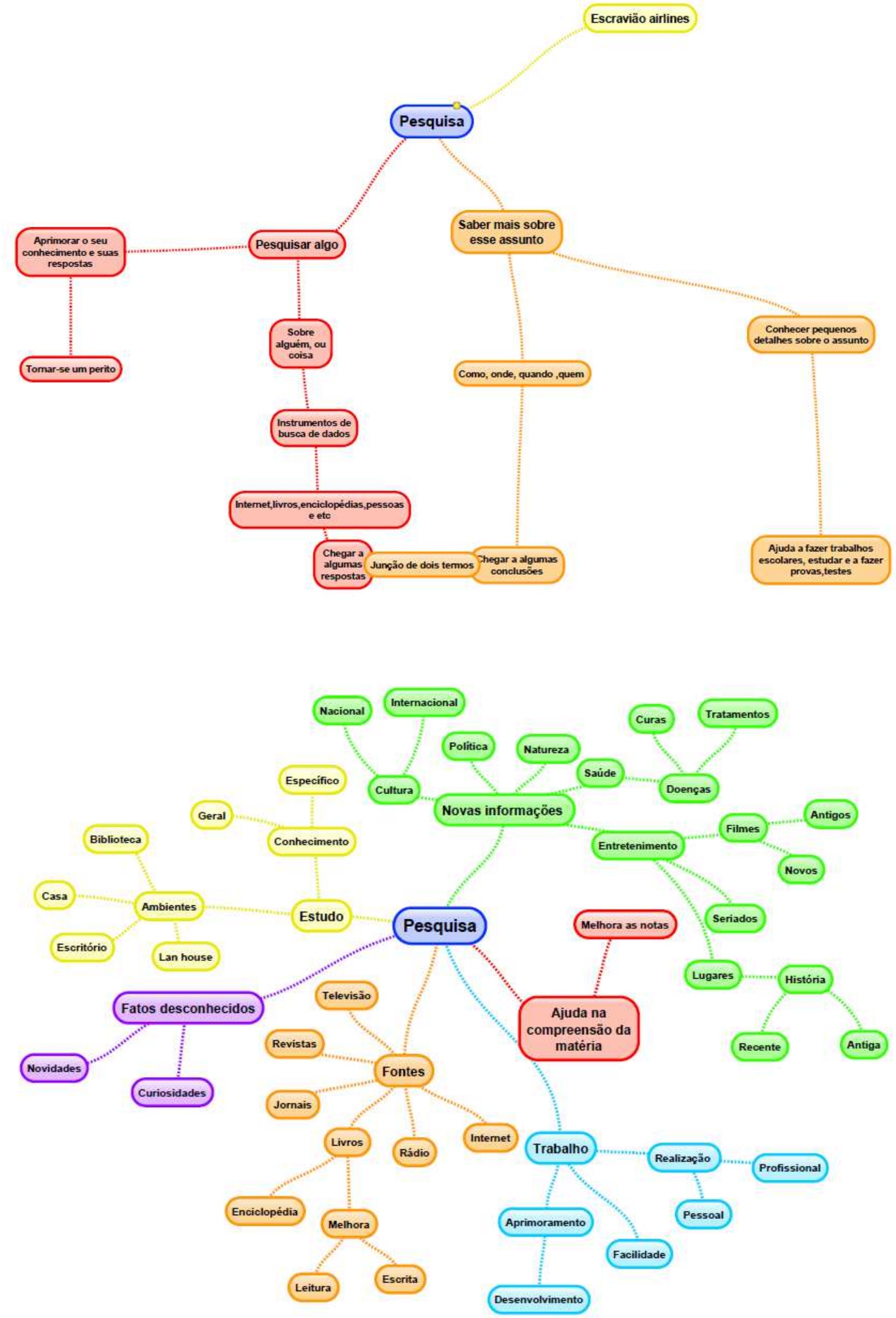


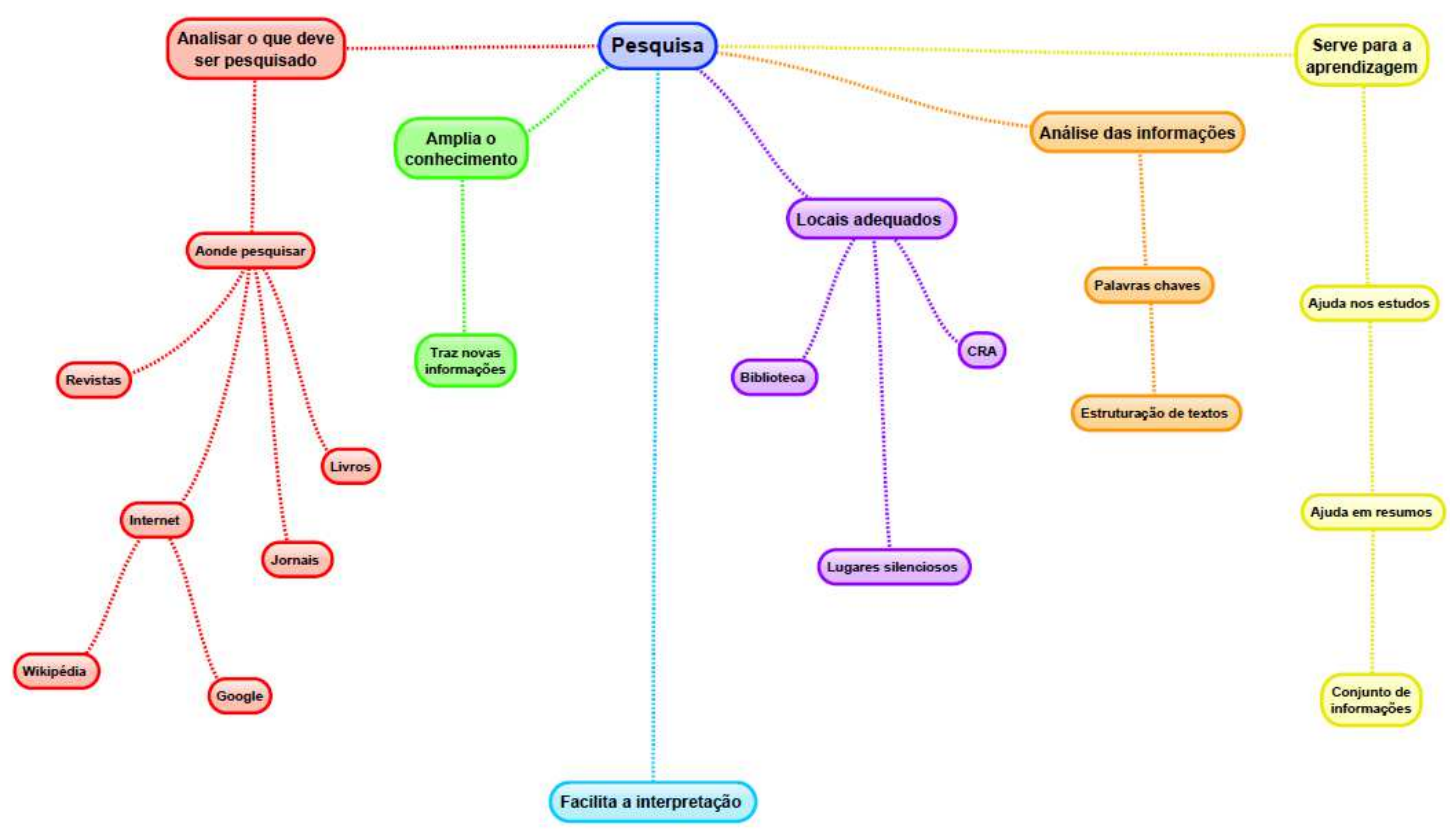

\section{Pesquisa}
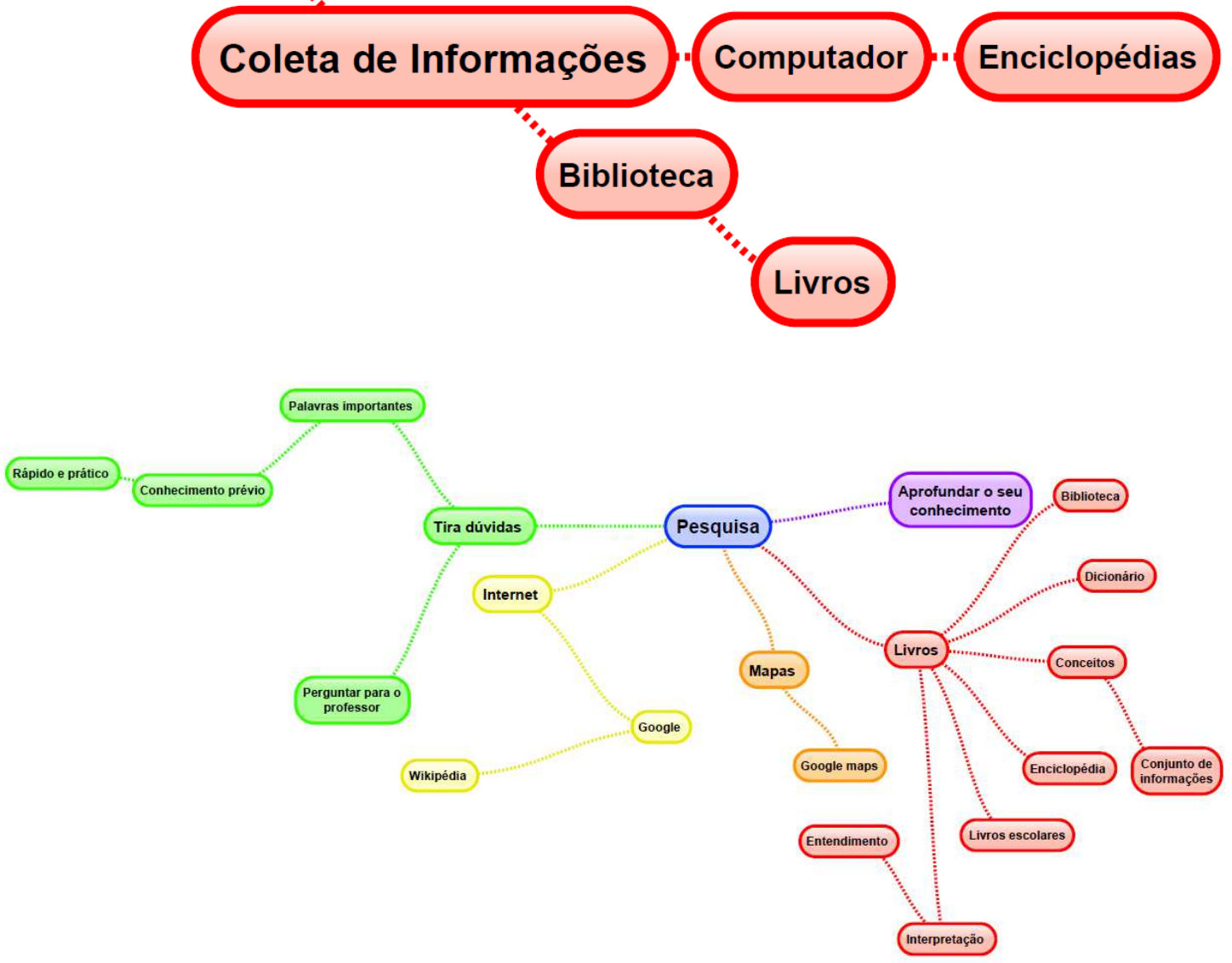
ANEXO 3 - MAPAS MENTAIS: GRUPO QUASE EXPERIMENTAL (2 $2^{\mathrm{a}}$ ELABORAÇÃO)

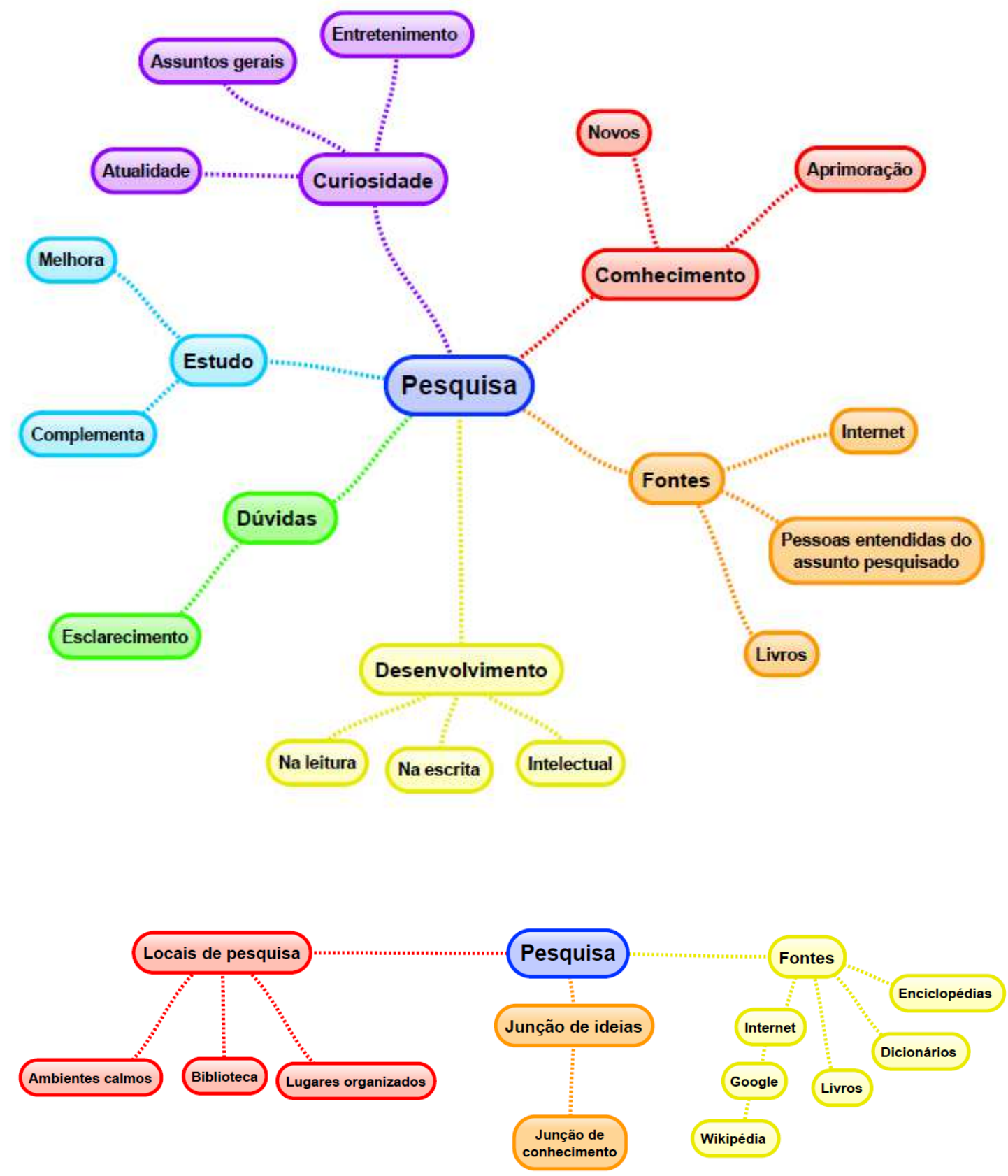



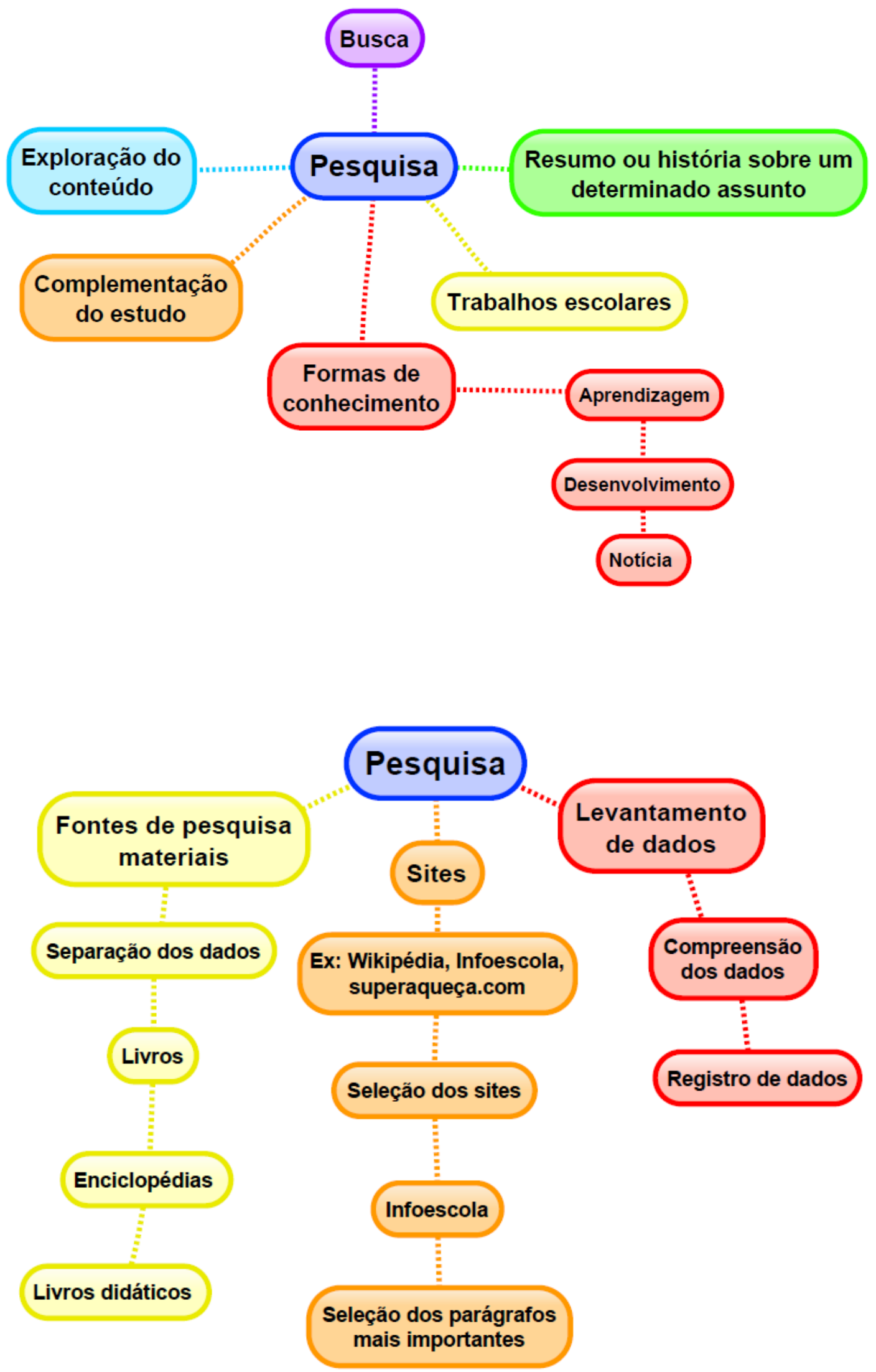

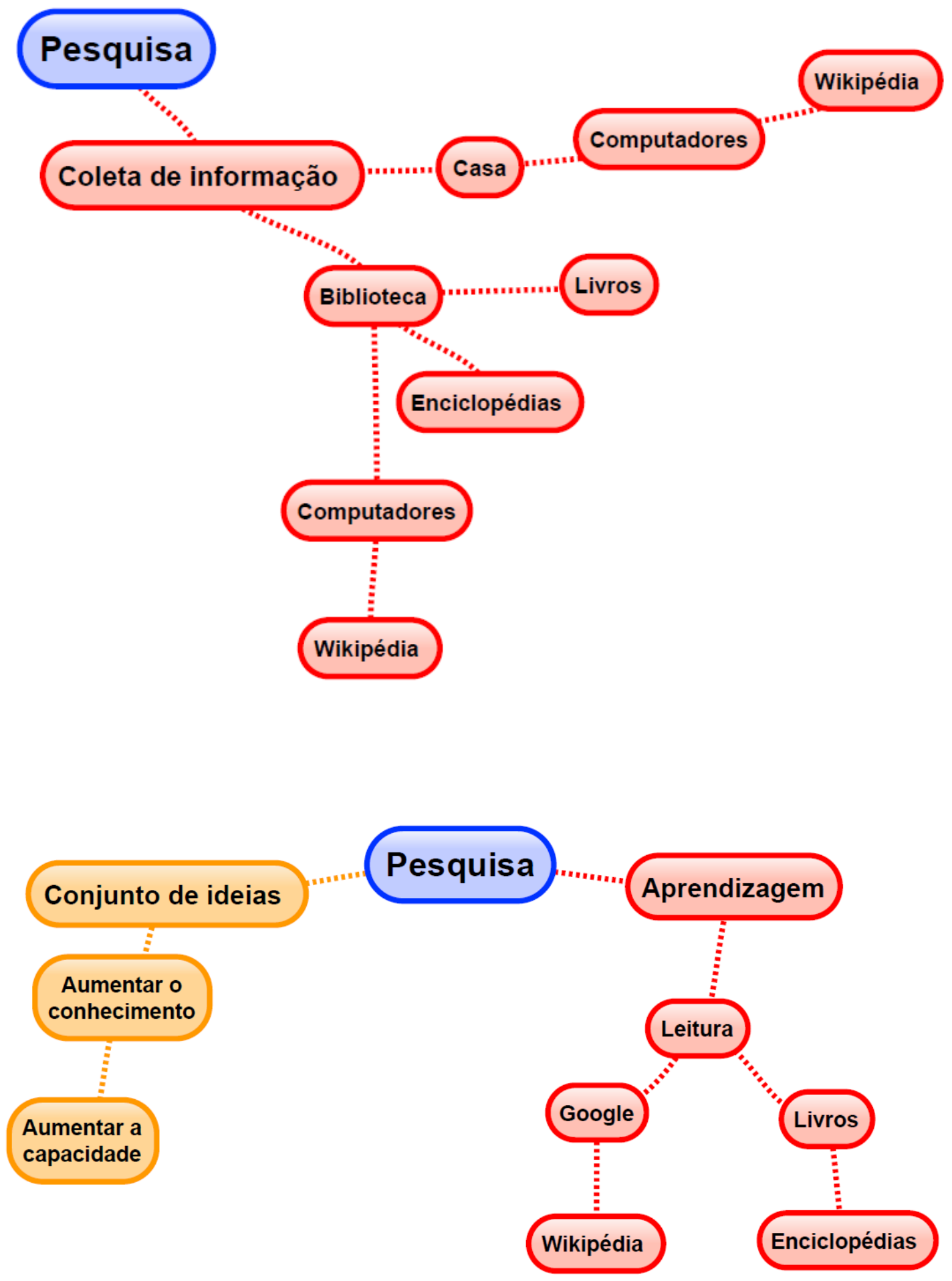

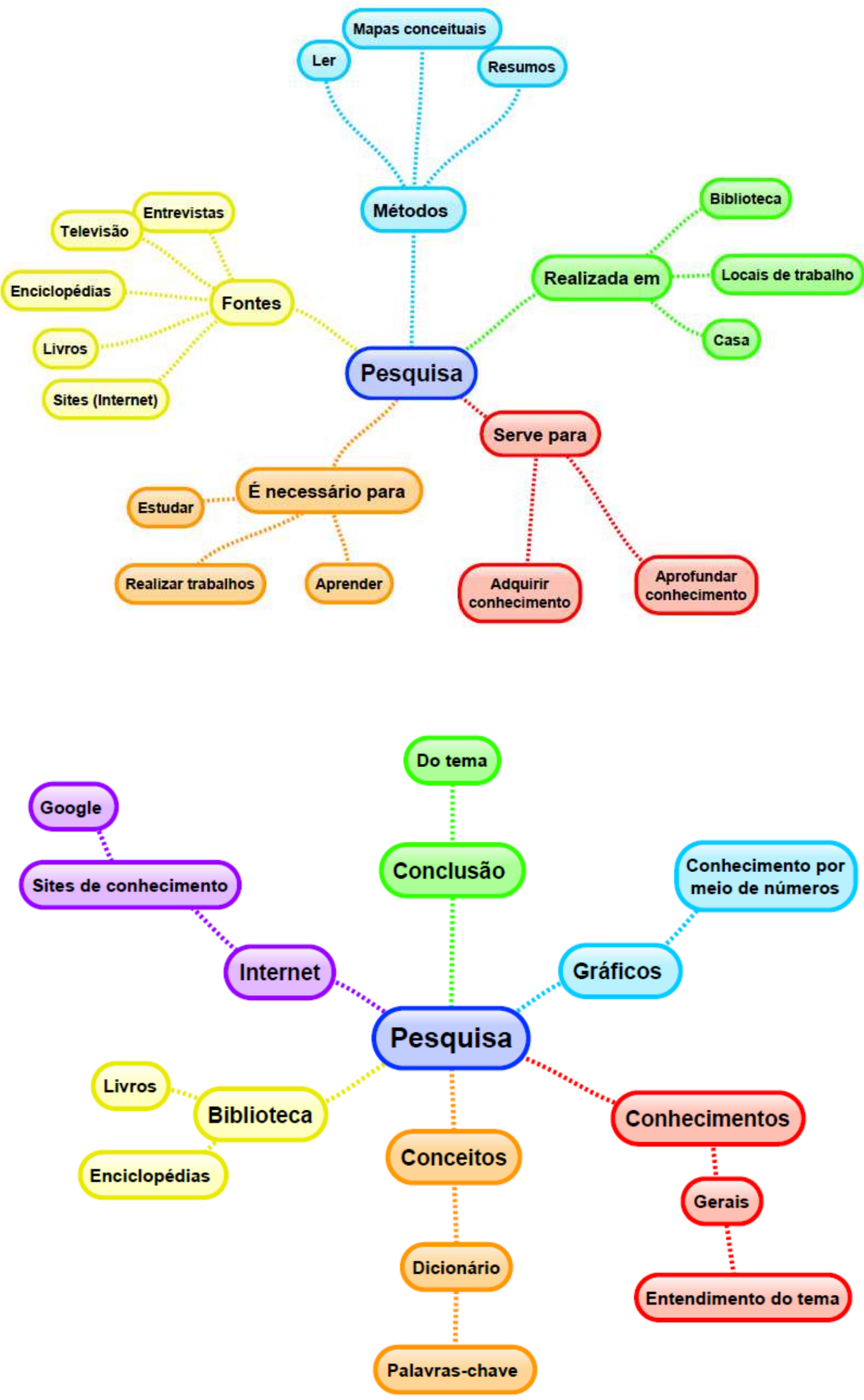

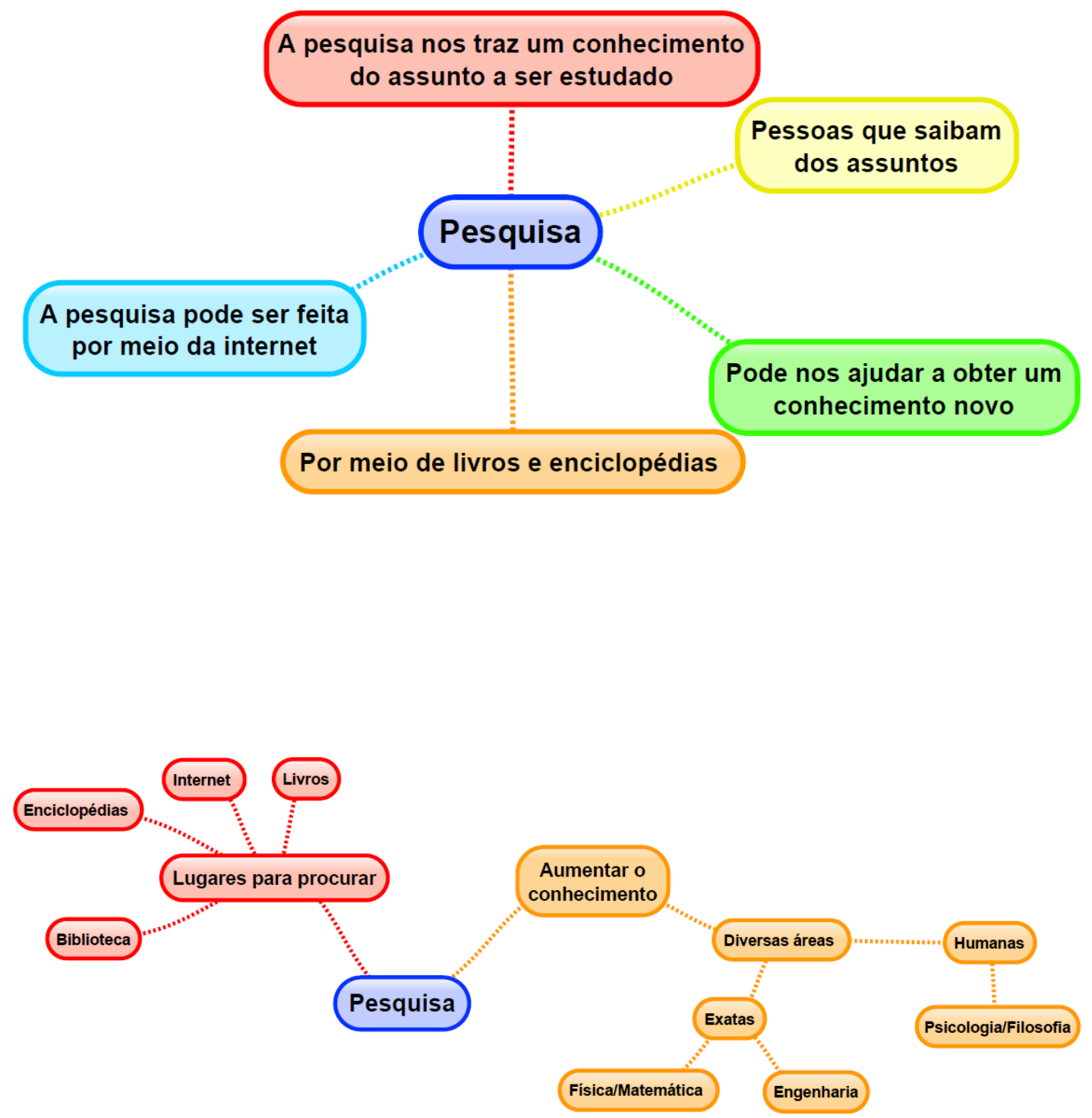
ANEXO 4 - MAPAS MENTAIS: GRUPO CONTROLE

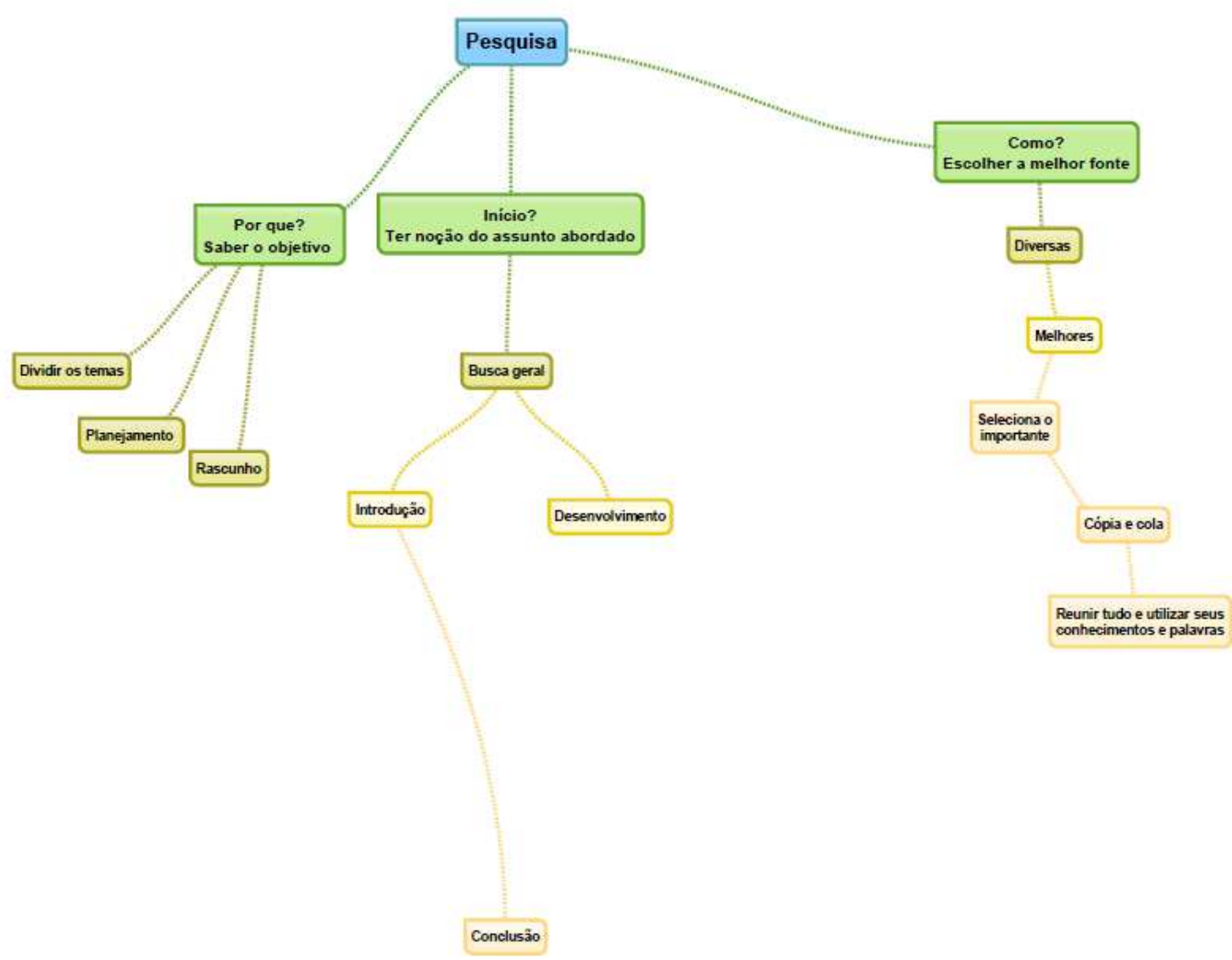




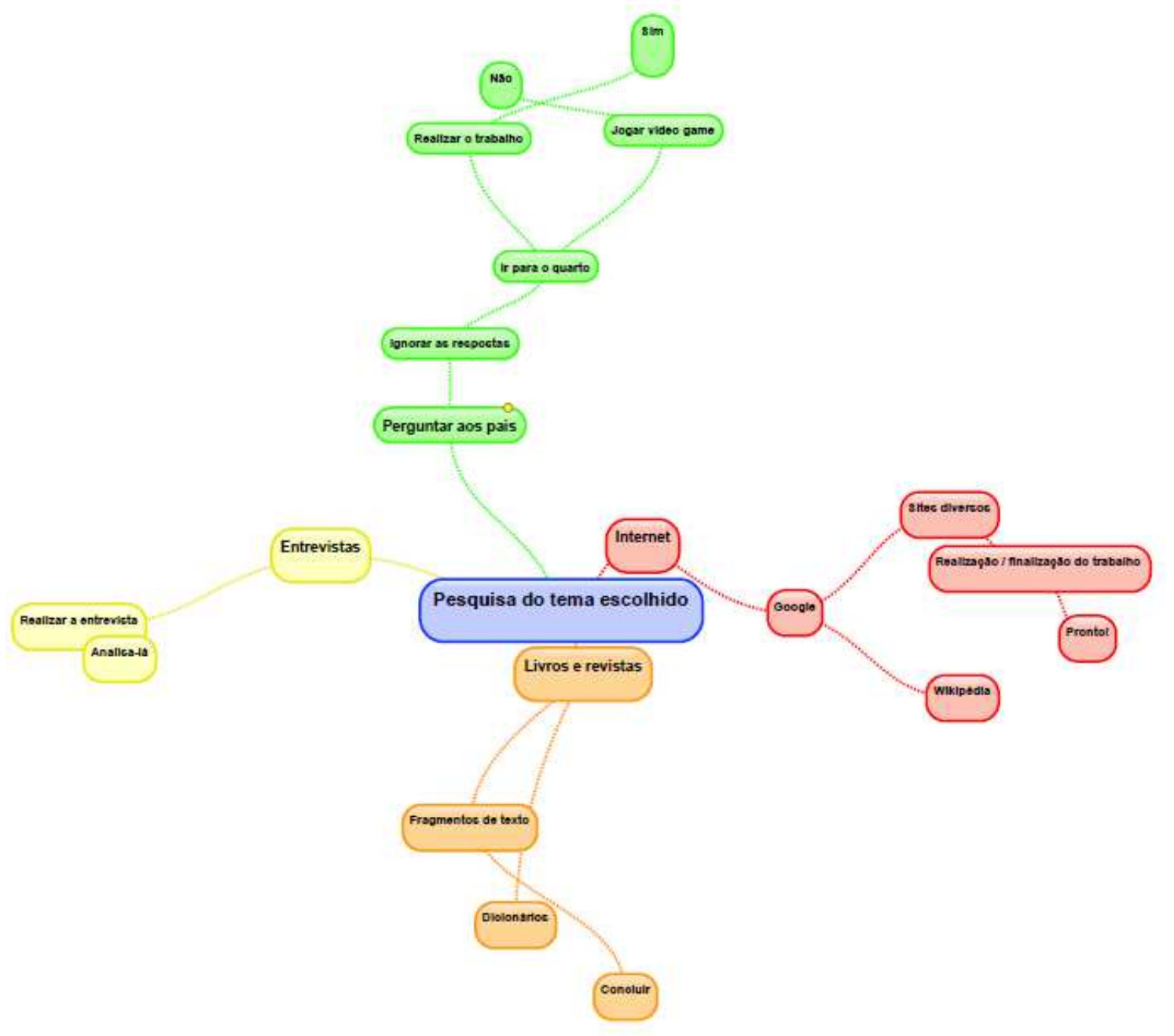




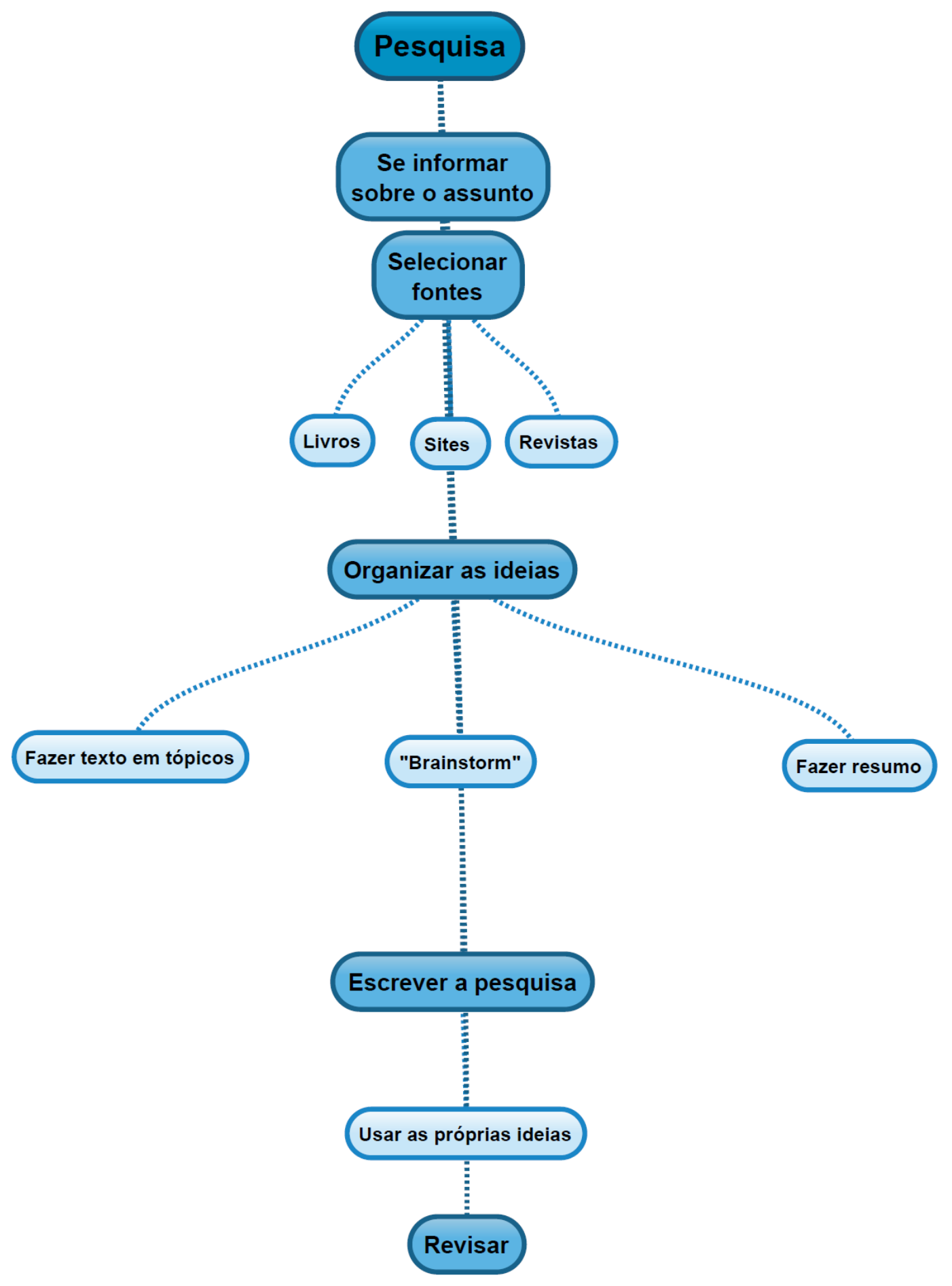

